\title{
Uneven growth between interdependent economies : an evolutionary view on technology gaps, trade and growth
}

Citation for published version (APA):

Verspagen, B. (1992). Uneven growth between interdependent economies : an evolutionary view on technology gaps, trade and growth. [Doctoral Thesis, Maastricht University]. Datawyse / Universitaire Pers Maastricht. https://doi.org/10.26481/dis.19921016bv

Document status and date:

Published: 01/01/1992

DOI:

10.26481/dis.19921016bv

Document Version:

Publisher's PDF, also known as Version of record

Please check the document version of this publication:

- A submitted manuscript is the version of the article upon submission and before peer-review. There can be important differences between the submitted version and the official published version of record.

People interested in the research are advised to contact the author for the final version of the publication, or visit the DOI to the publisher's website.

- The final author version and the galley proof are versions of the publication after peer review.

- The final published version features the final layout of the paper including the volume, issue and page numbers.

Link to publication

\footnotetext{
General rights rights.

- You may freely distribute the URL identifying the publication in the public portal. please follow below link for the End User Agreement:

www.umlib.nl/taverne-license

Take down policy

If you believe that this document breaches copyright please contact us at:

repository@maastrichtuniversity.nl

providing details and we will investigate your claim.
}

Copyright and moral rights for the publications made accessible in the public portal are retained by the authors and/or other copyright owners and it is a condition of accessing publications that users recognise and abide by the legal requirements associated with these

- Users may download and print one copy of any publication from the public portal for the purpose of private study or research.

- You may not further distribute the material or use it for any profit-making activity or commercial gain

If the publication is distributed under the terms of Article $25 \mathrm{fa}$ of the Dutch Copyright Act, indicated by the "Taverne" license above, 


\section{UINEVEN GROWTH BETWEEN \\ INTERDEPENDENT ECONOMIES}

An evolutionary view on technology gaps, trade and growth

\section{ONEVENWICHTIGE GROEI TUSSEN INTERAGERENDE EKONOMIEEN}

Een evolutionaire benadering van technologie, intemationale handel $\mathrm{cm}$ ekonomische groei

\section{PROEFSCHRIFT}

ter verkrijging van de graad van doctor aan de Rijksuniversiteit Limburg te Maastricht, op gezag van de Rector Magnificus, Prof. mr. M.J. Cohen, volgens het besluit van het College van Dekanen, in het openbaar te verdedigen op vrijdag, 16 oktober 1992 om 14.00 uur

door

Hubertus Henricus Gerardus Verspagen

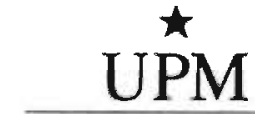

UNIVERSITAIRE PERS MAUSTRICHT 
Promotor:

Prof. Dr. L.L.G. Soete

Beoordelingscommissie: Prof. Dr. J. Muysken (voorzitter)

Prof. Dr. G. Dosi (Universiteit van Rome "La Sapienza")

Prof. Dr. A. Maddison (Universiteit van Groningen)

Prof. Dr. F.C. Palm

CIP-GEGEVENS KONINKLIJKE BIBLIOTHEEK, DEN HAAG

Verspagen, Hubertus Henricus Gerardus

Uneven growth between interdependent economies : an

evolutionary view on technology gaps, trade and growth /

Hubertus Henricus Gerardus Verspagen - Maastricht :

Universitaire Pers Maastricht. - Ill.

Proetschrift Maastricht. - Met index, lit. opg. - Met

samenvatting in het Nederlands.

ISBN 9052780420

NUGI 681

Trefw.: economische groei / technologie en economie /

internationale handel.

Software support by the Menhir Software Group is gratefully acknowledged.

Menhir Software Group, Ringweg 46, 6271 AK Gulpen, The Netherlands 


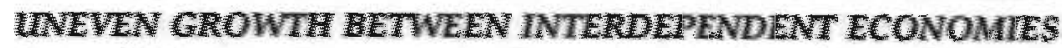

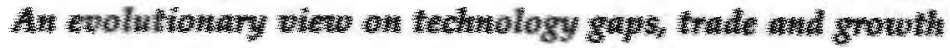

Foreword

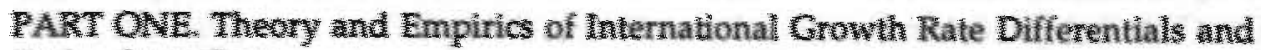

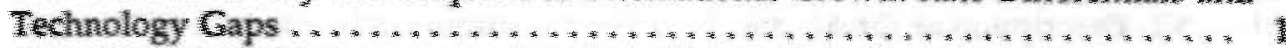

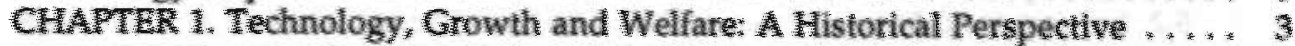

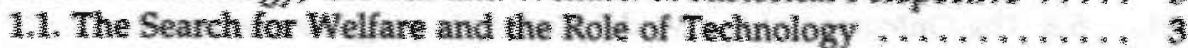

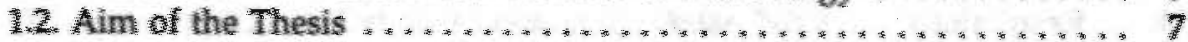

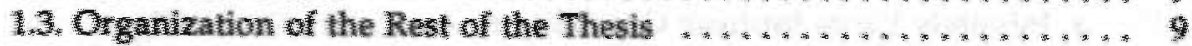

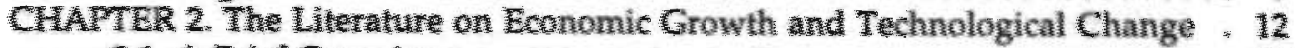

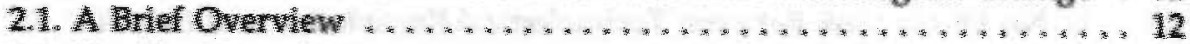

2.2. The Tradininal Leterinute on Fconomic Growh

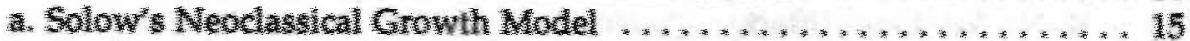

b. The Post-Keymesan Horod-Domar Model of Economic Growth, : * * 17

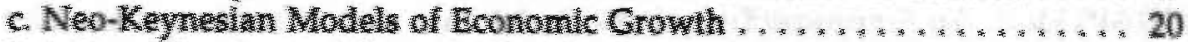

23. New Neodasalcal Growth Models: Endogenouk Inovation $\ldots \ldots \ldots, 24$

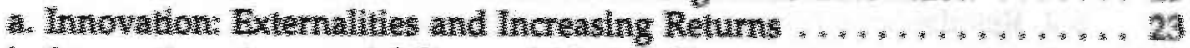

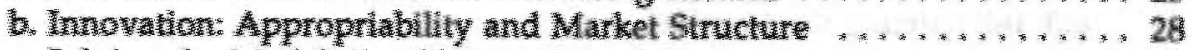

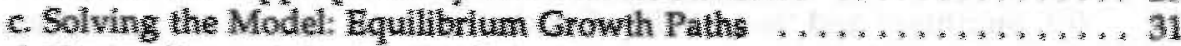

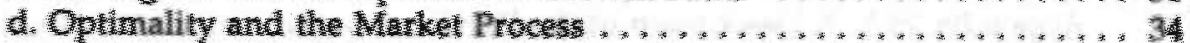

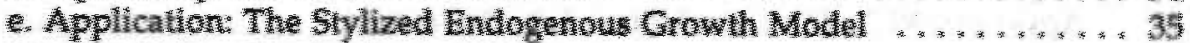

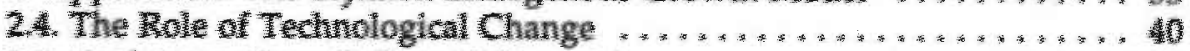

2.5. Explaining Growth Rate Differentials . . . . . . . . . . . . . 42

CHAPTER 3. An Evolutionary Theory of Economic Growth and Technological

Change: The Basics $\ldots \ldots \ldots \ldots \ldots \ldots \ldots \ldots \ldots \ldots \ldots \ldots \ldots, \ldots \ldots$

3.1. Economic Growth as an Evolutionary Process: A Macroeconomic

Interpretation $\ldots \ldots \ldots \ldots \ldots \ldots \ldots \ldots \ldots \ldots \ldots \ldots$

3.2. Economic Growth as an Evolutionary Process: A Microeconomic

Interpretation $\ldots \ldots \ldots \ldots \ldots \ldots \ldots \ldots \ldots \ldots \ldots \ldots \ldots$

3.3. Towards an Evolutionary Theory ... . . . . . . . . . . 56

CHAPTER 4. Technology and Growth in an International Perspective, 1960-1990.

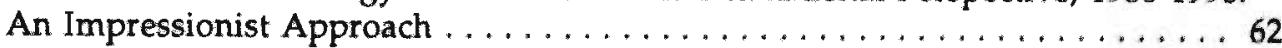

4.1. Economic Growth and Structural Change ..............62 62

a. Do (Aggregate) Growth Rates Differ? . . . . . . . . . . . . . . 62

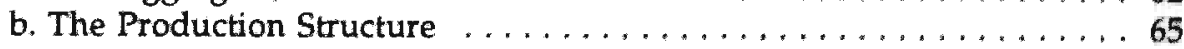

c. Sectoral Growth Patterns . . . . . . . . . . . . . . . . . . 72

4.2. Technology . . . . . . . . . . . . . . . . . . . . . 74

a. How Exogenous is Solow's Residual? . . . . . . . . . . . . 74

b. Sectoral Trends in Technological Change $\ldots \ldots \ldots \ldots \ldots \ldots \ldots \ldots$

4.3. Technology and Growth: Catching Up or Falling Behind? A

Global Issue $\ldots \ldots \ldots \ldots \ldots \ldots \ldots \ldots \ldots \ldots \ldots \ldots \ldots$

4.4. Summary and Conclusions $\ldots . \ldots \ldots \ldots \ldots \ldots \ldots \ldots$

Appendix IV.1. Postwar Economic Welfare and the Selection of

Country Samples . . . . . . . . . . . . . . . . . . . . . . . 92

Appendix IV.2. The 3-Digit ISIC Sector Classification (Revision 2) .... 95 
Appendix IV.3. On Measuring and Graphing Structural Differences Between Countries

Appendix IV.4. Some Tests for the Influence of Multicollinearity on the Regressions in Section 4.2

PART TWO. Technology Spillovers in Interdependent Economies: Catching Up or Falling Behind?

CHAPTER 5. A Model of Catching Up or Falling Behind . . . . . . . . . 103

5.1. Description of the Model .................... 104

5.2. Solving the Model ... . . . . . . . . . . . . . . . . . . 108

5.3. The Outcomes of the Model Under Varying Parameter

Restrictions .................................. 115

a. Infinitely Large Intrinsic Capability to Assimilate Knowledge

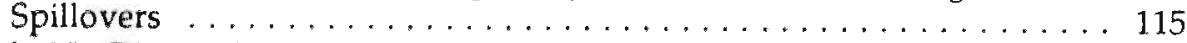

b. No Direct Link Between Technological Knowledge and Growth . . . 116

c. No Link Between Exports and Growth . . . . . . . . . . . . . . 116

d. No Verdoorn Effect . . . . . . . . . . . . . . . . . . . . . . . . . 117

5.4 . Conclusions of the Model . . . . . . . . . . . . . . 118

CHAPTER 6. An Empirical Test of the Model . . . . . . . . . . . . . . . . 119

6.1. Testing Procedure and Data Sources . . . . . . . . . . . . . . 119

6.2. Results . . . . . . . . . . . . . . . . . . . . . . . . 122

6.3. Interpreting the Results . . . . . . . . . . . . . . . . . . 127

6.4. Summary and Some Policy Conclusions . . . . . . . . . . . . . . 129

Appendix VI.1. A Description of the Data . . . . . . . . . . . . . 131

Appendix VI.2. The Calculation of the N-statistic ............. 131

PART THREE. Technological Change, International Trade and Growth Rate

Differentials . . . . . . . . . . . . . . . . . . . . . . 133

CHAPTER 7. An Evolutionary Model of Technological Change, Specialization and

Economic Growth . . . . . . . . . . . . . . . . . . . . . . . 135

7.1. A Descriptive Interpretation .................. 136

a. Trade and Growth . . . . . . . . . . . . . . . . . . 136

b. Trade and Technology ... . . . . . . . . . . . . . . 137

c. The International Location of Innovation . . . . . . . . . . . . 138

d. Specialization Patterns and Economic Growth . . . . . . . . . . . 138

7.2. The Model ... . . . . . . . . . . . . . . . . . . . . . . 139

a. The Selection Environment ... . . . . . . . . . . . . . . . . . 139

b. Endogenizing Competitiveness: Learning, Wage Rate Dynamics

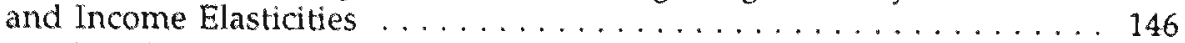

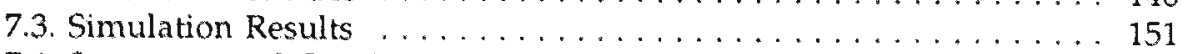

7.4. Summary and Conclusions . . . . . . . . . . . . . . . . 157

Appendix VII.1. Initial Values of the Simulation Runs for the 3Country 2-Sector Case . . . . . . . . . . . . . . . . . . . . . . 158

Appendix VII.2. Some Mathematical Details of the Selection Equation in Discrete Time . . . . . . . . . . . . . . . . . . . 158

Appendix VII.3. Accessing the Complete Simulation Results on

Floppy Disk ... . . . . . . . . . . . . . . . . . . . . . . . . . . 159

CHAPTER 8. An Empirical View on the Evolution of Trade and Technology . 161

8.1. Patents as Indicators of Innovation . . . . . . . . . . . 162 
8.2. Summarizing Some Known Correlations . . . . . . . . . . 166

8.3. Trade and Technology: A Dynamic Evolutionary Framework .... 175

8.4. Estimation of the Replicator Equation . . . . . . . . . . . . 177

8.5. Some Further Tests on the Robustness of the Replicator Estimates . 183

8.6. Explaining the Results for the Patent Variables . . . . . . . . . 191

8.7. Summary and Conclusions .................... 193

Appendix VII. 1 Concordance between STC-1, ISIC-2 and the SIC-

classification $\ldots \ldots \ldots \ldots \ldots \ldots \ldots \ldots \ldots \ldots \ldots \ldots \ldots \ldots$

CHAPTER 9. A Broader Empirical View on Trade, Technology and Growth . . 196

9.1. A General Test of the Relation Between Competitiveness,

Structure and Growth Rate Differentials . . . . . . . . . . . . . 196

9.2. Catching Up: A Detalled Look at the Asian NICs . . . . . . . . . . 206

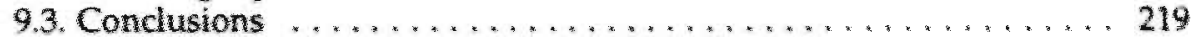

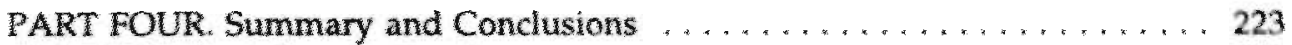

CHAPTER 10. A Concluding Summary . . . . . . . . . . . . . . 223

10.1. The Merits of a Dynamic Evolutionary Approach . . . . . . . . . . . 223

10.2. Knowledge Spllovers: Catching Up or Falling Behind? . . . . . 226

10.3. Intemational Trade, Growth and Competitiveness . . . . . . . . 227

10.4. The Connection to Other Fields of Research on International

Growth and Technology: Possibilities for Further Research . . . . . . . 230

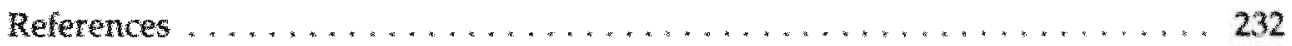

Nederlandse Samenvatting - Dutch Summary . . . . . . . . . . . . . 243

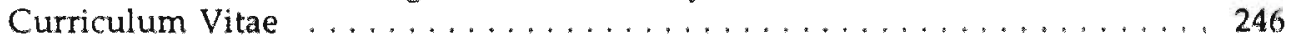

Authors Index . . . . . . . . . . . . . . . . . . . . . . . 247 


\section{Foreword}

In an open letter to his audience, the Dutch writer A.F.Th. van der Heijden describes the creation of his cycle of novels 'De Tandeloze Tijd' (The Toothless Time). He sets out how an initially vague idea for one novel was transformed in his mind, and through various stages of manuscripts, into what is now a series of three bestsellers. Along the way, the initial central theme was sidetracked and developed into a completely new narrative line. Three more volumes of the series are still in the twilight zone between thoughts and the publisher.

In this sense, the creation of literature resembles the writing of a PhD thesis, at least in these two specific cases. Four years ago, a proposal for a PhD project on growth and technology was submitted by Luc Soete and myself. After its approval, I started a literature survey on productivity growth and the neoclassical production function. Gradually, the idea that research in this field had reached the stage of decreasing marginal returns settled in my mind, and I started searching for an alternative approach.

Such an alternative seemed to be available in the form of evolutionary economics, which was 'practised' by a number of influential colleagues at MERIT. By the time I had decided that my PhD project would develop into the direction of evolutionary economic theory, the profession was shocked hv what latar hanmen lanovire as the new growth theory'. So much for decreasing returns: Here was a wholly new field which would become a source for a voluminous literature full of interesting findings and new conclusions.

Still, I decided to stick to the evolutionary approach, while taking close notice of what was happening in the newly developed growth field. This choice became the source of many lively debates with colleagues, on almost 'literary' topics as the notion of rationality, dynamics, and out-of-equilibrium behaviour. Finally, this resulted in the 'hybrid' thesis presented here.

Like in all $\mathrm{PhD}$ projects, I am indebted to a number of people who influenced my thoughts on the topics of growth, trade and technology. And although they are not responsible for any of the views expressed here, nor any remaining errors, this thesis would not have been the same without their influence. Here is the list of names.

My supervisor Luc Soete provided me with the necessary direction when I was searching for new directions, and was always ready to make his original comments on drafts and redrafts. Gerard Pfann continued to be an inspirator for the econometric parts of the analysis. Gerald Silverberg provided me with the necessary approach to leap from ideas to the model in Part Two. Paul Diederen and Adriaan van Zon were a big inspiration in times when things would not immediately work the way I expected them, and the latter also made available the necessary software to carry out the simulations in Part Three. The software used to present the simulation results on the floppy disk was created by Huub Meijers.

Discussions with Rohini Acharya, Theon van Dijk, Hugo Hollanders and Thomas Ziesemer in MERIT's TM group helped me to review the new growth literature in a 
relatively fast and efficient way. The members of the 'Productivity Group', Paul Diederen, Fabienne Fecher, René Kemp, Huub Meijers, Rombout de Wit and Adriaan van Zon, were a very useful platform to get comments on drafts of parts of the thesis. Chris Freeman also gave me useful comments on parts of the thesis.

The research environment at MERIT provided me with facilities for the necessary hard- and software, and to discuss ideas with a broad range of foreign colleagues at various conferences, summer schools and workshops. Among the many people from whom I have learned, Jerry Courvisanos, Giovanni Dosi, Anders Skonhoft and Jan Fagerberg deserve special mentioning. The latter, together with Keith Smith, invited me for a stay in Oslo (to visit both NUPI and Norsk Regnesentral), thus providing me with an excellent opportunity to present almost my full range of ideas to a critical audience.

Within MERIT, Marjolein Caniëls and Ton van Moergastel helped me to handle the large amounts of data used in the analysis. Corien Gijsbers corrected the English, which she did with a very skilful eye for detail. Finally, Wilma Coenegrachts, Mieke Donders and JoAnn van Rooijen took care of many day-to-day details in a way that gives the MERIT environment its specific inspiring flavour.

I thank all these people and hope to be able to return their favours some day.

Maastricht, July 1992 


\section{PART ONE}

\section{Theory and Empirics of International Growth Rate Differentials and Technology Gaps}




\section{HИO TYA9}

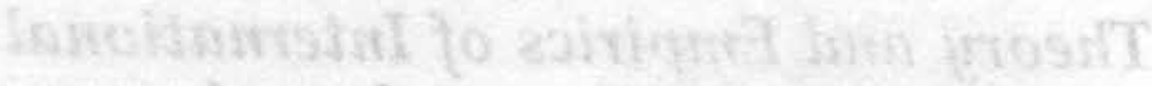

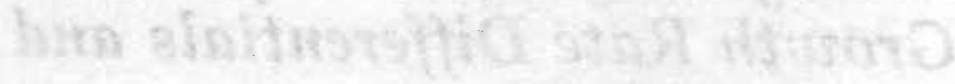

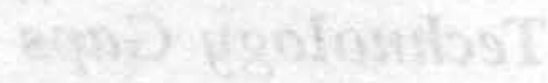




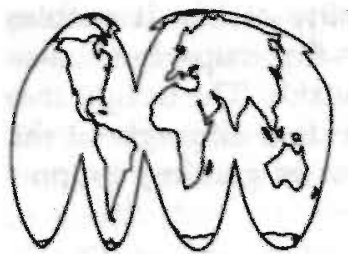

\section{CHAPTER 1. Technology, Growth and Welfare: A Historical Perspective}

\subsection{The Search for Welfare and the Role of Technology}

The story of man's search for more material, and from there also immaterial, wealth, is one of constant improvements in technological methods of using earth's resources. The long way that brought Homo Sapiens from its origin to the modern times certainly must appeal to everyone's imagination. The knowledge embodied in the principles that are taught in primary and secondary schools (let alone universities) has taken thousands of years to develop. The tremendous potential of this development of knowledge that has revealed itself has been the inspiration for many authors of (both optimistic and pessimistic) future world views (as for example in the so-called science fiction literature). However, the process of technological development has hardly been one that can be represented by a simple, linear development towards more welfare for all members of the human species.

A number of historical and contemporary examples can be given to illustrate the importance of scientific and technological development. Some of the inventions that were made during the early ages of human civilization still play a role in economic life, like the alphabet (invented around 3200 B.C., generally attributed to the Sumerians, living in Babylonia, part of the current state of Iraq). Others, such as the sail (already used on seaworthy boats by the Egyptians around 2000 B.C.) have lost their central (economic) importance, but are still used in some parts of the world. Still others, like stone tools (believed to have been used from around 60000 B.C. until iron tools were introduced in some parts of the world around 2700 B.C.), have vanished almost completely from the technological scene. Each of these inventions represented an important potential for more welfare, and, mostly only after important gestation lags, changed life in a drastic way.

Perhaps the most impressive jump towards our modern age of technology was the industrial revolution that began to take shape in the middle of the 18th century in Britain. The introduction of steam as a powersource and large-scale (compared to the methods used at that time) mechanical devices for weaving and spinning paved the way for industrial development. Today, the potential of information technology and space travelling seems to open up possibilities for the spread of mankind outside of the planet Earth.

Obviously, the blessing of technology and science is, in several ways, a mixed one. First, the direct and indirect effects of technological innovation are not purely beneficial. Contemporary leading centres of technological and economic activities 
are clear examples of what technology can do to the quality of life: It enables modern man to manipulate his environment by moving his fingertips, but it also brings with it the need to wear little air filters when going outside. The insight that we will not be able continue using technology as we have done throughout the past few hundred years without ruining the environment is gaining support rapidly.

No matter how important this question is, it is not the main interest of this thesis. The main interest is a second aspect of mixed blessings of technology: it differential impact on separate nations and cultures. Again, numerous historical examples may be referred to to illustrate this. One example which shows how local institutional factors have influenced the development of technological innovation is the status of technological change in ancient Babylonian society (Viljoen 1974: 47). The Babylonians believed that production techniques were given by the gods, implying that there is only one ('holy approved') way of doing things. Besides taking male and female animals, the Babylonian Noah (Ut-Napischti) also took craftsmen (and presumably women!) aboard of his ark, so that the art of handwork created by the god Ea was preserved for the human race. Surely this view was not very encouraging for the development of new technological methods.

Another example are the numerous inventions made by the Chinese during the period that is known in the Western world as the Middle Ages (Viljoen 1974: 64-6). Among the Chinese achievements are the art of printing (the Confucian Classics were published in printed form in China in the year 953), the invention of the magnet, the invention of gunpowder (which they are believed only to have used for fireworks), the mechanical clock, bow bridges and many others. The first three of these drastically changed the history of the world. Printing was an important step forward in the diffusion of written documents. Gunpowder teared down the best-practice technology in the 'art of war', and thereby caused power relations to change radically. The magnet, used in the compass, enabled sailors to navigate in a much more precise way than they had before.

The peculiarity of all these inventions, however, is that while they were invented by the Chinese, they were used by the Europeans, for whom they became important tools to make their continent the 'centre of the world'. The impact of these inventions in the Chinese society itself was minor during the first few hundred of years after their introduction. Apparently, there were forces in China which prevented the diffusion of the inventions through the economic system. Viljoen (1974: 64-5) identifies the differences between the organization of the economy in China and Europe (which was much closer to what is now called a market economy) as the explanation for this lack of diffusion.

A more recent example of the lack of integration between scientific (i.e., scholarly) and technological (i.e., economic) development in the former communist countries is often explained by the same factor: The absence of market forces driving the economy towards more efficient use of its resources. The investment in science in these countries has been relatively high. Nevertheless, their economies have not been able to perform on such a high technological level. The same argument applies to a number of developing countries. In spite of the purchase of high-tech 
products (often weapons and related products), they have not been able to develop ways of providing the basic health and food necessities for their population.

These examples put forward the role of technology as a means of international competition between nations. During the centuries that passed between the periods in which they are situated (the Middle Ages and the present), technology has played an important role in this respect. The most direct and radical way of international competition is without doubt war. It is somewhat depressing to recall that the geographic scene where the USA and its allies recently showed their great military technological potential by destroying the Iraqi military force by means of computer-guided missiles, communication techniques and the like, withessed the introduction on the battlegrounds of (then) modern innovations such as the horsepulled chariot and weapons made of iron already during the first millennium B.C. (Roberts 1987).

But technological power is also an important aspect of competitiveness in a less direct and repelling battleground: the world goods market. The changes of economic leadership, as described in Maddison (1991), from the Dutch (18th century) to the British (the dawn of the industrial age), to the Americans (the late 19 th and early 20 th century), and perhaps to the Japanese (recently), are without doubt all connected to changes in technological leadership.

This process of catching up and overtaking, which is much closer to the imagination of modern economists than the historical examples used so far, also shows the importance of institutional, political and geographical factors in explaining international growth rate differentials. Maddison (1991: 33-4) describes the factors that explain the emergence and erosion of leadership in the three cases mentioned above. In the Dutch case, the three main factors explaining success around 1700 were institutions (landownership, the role of the church and the spread of political power, which was mainly controlled by the middle classes), geography (the availability of sea ports and rivers which gave access to the European main land), and the active pursuit of mercantilist policies.

The loss of the Netherlands' central role in world trade after conflicts with France and the UK gave way to British leadership around 1820. Maddison (1991: 36) mentions the same three reasons for UK leadership as in the Dutch case: favourable institutions, geographical advantages, and world trade leadership. During this epoch, the world saw the birth of the industrial revolution, which originated in the British textiles industries, but had its major impact through innovations like steam power, steel, and the rallway.

While the industrial revolution changed the way in which products were produced drastically (process innovation), it was only after the leadership take-over by the Americans (late 19th century) that new products became more important (Maddison 1991: 42). Its high investment ratios (Maddison 1991: 40) had led the USA to the leading role which has only recently been challenged by the 'newcomer' Japan, and some of the more traditional European economies (Germany). The introduction of new products together with strong cost-reducing process innovations (economies of scale) introduced 'mass-consumption' as a 
driving force of the economy. A prime example of this tendency can be found in the automobile industry, where the term Fordism was used to describe the broad context of ('Taylor-based') process innovation and consumer-oriented production".

So far, the terms technology and science have mainly been used as referring to one and the same phenomenon. However, there are important differences between technology and science. Science stems from the general human urge to understand the world around us. Its driving force is curiosity. Technology on the other hand emanates from the urge to use events observed around us (nowadays mostly by use of so-called scientific methods) for the benefit of ourselves. Thus, science mainly has an explanatory character, while technology has an applicatory character.

The interaction between science and technology as we know it now, has only gradually emerged in the process of economic development briefly described above. In ancient times, technological inventions were mostly rooted in empirical observations rather than systematic scientific progress, although there are also exceptions to this rule (e.g., gunpowder was invented by Chinese alchemists systematically in search for a way of reaching a longer life or even immortality, Viljoen 1974: 64 cites Needham on this matter). It were the Greek philosophers (especially Plato) that began to develop scientific methods to investigate the world around us. Before them (and also long after them), technological development was dependent upon the activities of practitioners (Viljoen 1974, Chapters 1-3).

To highlight the (recent) change in the relationship between technology and science, the following quotation from an article introducing a special issue of Scientific American on the greatest discoveries in the 20th century (Piel 1991: 4) is illustrative:

"The 20th century is the first in which inquiry into nature has become the source of technologies that amplify the power of the human mind and may even render human intelligence redundant. (...) The 20 th century has experienced a sea change in the relationship between science and technology, In the 18 th century the members of Birmingham's Lunar Sociery learned more about physics from their mill machinery than physics contributed to productivity. The study of illness has traditionally illuminated biological processes; now medicine rakes lessons from molecular biology. Finally, science has become a global profession with its own rules and culture. It is a profession institutionalized in university, government and industrial research laboratories. Political leaders and entrepreneurs have begun to listen to what science has to say."

Certainly, modern examples show the need to study the international dimension and spreading of (the interaction between) science, technology and growth. Why are some countries able to assimilate the potential of scientific and technological development so much better than others? An economist who asks in what way economic growth and technology interact, cannot pass by this international aspect. He must study local circumstances that influence this relation, and try to explain how the interaction between different national economies influences this process.

\footnotetext{
' See Boyer (1989) for a general treatment of Fordism and similar 'modes of production'.
} 
However, modern economics has not paid much attention to these issues. Two factors that emerge from the above examples as being particularly important for economic development, technological change and institutions, have by and large been treated as exogenous phenomena in modern economic science. Therefore, one might expect that the explanatory power of economic theory in this field is not very high.

\subsection{Aim of the Thesis}

The aim of what follows below is to explain some of the aspects of the relationship between technological change and economic growth in an international context. Despite the size of the work, the focus of the analysis is quite narrow, and will only address a limited part of the issues touched upon in the broad overview in the previous section. There are four issues that are at the core of the analysis: technological change, economic theory and empirical analysis, and the international setting.

With regard to technological change, it is necessary to make it clear at the outset that its role will only be taken into account in a very stylized way. The perspective of this thesis is primarily an economic one, and the way technological change will be analyzed is by giving it an explicit role in stylized mathematical models of the international economy. This way of treating such a complex phenomenon as technological change can never do justice to all the important issues that are connected to its use and limitations. However, as will be argued in more detail below, economic models have only given little attention to technological change. Therefore, by thinking about it more deeply, and by consulting experts from outside the economics field, the economic modeller can strongly improve upon the previous work in the field. Thus, although the result of these modelling exercises will remain of limited value, useful work still remains to be done. Recent overviews of the state of the art in this field can be found in Dosi et al. (1988) and Gomulka (1990).

This brings up the second and third items in the list of central issues in this thesis: economic and empirical analysis. Although economic analysis is much richer than mathematical modelling alone (note particularly the contemporary and historical exercises outside the field of neoclassical theory ${ }^{2}$ ), the present focus will mainly be formal. However, where necessary, ideas will be taken from the more detailed descriptive branches in economics. This approach brings with it the possibility of disappointment, when the rich ideas found in the descriptive, historical approach are translated into mathematical equations and empirical indicators. For some of the models presented below, the representation of technological change and its consequences will certainly fall under this heading. Nevertheless, the formal approach is worth developing, and future research should be aimed at enlarging the scope of the present models and methods.

Ever since the birth of economics as a science, there have been intense polemics

\footnotetext{
${ }^{2}$ Especially relevant contributions to the current topic are among others Gerschenkron (1962), Rostow (1960, 1980) and Maddison $(1982,1991)$.
} 
between different practitioners (note for example the interesting references to Smith in the original works by Marx). Partly, these debates concentrated on issues that were at some stage resolved (or seemed to be resolved). However, a large number of the issues in the debates have not been resolved, and live on in numerous recent publications. Many of these debates are in some way related to almost political issues like the value of the free market, and individual liberty.

The present work adds in some way to these polemics. After a detailed survey of the approaches found in growth theory, an explicit choice for one approach to modelling is taken. This approach, the evolutionary way of looking at economics, is relatively new, and needs to be developed more thoroughly before it can compete with other, more established schools of thought. This choice is partly made on the basis of issues that have been resolved (such as the character of technological change, see Chapter 4), and partly motivated by arguments that cannot be tested in practice (such as the role of market equilibrium). Therefore, this choice should mainly be seen as a useful way of exploring some of the consequences of evolutionary thinking in economics, rather than looking at it as a hostile action against mainstream economics.

The last central issue to be explained is the international context of the analysis. In economics, switching from closed economy analysis to open economy analysis means introducing interdependencies into the models. There is no reason to include foreign economies in a model, unless there is some influence from this foreign economy on the domestic economy. Often, textbook models concentrate on this one-way influence only. However, in a more integrated setting, the effect of each economy on each other economy in the world should be modelled. This justifies a multi-directional approach to modelling the international economy.

In the present context, there are two sorts of interdependencies that are relevant: technological and economic interdependencies. In a technological sense, economies depend on each other because innovations diffuse across national borders. Inventions made in one country can be applied in another. This phenomenon is very common in today's world due to the presence of multi-national corporations. However, the role of these firms will not be explicitly addressed here. Instead, the unit of analysis will mainly be the country (or sector in a country), and overlaps between countries in the form of multi-national firms will be ignored. Moreover, while looking at the consequences of technological interdependencies, (al)most (exclusive) attention will be paid to countries at the 'receiving end' of the diffusion process.

Technological interdependencies have not been at the core of economic analysis. Much more attention has been given to economic interdependencies. The explanation of international trade was already one of the subjects in classical economics $\left(\right.$ Ricardo ${ }^{3}$ ). Also in modern economics, international trade remains at the core of the analysis, and technological change is identified as one of the main explaining factors (for example Hughes 1986, Dosi et al. 1990). In macroeconomic modelling, the influence of international trade through the trade balance has been

\footnotetext{
${ }^{3}$ And before him, the mercantilist writers, see for example Schumpeter (1954, chapter 7$)$.
} 
neatly incorporated in the mainstream models (the so-called neo-Keynesian synthesis)".

However, the issue of the relationship between trade and growth, which is at the core of the present analysis, has never been addressed in much detail. Only recently, mainstream growth models have begun to look at the consequences of trade. Following some early contributions in the neo-Keynesian tradition (see Chapter 2), recent models look at the influence of endogenous international trade (in its turn influenced by endogenous technological change) on intermational growth patterns. Some of these models will be reviewed in Chapter 2, others will briefly be commented upon in Chapter 7.

\subsection{Organization of the Rest of the Thesis}

The rest of the analysis is organized as follows. Part One serves to give the reader an overview of previous work in the field of (international) growth and technology. It starts off with Chapter 2, which reviews the theoretical roots of growth models in economics. Some stylized versions of models in the literature (starting in the 1940s and 1950s, and ending in the 1990s) will be given and compared with one another. A discussion on the usefulness of the way in which technology is represented, and the usefulness of the models in explaining international growth rate differentials is undertaken in the two concluding sections of the chapter.

After having set out the basic theoretical lines available from previous work in Chapter 2, the Chapter 3 provides the link from previous work to what can be viewed as the original theoretical contribution of this thesis. It discusses some of the detailed historical work on the nature of the innovation process and its relation to economic growth, and confronts ideas in this part of the literature with the representation of technological change in the models in Chapter 2. The second part of the chapter makes some methodological propositions about the nature of the economic theory that can deal with these issues, based on the historical interpretation of the innovation process. This section is more oriented towards the micro side of the economic process, and criticizes the concepts of rational behaviour, the representative agent and market equilibrium. The resulting propositions will be shown to be useful in the context of an analogy between the biological idea of evolutionary selection and economic modelling.

Chapter 4, the last one in the 'review of the literature' part, gives an empirical overview of the facts of postwar growth and technology. Subsections, in turn, consider the observed trends in economic growth, technological change, and some of the relations between them. The analysis will concentrate both on aggregate and on sectoral trends. The concluding section of this chapter lists some stylized facts.

Parts Two and Three contain the 'original' contribution of this thesis. Based on the theoretical considerations in Chapter 3, they provide some interpretations of the

\footnotetext{
"A standard textbook on international macroeconomics is for example Rivera-Batiz and Rivera* Batiz (1985).
} 
stylized facts observed in Chapter 4. In Part Two, the issue of technological interdependencies and their influence on growth rate differentials will be treated in more detail. This part will try to model the issue of technology diffusion between countries, as dealt with in the so-called catching-up debate (see also Chapters 2 and 4). A simple model of technology spillovers will be set up in Chapter 5. The model does not consider technology spillovers as an automatic process, but stresses the way in which these spillovers are assimilated in the receiving country. It also includes some elements of economic linkages between countries, but these are not the core of the analysis. (It is shown that the basic conclusions of the model also hold under the assumption that these economic linkages are absent).

An empirical test of (a simple version of) the model is undertaken in Chapter 6. The analysis in this chapter tests whether the model proposed in Chapter 5 does a better job in explaining the pattern of aggregate international (114 countries) growth observed in Chapter 4 than some other models found in the literature. This is done by setting up these other models as special cases of the model in Chapter 5 , and by using the technique of non-nested hypothesis testing.

In Part Three, the full set of interdependencies between trade, growth and technological change will be analyzed. In Chapter 7, a multi-sectoral model of international growth is specified, which looks at the interaction between (cumulative) technological change, wage rate dynamics, specialization patterns, and growth. Technological change, wages, specialization and growth are all modelled in a dynamic, endogenous, but also stylized, way. The driving force of growth in this model is an evolutionary selection equation, which brings a tendency to selection of the most competitive producers. Since other parts of the model are taken from neo-Keynesian theories, it can be characterized as an evolutionary model with neo-Keynesian features. The equations of the model are presented, and analyzed, to the extent possible, by means of analytical methods. In view of the complex (nonlinear) character of the model, however, the most important way of analyzing it will be by means of a simulation approach.

The two remaining chapters in Part Three are aimed at providing some preliminary tests of parts of the model in Chapter 7. Because of the stylized nature of the model, it is not possible to apply it directly to actual data. Therefore, its main propositions will be tested in an indirect way.

In Chapter 8, an empirical test of the trade 'block' of the model is undertaken for 35 countries, including OECD countries and NICs. A slightly modified version of the main trade equation in the model of the preceding chapter will be estimated on the sectoral level using regression techniques. The chapter also includes a section where results of earlier work by Dosi et al. (1990) are re-established, as well as a section on the usefulness of patents as indicators of innovation.

The results of Chapter 8 are used in Chapter 9, where a more general test of the model proposed in Chapter 7 is undertaken. This chapter is aimed at testing the relationship between competitiveness, structural differences between countries, and growth rate differentials. The chapter includes a general approach with data on 
aggregate and manufacturing growth rate differentials for all the countries used in Chapter 8, and a more detailed approach similar to a case study which looks at the Asian NICs (being recent successful examples of catching-up countries), the USA and Japan only. In the general approach, the main equation of the model in Chapter 7 is used to derive a general hypothesis about growth rate differentials. Using the parameter estimates obtained in Chapter 8, this hypothesis is tested in several ways. The case study approach of the NICs is used to illustrate the importance of several factors that are difficult to capture in a general regression framework.

The main results are summarized, and conclusions are drawn, in Part Four, which consists only of Chapter 10 . This chapter will outline the main lines along which the analysis has been undertaken and will relate these to some other research in the field. 


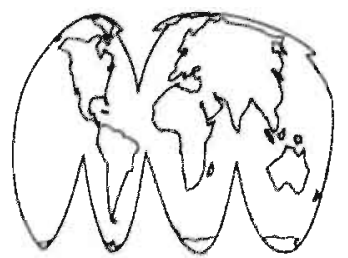

\section{CHAPTER 2. The Literature on Economic Growth and Technological Change}

\subsection{A Brief Overview}

What have economists said about the relation between technological change and economic growth? Figure II.1 gives a schematic overview of the interlinkages between the main authors / contributions.

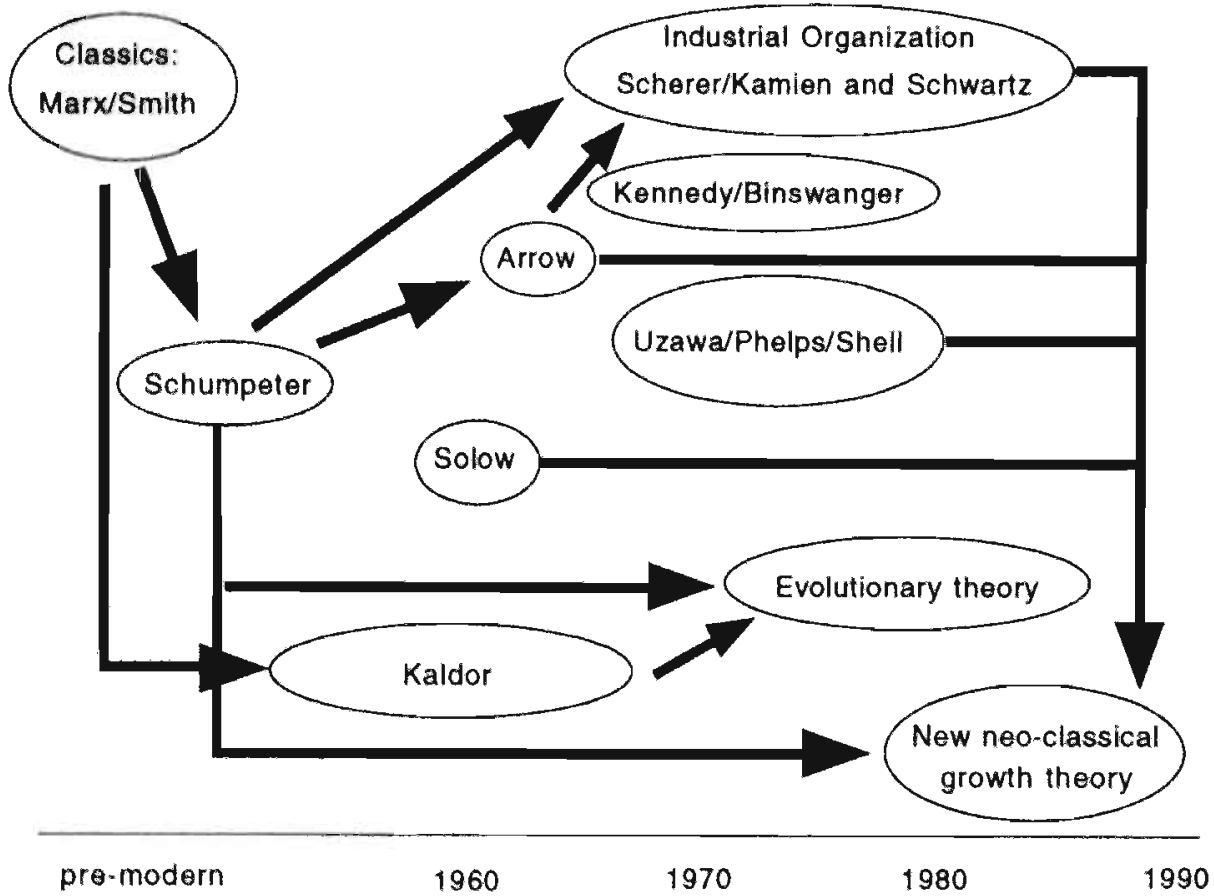

Figure II.1. An interpretation of the structure of the literature on rechnological change and economic growth

The notion of economic growth explained by endogenous technological progress was already present in the work of the classic school (see Gourvitch 1940 for a detailed overview). In Adam Smith's pin factory, technological change took the form of further and further division of labour, enabling an increase in productivity in the system as a whole. Ricardo was more pessimistic when he first wrote the 
chapter on machinery in his Principles of Political Economy and Taxation. Dealing with the employment consequences of technological change, he assessed the innovations of his time as employment-reducing, thus confirming the concern in the labour class of that time. In Marx' work, technological change was seen as the principal means of capitalists in their search for more surplus value. In his view, technological change, through the 'organic composition of capital', was the driving force behind the 'tendential fall' of the profit rate, and eventually, the decline of the capitalist era.

Via Marx, endogenous technological change became prominent in the work of Schumpeter (for example, Schumpeter 1934). In his long wave theory, Schumpeter describes the disrupting effect of major technological breakthroughs on economic growth paths. In his view, major innovations are introduced in a process of creative destruction, drastically changing the structure of the capital stock in the economy. The major innovations, which are introduced in the depression phase of the long wave, are followed by a bandwagon of incremental innovations during the early upswing.

In the first growth models, developed during the 1940 s and 1950 s, technological change was reduced to an exogenous phenomenon, basically for analytical convenience. These early growth models did not specifically deal with the relationship between technological change and economic growth, but focused primarily on issues like the influence of factor substitutability and the savings rate on the stability of macroeconomic growth paths. Kaldor's growth model is an exception to the 'rule' of exogenous technological change.

Intuitive support for the assumption of exogenous technological change in these models might be found in the public good characteristics of innovation. The user of technological change does not have to develop the innovation himself, but can (partly) rely upon other agents to develop the knowledge and then simply copy (or buy) it. This notion was formalized in the (neoclassical) literature by Arrow (1962). However, the question remains why innovations would be 'produced' at all if public good characteristics are used as an explanation for the assumption of exogenous technological change ${ }^{1}$. If technological change is a purely public good, there will be no incentive whatsoever to produce and sell it in the market.

Possible answers to this are the following. First, Schumpeter argued that monopoly power is the principal means of appropriating an innovation. Second, a patent system might create legal protection from imitation. Third, a time-lead might give the innovator enough opportunities to earn back the innovation costs. All these possibilities have been developed in an analytical way in the literature on industrial organisation (for an overview see among others Kamien and Schwartz 1982, Scherer and Ross 1990).

Other neoclassical models of endogenous innovation have also been formulated.

'Moreover, as has been recognized by among others Dosi (1988a, 1988b) and Cohen and Levinthal (1989), imitation of technological knowledge developed elsewhere might be a costly activity. 
Most of these models were, similar to the literature on industrial organisation, mainly dealing with the character and pace of innovation itself, rather than economic growth. In contributions by among others Kennedy and Binswanger (for a survey and exact references see Thirtle and Ruttan 1987), the factor price ratio was identified as being one of the main (endogenous) determinants of the character of innovation in models on endogenous biases of innovation. In another approach (initiated by the seminal work of Schmookler 1966), effective demand was considered a main vehicle for the pace of innovation. However, the literature on endogenous technological change in growth models 'died out' after a few early contributions by Uzawa (1965), Phelps (1966) and Shell (1967). These papers specified models in which human capital formation is a main determinant of technological change.

It was only recently that the interest in endogenous technological change as a motor for economic growth revived again. First, the idea of endogenous innovation in a theory of economic growth was a major source of inspiration for the evolutionary or neo-Schumpeterian literature, which was initiated in the 1980s by authors like Nelson and Winter (1982) and Dosi et al. (1988). The ideas underlying these theories will be introduced in Chapter 3 , and further developed in the rest of the thesis. Out-of-equilibrium dynamics and bounded rational behaviour are key concepts in this literature, which distinguishes it from the 'new' neoclassical growth models, the second group of theories dealing with endogenous technological change. These models try to link some of the insights gained from industrial organisation to the issue of economic growth, and will be discussed in depth in section 2.3 below.

\subsection{The Traditional Literature on Economic Growth}

This section will briefly summarize the main streams of thought on economic growth found in the postwar literature. As the discussion in sections 2.4 and 2.5 will show, these models are not the most interesting ones from the perspective of technological change and growth rate differentials. The reason why they are discussed, however, is that they provide the basic tools in the modern economist's toolkit. Virtually all formal approaches to growth are rooted in one of the basic models discussed here ${ }^{2}$, and as such this chapter is meant to give the reader a short overview of the basic facilities in the profession.

The models found can be distinguished according to their basic underlying ideas. This typically leads to a division into neoclassical models, neo-Keynesian models and post-Keynesian models. The neoclassical model assumes market equilibrium and optimizing behaviour, leading to a stable growth path. The post-Keynesian approach, on the other hand, does not use optimizing behaviour, and typically finds unstable growth paths. Neo-Keynesian models are somewhat in between, leading to growth paths which are sometimes stable and sometimes are not.

\footnotetext{
${ }^{2}$ The evolutionary approach, which is developed further in Chapters 3 et seq., might be called the exception.
} 


\section{a. Solow's Neoclassical Growth Model}

The basic neoclassical growth model was developed by Solow (1956, 1970), and included the following basic equations:

$$
\begin{aligned}
& Q_{i}=A\left(e^{(x)} L_{p}\right) K_{i}^{1-1} \\
& E_{z}=e^{a t} L_{i} \\
& L_{1}=L_{0} e^{x t} \\
& k_{i}=\frac{K_{1}}{E_{1}} \\
& \hat{K}_{\mathrm{i}}=1 \\
& J_{1}=S_{\text {, }} \\
& S_{1}=s Q_{1}
\end{aligned}
$$

Dots above variables denote time derivatives. Hats denote proportionate growth rates. $Q$ stands for production, $L$ is (raw) labour input, $K$ is capital input, $\alpha$ is the exogenous rate of technical progress, $E$ is labour input expressed in efficiency units, $A$ is a constant, $I$ is investment (depreciation is assumed to be absent), $S$ represents savings, $k$ is the capital / labour (in efficiency units) ratio, $v$ is the rate of growth of the labour force (population), $s$ is the exogenous savings rate, $\beta$ is a parameter, and $t$ refers to time (a subscript 0 indicates a starting value). Equation (II.1) is the production function, specified as a Cobb Douglas form with labouraugmenting technological progress and constant returns to scale (CRS). Equations (II.2) - (II.4) are definitions and (II.5) - (II.7) define capital accumulation. In order to find the market equilibrium growth path, one proceeds as follows. First, one can solve for the growth rate of $E$ and $K$.

$$
\begin{aligned}
& \hat{E}_{t}=\alpha+v \\
& \hat{K}_{i}=s A k_{l}^{-\beta}
\end{aligned}
$$

Then, the motion of $k$ can be written as follows.

$$
k_{i}=k_{i}-E_{i}=s A k_{i}^{-\beta}-(\alpha+v)
$$

The differential equation (II.10) is depicted in Figure II.2. It can be easily seen that $k$ tends to its (stable) equilibrium value $k^{*}$ for all initial values. The exact value of this equilibrium value is:

$$
k_{i}=\left(\frac{s A}{\alpha+0}\right)
$$

Writing the production function in its capital-intensive form, and substituting $k$, one finds that the growth rate of output and the growth rate of the capital stock are equal along the path where $k$ takes on its equilibrium value. From (II.8) and 
(II.11) it then follows that the following must hold:

$$
Q_{i}=K_{t}=\alpha+v \text {. }
$$

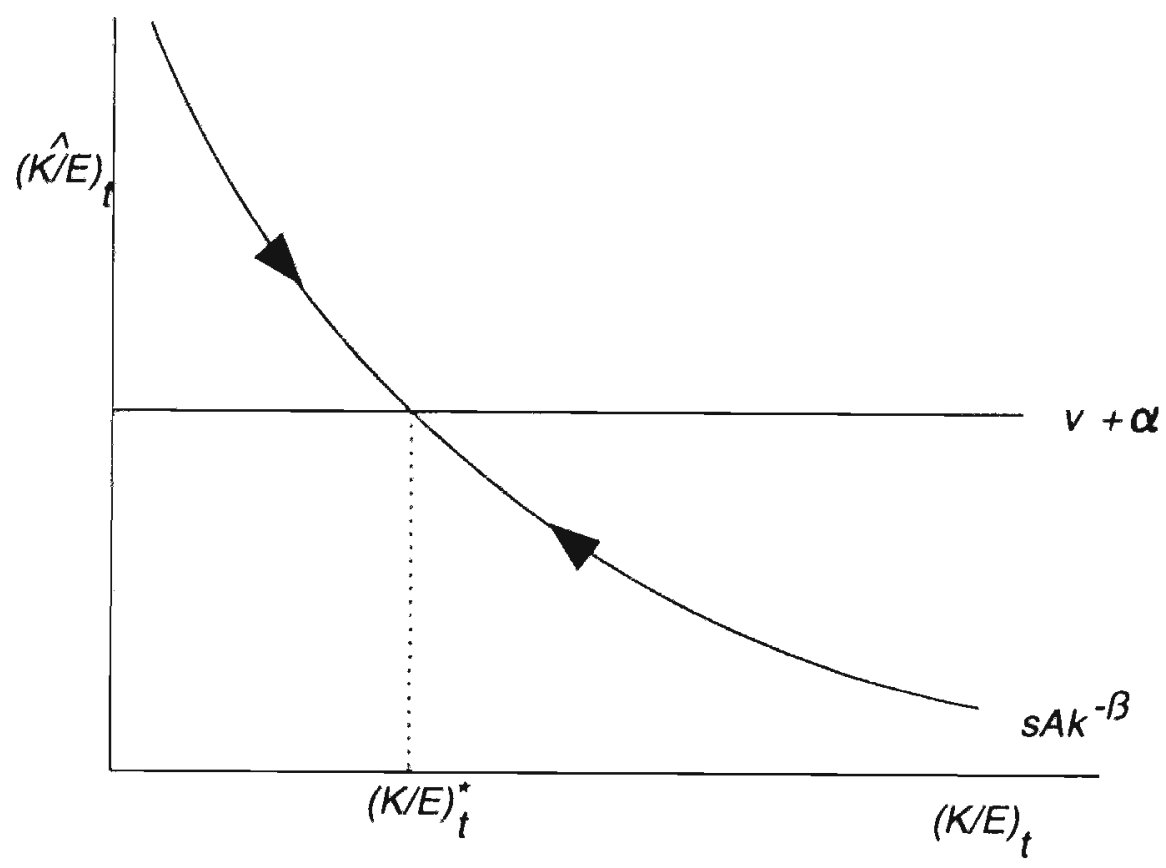

Figure II.2. The Dynamics of the capital labour ratio in the Solow model

Thus, the outcome of the model is that output and the capital stock grow along a balanced growth path at a rate equal to the sum of population growth and the rate of labour-augmenting technological progress. The economic mechanism behind this balanced growth path is the following. Whenever one of the input factors (labour or capital) grows at a faster rate, the supply of the other factor will be relatively tight. This will induce price movements and thus substitution (note the importance of a functional specification of the production function $f$ that allows for substitution) between factors, and change the (optimal) capital labour ratio ( $k$ ). Whenever this ratio takes on its equilibrium value again $(k)$, the economy will be back at a (new) balanced growth path. From this intuition, and from equation (II.11) above, one can deduce that the equilibrium value of $k$ is a positive function of the savings rate ( $s$ ), and a negative function of the rate of growth of the population (v) and the rate of technological progress $\alpha$.

Following his early contribution to growth theory, Solow (1957) derived a simple and elegant formula to assess the influence of several supply side factors upon the economic growth performance of a country in a quantitative way, thus setting the first steps along a path that later became known as growth accounting (see also 
section 2.5). This method assumes that the production function has the following general form, which allows for substitution between capital and labour.

$$
Q_{t}=A_{i} f\left(K_{,}, L_{k}\right)
$$

Here, $A$ is an index representing neutral technological change. Logarithmically differentiating this equation with respect to time and assuming that factors are paid their marginal product, one obtains the following expression.

$$
Q=A+\sigma_{k} R+\sigma_{i} C
$$

In this equation, $\sigma_{k}$ and $\sigma_{1}$ are the shares of capital and labour (respectively) in income ${ }^{3}$. This equation allows for a division of the growth rate of output into the contributions of the growth rates of labour and capital, and a residual factor (the growth rate of $A$, or total factor productivity), which is usually regarded as a measure of technological change.

\section{b. The Post-Keynesian Harrod-Domar Model of Economic Growth}

The post-Keynesian ideas on economic growth can be clarified using the HarrodDomar model. This model largely uses the same variables as the Solow model described above. The equations of the model can be specified as follows.

$$
\begin{gathered}
Q_{t}=\min \left(\frac{1}{a} K_{t}^{m}, \frac{1}{n} e^{\alpha u} L_{t}^{m}\right) \\
E_{t}^{m}=e^{\alpha i} L_{t}^{m} \\
\dot{K}_{t}^{m}=I_{t} \\
S_{i}=s Q_{t} \\
I_{i}=S_{i} \\
\frac{K_{t}}{K_{t}^{m}}=u_{t} \\
L_{i}^{m}=L_{0} e^{m}
\end{gathered}
$$

The capital and labour coefficients are denoted by $a$ and $n$, respectively. Looking at the equations of this model, one finds that there is only one difference with the neoclassical growth model: the form of the production function. While in Solow's model substitution between factors is possible, the Harrod-Domar model assumes that the elasticity of substitution is zero. This means that the production function (II.15) is of the Leontief type. In this case, a distinction must be made between the available quantity of a factor (denoted by a superscript $m$ ) and the quantity actually used (without superscripts). Thus, $u$ is defined as the capital utilization ratio.

${ }^{3}$ In the Cobb Douglas production function with CRS, $\sigma_{1}$ and $\sigma_{k}$ are equal to $\beta$ and $1-\beta$, respectively. 
Solving for the growth rates of the available capital stock $\left(K^{m}\right)$ and labour in efficiency units, it is found that the following holds.

$$
\begin{gathered}
\hat{K}_{t}^{m}=\frac{I_{t}}{K_{t}^{m}}=s \frac{Q_{t} K_{t}}{K_{t} K_{t}^{m}}=\frac{s}{a} u_{t} \\
\hat{E}_{t}^{m}=\alpha+v
\end{gathered}
$$

Now the question arises as to whether a growth path exists along which both factors are used completely at all times, as in the Solow model. Obviously, looking at the production function (II.15), such a path can only exist if 1) both factors are used completely initially, and 2) subsequently have the same growth rate. The first of these requires that none of the two factors is in abundance, or $K^{m} / a=E^{m} / n$, leading to $K^{m} / E^{m}=k=a / n$. Moreover, equations (II.22) and (II.23) immediately reveal that the second will only hold by chance, since the growth rates of $K^{m}$ and $E^{m}$ are completely determined outside the model (note that along the path searched here, $u=1$ ).

Hence, the conclusion drawn from the Harrod-Domar model is that balanced growth will only arise by chance. The rate s/a, at which capital expansion will grow in a situation of full utilization of capital $(u=1)$, is called the warranted rate of growth. If the actual rate of growth is equal to this warranted rate (i.e., $u=1$ ), there is some kind of balanced growth, in the sense that the capital stock will grow as rapidly as the production. If $\alpha+v$, which is called the natural rate of growth, is equal to the warranted rate of growth, a situation of completely balanced growth, as was found in Solow's model, will arise if the economy starts from a situation of full utilization of both factors. Slight differences between the warranted and natural rates will lead to unbalanced growth paths ('knife edge' property).

However, the natural and warranted rate need not be equal. Figure II.3 depicts three possible different situations. In each of the figures, the growth path of the economy is to be found on the line that crosses the horizontal axis at the point $a / n$ (see above). In II.3a, the natural and warranted rates are equal and the economy grows at a balanced path. In II. $3 \mathrm{~b}$, the warranted rate is smaller than the natural rate, and will restrict the growth path, leading to unemployment. In II.3c, the natural rate is smaller than the warranted rate, thus restricting the growth rate. In this case, the utilization rate of capital will fall to some equilibrium value for which the actual rate of growth (us/a) is equal to the natural rate. 


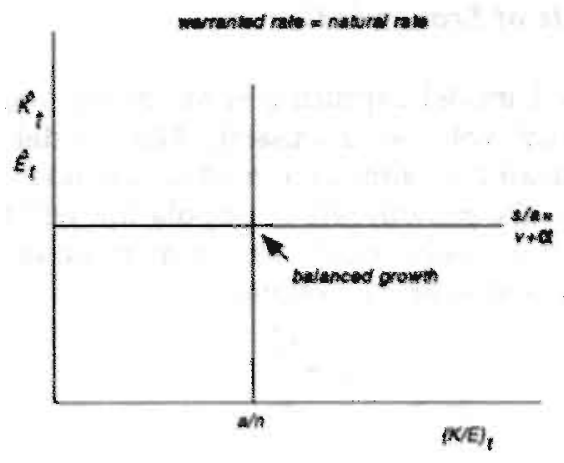

Figure 11.32. The dynamics of capital and labour inpurs in the Harrod-Domar model, balanced growth

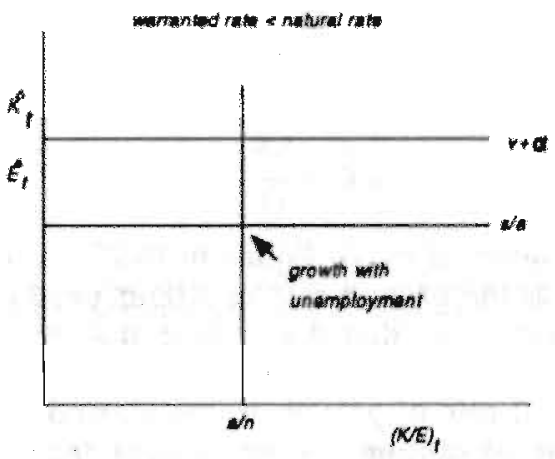

Figure II.3b. The dynamics of capital and labour inputs in the Harrod-Domar model, growth with unemployment

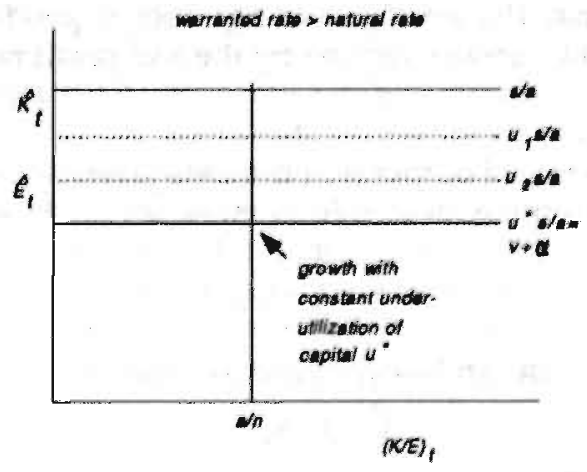

Figure 11.3c. The dynamics of capital and labour inputs in the Harrod-Domar model, growth with capital under-urilizarion 
In this section, a stylized model capturing some of the basic ideas of the neoKeynesian growth theory will be discussed. The model as such cannot be attributed to any specific author, although most of it is taken from Kaldor (1957). For reasons of simplicity, the growth rate of population will be set to zero, so that technological progress is the only source for an increase of the labour input (in efficiency units). The equations are as follows.

$$
\begin{gathered}
G_{t}=\frac{Q_{t}}{L_{t}} \\
G_{t}=\alpha+\beta \frac{I_{t}}{K_{t}} \\
S_{t}=s_{w} \sigma_{t t} Q_{t}+s_{k} \sigma_{k t} Q_{t} \\
\dot{K}_{t}=I_{t} \\
S_{t}=I_{t} \\
\sigma_{k t}=\frac{r_{t} K_{t}}{Q_{t}}
\end{gathered}
$$

Labour productivity is denoted by G. Equation (II.25) is the technical progress function, which says that the growth rate of labour productivity is equal to an exogenous part $(\alpha>0)$ and a part that depends on the growth rate of the capital stock $(1>\beta>0)$. This equation is taken from Kaldor (1957). It presents the counterpart of the natural rate of growth in the Harrod-Domar model, since it gives the maximum rate of output growth starting from a situation with full utilization of resources.

Another essential part of the neo-Keynesian model, taken from Robinson and Kaldor, is the savings function (II.26). This function assumes that the proportion saved out of labour income $\left(s_{w}\right)$ is smaller than the proportion saved out of profits $\left(s_{k}>s_{w}\right)$. This means that the average savings rate depends upon the income distribution, which is in turn determined by the real profit rate $r^{4}$, as in equation (II.29),

The warranted growth rate of output is in this case given by the growth rate of the capital stock, which, assuming for simplicity that $s_{w}=0$, can be expressed as follows:

$$
R_{t}=\frac{S_{t}}{K_{t}}=s_{k} r_{t}
$$

The natural rate of growth can be expressed as follows:

$$
G_{i}=\alpha+\beta s_{k} r_{i}
$$

The profit rate is defined as the ratio of total profits to the capital stock. 


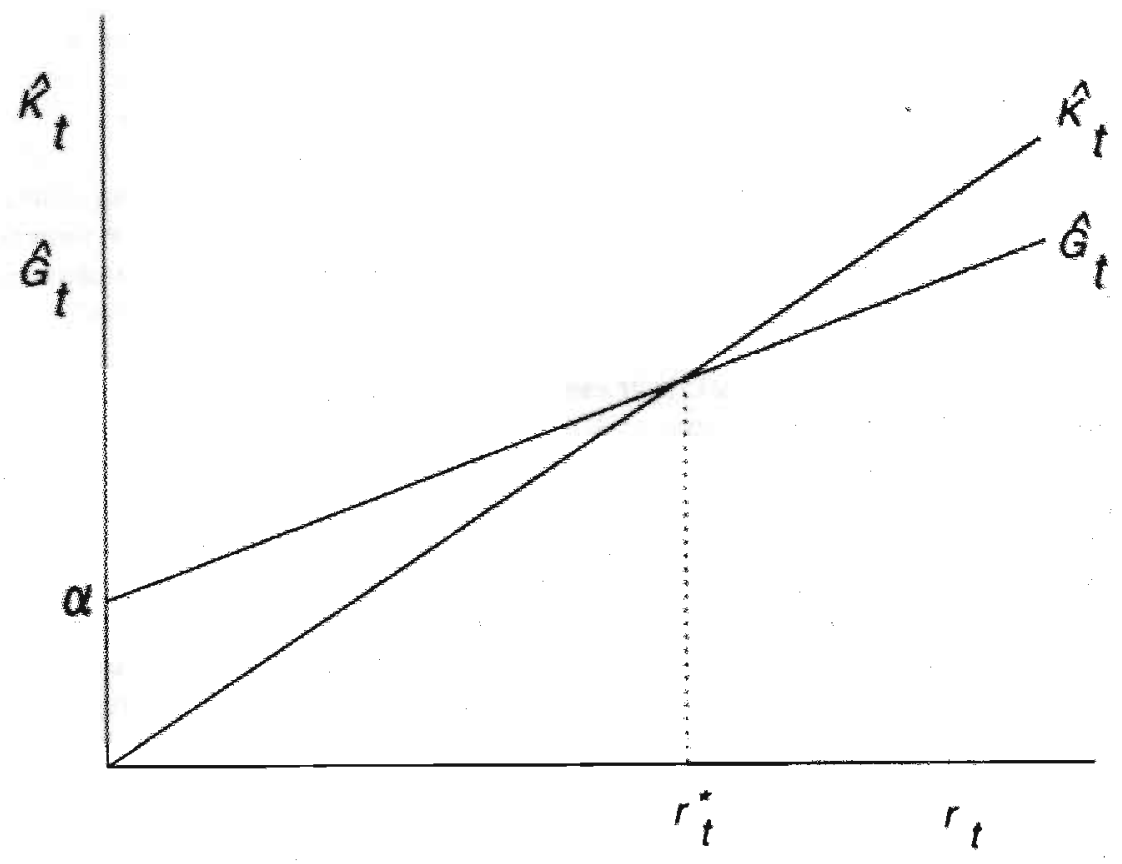

Figure II.4. The dynamics of labour productivity and the capital stock in the neo-Keynesian growth model

Both the warranted and the natural rate of growth are a function of the profit rate (income distribution). Equations (II.30) and (II.31) are drawn in Figure II.4. Since $\beta<1$ and $\alpha>0$, there will always be an intersection point between the two curves. A balanced growth path is found at this point of intersection, since the capital stock and the amount of labour (in efficiency units) will grow at equal rates.

Although a formal argument will not be given here, the general neo-Keynesian idea is that for unequal rates of growth of labour and capital (i.e., for points to the left or right of $r^{\circ}$ in Figure II.4), the profit rate will change. In a situation where the capital stock grows faster than labour supply, a demand shortage on the consumer good market will drive the profit rate down. In case the labour supply grows faster than the capital stock, excess demand will drive the profit rate up. Thus, for points to the left of $r$ in Figure II.4, the profit rate will increase, while for points to the right of $r^{*}$ it will go down. Hence, $r$ is the stable equilibrium rate of profit in this model. As in the neoclassical model, a stable (balanced) growth path (with zero population growth) is found through equations (II.24), (II.30) and (II.31).

\footnotetext{
${ }^{5}$ The interested reader is referred to, for example, Kaldor (1957) and Coodwin (1967).
} 


$$
Q_{t}^{*}=R_{t}^{*}=G_{i}^{*}=\frac{\alpha}{1-\beta}
$$

This stability characteristic is described by Kaldor (1957: 285) as follows:

"(...) the system tends towards an equilibrium rate of growth at which che 'natural' and the 'warranted' rates are equal, since any divergence between the two will set up forces tending to eliminate the difference; and these forces act partly through an adjustment of the 'natural' rate, and partly through an adjustment of the 'warranted' rate".

Later, Kaldor $(1966,1970)$ added another element to his description of the process of economic growth, generally known as Verdoorn's law. According to this 'law', there is a positive relation between economic growth and productivity, with causality indeed going from the first to the latter. This positive relationship is caused by static and dynamic economies of scale arising from the growth of production. Static economies of scale in this sense correspond to the notion that a larger production volume provides opportunities for a further division of labour (similar to that proposed by Smith) and economies of scale at the individual firm level. Dynamic economies of scale are associated with the effects of learning-bydoing and incremental technical progress which occur as increasing experience is gained from using a production process.

The application of Verdoorn's law opens up possibilities for dynamic models of economic growth, in which cumulative causation is an important element. This potential can easily be recognized when considering the dual relationship between economic growth and productivity growth. The traditional viewpoint is that there is a strong causal relationship from productivity to economic growth. Verdoorn's law assumes that there is also an important relationship going the other way. Thus, a combination of these two relationships opens up the possibility of selfreinforcing growth, where an initial advantage can be of decisive importance for growth rate differentials. This feature of the neo-Keynesian model will be discussed in more detail in section 2.5, as well as in Parts Two and Three. 


\subsection{Nete Neoclassical Growth Models: Endogenous Innovation}

As reaction to the unrealistic assumption of exogenous technological change, and long after endogenous technological change had been incorporated in Schumpeter's theory and the evolutionary tradition, neoclassical scholars began to introduce endogenous technological change in growth models. In order to endogenize innovation, the 'new' neoclassical models have to deal with the public good features of technological progress, and the problems this poses with regard to appropriability of innovation. The way in which this is done will brieny be discussed below.

\section{a. Innovation: Extemalities and Increasing Returns}

New neoclassical growth models follow Arrow (1962) in assuming that there are important externalities concerned with the development of technical knowledge. In most cases, these externalities take the form of general technological knowledge which can be used to develop new methods of production and which is avallable to all firms. An exception to this specification is Lucas (1988), where the externalities take the form of public learning, which increases the stock of human capital.

The existence of externalities in the innowation process is closely connected to an important novelty in new neoclassical growth models: the existence of increasing returns to scale in the aggregate production function. In the old neoclassical model, it is typically assumed that the production structure is characterized by constant returns to scale. In mathematical terms, the production function is homogenous of degree one. Multiplying factor inputs by some (positive) number will also multiply output by that number. The presence of externalities, however, means that if one firm doubles its inputs, the inputs of other firms will also increase. Hence, this results in a more than proportionate increase in aggregate output.

Thus, in the case of constant returns to scale, a larger resource base can influence the level of output, but not the growth rate. In case of endogenous technological change, innovation itself is a factor of production. Since innovation can influence the growth rate of production, as in the old model, the case of constant returns to scale no longer applies. Instead, the production function is characterized by increasing rehurns to scale.

An overview of the different models, as well as a more precise indication of the mathematical implication of the ideas discussed, is given in Diagram II.1. Perhaps the most clear and simple way of modelling the externalities involved in the innovation process is found in early papers like Romer (1986) and Lucas (1988). In this approach, technological change is treated as a separate factor in the (aggregate) production function. Individual agents (firms, labourers) invest in (some form) of technological change, and spillovers of this investment are added to the inputs of all other firms. These models have no explicit microeconomic foundation for the production of knowledge (in a separate research sector) itself, and,

\footnotetext{
This section, as well as sections b up to d below, draw largely on Verspagen (1992a),
} 
Dlagram IL.1. A schematic description of the endogenization of technological change in new neoclassical growth modets

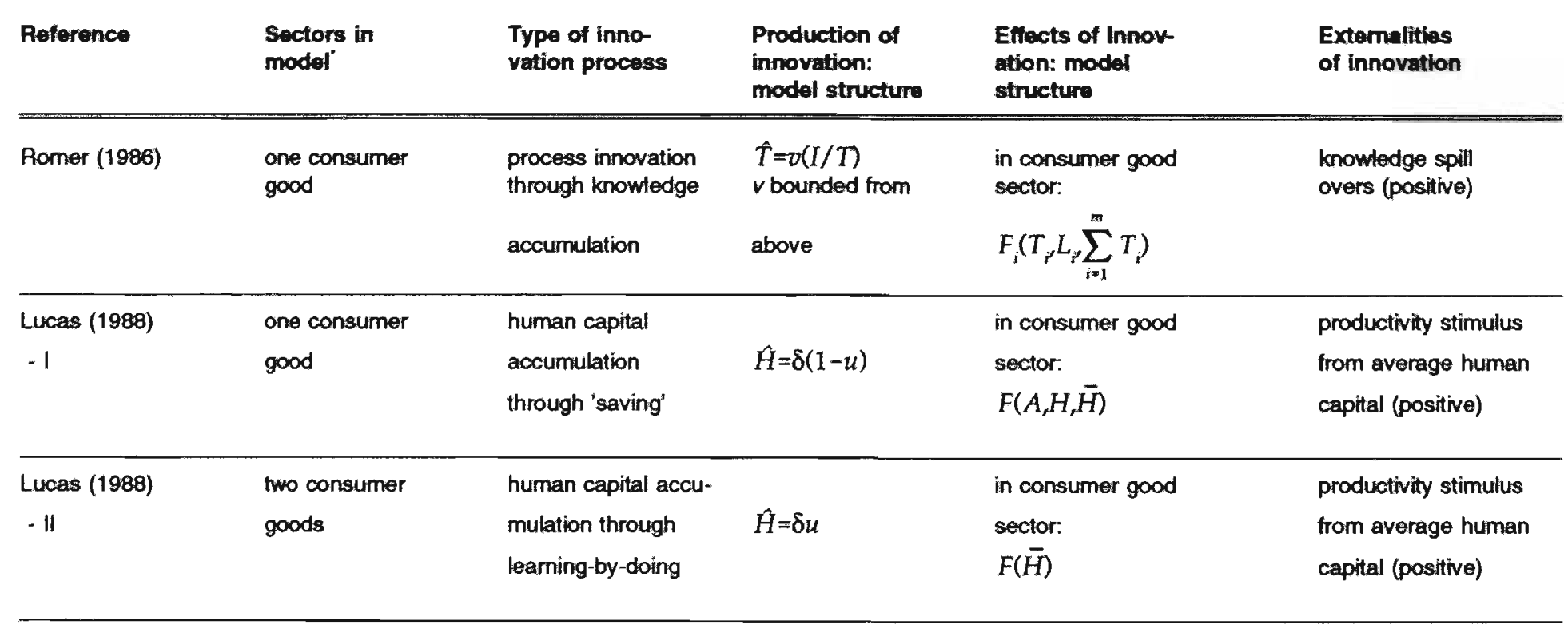

(continued on next page) 


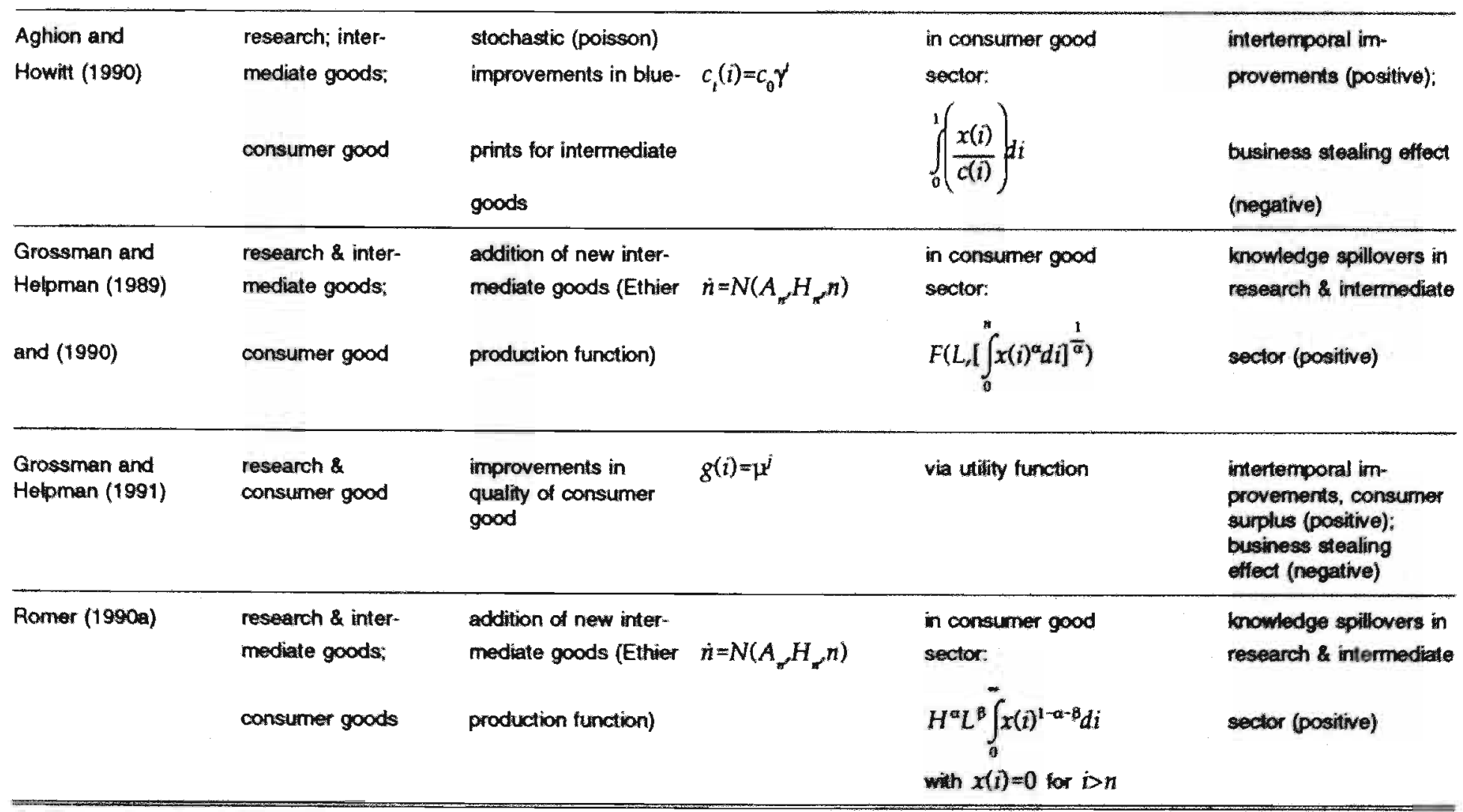


therefore, do not explicitly address the question of market structure and a market price for technological change. They only look at the consequences of investment in knowledge.

The general form of these models assumes that technological change enters the production function of an individual entrepreneur in two separate terms. The first term describes the outputs of private investments in knowledge, which have the normal characteristics (decreasing marginal returns). The second term describes the existence of knowledge spillovers. This term is related to the other firms' investment in knowledge. In mathematical terms, this can be stated as follows:

$$
Q_{i}=F_{i}\left(T_{i} L_{i}, \bar{T}\right)
$$

In this equation $Q$ is output, $L$ is some (conventional) production factor like labour, $T$ represents the stock of investment in technological change (human capital in Lucas 1988) and $i(1 . m)$ is an index representing the $i$ th firm. The bar indicates a general volume, available to all firms in the economy. In Romer (1986), it indicates the sum of all individual $T \mathrm{~s}$, while in Lucas (1988) it is the average level of human capital.

An obvious drawback of this simple approach is the lack of a clear microeconomic foundation explaining the working of the externalities, and the decision to invest in technological change. Later models following the early contributions of Romer (1986) and Lucas (1988) have tried to fill this gap. Most notable contributions are in Aghion and Howitt (1990), Romer (1990a) and Grossman and Helpman (1989, 1990, 1991a). Some of the implicit assumptions about (the output of the research sector made in the early approach are made explicit in this second approach. The general approach chosen in this second type of models is to make a distinction between a research sector and other sectors in the economy, i, $e_{,}$technological change is explained from the perspective of market structure and price relations.

The research sector fypically produces two types of goods: blueprints of new (intermediate) goods and (general) technological knowledge. A (first) difference between blueprints and general knowledge is concerned with their application in the production process. General technological knowledge cannot be applied directly in the production of goods, but has a more general nature. It adds to the productivity in the research sector, and is thus used in the production of blueprints. General knowledge is produced as a by-product of the innovation process. It can be used not only by the entrepreneur who developed it, but also by other firms in the rescarch sector (non-appropriability). This effect is completely public, so that it embodies the externalities in the innovation process.

Blueprints are specific. They provide the guidelines to produce a given type of intermediate good (or consumer good). Firms operating in the research sector devote their efforts to producing and selling these blueprints. The level of output (in the form of blueprints) in the research sector depends on human capital input, general knowledge input and a (fixed) productivity parameter. Blueprints yield a positive price because they enable producers of consumer or intermediate goods to produce at lower cost or higher quality. 
Two different approaches to modelling the advance in general knowledge are found. In the first one, introduced in Aghion and Howitt (1990), technological change increases the productivity in the production of intermediate goods. It is assumed that the development of production costs of intermediate goods over time takes the following form:

$$
c_{i}(i)=c_{i}=c_{0} \gamma
$$

where $c$ stands for production costs, $\gamma$ is a parameter indicating the size of the innovation (technological opportunity), and $i$ denotes a specific intermediate good. A period $t$ is specified as the time span during which one blueprint is used, so that each time an innovation occurs, the production costs are reduced.

Grossman and Helpman (1991a) use the same type of relation, but specify product innovation as steps up the quality ladder of a (fixed) range of consumer goods $g$. Similar to equation (II.34), the highest quality version of each variant $i$ of the consumer good is specified as follows:

$$
g(i)=\mu^{j}
$$

In this equation, $\mu$ is a parameter, and $j$ is an index for the highest attained position on the quality ladder.

Both these equations reflect the notion that each new innovation (blueprint) builds upon the previous one, so that the productivity (quality) of the intermediate (consumer) goods is always higher for the next innovation. This means that the impact of an innovation is not only to raise productivity (quality) in the present period, but also in the periods that follow. Since innovations in future periods may (and will) be sold by different firms, the value of an innovation to society as a whole goes beyond its value for the innovating firm in the present period. Thus, there is a positive (intertemporal) externality in the innovation process.

However, there is also a negative externality involved in the production of innovation. This effect, which is called creative destruction after Schumpeter, or alternatively, the business stealing effect, is due to the fact that a new innovator, by bringing his innovation on the market, destroys the monopoly rents for the previous innovator. This is implicit in equations (II.34) and (II.35), where each new innovation makes the previous one obsolete. This negative externality is not present in the other models of endogenous technological change considered below, This leads to a difference in the 'welfare properties' of these two types of models, which will be discussed in more detail below.

The second approach to modelling the research sector is found in Romer (1990a) and Grossman and Helpman (1989, 1990). In these models, the development of general knowledge is typically seen as a by-product of the research process. The following general form of the production function for blueprints is used: 


$$
\dot{n}=N\left(A_{n} H_{n}, n\right) \text {. }
$$

$A$ is a productivity parameter, $H$ is human capital input, $n$ is the number of blueprints, a subscript $n$ points to the research sector. The presence of $n$ itself in the (aggregate) production function for $n$ points to an important positive externality engaged in the production of blueprints. Each new blueprint generates general knowledge as a by-product, which is a stimulus for the development of new blueprints by all firms in the research sector. This amount of general knowledge is measured by $n$ itself, which explains the presence of $n$ in the rhs of (II.36).

\section{b. Innovation: Appropriability and Market Structure}

If innovation was a purely public good, obviously none of it would be produced in a purely free market economy. Therefore, the new theory has to introduce some effects of technological change that are appropriable. In order to do this, the models build to a large extent on work in the field of industrial organization, thus more or less incorporating this branch of literature in macroeconomic growth models. Monopolistic tendencies in the research market, enabling the producer to earn monopoly rents that cover its research costs, are an important issue in these models.

An overview of the different models and the mathematical details can be found in Diagram II.1 above. The early models discussed above do not elaborate explicitly upon modelling the microeconomics of innovation. All markets (including the implicit technology market) are competitive in these models. In Romer (1986) there is only an assumption about maximization of profits by means of investment in knowledge, which has its effect through a very general production function of technological knowledge. In the first version of the Lucas model, human capital is accumulated through explicit production: A part of (individual) working time is devoted to accumulation of skills. It is assumed that the growth rate of human capital is a linear function of the time devoted to accumulation:

$$
\hat{H}=\delta(1-u) \text {, }
$$

where $u$ is the fraction of time devoted to productive (in a direct way) labour.

Lucas' (1988) second model assumes a different structure of technological change. In this case all technological change (human capital accumulation) is related to endogenous learning-by-doing. Instead of assuming that the rate of accumulation of human capital is dependent on the time explicitly devoted to this accumulation, it is assumed that the time devoted to (direct) production determines the rate of growth.

The process of innovation and the role of appropriability is more complex in the second (later) type of models. These models of endogenous technological change tackle the problem of the public good characteristics of technological knowledge 
by assuming that part of the effects of the innovation can be appropriated (by monopoly power) and that another part takes the form of external effects. Thus, there will be an incentive to produce innovations (because of monopoly power), but there will also be a spillover effect (externality).

Once again, the distinction between blueprints and general knowledge is important. As already touched upon above, a second difference between blueprints and technological knowledge is the degree of appropriability. Blueprints can be appropriated completely (for example by means of a patent) by the producer, who thus becomes a monopolist (oligopolist if there are close substitutes). On the other hand, general technological knowledge, as explained above, cannot be appropriated and flows over directly to the other producers of blueprints. Thus, the problem of the lack of incentive to produce technological change in the presence of public good features is solved by making the distinction between general technological knowledge (non-appropriable) and specific technological knowledge (appropriable).

A closer look at the different models reveals another distinction between two types (this distinction corresponds to the one made above). A first approach to the modelling of the innovation sector is found in Aghion and Howitt (1990) and Grossman and Helpman (1991a). In Aghion and Howitt, technological change enters the consumer goods sectors (indirectly) via the intermediate goods sector. A fixed continuum of intermediate goods $i \in[0 . .1]$ exists, the production costs of which are influenced by innovation via equation (II.34). In each period, (only) one patented blueprint is sold by the patent holder (monopolist) to the (fixed) range of sectors ([0..1]) which produce intermediate goods. Each innovation (blueprint) affects all intermediate sectors in the sense that it lowers costs of the intermediate good to the same extent. The value of a patent is thus determined by the profits made in the intermediate sector. In Grossman and Helpman (1991a), each new blueprint increases the quality of each consumer good in the fixed continuum.

Both in the case of this 'quality ladder' approach and in the case of the Aghion and Howitt model of the research sector, technological advances are stochastic: The chance of success of research efforts is represented by a Poisson distribution, i.e., the arrival rate of research success in a given period depends upon the research efforts (intensity) and the parameters of the distribution. In deterministic innovation models there exists a fixed relation between inputs and outputs in the research process. Input in the innovation process is human capital. In these stochastic models of innovation, the more human capital is used, the bigger is the chance of research success. The (expected) rate of return to human capital is thus the main determinant of the wage rate (human capital is assumed to be the only form of labour input). Human capital is also used in the production of other (intermediate, consumer) goods, so that producers have to choose in which sector to use it.

Each producer of blueprints sells its products to the intermediate/consumer good sector. Each blueprint is patented, so that the producer can make a monopoly profit provided that his blueprint is the most advanced one available. As soon as a new blueprint occurs, the current producer leaves the market. The time span in 
which one blueprint is used is called a period (and is variable). Profit maximization and free entrance to the research sector ensures that expected profits are equal to the development costs of the blueprint (limit pricing, as it is called in Grossman and Helpman 1991a).

This stochastic approach to innovation captures the basic notion of innovation as a search process with an uncertain outcome. In the evolutionary tradition, Dosi $(1988 \mathrm{a}, 1988 \mathrm{~b})$ has pointed to this aspect of the innovation process. Dosi makes a distinction between weak uncertainty (the probability distribution of an event is known) and strong uncertainty (not even the probability distribution is known). He argues that innovation involves a considerable degree of strong uncertainty. Of course, this latter notion is not captured in the stochastic model discussed above (where the probability distribution is known explicitly). However, modelling strong uncertainty is extremely difficult and involves a wholly different approach than the one used in the neoclassical tradition (see Chapter 3).

A different approach to modelling the innovation sector is found in Romer (1990a) and Grossman and Helpman $(1989,1990)$, where each new blueprint leads to a new variety of the intermediate good used in the production of consumer goods. In these models, three sectors exist: a research sector, an intermediate goods sector and a final goods sector. The first two sectors can be thought of as being combined in one. All sectors use human capital, while the final goods sector also uses intermediate inputs produced in the other sector. The production function in the consumer goods sector has a functional form borrowed from Ethier (1982). In Grossman and Helpman $(1989,1990)$ it has the following form.

$$
Q=F\left(L,\left[\int_{0}^{n} x(i)^{\alpha} d i\right]^{\frac{1}{\alpha}}\right)
$$

$x(i)$ is an intermediate good, and $\alpha$ is a parameter. All other symbols have the meaning defined before. The Ethier functional form of the production function has the property that an increase in the number of varieties increases productivity. Thus, an increase in $n$ through efforts in the research sector raises productivity in the consumer goods sector. The varieties of the intermediate good are not complete substitutes, since every new variety adds to the productivity in the consumer goods sector (product differentiation). Therefore, different producers (each producing one variety of the intermediate good and thus having some degree of monopoly power) can co-exist in this sector without prices being driven to marginal costs. Assuming free entry in the research sector, prices are set by a markup above marginal costs, as in the standard monopolistic competition (oligopoly) case. This markup just covers the research costs, so that net profits are equal to zero. As in the stochastic models, human capital is the input in the innovation process in these deterministic approaches to the innovation process. The more human capital is used, the larger is the research output, so that the (certain) rate of return to innovation efforts determines the wage rate.

The framework of rationality used in the models discussed is usually strongly criticized in evolutionary theories (Dosi 1988a, 1988b, Dosi et al. 1988). In this type 
of theories, it is argued that firms, given the strong uncertainty they face, cannot optimize profits in the usual way. Instead, bounded rationality is used as the framework in which firms make decisions. Bounded rationality (Simon 1986) reflects the notion that agents only take into account some variables and relations in predicting the outcome of alternative behavioural patterns. The first efforts to use the concept of bounded rationality in (growth) models have been undertaken only recently, and are still in the early phases of development. They will be discussed in more detail in the next chapter.

Summarizing, it can be said that endogenization of technological change in neoclassical growth models basically comes down to assuming that there is a distinction between appropriable and non-appropriable effects in the production of innovation. In the neoclassical literature, this notion goes back to Arrow (1962). The distinction is necessary because the existence of externalities poses the problem of whether there is an incentive to produce innovation. It is typically assumed that some degree of monopoly power (patent protection, product differentiation) is needed in order for appropriability.

\section{c. Solving the Model: Equilibrium Growth Paths}

The explicit modelling of the externalities, increasing returns and market structures in new neoclassical models would only be of limited use, if the conclusions from the overall model did not differ from those drawn from the basic neoclassical model. In that case, the innovation-modelling exercise would merely have a cosmetic effect. However, in this subsection it is shown that endogenous technological change has consequences for the equilibrium growth paths of an economy. An overview of the results is given in Diagram II.2.

In Romer (1986) and Lucas (1988), the model is solved by maximizing the single objective function (utility). The procedure is more difficult in the later models, because these include more (interrelated) sectors (equations). The general way of solving these models is to assume equilibrium on the market for human capital (labour) (Aghion and Howitt 1990, Romer 1990a, Grossman and Helpman 1989, 1990) or the markets for human capital and capital (Grossman and Helpman 1991a). In the former papers, equating the reward for human capital in both (research \& intermediate goods and consumer goods) sectors yields a single price for human capital inputs. This price is equal to the marginal product of human capital in the two sectors, and thus, given the production functions in the two sectors, determines the allocation of human capital resources over the two sectors and the levels of output. This yields an equilibrium growth path of the production and consumption of all goods.

In Grossman and Helpman (1991a) equilibrium is found at the point where labour market equilibrium coincides with capital market equilibrium. The capital market equilibrium ensures that an equilibrium rate of interest is reached which both satisfies intertemporal consumer utility maximization and equals the rate of return of the 'quality leading' firm which operates in the research sector and the consumer goods sector (arbitrage). Together with labour market equilibrium (as in the other models), this determines the equilibrium growth path. 
Diagram II.2. A sctrematic description of the characteristics of the growth path in new, neoctassical growth models.

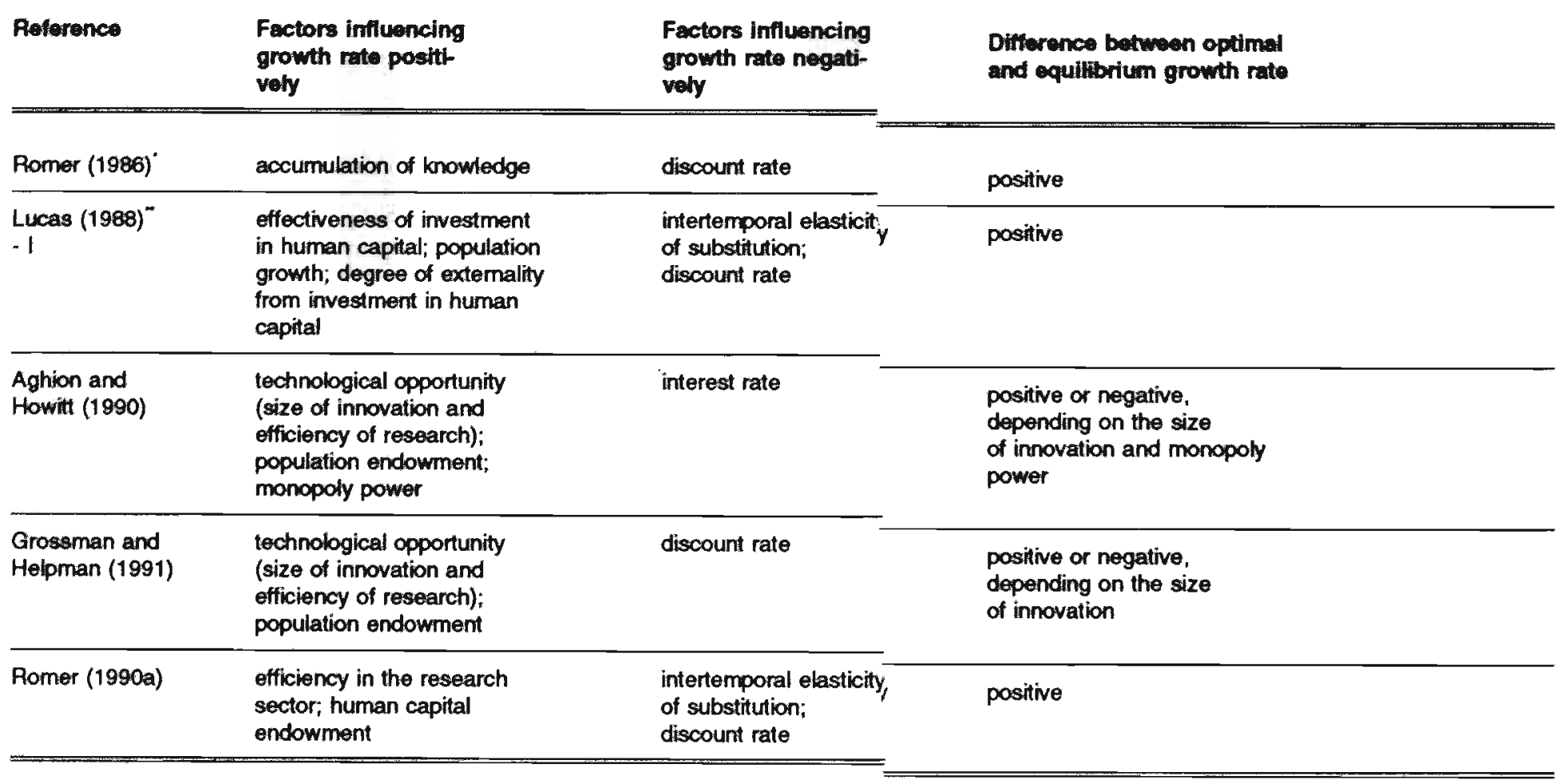

- Romer's (1986) model is formulated in very general terms, and the equation for the growth rate is not fully specified.
- Here, the growth rate is defined as the growth rate of efficient human capital. 
The general characteristics of the growth paths found are as follows. The growth rate of the economy is a positive function of technological opportunities and the size of human capital (labour) endoroment. In addition, factors found in the basic growth model, such as the time preference parameter, the interest rate and the intertemporal elasticity of substitution, affect the growth rate in their usual way.

Technological opportunities are reflected in the arrival rate parameter in the poisson distribution for innovation and the size of innovations $(\gamma, \mu)$ in Aghion and Howitt (1990) and Grossman and Helpman (1991a) or the productivity of research in Romer (1990a) and Grossman and Helpman (1989, 1990). Their effect is intuitively plausible. The role of increasing returns is reflected by the role of the supply of human capital in the equation for the growth rate. This role of human capital (functionally equal to labour) endowment as the factor responsible for increasing returns is somewhat awkward. One would expect a factor more closely related to technical change to embody this effect.

Being as it is, the models lead to the conclusion that the largest countries (simply measured in terms of population) should also experience the highest growth rates, a hypothesis that is not only implausible, but also inconsistent with the empirical facts. As Aghion and Howitt (1990: 22, emphasis added) note when they discuss this result, "the positive effect of [the total supply of labour] on [the average growth rate] has the unfortunate implication (...) that larger economies should grow faster. (...) We accept the obvious implication that this class of models has little to say, without considerable modification, about the relationship between population size and growth rate". The most obvious interpretation of this peculiarity is probably that it is the result of the stylized way of modelling the inputs into the innovation sector. A more realistic (but also more complicated) way to tackle the innovation process would be necessary to solve this deficiency and attribute the increasing returns argument more directly to innovation.

Each of the models treated above has some specific additional factors influencing the growth path. The most notable of these are the following. In Romer (1990a), the value of the growth rate does not depend on the level of population, like in other models, because it is assumed that the amount of human capital is fixed. In Aghion and Howitt (1990) the degree of monopoly power has a positive influence on the growth rate. The role of monopoly power reflects the Schumpeterian notion that the appropriability of innovation rents spurs innovation efforts, and therefore economic growth. Moreover, their paper shows four types of equilibria (a stationary equilibrium with positive growth, a stationary equilibrium with zero growth, a 2-period cycle and a no-growth trap). Since there is a stochastic element in the production function for innovation in this model, the average growth rate shows (random) variability (this also holds for Grossman and Helpman 1991a). Thus, a measure of the average variability of the growth rate can be formulated.

To sum up, it can be said that the basic driving forces behind the growth rate in the models discussed above are technological opportunity, as measured by the (average) size of innovation and the efficiency in the research sector, and population (human capital) endowment. 


\section{d. Optimality and the Market Process}

From welfare economics, it is generally known that the presence of externalities has important consequences for the distinction between the optimal and the equilibrium market result. This is also true of the new neoclassical growth models. An overview of the differences between the equilibrium and optimal growth path in the different models is given in Diagram II. 2 above.

The effect of externalities is perhaps made most clearly visible in the early aggregate models in Romer (1986) and Lucas (1988). The procedure followed there is simply to calculate the optimal rate of return by intertemporally maximizing the aggregate utility function subject to the restriction of the production function. The outcome of this exercise is that the equilibrium growth rate is smaller than the optimal growth rate, due to the existence of externalities. This leads to the conclusion that government policies (subsidies) are necessary to increase the equilibrium growth rate up to the level of the optimal growth rate.

This procedure is repeated in more or less the same, although more detailed, way in the other models. For the characterization of the differences between the optimal and the equilibrium growth paths of the economy, it is again useful to make the distinction between the models by Aghion and Howitt (1990) and Grossman and Helpman (1991a) on the one hand and the other models on the other. This is because the first type of models takes into account the negative externality that is not taken into account in the other models, as explained above.

In the former two models, the difference between the equilibrium growth rate and the outcome of the 'social planning exercise' is not unambiguous in sign. It is possible that too much is invested in research from a welfare perspective. The positive externality in the innovation process (i.e., the effect that an innovation lowers production costs beyond the period of the current innovation) leads to underinvestment in innovation. However, the negative externality (the businessstealing effect) leads to overinvestment. In addition to these two externalities in the innovation process, there is also a monopolistic distortion effect which creates a difference between the equilibrium and optimal growth rate: The presence of monopolistic market structures allows for innovation, but reduces the consumer surplus. This effect can also work either way, and vanishes in case of some functional specifications of the production structure. The question as to which of the two external effects will dominate, and hence the question of whether the equilibrium growth rate is smaller or larger than the optimal growth rate, depends on the size of innovation and the degree of monopoly power. For large innovations (and little monopoly power), the social value of innovation is large relative to the private value to the monopolist, so that the optimal growth rate is larger than the equilibrium growth rate. When the size of innovation is small (and monopoly power large) the opposite case arises.

In the Grossman and Helpman (1991a) paper based on the Aghion and Howitt approach, the positive externalities of innovation concern the intertemporal quality

\footnotetext{
The choice of the functional form of the utility function is generally without discussion.
} 
spillover, which is part of the consumer surplus due to innovation. Innovation is passed onto the consumer in the form of quality improvements with constant prices $^{8}$. The business-stealing effect is also present in this model. This effect is relatively large for small and for large innovations, so that the optimal growth rate exceeds the equilibrium growth rate only for intermediately sized innovations.

In Romer (1990a) and Grossman and Helpman (1989), the socially optimal rate of growth is unambiguously larger than the equilibrium growth rate. This is caused by the presence of positive and the absence of negative externalities. Thus, the growth rate (and welfare) can be increased by subsidizing research efforts. This is a simple reproduction of the results in early models as proposed in Romer (1986) and Lucas (1988).

\section{e. Application: The Stylized Endogenous Growth Model 9}

After the above review the new neoclassical growth models and the role of endogenous innovation, the present section will present a simple illustration of these models. The model chosen is very simple, and draws mainly on Lucas (1988). Similar to Lucas, first a version of the model with exogenous innovation will be presented, in order to explain the differences between endogenous and exogenous innovation. The result of this exercise, i.e., a reproduction of the outcomes of Solow's growth model, is due to Cass (1965).

The central equation of the model is the production function. As in Solow's growth model (section 2.2), this function is assumed to have a Cobb-Douglas form with labour-augmenting technological change.

$$
Q_{t}=A\left(e^{\alpha} L_{t}\right)^{\beta} K_{t}^{1-\beta}
$$

The intertemporal utility function is defined in terms of per capita consumption, and has the CES form. In aggregate form, utility is defined as

$$
\int_{0}^{\infty} e^{-\rho t} \frac{1}{1-\sigma}\left(c_{t}^{1-\alpha}-1\right) L_{i} d t .
$$

with $c$ denoting per capita consumption, $\sigma$ standing for the intertemporal elasticity of substitution, and $\rho$ denoting the discount rate. Equation (II.40) assumes that consumers have equal preferences, so that per capita income is constant over population. Moreover, it is assumed that all labour is used, so that $L$ is equal to population. Finally, there is a budget constraint which holds at each point in time ${ }^{10}$.

According to this equation, the sum of consumption and investment is equal to

\footnotetext{
The result that prices are independent of quality hinges on the functional specification of the quality function. It can be shown that for different functional specifications than the one used in Grossman and Helpman (1991a) prices change (rise) over time.

This section draws mainly on Lucas (1988).

so In a more complicated model, one could allow for a capital market for intertemporal borrowing. This yields the same results if one lays certain restrictions on borrowing (No-Ponzi game condition). See Blanchard and Fisher (1989).
} 


$$
\dot{K}_{t}=I_{i}=Q_{t}-L_{i} c_{t}
$$

production (the equivalent of the definition of the savings rate in the early growth models. Growth paths of the economy described by (II.39) - (II.41) are found by maximizing (II.40) under the restriction (II.41). To find this path, substitute (II.39) in (II.41) and set up the current value Hamiltonian".

$$
H=\frac{L_{t}}{1-\sigma}\left(c_{l}^{1-\sigma}-1\right)+\theta\left(A\left(e^{\alpha t} L_{t}\right)^{\beta} K_{t}^{1-\beta}-c_{t} L_{t}\right)
$$

In this optimal control problem, $c$ is the control variable, $K$ is the state variable, and $\theta$ is the current value multiplier. A path maximizing (II.40) must satisfy the budget constraint (II.41) and the following conditions.

$$
\begin{gathered}
\frac{\partial H}{\partial c}=0 \quad \Rightarrow \quad c_{t}^{-\sigma} L_{t}-\theta L_{t}=0 \\
\rho \theta-\frac{\partial H}{\partial K}=\theta \Rightarrow \rho \theta-\theta(1-\beta) A\left(e^{\infty} L_{t}\right)^{\beta} K_{t}^{-\beta}=\theta \\
\lim _{t \rightarrow \infty} e^{-\rho t} \theta_{t} K_{t}=0
\end{gathered}
$$

The last equation is the terminal condition, or the transversality condition.

While there are more paths that satisfy (II.41) and (II.43)-(II.45), only the balanced growth path will be considered here. Cass (1965) shows that under reasonable circumstances any solution for the system will converge to this balanced path. Along the balanced growth path, all variables grow at a fixed rate. Assume first that the (fixed) rate of growth of $c$ is equal to $t$. Then, by (logarithmically) differentiating (II.43) and substituting the result in (II.44), one arrives at an expression for the marginal product of capital.

$$
(1-\beta) A\left(e^{\alpha t} L_{t}\right)^{\beta} K_{t}^{-\beta}=\frac{\partial Q}{\partial K}=\rho+\sigma i
$$

Dividing (II.41) by $K$, and substituting (II.46) in the result gives the following.

$$
R_{1}=\frac{\rho+\sigma}{1-\beta}-\frac{c_{t} L_{t}}{K_{t}}
$$

Along the balanced path, the growth rate of $K$ is constant, so that (II.47) implies that $c L / K$ is also constant. Thus, the following must hold.

$$
\hat{c}_{i}+\hat{L}_{i}=v+1=\hat{R}_{t}
$$

This equation implies that the growth rate of the capital stock is equal to the sum of the growth rates of population and per capita consumption. Substituting the definition of $I$ in this expression and differentiating yields the obvious result that the growth rate of investment is equal to the growth rate of capital. Differentiating the production function yields the following expression for the growth rate of output.

\footnotetext{
"For this application of Pontryagin's Maximum Principle, see Kamien and Schwartz (1981).
} 


$$
Q_{1}=\alpha \beta+\beta \nu+(1-\beta) R_{1}=\alpha \beta+v+(1-\beta)
$$

Finally, one can differentiate the budget constraint and substitute the expression for the growth rate of output in the result, finding that the growth rate of per capita consumption is equal to the rate of labour-augmenting technical progress, $\alpha$. Substituting various occurrences of $k$, one finds that, along the balanced growth path, the growth rates of the endogenous variables $Q, K$ and $c$ are equal to $v+\alpha$, $D+\alpha$ and $\alpha$, respectively. Thus, this exercise reproduces the results of the Solow growth model in section 2.2 .

Now consider the same model with endogenous technological change. Lucas (1988) assumes that endogenous technological change takes the form of human capital accumulation. Denoting the stock of human capital by $h$, assume that an individual can divide his time between producing output and learning. Let $u$ denote the fraction of total time devoted to producing output. Then assume that the rate of growth of human capital is a linear function of the fraction of time devoted to learning.

$$
h_{t}=h_{t} \delta\left(1-u_{t}\right)
$$

Next, the influence of human capital accumulation (i.e., technological change) is defined to be twofold. First, as before, there is labour-augmenting technical progress, and second, there is an externality in the form of the average level of human capital having an influence through neutral technical progress. The average level of human capital is defined as the total sum of human capital over total labour.

$$
\bar{h}_{t}=\frac{\int_{0}^{\infty} h L_{h} d h}{\int_{0}^{\infty} L_{k} d h}
$$

It is important to understand that although the average level of human capital is endogenously determined, an individual has no influence whatsoever on its level, due to the assumption of a large (infinite) population. Now the production technology can be defined by a new production function, which looks as follows.

$$
Q_{t}=A \bar{h}_{t}\left(h_{t} u_{t} L_{t}{ }^{p} K_{t}^{i-\beta}\right.
$$

The model can be solved in two different ways. In each case, the integral (II.40) is maximized under the restrictions (11.41) and (11.50), using definition (11.52) of the production function. However, in one case, the socially optimal path, one treats the average level of human capital as oarying with decisions on human capital accumulation by the individual households. In the other case, which is the private equilibrium path, one treats the average level of human capital as given at each point in time, which is what households would do when they try to maximize utility by dividing time between producing and learning, and output between consumption and investment. In any case, the current value Hamiltonian is defined as follows.

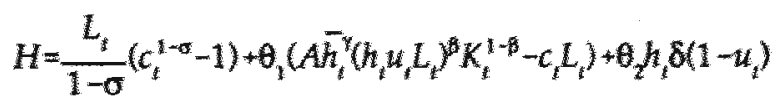


Control variables are $K$ and $h$, state variables are $c$ and $u$. Since there are two restrictions now, there are also two current value multipliers. Restrictions (II.41) and (II.50), and the following conditions are necessary for an optimal (social or private) path.

$$
\begin{gathered}
\frac{\partial H}{\partial c}=0 \Rightarrow c_{t}^{-\theta}=\theta_{1} \\
\rho \theta_{1}-\frac{\partial H}{\partial K}=\theta_{1} \Rightarrow \theta_{1}=\rho \theta_{1}-\theta_{1}(1-\beta) A \bar{h}_{t}^{\gamma}\left(h_{t} u_{t} L_{t}\right)^{\beta} K_{t}^{-\beta} \\
\rho \theta_{2}-\frac{\partial H}{\partial h}=\theta_{2} \Rightarrow \\
\theta_{2}=\rho \theta_{2}-\theta_{1} \beta A \bar{h}_{t}^{\gamma} h_{t}^{\beta-1}\left(u_{t} L_{t}\right)^{\beta} K_{t}^{1-\beta}-\theta_{1} \gamma A \bar{h}_{t}^{\gamma-1} \frac{\partial \bar{h}^{\prime}}{\partial h}\left(h_{t} u_{t} L_{t}\right)^{\beta} K_{t}^{t-1}-\theta_{2} \delta\left(1-u_{t}\right) \\
\frac{\partial H}{\partial u}=0 \Rightarrow \theta_{1} \beta A \bar{h}_{1}^{\gamma} u^{\beta-1}\left(h_{t} L_{t}\right)^{\beta} K_{t}^{1-\beta}=\theta_{2} \delta\left(1-u_{t}\right)
\end{gathered}
$$

Transversality conditions are no longer documented explicitly. Condition (II.56) contains the partial derivative of the average level of human capital with respect to private human capital. It is with regard to this derivative that the cases of a socially optimal path and a private equilibrium path differ. Since individuals are identical in all respects, the individual level of human capital is equal to the average. Thus, $\partial \bar{h} / \partial h=1$ is the relevant expression for finding a socially optimal path. In case of a private equilibrium path, an individual's personal influence on average human capital is zero, which comes down to $\partial \bar{h} / \partial h=0$.

Thus, for each of the two cases (II.56) can be simplified in the following manner. For a socially optimal path, (II.56) reduces to

$$
\theta_{2}=\rho \theta_{2}-\theta_{1}(\gamma+\beta) A h^{\gamma+\beta-1}\left(u_{t} L_{t}\right)^{\beta} K_{1}^{1-\beta}-\theta_{2} \delta\left(1-u_{t}\right) \text {. }
$$

The expression that is relevant to the private equilibrium path is

$$
\theta_{2}=p \theta_{2}-\theta_{1} a \beta h_{t}^{\gamma+\beta-1}\left(u_{t} L_{1}\right)^{\beta}-\theta_{2} \delta\left(1-u_{1}\right) \text {. }
$$

Note that if $\gamma=0$, the two expressions are the same. In other words, only "the presence of the external effect (..) creates a divergence between the 'social' valuation formula and the private valuation" (Lucas 1988: 21). Again, the model is solved for balanced growth paths (defined as before, plus the assumption that the growth rate of $u$ is equal to zero). Denoting the growth rates of $c$ and $h$ by 1 and $\mu$ respectively, one can derive expressions for the growth rate of output $[(\beta+\gamma) \mu+1(1-\beta)+v]$ and capital $(v+1)$ in the above manner. Then differentiate (II.54) and (II.57), eliminate the growth rate of $\theta_{1}$ and use definition (II.48), so that the following results.

$$
\theta_{2}=1(1-\beta-\sigma)-\mu(1-\beta-\gamma)+0
$$

Furthermore, by applying the same way of reasoning as above, one can derive the following expression for $\mathrm{t}$. 


$$
i=\mu \frac{\beta+\gamma}{\beta}
$$

In order to find the expression for $\mu$, one can substitute (II.57) in (II.58) / (II.59), and by using (II.50), derive the following expressions for the optimal growth path and the equilibrium growth path, respectively.

$$
\begin{gathered}
\theta_{2}=\rho-\delta-\frac{\gamma}{\beta}(\delta-\mu) \\
\theta_{2}=\rho-\delta
\end{gathered}
$$

By substituting (II.61) in (1I.60) and cancelling out the growth rate of $\theta_{2}$ by means of the derived expression and (II.62) / (II.63), one arrives at expressions for $\mu$ in terms of exogenous parameters in the model. For the case of an optimal growth path $\left(\mu_{0}\right)$, this rate is defined as follows.

$$
\mu_{0}=\sigma^{-1}\left(\delta-(\rho-v) \frac{\beta}{\beta+\gamma}\right)
$$

For the case of the equilibrium growth path $\left(\mu_{0}\right)$, it is equal to

$$
\mu_{c}=\frac{\beta(\delta-(\rho-\nu))}{\sigma(\beta+\gamma)-\gamma}
$$

The difference between these two rates is equal to

$$
\mu_{o}-\mu_{e}=\frac{\delta \gamma \sigma-1)+(\rho-v) \beta \gamma /(\beta+\gamma)}{\sigma(\sigma \beta+\gamma(\sigma-1))}
$$

Note that equation (II.66) theoretically allows for a welfare gain along a private equilibrium growth path, if the expression on the rhs is negative. However, for 'reasonable' parameter values $(\sigma>1-[\beta /(\beta+\gamma)][(p-v) / \delta])$, the expression is positive. This establishes the result of a positive welfare gain through public innovation policy already indicated above. 


\subsection{The Role of Technological Change}

Having reviewed the basic growth models of modern economic theory, it is now time to look more closely at the role of technological change. Two observations about the assumptions on the role of technological change stand out from the above. First, the formulation of the production process in neoclassical theory leads to a distinction between the state of technological knowledge and the technique used. This distinction is related to the difference between short and long-term analysis. In the short run, the firm chooses the optimal technique, given the general state of knowledge. In the longer run, this general state of knowledge is growing (in the early models, exogenously), and thus increases the (total factor) productivity of the production process.

In terms of the production function, a technique is defined as a combination (ratio) of the production factors labour and capital. Some techniques are labour-intensive, others are capital-intensive. The production function is supposed to give the relation between output and the technique chosen, given the state of knowledge. The technique chosen depends on the factor price ratio, in the sense that given factor prices, there is only one technique that maximizes profits (or minimizes costs). Changing factor prices therefore invoke a different capital labour ratio, or, in other words, cause substitution. Usually, it is assumed that there is an infinitely large amount of techniques, so that the set of techniques in the production function can be represented on a continuum.

The production function can take on different forms, usually to be distinguished by the possible degree of substitution between the factors (or the elasticity of substitution, defined as the percentage change of the capital labour ratio due to a one percent change in the factor price ratio). On the one end of the spectrum is the Leontief production function (as in the above post-Keynesian growth model), with 'fixed coefficients' and thus zero elasticity of substitution. On the other end is a production function with infinite elasticity of substitution (such as the constant elasticity of substitution, or CES-production function with a substitution parameter equal to -1). In between is the Cobb Douglas production function (as in the Solow model) with an elasticity of substitution of 1 .

Thus, the general state of technological knowledge is assumed to be something quite different from the choice of techniques. For a given (infinite) set of techniques, an increase in the general state of knowledge (or technological progress) is assumed to increase only the productivity of each technique, and not to influence the amount of techniques available. The extent to which separate techniques are influenced by an increase in technological change might be different (in which case one speaks of a bias in technological change) as in the Solow model, or equal (in which case technological change is said to be neutral). A bias in technological change might either be labour-saving or capital-saving. The concepts of biases and neutrality can be defined in different ways, so that in production function theory a distinction is made between Harrod, Hicks and Solow neutrality/bias.

As a critique to the neoclassical production function, it has been argued that the 
distinction between the choice of technique (substitution) and technological progress is artificial and leads to insights which are, however elegant in a mathematical way, irrelevant in practice. One of the arguments in favour of this view is that in practice one does not observe substitution and technological progress separately. For example, Rosenberg (1976: 253, original emphasis) states that

"(...) the analycical distinction between rechnological change and mere factor substitution becomes extremely difficult to maintain. Historically, establishing new possibilities for factor substitution has typically been the ourcome of a search process involving substantial costs and the use of specialized knowledge and creative skills. The kinds of new knowledge underlying both substitution and innovarion possibilities are, in orher words, the historical estcome of research activities. The range of substitution possibilities conveniendy summarized on a single isoquant are the product of such past research efforts and their resulting rechnological changes. Today's factor substitution possibilities are made possible by yesterday's technological innovations".

Thus, Rosenberg argues that substitution does take place, but that it is not due to factor price differences. Rather, there is a general tendency connected to technological change which brings about a historical trend towards more capitalintensive production. The neo-Keynesian approach outlined above seems to be able to deal with this critique in a natural way. The Kaldorian technical progress function (II.25) assumes a relation between technological progress in the form of labour productivity increases and capital accumulation. Applied to Rosenberg's view and the substitution principle, this means that technological change causes a tendency to using (relatively) more capital and less labour.

Another strand of research, this time in the neoclassical tradition, which seems to take up this point is the literature on 'induced bias' in innovation (see also section 2.1). Papers in this field develop the argument that innovation efforts are directed towards the direction in which it is most profitable, given (current) factor prices. The result is an endogenous bias into the labour- or capital-saving direction, leading to an expansion path along which substitution and innovation occur simultaneously. However, contributions in this field more or less stopped in the 1970 s (although there seems to be an increase in interest again, as in Diederen 1991).

Second, in two of the three early growth models, it is assumed that technological progress falls like 'manna from heaven' (Jones 1975: 158) (with the exception of Kaldor's growth model). In less metaphorical terms, technological progress is assumed to be exogenous to the economic system, while the choice of techniques is endogenously determined. Thus, in the Solow growth model, $\alpha$ and $v$ are assumed to be constant and determined outside the model, while the growth of $K$ and thus the ratio between $K$ and $L$ is determined within the model.

As already argued in section 2.1, microeconomic theory, on the contrary, has devoted a great deal of efforts to finding ways to endogenize technological change. Recognizing that R\&D efforts undertaken by firms (and thus endogenous to microeconomic theory) are a main determinant of technological progress in 
modern society, economists in the tradition of industrial organization have developed theories and models describing the influence of market structure, firm size, technological opportunities and the growth of demand upon R\&D efforts. A survey of these models is given in Gomulka (1990).

Since innovation is at the core of the analysis in the rest of this thesis, the growth theories assuming exogenous innovation are not suitable for the theoretical basis of further work. This leaves the new neoclassical growth models and neoKeynesian theory as candidates. The most important difference between these two theories with regard to the way innovation is endogenized is related to the basic motivation behind economic (firm) behaviour. Neoclassical models assume that firms strictly maximize profits, usually under the assumption of full information (see above). The neo-Keynesian approach has a less clear idea of what motivates behaviour. Keynes' idea of 'animal spirits' seems to be underlying much of the ideas in this tradition. Most of the next chapter will be devoted to a discussion about the usefulness of the profit maximization assumption. At the end of that chapter, which also introduces evolutionary theories of economic development, a definite choice of theoretical paradigm will be made. As a quick advance on this discussion, it is useful to cite Gomulka (1990: 27-8), who states:

"The (...) important characteristic of the inventive/innovation process is that it involves in an essential way uncertainty or even ignorance (...) Consequently, very different 'optimal' choice might be made by different research teams."

\subsection{Explaining Growth Rate Differentials}

The last question (briefly) addressed in this chapter is: What can be said about growth rate differentials on the basis of the above theories? First, the models offer an explanation for growth rate differentials in the form of different parameter values. Thus, countries would typically grow at a faster rate than others because their natural or warranted rate of growth is larger. The rate of population growth and the rate of technological change (both exogenous) will then explain growth rate differentials. In the various models, it is also possible that other variables than just these influence growth rates during the transition phase from one to another steady growth path. In case of the Solow model, for example, the growth rate of countries still in the transition phase (not having reached $\dot{k}^{*}$ yet) is influenced by the savings rate and the value of $k$.

The method of growth accounting is basically a (neoclassical) application of this way of looking at the models ${ }^{12}$. This method, which was explained briefly above while discussing Solow's model, has been applied to a cross-country sample of countries by among others Denison (1967), Christensen et al. (1980) and Maddison (1987). Empirically based as it is, the growth accounting approach does not only explain growth rates from the perspective of exogenous parameters $(\alpha, v)$, but also assumes that some variables that are endogenous in the above models (such as $K$ or $u)$ are exogenous.

${ }^{12}$ For an interpretation of growth accounting in this context, see among others Fagerberg (1988b). 
However, this way of explaining different growth performance is not attractive from a theoretical point of view, since it does not answer any real questions. The parameters and variables (the rate of growth of TFP, labour or capital input) are all assumed to be exogenous. Thus, in order to explain why growth rate differentials occur, these methods have to fall back on exogenous explanations for the different patterns in knowledge and capital accumulation being observed, such as cultural, geographic or even religious explanations. It seems to be very difficult to provide a real economic explanation on the basis of such an approach. This is not to say that there is no merit at all in the growth accounting approach. Its applied nature has led to a number of interesting observations regarding the sources (as opposed to explanations) of growth in various countries. Moreover, it was in many ways Solow's (1957) original growth accounting contribution that aroused mainstream theorists' desire to learn more about the topic of technological change.

Second, the neo-Keynesian tradition offers an additional explanation for growth rate differentials, besides differences in parameter values. As will be seen (also in Parts Two and Three), this explanation is much more satisfying from an economic point of view, since it is an economic mechanism which is underlying the process of diverging / converging growth.

On the basis of Kaldor (1966), Dixon and Thirlwall (1975) presented a model explaining international or inter-regional differences in economic growth. Their model is based on the principle of cumulative causation and provides an explanation of growth rate differentials persistent in time. Contrary to the idea of catching up to be introduced below, their model predicts that divergence of growth rates (at least up to certain point) will (can) take place. In the model set out by Dixon and Thirlwall, productivity is the main determinant of a country's growth rate. High productivity growth improves the country's competitive position and has a positive influence on exports and thus economic growth. This relationship is combined with Verdoorn's law, and yields a circle of cumulative causation. Suppose that in a world characterized by the Dixon and Thirlwall model two regions initially have the same growth rate. Then, due to an exogenous event, one region gets a (one period) stimulus of the growth rate. This higher growth rate will yield a higher rate of growth of productivity via Verdoorn's law, and thus generate a new impulse for a higher growth rate. Since the other region did not experience the exogenous shock, growth rates will diverge. Under the assumption that certain parameters take specific values (see Dixon and Thirlwall 1975: 207208), the self-reinforcing growth effect of the model will damp out, and the region's growth rate will converge towards an equilibrium rate, leaving, however, a sustained growth rate differential.

Another important concept in explaining growth rate differentials, which has not been mentioned until now, is the principle of catching up. Like the previous example, catching up gives an endogenous logic for differential growth rates, which makes it attractive from the point of view of the present analysis. Catching up is a phenomenon that is not specifically related to one of the theoretical schools discussed above. It has been applied in historical studies (Gerschenkron 1962), neoclassical production function models (Dowrick and Nguyen 1989), more 
evolutionary inspired studies (Perez and Soete 1988), Keynesian type models (Cornwall 1977) as well as empirical studies without a clear theoretical background (Baumol 1986, Abramovitz 1983, 1986). The literature on catching up is also referred to as the 'convergence' literature, for the obvious reason that if countries with low initial per capita incomes tend to grow faster, per capita income levels and growth rates will eventually show a tendency to converge.

On the pure basis of neoclassical theory, catching up is related to the difference in marginal capital productivity between nations. The neoclassical production function has the property of decreasing marginal returns to capital. Applied to a cross-section of nations, this means that one unit of investment in a country which is at a low level of development will pay off more than the same amount of investment in a more developed country. Thus, countries at a lower level of development have a larger potential to grow fast than the most developed countries (Rebelo 1992).

In a broader (theoretical) concept, catching up refers to the principle that countries with relatively low technological levels are able to exploit a backlog of existing knowledge and therefore attain high productivity growth rates, while countries that operate at (or near to) the technological frontier have fewer opportunities for high productivity growth. Therefore, countries with lower levels of technological knowledge will tend to achieve higher growth rates. Some early approaches to catching up in this vein can be found in Ames and Rosenberg (1963), Nelson (1968) and Gomulka (1971). Implicitly, this interpretation of the catching-up hypothesis is based on the intuition that technological change is to some extent a 'public' good, i.e., it can be used 'freely' by countries other than the initial innovator. International knowledge spillovers enable countries with lower technological levels to achieve faster productivity growth.

Empirical studies that investigate the strength of the catching-up phenomenon, such as Abramovitz (1979, 1983, 1986), Baumol (1986), Dollar and Wolff (1988) and Dowrick and Nguyen (1989), generally arrive at the conclusion that there is indeed a strong (negative) correlation between growth rates and (initial) per capita income (the latter is taken as a measure of the technological level of a country) ${ }^{13}$. But while there is agreement on the relevance of the argument for some countries, it is also clear that catching up is not a global phenomenon. Most studies only take into account the industrialized (OECD) countries, and do not look at convergence between the industrialized world, socialist economies and developing nations. Baumol (1986) is a notable exception to this rule. The conclusion reached there is that "rather than sharing in convergence, some of the poorest countries have also been growing most slowly" (Baumol 1986: 1079). Lucas (1988: 4) connects these growth rate differentials directly to the per capita income level of countries: "the poorest countries tend to have the lowest growth; the wealthiest next; the 'middleincome' countries highest". De Long (1988), in a comment on Baumol (1986), has also convincingly shown that catching up is not a global phenomenon. His analysis demonstrates that some countries which could initially be identified as 'candidates'

\footnotetext{
${ }^{13}$ However, Quah (1990a, b) has applied a convergence model with a stochastic trend with mixed success.
} 
for taking part in the catching-up process, have failed to do so in actual practice. Baumol et al. (1989) have demonstrated that education might be an important variable in explaining this failure.

There is an obvious relation between the catching-up idea and the method of growth accounting. One of the explanations for cross-country differences in total factor productivity might be the catching-up phenomenon. For example, Denison (1967: $287 \mathrm{ff}$.) divided the total factor productivity growth of the lagging countries in the sample (all except the USA) into a part that is due to the rate of growth of knowledge (equal to the USA total factor productivity growth) and a part that is due to other sources, including a lag in the application of knowledge. A more direct application of the catching-up principle is provided by Dowrick and Nguyen (1989). Their attempt to explain growth rate differentials is essentially a growth accounting method, in which a model relating total factor productivity growth to the level of per capita income is specified. On the basis of this variable they present estimates for growth rate differentials that are 'adjusted' for the influence of catching up.

What do the new neoclassical growth models have to offer with respect to explaining international growth patterns? First, broadening the application of the new growth theories to the open economy case leads also to important conclusions about trade and technology policy. In line with 'strategic' trade theory (Krugman 1990), the basic conclusion is that the arguments in favour of free trade no longer have unlimited (with respect to time and place) validity. In some specific cases, trade policies, in the form of tariffs, or technology policies, in the form of research subsidies, may influence aggregate economic growth or welfare by changing the factor proportions devoted to research and/or manufacturing (Grossman and Helpman, 1990, 1991a). The exact outcomes of the policy measures are not, however, very clear cut from the international perspective. Much depends on the 'comparative advantages' with regard to technology and manufacturing activities.

The basic mechanism that leads to this conclusion is the general equilibrium framework that is applied in the new growth models. As a result of this, the world growth rate is dependent upon the allocation of resources (human capital) between sectors or countries and the structure of demand. For example, relatively higher demand for consumer goods produced in the country with a comparative advantage in research will lower the world's growth rate, since human capital is pulled out of research activities in that country. A rise in human capital resources (both total resources and resources in the country with comparative advantage in research) spurs research and therefore has a positive influence on the growth rate. Also, a reallocation of human capital resources can influence the growth rate (positively if the share in effective labour of the country with comparative advantage in research grows).

Second, endogenous technological change modelled in this way has important implications for growth rate differentials. However, this aspect of new growth theories has received little attention up until now. Both closed and open economy approaches have strongly focused on welfare properties of growth paths, and not so much on growth rate differentials. Moreover, the empirical implication of new 
growth theories is still in an early phase (the contribution in Romer 1989 shows the limitations of applying these models to a broad sample of countries, another useful contribution is in Amable and Boyer 1992).

Nevertheless, the scope for further investigation of the consequences of the ideas found in new growth theory for the current topic is undoubtedly a promising avenue for further research in this area. However, this will not be done in the rest of this thesis. Instead, the focus will be on developing some approaches based on the endogenous economic explanations for growth rate differentials found in the evolutionary and neo-Keynesian traditions, as well as the more hybrid catching-up approach. The catching-up idea, interpreted in terms of knowledge spillovers, will be applied in a theoretical and empirical model in Part Two below. The neoKeynesian logic of cumulative causation, combined with an evolutionary view on the economic process (to be introduced in the next chapter) will be applied in Part Three. 


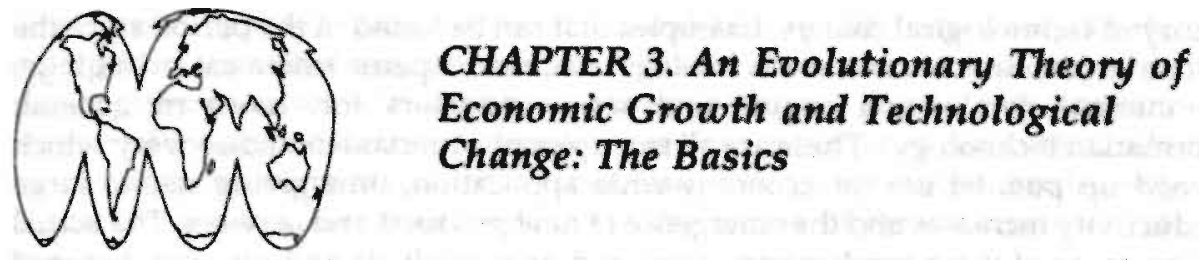

The aim of this chapter is to introduce the idea of economic growth as an evolutionary process. Whereas other theoretical approaches to economic growth have been outlined in Chapter 2 by means of small stylized models, this is not possible in the case of evolutionary theory. The reason for this is that the body of evolutionary theorizing in economics has not made much use of formal methods, and the few papers that have done this cannot easily be grouped under one general heading. Therefore, the approach in this chapter is somewhat different. First, a general description of macroeconomic growth as an evolutionary process will be given. Then, the microeconomic logic behind economic evolution will be explained. Finally, some ideas about how to formalize these microeconomic propositions will be summarized.

\subsection{Economic Growth as an Evolutionary Process: A Macroeconomic Interpreta- tion}

Dosi (1982) argued that technological progress is (in most cases) grouped around certain key items of attention. Instead of the 'production function' viewpoint of technological change as a global phenomenon without a specific direction, Dosi assumes that 'normal' technological change consists of relatively small improvements upon bigger, revolutionary (and therefore 'scarce') technological breakthroughs. He draws an analogy with Kuhnian philosophy of science, and develops the hypothesis that technological discoveries are grouped in 'technological paradigms.

A technological paradigm is defined as a "model and a pattern of solution of selected technological problems, based on selected principles from the natural sciences and on selected material technologies" (Dosi 1982: 152, original emphasis). The discovery of such a 'model and pattern of solution' corresponds to Kuhn's notion of a scientific reoolution. In economic theory, it closely links up to Schumpeter's innovation theory, in which an important innovation creates a bandwagon effect of smaller (incremental) follow-up innovations. Dosi (1982) uses a similar concept when he makes the distinction between technological paradigms and technological trajectories. In his view, 'normal' technological change (compare the Kuhnian term 'normal' science) takes place along a direction set out by the discovery of an important general principle which provides the opportunity for application in a number of economic sectors. A technological trajectory is the development of a technology along the lines set out by the technological paradigm.

The notion of a technological paradigm stems from empirical observations in the 
history of technological change. Examples that can be found in the period since the industrial revolution are steam technology, electricity, (petro-)chemical technology, the internal combustion engine and semi-conductors (or, more in general, information technology). These are all examples of a fundamental discovery which opened up possibilities for economy-wide application, thus giving rise to large productivity increases and the emergence of new products and services. The actual achievement of these productivity gains and new products and services does not take place at once, but rather comprises a long period of 'normal' technological change, or the development along a technological trajectory (Freeman and Soete 1990).

It is indeed an important characteristic of some technological paradigms that their influence goes beyond that of a single, isolated part (sector) of the economy. Examples of technological (scientific) discoveries which might well be labelled as technological paradigms, but which have not (as yet) had an influence upon the whole spectrum of economic sectors are optics and nuclear technology. To stress this aspect of technological paradigms, Freeman (for example 1991) has introduced the concept of peroasiveness of a technology. If a technology only affects the production structure in one sector, the emergence of a new paradigm will not have strong effects upon the whole economy. If, on the contrary, the pervasiveness of a technology is very large (i.e., it affects most sectors' productions structure), the macroeconomic effect will be large.

In this respect, Perez (1983) has introduced the term techno-economic paradigm to make a distinction between pervasive and non-pervasive technological paradigms. A techno-economic paradigm describes the economic, institutional and technological inter-linkages between sectors. A new technological paradigm will thus also imply a shift towards a new techno-economic paradigm if the technological principle (or the products associated with it) can be used throughout the economy, so that institutional and economic relations between all economic agents are affected". Without doubt, technological paradigms such as steam power, electricity and iron and steel fall in the category of techno-economic paradigms.

If it also implies a new techno-economic paradigm, a new technological paradigm will have a large effect upon the whole economy. A takeoff of such a paradigm will require new investment and thus imply creatioe destruction of old capital in most sectors. On the other hand, if a new technological paradigm does not imply the change of the techno-economic paradigm as a whole, the macroeconomic effect will be much smaller. In that case, the main effect will be limited to one or a few sector(s).

The idea that the emergence of technological paradigms are not distributed randomly over time has led to the interesting hypothesis that long-term economic development occurs in long-wave patterns. It was Schumpeter (1939) who first raised the idea that major technological breakthroughs would lead to such a long-

\footnotetext{
'One could argue that microelectronics is a recent example of such a techno-economic paradigm.
} 
term cyclical growth path ${ }^{2}$. However, the details of the long-wave debate that emerged in the 1980s will not be discussed here. The reason for this is that, for the present interpretation of the relation between economic growth and innovation, it is not really relevant (yet, see Chapter 10 for more extensive discussion) whether or not long-wave patterns exist. Therefore, reference will be made only the arguments used in the debate useful for the course of the argument developed here.

The rest of this section will go into the process of (possible) introduction of a technological paradigm with a level of pervasiveness which assures a fundamental effect on the nature and level of macroeconomic activity. It will be concerned with the question of how the process of introduction and (possible) retardation of such a paradigm takes place, and look at the forces determining this process.

The concept of technological paradigms is, in the first place, concept that arises from observing technological change at a level beyond that of the firm (i.e., a sector or the whole economy). A single decision unit (firm) cannot launch a (new) technological paradigm by itself. A new technological paradigm manifests itself only when a whole set of firms begins to apply a new basic principle on the market. Therefore, in general, the emergence of a new technological paradigm can be regarded as exogenous at the single firm level (microeconomic level). It can, however, not be denied that the emergence of a new technological paradigm depends on decisions taken at the microeconomic level.

To a certain extent, technological paradigms will always be exogenous to the economy, even at the macroeconomic level. What is economically possible is bounded by what is technologically possible. And what is technologically possible will always be limited by scientific principles (or laws, if one may call it that way) like gravity, the speed of light, etc. (note that this is a qualitative limitation rather than that it implies that the set of technological possibilities is limited in a quantitative way). This does, however, not mean that technological change is completely exogenous to the economic system, as it was assumed in the old theories of economic growth. The emergence of a new technological paradigm depends upon the availability of a technological (scientific) principle that can be at its basis. The steam-power paradigm could not have been developed without the invention of the steam-engine, and the same goes for other paradigms that have emerged during the development of capitalism. Obviously, the chance that a 'basic invention' (as Schumpeter called it) takes place varies with the quantity of efforts devoted to it. In the present-day industrialized world, these efforts mainly consist of industrial research and development (R\&D) and related activities.

In the debate on long waves it has been suggested that more efforts are devoted to finding a new technological principle (or paradigm), the less satisfactory the (economic) results from an old, existing paradigm are. Mensch (1979) and Kleinknecht (1987) have called this effect the depression trigger effect: Whenever the payoffs of an old technological paradigm begin to diminish, the direction of search

\footnotetext{
${ }^{2}$ For a treatment of Marx' vision on the relationship between technological change and (shorter) business cycles, see Gourvitch (1940).
} 
and the efforts devoted to R\&D react in order to find an alternative. So far, the empirical evidence on this depression trigger effect has, however, not been given. A related argument which has some more, although still scarce, empirical backing is the so-called sailing ship effect. The invention of a new technological paradigm (regardless its underlying factors) means potential (technological) competition for the old paradigm. Firms with a firm technological base in the old paradigm will therefore respond by devoting more efforts to improving their competitive position. Even if the new paradigm has a higher potential than the old one, the latter may 'rule' for some time because the new paradigm is still in its infancy. In Rosenberg's (1976: 205-206) example of the competition between the (existing) salling ships and the (newly invented) steam-powered ships, a series of minor inventions in the field of sailing 'technology' was able to keep off the competition for quite a long while.

These two specific (and rather ad hoc) effects illustrate a more general principle. The introduction or retardation of a techno-economic paradigm depends on the specific way in which the economic potential of the paradigm itself and the economic, social and institutional environment interact with each other. A paradigm might take off quickly because the specific historical context is suitable, or it might, on the contrary, not take off at all because this context is highly unsuitable. Much in the sense of this interpretation, Freeman (1991) draws an analogy between biology and economics, suggesting that the emergence and retardation of technological paradigms is an evolutionary selection process. The process of evolutionary selection is essentially a process of competition. The relative competitiveness of different paradigms together with the selective environment determines the outcome of the process. In case of two competing paradigms, the introduction of a new paradigm is more likely to occur as the old paradigm is more vulnerable (this idea has been developed in a context of institutional change and North / South relations by Perez and Soete 1988). In case of two complementary paradigms, the introduction of the one is more likely to occur as the other is stronger.

An important question in this respect is: What determines the competitiveness of a paradigm? A distinction between technological, economic and institutional factors that have an influence on this can be made ${ }^{3}$. Technological competitiveness relates both to production costs (process innovation) and quality (product innovation). Technological competitiveness is increased by incremental innovations ('normal technological change'), which to a large extent take the form of learning effects. Due to their cumulative nature, the impact of incremental innovation and learning effects is likely to vary over the lifetime of a technology. In the initial (laboratory) phase of the development of a technology, progress may be very slow. But after a certain period of introduction, it is likely that incremental innovations and learning effects take place at increasing rates. In the later phases of the development of the paradigm, so it is often heard, decreasing marginal returns to research efforts set in and learning effects become smaller and smaller. This is due to the effect that the technological base of a paradigm is not infinite. This principle

${ }^{3}$ For a more detailed discusstion, see Freeman (1991). 
of decreasing marginal returns to research is also known as Wolff's law". Therefore, in the later phases of the technological paradigm, 'normal' technological change will take place at decreasing rates.

Note that the emergence of decreasing marginal returns to innovation efforts along a technological trajectory (i.e., given a technological paradigm), does not imply that in general there are decreasing returns to innovation efforts. Because successive paradigms improve upon each other, the pattern of marginal returns to innovation efforts is most likely to have the form of a cyclical pattern which develops around a (monotonically) increasing trend (see also Dosi 1988a: 229-230).

Another aspect that plays a similar role in most (although not all) technologies is the presence of network externalities. These may cause the takeoff of a technology to be quite slow initially, but after a certain critical mass of users has been established, network externalities may cause a boost of the number of users. Again, at some stage saturation sets in (almost all potential users are served). The existence of network externalities and the implied sigmoid pattern of technological competitiveness has important consequences for the possibility of lock-in effects and path dependency. Due to specific historical circumstances, such as the existence of a competing technology or the specific institutional setting, a new paradigm may not reach the stage in which increasing returns set in. Thus, it might simply not, or only very slowly develop. This argument has been developed in more detail by among others David (1990) and Arthur (1988).

Turning to economic factors, market demand is an important factor that plays a role in the competitiveness of a paradigm. This factor basically works through the aspect of (firm-level) profitability; in fact, without market demand a product cannot be profitable. In the economics of technological change, this has already been emphasized by Schmookler (1966) and work following his demand pull hypothesis (see Mowery and Rosenberg 1979 and Kleinknecht and Verspagen 1990 for critical reviews). A useful, dynamic, way of taking this aspect into account is provided by Pasinetti (1981). In his analysis of structural change, he uses the concept of the Engel curve. The Engel curve gives the relation between (macro or micro) spending on one (group of) product(s) and income. The shape of the Engel curve is such that for some range of income, the marginal increase in spending on a product diminishes. In other words, at some stage the income elasticity of demand will diminish for all goods, due to saturation effects. Pasinetti (1981: 7273) distinguishes between three different cases. In the first case (basic necessities of life) the marginal increase in spending diminishes for the whole range of incomes (a curve increasing at a monotonically decreasing rate). In the second case, representing luxury goods, the Engel curve is sigmoid, so that the diminishing marginal increases only occur in the last part of the curve. In the third case, the Engel curve has a maximum. This case corresponds to inferior goods.

\footnotetext{
4 "Wolff's law: Wolff was a German economist who in 1912 published four 'laws of retardation of progress'. Essentially, he argued that the scope for improvement in any technology is limited, and that the cost of incremental improvement increases as the technology approaches its long-run performance level." (Freeman 1982: 216, note 2).
} 
What is important here about the Engel curves is not so much the precise relation between spending and income, but the fact that income elasticities of demand, and therefore the shares of certain categories of products in total spending, may vary over time. Since a technological paradigm consists of some basic technological principles, there are also some basic categories of goods associated with it. These goods may either be intermediate goods, related to the input-output relations within the paradigm, or they may be consumer goods. The paradigm of the internal combustion engine is associated with the automobile. The paradigm of computer technology (or more generally information technology) is related to (intermediate) demand of semi-conductors. If the attention is limited to consumer goods for a moment (i.e., following Pasinetti's framework of vertically integrated sectors), the demand for the paradigm's 'basic' good(s) will vary with income and, thus, with time. The demand effect given by the Engel curve can be a strong factor in 'launching' or slowing down a paradigm. On the one hand, if the demand for the paradigm's basic good is particularly high in the beginning phases, this can stimulate its emergence. On the other hand, if the demand for the paradigm's basic good is saturating, this might be an important factor in the retardation of the paradigm. At the point where the saturation effect becomes noticeable in the consumers market, the overall power of the paradigm will diminish ${ }^{5}$. This effect is even increased when input-output relations are taken into account, because the effect of an increasing / saturating consumer demand will have the well-known (Leontief type) (negative or positive) multiplier effect.

The relationship between prices and demand is also very important. Decreasing production costs and increased competition along the technological paradigm will lead to lower prices, which will spur demand, especially when one takes into account input-output linkages in the case of intermediate (or capital) goods. This is the reason why decreasing prices (process innovation) is mentioned in Freeman (1991) as an important factor in the emergence of a new techno-economic paradigm.

Finally, the general institutional setting of the economy has an influence on the competitiveness of a paradigm. Freeman (1986) and Perez (1983) have argued that there are strong links between the technological (and economic) paradigm and the institutional setting in society. If the two match, this increases the power of the paradigm, while the opposite holds in case of a mismatch. Institutional factors that are of particular importance with regard to long-run growth are education and schooling systems (see for example the recent debate in the USA, Baumol et al. 1989 and Baily and Gordon 1988), labour relations (for example the differences between Japan and the USA, see Freeman 1986), politics (for example differences between centrally planned economies and market economies, see Gomulka 1990) and legal issues (for example a patent system, see Taylor and Silberston 1973). Freeman (1986) has suggested that the mismatch between the information technology paradigm and the current institutional setting in the industrialized countries (except perhaps Japan) is one of the explanations for the so-called productivity paradox. Of course there are all sorts of interconnections between the

\footnotetext{
${ }^{5}$ Note the similarity to product life cycle theories found in business economics, for example Utterback and Abernathy (1975) and Abernathy (1978).
} 
institutional setting and the previously mentioned points. For example, labour relations in the post-war period allowed for sufficient real wage (i.e., effective demand) growth to make mass production profitable (see in particular the socalled regulations school, for example Boyer 1989).

\subsection{Economic Growth as an Evolutionary Process: A Microeconomic Interpreta- tion}

Attention will now be switched to the individual firm. In line with the new neoclassical growth theory, the firm cannot take the general state of knowledge for granted, but must make investment decisions in order to enlarge the quantity of knowledge available to it. As will be argued in more detail below, this is even the case if the firm follows an imitative rather than an innovative strategy (i.e., firms try to copy innovations made by other firms), since even imitation requires skills from the imitator. Technological progress can therefore not be taken as a datum of the economic analysis of the firm, but must indeed be a variable explained by any theory aiming to explain firm behaviour'.

In order to endogenize technological change at the microeconomic level in an evolutionary way, it is useful to redefine the concept of technological change. Instead of the neoclassical definition of technological change as the increase in productivity of all techniques available, technological change is now defined as the search for an increase of the known set of production techniques (see also Gomulka 1990, Chapter 1, where a similar definition is given). Note that the term technique is given a different interpretation here. 'Technique' should be interpreted as being a mode of production, characterized not only by the quantity of capital and labour used, but also (and most importantly) by the quality of these factors. Two techniques may have the same factor intensity (in whatever way this intensity is measured), but still require completely different skills (from the side of labour) and capital good varieties. The motive driving the firm's search for new technologies is profit. To conduct the search for new techniques, firms might employ different methods. Mostly, one likes to think of R\&D and related activities as some measure of inputs into the search, and innovations (and patents) as a measure of outputs from this process. The exact way in which the process of innovative search is conducted at the firm level is not the main interest here. Instead, attention is concentrated on an outline of some general characteristics of the process.

For the characteristics of microeconomic firm behaviour with regard to technological change, inspiration can (again) be drawn from Dosi. Dosi (1988a) has defined five different stylized facts of technological change which can be the starting point of a microeconomic description of the process of technological change. These stylized facts are:

(i) "(...) innovation involves a fundamental element of uncertainty, which is not simply a lack of all the relevant information about the occurrence of known events but, more

\footnotetext{
${ }^{6}$ Note that it is not the aim of the present analysis to develop such a theory of the firm. Attempts to do this along the lines set out in the rest of this chapter are in Dosi and Chiaromonte (1990) and Kwasnicki and Kwasnicki (1990).
} 
fundamentally, entails also (a) the existence of techno-economic problems whose solution procedures are unknown (...) and (b) the impossibility of precisely tracing consequences to acrions"

(ii) "The increasing reliance of major new technological opportunities on advances in scientific knowledge"

(iii) "the increasing complexity of research and innovative activities militates in favour of formal organisations (...) as opposed to individual innovators as the most conducive environment to the production of innovations. Moreover, the formal research activities in the business sector tends to be integrated within more or less integrated manufacturing firms"

(iv) "a significant amount of innovations and improvements are originated through 'learning-by-doing' and 'learning-by-using'"

(v) "rechnical change is a cumulative activity".

These (microeconomic) stylized facts are largely consistent with the (macroeconomic) view of the innovation process adopted above. Points (i) and (ii) stress the character of innovation as a search activity, as opposed to a planned activity. Points (iv) and (v) cause a tendency towards path dependency in the innovation system, which is consistent with the description of the techno-economic system as paradigmatic.

What is the relevance of these stylized facts for microeconomic theory? Consider the following three suggestive claims as a first answer to this question.

(a) It cannot be assumed that firms can maximize their profit function, especially not in an intertemporal sense. Rather, firm behaviour is profitseeking.

(b) There is no such firm as the representative firm, since all firms react differently to changing business environments.

(c) The ability to innovate is dependent upon some firm-specific learning skills.

The motivation behind these claims is as follows. Regarding point (a), the usual optimization routines applied in (micro)economic models depend either on full certainty or rational expectations, or on a known distribution of some uncertain (risky) events. In the first case (full certainty or rational expectations) the firm simply puts its expectations in a mathematical function to optimize and finds the optimal value of the variable to decide on, which will always (full certainty) or on average (rational expectations) prove to be correct. In the second case (a known distribution of some uncertain event) the factors in the function are weighted by their expected chance of appearance, and then the optimum of the expected value of the variable to be optimized is found (like in the well-known Von NeumannMorgenstern utility function). This leads to a risk-premium on the normal rate of return under circumstances of full certainty. The weighting of alternative outcomes by their likelihood or the introduction of rational expectations both come down to 
In the event that neither rational expectations or full certainty applies nor the chance distribution of an event is known (i.e., if there is a situation of strong uncertainty), these methods do not hold. In those cases, the concept of bounded rationality (Simon 1986) seems to be more appropriate. The bounded rationality hypothesis says that economic decision makers do not work with a model which represents influences from the total economy, not even in an implicit way. They rather attend only a small part of the world around them, and (implicitly) make a highly simplified model of their environment, in which some highly subjective attitudes towards strong uncertainty are incorporated. The outcome of the decision rules used in such a bounded rationality context will differ (except by chance) from the outcome of a fully rational procedure under full information.

Of course firms' behaviour is motivated by making profits, even in a context of bounded rationality. But instead of maximizing profits in a fully rational model, firms can be assumed to try to enlarge their current profits by changing their behaviour. This latter motive for firm behaviour can be called profit-seeking. The difference between profit-maximizing and profit-seeking behaviour may appear to be only very subtle and unimportant (and indeed most neoclassical economists tend to present it this way), but as will be seen in the next section it might have consequences for the nature of an economic theory or model.

How does profit-seeking behaviour work in a world of bounded rationality? Instead of a mathematical function that firms optimize, one will typically see that simple, standardized rules of thumb are used to make decisions about investment in (the search for) new technologies (see for example Silverberg et al. 1988). Gomulka (1990: 29) calls these rules 'conventional rules'. As a consequence of their simple nature, these rules yield outcomes that are sometimes positive and sometimes negative. They are, however, the best a firm can do, given the strong uncertainty it faces.

Point (b) follows from the above reasoning. Firms do not behave according to some fully rational model, but apply rules of thumb instead. Almost by definition, these rules are not the same for every firm. They are based on such things as past experience, the efficiency of a firm's information system and psychological factors determining the way managers react to changing circumstances. Put in one term, the subjective rules of thumb are closely related to the 'animal spirits' of business (wo)men. Examples of rules of thumb are the pay back rule (Silverberg 1987), markup pricing and the discounted cash flow method, both methods well known from the field of business studies. Of course, the actions of entrepreneurs using this type of rules might at some point in time resemble each other, especially if one takes into account the existence of some general 'market expectations', or common factors influencing decisions. Therefore, the actions of different entrepreneurs may look coordinated, i.e, they point in one general direction?. For

\footnotetext{
${ }^{7}$ This suggests that there is a self-organizing tendency in the system. For an introduction of the (mathematical) concept of self-organization see Silverberg (1988). For an application to management of the firm, see Romme (1992).
} 
the emergence of a new technological paradigm, as described in the previous section, it is necessary that such coordination exists. However, since the period of introduction of a new paradigm is also the one in which uncertainty is strongest, one might expect that it takes some time to reach the necessary degree of coordination.

For the present analysis, however, it is important to stress that while the actions of different entrepreneurs may look coordinated, they may still be based on wrong interpretations of the business environment, and therefore might imply ex post inefficient behaviour. Moreover, even if the general market expectations prove to be right ex post, the specific way each of the entrepreneurs has used them in decision making will differ, and therefore the outcome will, in general, be different from a full-fledged optimum in the neoclassical sense.

The third and last point follows from the (cumulative) character of technological change combined with the second point. Cumulative technological change means that "[w]hat a firm can hope to do in the future is narrowly constrained by what it has been capable of doing in the past" (Dosi 1988b: 1130). And since firms take different decisions with regard to a changing business environment (due to their different rules of thumb), "what the firm was doing in the past" is different from what all other firms were doing in the past. Hence, "what the firm can hope to do in the future" is different from what all the other firms can hope to do in the future.

\subsection{Towards an Evolutionary Theory}

Is it possible to formulate a microeconomic foundation for an evolutionary theory of economic growth on the basis of the above? In most microfounded economic models, the 'regulation' principle that governs the outcome of the economic process is the market equilibrium. There are two aspects regarding the market equilibrium that make it less attractive as a regulation mechanism in a theory built on the basis of the above. The first of these is the inherent static character of the concept. The second is the idea of the representative agent that underlies most procedures to calculate the market equilibrium. Both points will be discussed below.

First, the idea of a market equilibrium is taken from the Newtonian mechanics developed in the previous century. The general idea here is to see how different forces (for example in physics: gravity and friction, in economics: supply and demand) interact with each other, resulting in a motionless situation in which each of the forces is exactly cancelled out by all the others. Thus, the emphasis is on the motionless situation rather than on the stage during which the system (object) is still moving. This has resulted in the characterization of market equilibrium as an essentially static concept. The basic demand and supply framework is perhaps the most clear example to illustrate this. In most economic models, the emphasis is on the state of equilibrium as such, and not on the way it is reached. Given the demand and supply functions, economists are supposed to calculate the intersection point, and draw conclusions on the basis of (ceteris paribus) changes in some parameters of these functions. Only in exceptional cases, the emphasis is 
on the dynamics behind the process of reaching this equilibrium (the cobweb theorem is one such exception).

In contrast, the picture of the macro- and microeconomics of innovation sketched above emphasizes the importance of the stage of motion. The emergence, development or retardation of paradigms constitutes a field in which the net effects of the different forces are rarely zero. The same goes for the firm which has to operate in this general environment. Thus, the market equilibrium as a static concept cannot be used as a way of describing what is actually going on in the economy. Schumpeter (for example 1934) has therefore argued that the concept of market equilibrium can only be used as a sort of 'moving target' to which the economy tends, but which it can never reach. Although this is already a much more realistic way of using the concept of equilibrium, there are two problems connected to this approach. First, it might be the case that in a situation which is not characterized by equilibrium, the implied behavioural patterns are quite different from those in equilibrium. This might lead the economy away from rather than towards the equilibrium. Second, the equilibrium itself might be (locally) unstable, so that the motion of the system is away from equilibrium.

The second point concerns the use of the representative agent. The assumptions of a representative consumer and firm are usually necessary to be able to calculate the market equilibrium. On the basis of the rationality assumption and some specification of the functions to optimize, one can deduce some general pattern of behaviour of an individual agent, for example the general form of a supply curve (upward sloping linear). Different agents all have a behaviour pattern that has this general form, but may differ from other agents' pattern by some parameter values, for example the magnitude of the slope of a supply curve (following from underlying exogenous differences such as risk aversion or age). These parameters transform the general form of the behaviour pattern into the individual pattern. The agent whose parameter values are exactly equal to the (weighted) average of all agents' values, can be called the representative agent.

Of course, this concept is only an analytical one, and the representative agent simply cannot be found in reality. Nevertheless, the representative agent is very important, for it enables one to calculate the aggregate market equilibrium. The usual procedure to do this is to substitute the behaviour pattern of the representatives of the different types of agents into the (microeconomic) equilibrium condition, and call the outcome (multiplied by the number of agents) the aggregate market equilibrium ${ }^{8}$. Obviously, if no generally valid pattern of behaviour exists, and moreover, agent-specific behaviour cannot be quantified in an exact way, this procedure is no longer possible. If the behavioural pattern of all agents is based on different rules of thumb whose exact nature is unknown to the model-builder, and might yield different reactions to identical stimuli, the representative agent looses its use as an analytical concept.

\footnotetext{
${ }^{8}$ As an experiment to see the need for a representative agent, the reader is invited to solve the stylized new growth model in Chapter 2 under the assumption of $n$ agents with different parameters in the various functions.
} 
Recently, it has been suggested by among others Silverberg (1988), Nelson and Winter (1982) and Boulding (1981) that the evolutionary principle of selection might be a useful substitute for market equilibrium. Drawing an analogy with biology, one would then speak of 'economic selection' (vs 'natural selection' in biology). The general idea behind the principle of (economic) selection is that it is based on differences in microeconomic behaviour. Each agent that takes part in the economic process, for example a firm, will have some specific degree of competitive power which stems from its past behaviour. On the basis of the above argument, this competitive power will in general differ between agents. In the selection process, these differences are the very driving force of the system. Agents whose (past and present) behaviour resulted in highly competitive power will grow (in terms of market share or profits), and others will loose the race, eventually forcing them to leave the market?. The selective environment makes the link between the behavioural patterns and the realized growth patterns.

Thus, the selection mechanism is essentially a dynamic way of describing the economy, since it explains the motion of the system (in terms of growing importance of some groups of agents) instead of the motionless equilibrium that might (theoretically) result. The notion of an evolutionary equilibrium (Dosi et al. 1990) or ecological equilibrium (Boulding 1981) can be defined to represent a steady state in which there is still motion. In this case, the different forces in the system do not cancel each other out to yield a motionless state, but their effects work together in such a way that the system is 'stable'. An example of this is the situation in which there is an imitator and an innovator, where the latter constantly invents new products, and the first constantly imitates these products (after a lag), and these two tendencies work together in such a way that the net market shares do not change. Thus, while an evolutionary equilibrium might arise from the selection process, this equilibrium can still be characterized as being dynamic ${ }^{10}$.

To sum up, the evolutionary way of looking at the world takes heterogeneity of individuals as the starting point, and, when applied to economic processes, leads to an explicit dynamic representation of the market process. Thus, it closely meets with the two points of critique to the use of market equilibrium as a regulatory mechanism in economic models, and seems to be an obvious candidate for replacing it in a theory of economic growth and technological change along the lines outlined above. Of course, this reasoning is nothing like a 'full-proof piece of evidence' that the concept of market equilibrium should be abolished in favour of the selection mechanism. Such evidence can never be given. The only way to make plausible that the selection mechanism is a useful concept, or better, is a more useful concept than the market equilibrium, is to apply it in economic theory. Among others, Silverberg et al. (1988) and Iwai (1984a, 1984b) have already done

\footnotetext{
"It has sometimes been argued that the process of selection leads to a situation which can be characterized as a neoclassical, profit-maximizing equilibrium. Hodgson (1990) has convincingly shown that this is, however, only true in some special cases.
}

${ }^{10}$ For a useful discussion of the notion of equilibrium in a dynamic framework, see Clark and Juma (1987). 
this. In Part Three of this thesis, an effort to do this will also be made.

One conditio sine qua non in modern economics (at least among practitioners of its neoclassical variant) seems to be that the arguments have to be put in mathematical terms ${ }^{11}$. Discussions about the value of mathematics in economics have been existing for a long time, like many other discussions in economics. One advantage of putting economic theory in mathematical terms is that it allows for a discussion in exact terms, without too great a risk of getting stuck in definitional and conceptual discussions. A clear disadvantage of mathematics is that it provides a much less rich language, thus leaving aside many interesting topics and leading to concentration on isolated parts of reality ${ }^{12}$. This discussion will not be pursued further here, but instead the argument will follow Gomulka (1990: 72) when he states that

"The behavioural and evolutionary ideas are usually phrased in a manner that is too general to be suitable for conducting a (theoretical) analysis capable of generating specific propositions that could be subjected to empirical tests. For that effort a further modelling effort is needed that would give the ideas an operational quality".

Based on this assertion, the point is taken that evolutionary theory, in order to be able to provide a useful alternative to neoclassical equilibrium analysis, should aim at developing formal methods which can compare to neoclassical models with respect to analytical and mathematical rigour. Of course, this does not mean that the non-mathematical theorizing in the evolutionary tradition is not useful. On the contrary, the strength of evolutionary theory is that the two types of analysis can closely interact.

In the sciences of biology and (mathematical) ecology, evolutionary concepts have already been put in mathematical terms. An overview of (mathematical) methods used in these fields is in Hofbauer and Sigmund (1988). The selection dynamics can easily be described by a system of differential or difference equations. Together with some other relations between variables in the system, one can thus specify a formal model describing the interactions in part of the (biological, ecological) problem in question. Basically, the selection mechanism can be described by the replicator equation

$$
\begin{gathered}
\dot{X}_{i}=\alpha X_{i}\left(E_{i}-\bar{E}\right) \\
\bar{E}=\sum_{i} E_{i} X_{\ell}
\end{gathered}
$$

where $X$ denotes the share of an individual (species) $i$ in some variable, $E$ is competitiveness (fitness), and a bar indicates an average level. Thus, the replicator

"The following quotation is illustrative of one point of view regarding this issue: "The individual intent on pursuing a career as economist has to be bright enough to understand the abstract ramifications of neoclassical theory and dumb enough to have faith in them" (Kay 1984: 188).

${ }^{12}$ One particular interesting contribution to this debate is Romer (1990b). 
equation says that the proportionate rate of growth of the share of some individual (species) is a (linear) function of the difference between this individual's (species') competitiveness and the average competitiveness.

Very similar to the way in which the basic methods of neoclassical economics were taken from physics during the end of the previous and the beginning of this century, one can imagine that present-day evolutionary economics would borrow heavily from these biological and ecological methods (see Allen 1988). A discussion of how these methods of formal modelling can be incorporated in economics is given in Silverberg (1988), while equation (III.1) - (III.2) will be applied in Part Three below.

Contrary to the idea that economics can learn from biology, is Gould's (1977; 88) assertion that Darwin took the basic idea for his evolution theory from Adam Smith's work. However, analogies between economics and biology are not uncontested. Throughout the classical era, there were some 'flirts' with biological sciences, and Darwin's work in particular. Clark and Juma (1987: 46) cite Marx' view of Darwin's work (expressed in a letter to Engels) as follows: "this is the book that contains the basis in natural history for our view". But they also show that in their later work, Marx and Engels "returned to a classical Newtonian world-view" (Clark and Juma 1987: 48). However, after Veblen (1898) the interest in biological analogies almost vanished. The general opinion about biological analogies during the neoclassical era is perhaps best illustrated by a quotation from Samuelson (1967):

\footnotetext{
"All this prattle about biological merhods in economics (...) cannot change this fact: any price taker who can sell more at the going price than he is now selling and who has falling marginal costs will not be in equilibrium. Talk of birds and bees, giant trees in the forest, and declining entrepreneurial dynasties, is all very well, but why blink at such an elementary point".
}

However, in order to make use of the selection mechanism in economics, some important questions remain to be answered. In which way is performance measured (what does $X$ stand for in the above equation)? What is the unit of selection (what does $i$ denote)? How is competitiveness $(E)$ measured? Obviously, these questions cannot be seen independent of one another. Some preliminary answers could be to use the firm as the unit of selection, and market share as a measure of performance. Measures of competitiveness would then be product price or quality. Market shares would change as a result of firm behaviour, and technological paradigms would emerge, develop and retard as an outcome of this firm-level selection process. Another approach would be to use a technology as the unit of selection, and make the development of firms secondary to this.

Regardless of the answer to these questions, while drawing the analogy between economic and natural selection, one should take into account the distinction between Darwinian and Lamarckian concepts of evolution. Darwin's evolutionary concept says that species are selected (or not) on the basis of the combination of some of their characteristics and the environment. These characteristics are exogenous, and only change as a result of random mutations. Consider the 
following example. Among all the animals living in an area where trees are scarce, the giraffe stood out because it (accidentally) was able to eat from the highest trees, and thus had a competitive advantage in the daily struggle for food. Other species, with shorter necks, became extinct because they were not able to eat from the highest trees. After Darwin, an explanation of this process was built on the basis of the laws of inheritance, as formulated first by Mendel (see Hofbauer and Sigmund 1988).

The Lamarckian idea is that species survive the selection process because they are able to change some of their inherent characteristics, i.e., they have an ability to learn. To continue the above example, giraffes were able to survive because their necks became longer and longer while reaching out for the high trees. Species which were not able to develop longer necks (through learning) did not survive, Thus, while the Darwinian view stresses the concept of selection of the 'survival of the fittest, the Lamarckian concept stresses the importance of the learning capability. One way to interpret this difference is to say that in Darwinian selection, mutation is exogenous (random), while in the Lamarckian view it is endogenous. While in biology the Darwinian concept might be more appropriate, the above discussion on endogenous innovation has shown that the Lamarckian concept might be more useful in economics. Obviously, in economics individual agents learn. Firms can change their behaviour on the basis of experience. Therefore, an evolutionary theory of economics would necessarily include some elements of Lamarckian thought.

A logical venue for modelling the Lamarckian learning idea in economics is the theory on learning curves (see for example Dosi 1988b, Spence 1981, Fudenberg and Tirole 1984, and the discussion on the Verdoorn effect in Chapter 2). This literature captures the idea that experience with new products or processes leads to higher efficiency in using them. Different modes of learning can be defined, such as learning-by-doing, learning-by-using, or even learning-by-learning (see for example Stiglitz 1987). The model that will be developed in Part Three below will mainly look at innovation as a learning process, as the natural way of implementing the Lamarckian concept of evolution in economics.

To conclude, a useful way of modelling the relation between technological change and economic growth should be of an explicit dynamic nature, and preferably take differences between firms as the starting point of the analysis. The model of knowledge spillovers in Part Two below, as well as the model of competition, specialization and growth in Part Three will make some efforts in this way. 


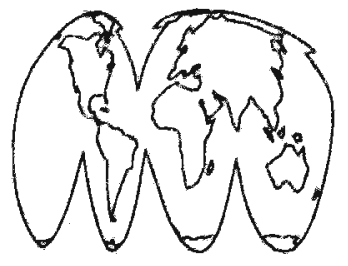

CHAPTER 4. Technology and Growth in an International Perspective, 1960-1990. An Impressionist Approach

After the theoretical perspective of the previous chapters, this chapter will review the empirical evidence on growth rate differentials and technology gaps in the postwar period. To do so, the analysis will be split into three major parts. The first part looks at the available economic data. The phenomena studied are economic growth at the macro and sectoral level, and structural change (between countries and over time). The second part looks at technological change, and tries to detect some regularities in the available indicators, such as total factor productivity, labour productivity and $R \& D$ efforts. The third part tries to connect economic growth to technological change, and looks at the world trends in technology gaps and growth rates in a preliminary way.

\subsection{Economic Growth and Structural Change a. Do (Aggregate) Growth Rates Differ?}

Before asking the question 'Why do growth rates differ?' (Parts Two and Three), it is useful to look at the data on world economic growth in order to understand to what extent the phenomenon to be explained actually exists. Recent data sets developed by the World Bank (Summers and Heston 1991) provide a good picture of growth performance at the world level. Figures IV.1 - IV.3 use these data to illustrate the degree to which growth rates differ in various subgroups of countries. The figures give the simple mean, and the dispersion (i.e., one standard deviation) around it, of the growth rates of real per capita income $e^{1}$ for the period 1961-1986. Hundred-and-fifteen countries were used in the calculations for the figures.

What emerges from the graphs first of all, is the variation of growth rates over time. In all three figures, the recessions in the 1970 s obviously leave their traces, as does the recent recovery of the world economy in the early 1980s. Of course, this resemblance results because the different economies in the world are not independent upon one another. Interacting with each other through trade, monetary flows and factor movements, growth patterns are exported. Second, it is clear that means of growth rates differ among subgroups of countries. Successively removing African and non-OECD countries from the sample raises

\footnotetext{
' RGDPCH from the PWT5 data set in Summers and Heston (1991). The figures give three-year moving averages of the mean growth rate and the standard deviation. The condusions drawn here generally also hold for total income (as opposed to per capita).
} 


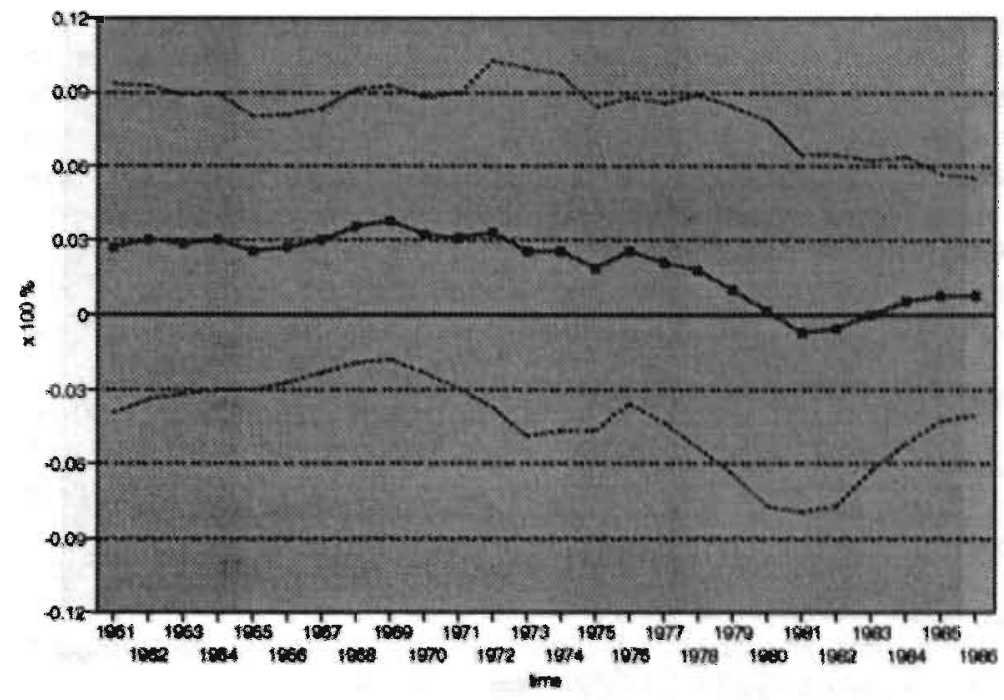

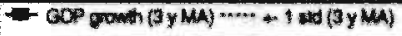

Figure IV.l. Variation around average growth rates of per capita GDP. All countries, 1961-1986

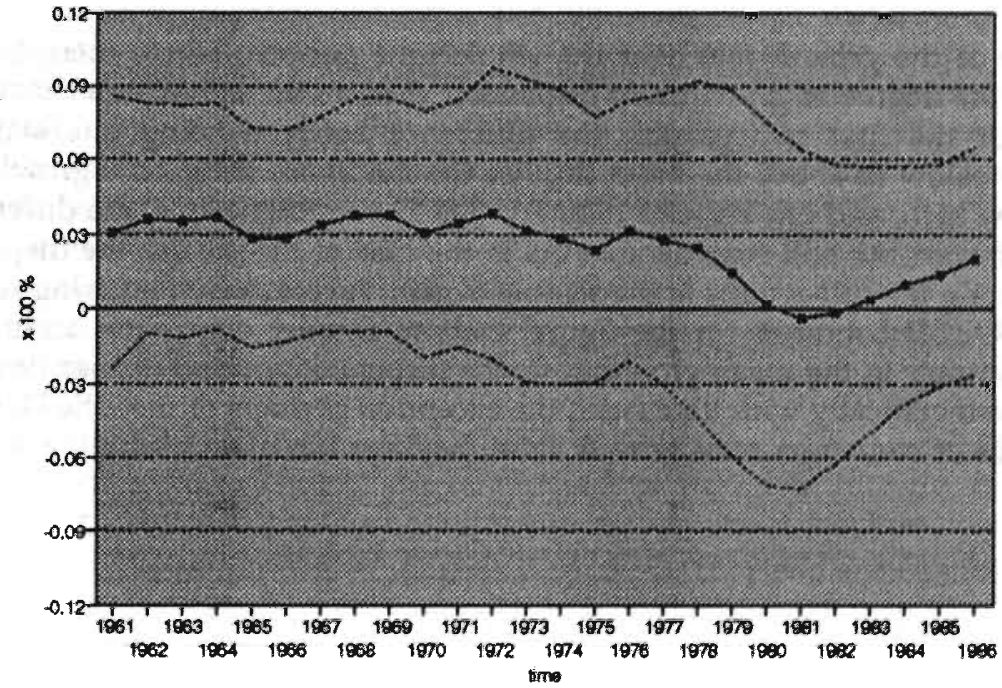

GOP grown $(3$ y MA) $\cdots+\cdots+1$ sid $(3$ y MA)

Figure IV.2. Variation around average growth of per capita income of GDP. NonAfrican countries, 1961-1986 


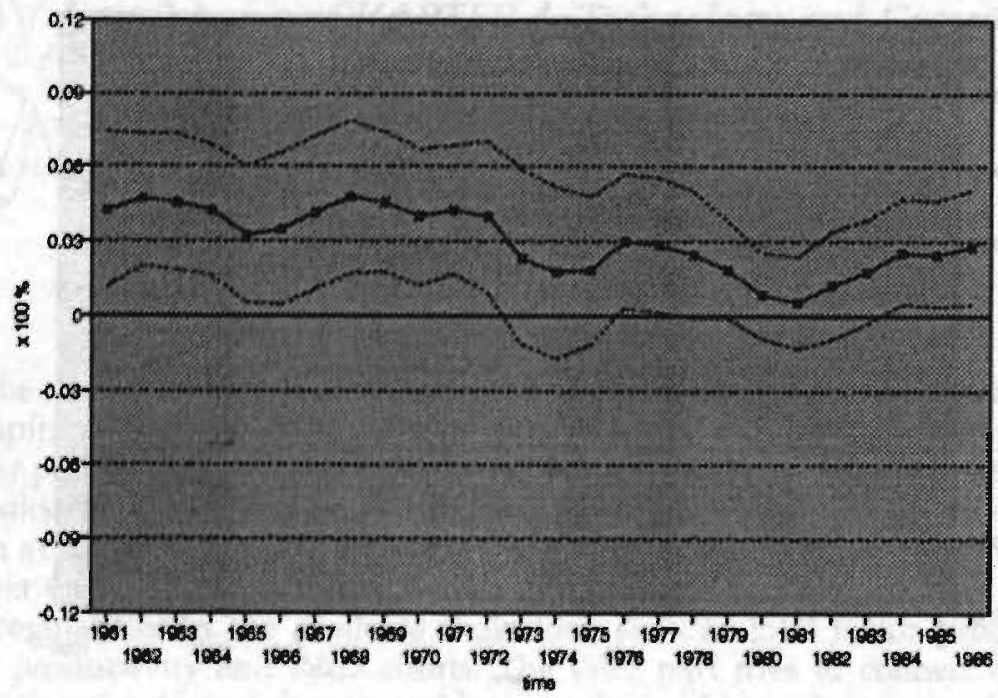

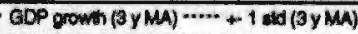

Figure IV.3. Variation around average growth rates of per capita GDP. OECD countries, 1961-1986

the mean of the growth rate over the whole time period ${ }^{2}$. Third, there exists a considerable degree of growth rate dispersion, despite the interaction mentioned above. For the first two graphs, the difference between being one standard deviation below or above the mean implies the difference between a growth rate well below zero, and one close to $10 \%$. For OECD countries alone, the differences are less drastic, but still considerable. As in the case of the means, the dispersion varies among the sub-groups in the sample. Again, successively removing African and non-OECD countries for the figure leads to smaller dispersion around the mean. Contrary to the mean growth rate, the dispersion around it does not seem to vary systematically with time (with the exception perhaps of the OECD, where some signs of convergence of growth rates over the 1980s are visible).

${ }^{2}$ Except for the 1970s, which indicates that the world economic crash coinciding with the two oil-crises shook the OECD countries harder than others. 


\section{b. The Production Structure}

Before investigating whether or not sectoral growth rates also differ, it is useful to look at the production structure in different countries. To do this, only data about the manufacturing sector in a limited number of countries will be used because of the absence of data for other countries. By way of introduction, Figures IV.4 IV.4b gives the shares of separate sectors ${ }^{3}$ in total manufacturing sectors for the Newly Industrializing Countries (NICs), Developed Market Economies (DMEs) ${ }^{4}$ and the total of the two groups for 1970 (IV.4a) and 1980 (IV.4b). A few points emerge from the figures. First, it appears that the differences between 1970 and 1980 shares are not very large. This points to the fact that, at the world level, the production structure only changes slowly over time. However, since the period under consideration here is not representative of the postwar period as a whole, the figure does not prove that, in general, structural change is slow. For example, in light of the recent technological developments, one could expect that changes in the production structure are much faster in the 1980s and 1990s.

A second point that emerges clearly from the figures is that there are huge differences in importance between sectors. While the largest sector occupies about one eighth of total production, the smallest sectors are typically responsible for less than one hundredth of total production. Partly, these differences are due to the arbitrary aggregation logic in the ISIC classifications, which identifies at the 3-digit level both such large sectors as total food or textiles industries and small sectors as for example professional and scientific instruments. It is true, however, that these levels of aggregation are some, although very rough, measure of the scope of a specific firm operating in one of these industries. The scope of a firm operating in one particular area of the food industry will certainly be so broad as to include most (if not all) other activities in this branch, but will certainly not include something like transportation equipment. Thus, the relative importance of each of the sectors gives some indication of the extent of the market for the activities of the group of firms in a country. The figure clearly indicates that it pays to occupy a large share of the market for food products or transport equipment $t^{6}$, but that it is less important to have a large market share in industries like pottery, tobacco or china and earthenware.

A third point that can be seen in the figures is the relative importance of high- and medium-tech sectors. Most of the largest sectors would fit into the category of medium-tech sectors (transport equipment, non-electrical machinery, petroleum refineries, industrial chemicals). Typically low-tech branches rank among the small IV.2.

${ }^{3}$ The classification used here and below is ISIC, revision 2. For an explanation see Appendix

- For the explanation of country grouping, see Appendix IV.1.

${ }^{5}$ Since only manufacturing is taken into account, non-manufactured food products (agriculture) are not considered.

6 Transport equipment is an example of the flaws in the aggregation logic, because, for example, both airplanes and bicycles are included. 


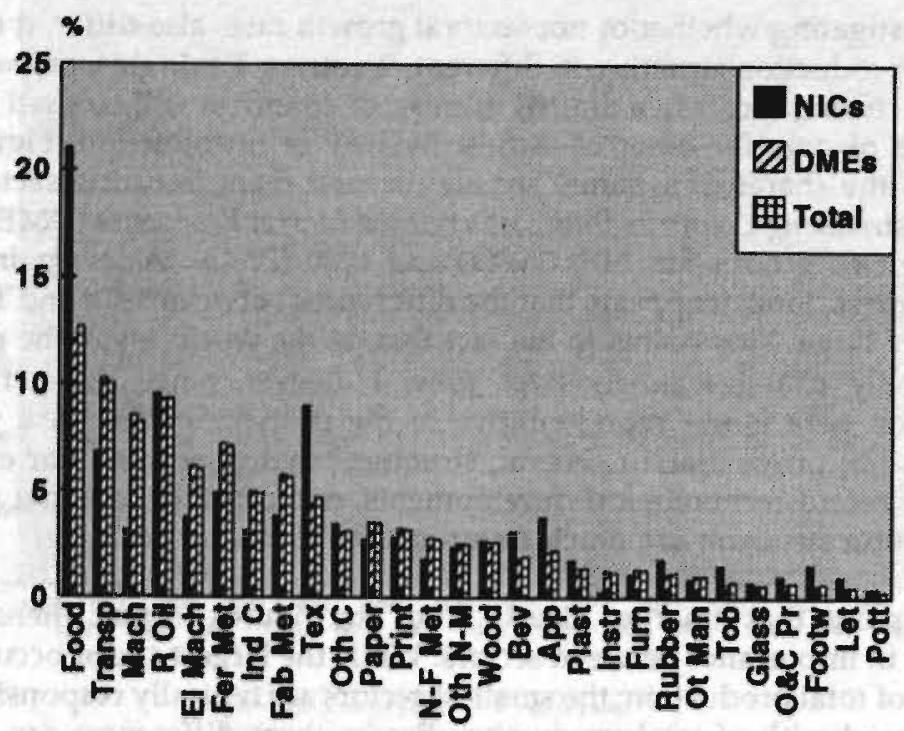

Figure IV.4a. Sectoral shares in total manufacturing production, NICs, DMEs and total, 1970

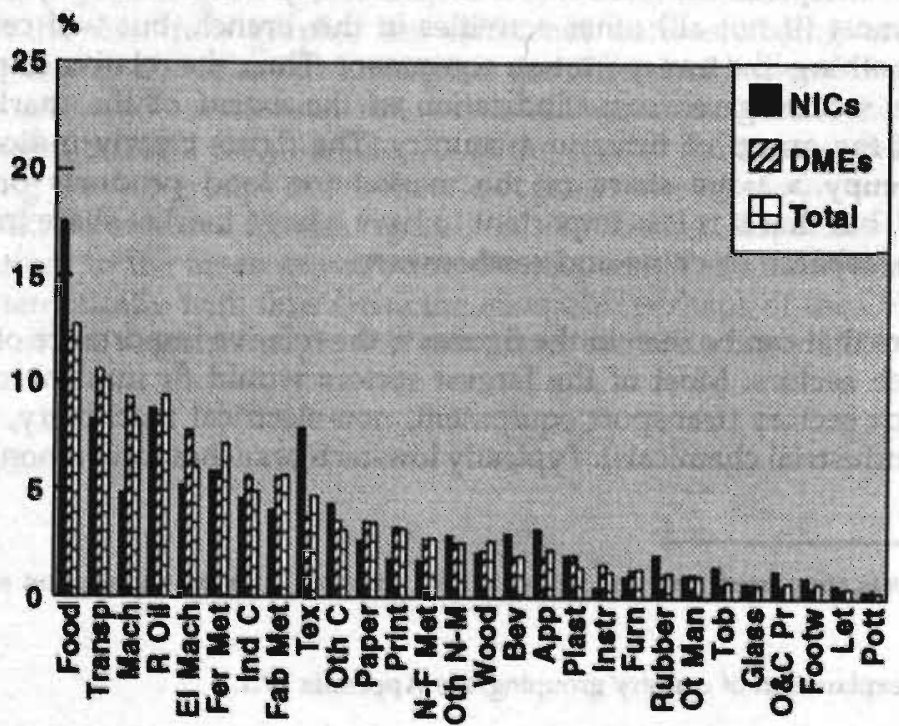

Figure IV.4b. Sectoral shares in toral manufacturing production, NICs, DMEs and tocal, 1980 
sectors (such as non-metallic mineral products, wood products and paper) or medium-size sectors (iron and steel, textiles). A notable exception is the food industry. Real high-tech sectors, of which there are only a few at the 3-digit ISIC level, can be found all over the size spectrum. Electrical machinery ranks among the large sectors, other chemicals (of which pharmaceuticals comprise a large part) is in the medium-size sectors, and professional and scientific instruments is a very small sector.

A last point that is worth stressing is that the production structure varies between NICs and DMEs. In particular, the importance of food products, textiles and apparel seems to be larger in the NICs, while the share of transport equipment, non-electrical machinery and printing and publishing is larger in the DMEs. This points to a certain specialization pattern between NICs and DMEs which is known from more detailed historical descriptions of the development process in the NICs (see also Chapter 9). This last point can also be shown by computing indexes of structural differences between countries. Instead of the usual way of looking at structural change in the same country, but between different points in time, the numbers presented here look at structural change between countries at the same point in time. An index which measures this is the following.

$$
\Delta_{i k t}=\sum_{j}\left|\frac{Q_{i j k}}{Q_{i k}}-\frac{Q_{k j}}{Q_{k t}}\right|
$$

In this equation, $\Delta$ is the index for structural differences, subscripts $i$ and $k$ denote a country, subscripts $j$ denote a sector. The index $\Delta$ ranges between zero and two, a value of zero pointing to no differences in the structural mix of production, and a value of two pointing to a complete opposition of the structure ${ }^{7}$.

In Figure IV.5, the values for $\Delta$ are presented for combinations of 15 countries. Each point gives the combination of the distance between two countries in 1970 (horizontal axis) and 1980 (vertical axis). Thus, the points in the graph give two sorts of information. First, the steepness of the line pointing from the origin to a particular point gives an indication of the change in the distance between the two countries. A steep line points to a rapidly increasing distance, and a flat line points to a rapidly decreasing distance. If a point is below (above) the $45^{\circ}$ line, the distance between the two countries it reflects became smaller (larger) during the period 1970-1980. Second, the distance of a point to the origin gives an indication of the average distance between the two countries. Measured on one axis only, the distance is, of course, that for one of the two years.

${ }^{7}$ This way of distance measurement is a special case of a more general formula known as the Minkowski p-metric. This special case is also known under the name of city block metric or Manhattan metric. Another special case of the Minkowski p-metric is the familiar Euclidean metric. For more information on the Minkowski p-metric and the interpretation of different special cases, see Appendix IV.3. Note that a value of two can only be reached in a (mutual) situation of complete specialization, in which a good is produced only in one country, and a country only produces one good. 
structural differences 1980

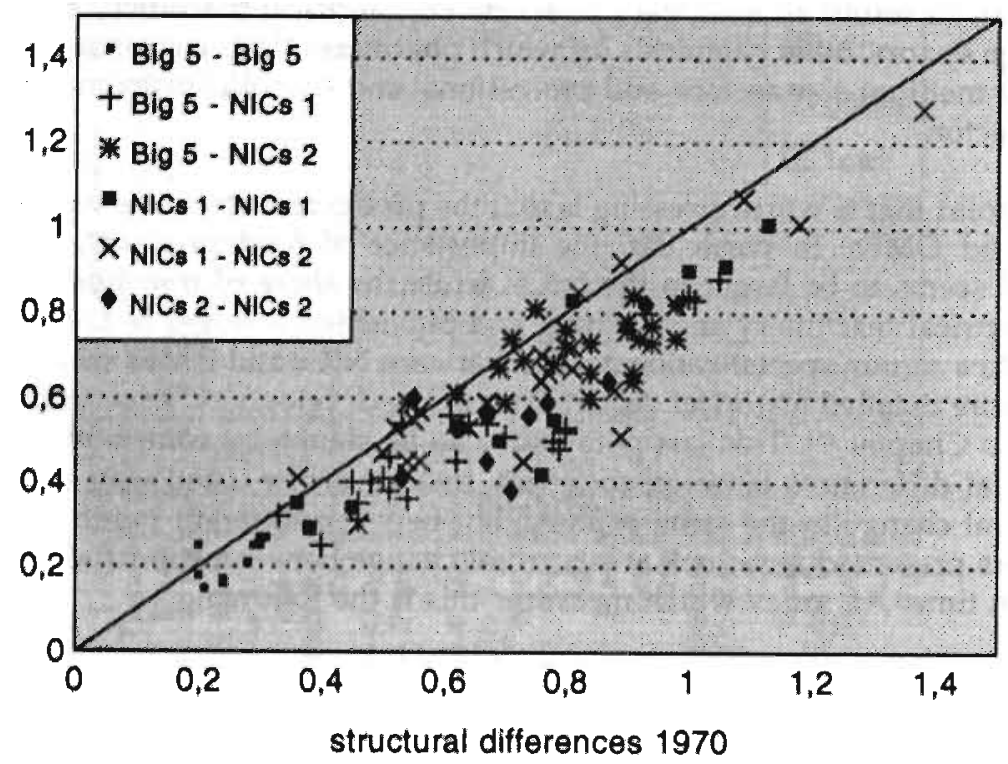

Figure IV.5. Structural differences in the world, 1970-1980

The countries represented in the figure are the Big 5 (USA, Japan, Germany, France, UK) and ten NICs. NICs are divided into two groups: high-income (1) and low-income (2) NICs (see Appendix IV.1). These three groups give six different combinations of country types, each represented by a unique marker type. The first impression one gets from the graph is that structural differences became smaller during the period 1970-1980 (almost all points are below the $45^{\circ}$ line). Thus, the NICs have been catching up to the economic leaders with respect to production structures. Second, the three different groups of countries can be identified quite well in terms of their location in the graph in a large number of cases. Some of the marker types used appear in relatively homogeneous clouds in an isolated part of the graph. This particularly goes for the groups in which the Big 5 are included, and only to some extent for the other groups. This means that the Big 5 countries are a relatively homogeneous group. The points representing 'internal' differences in this group are all very close to the origin. The cloud of points giving the distance between NICs 1 and the Big 5 appears to be further away from the origin, indicating that the average distance within this group is larger than among the Big 5 countries themselves. Moving further to the top right of the graph, the markers for Big 5 and NICs 2 countries are found, indicating that the average distance between these two groups is even larger. Internal distances between NICs are all fairly large and not very homogeneous. 


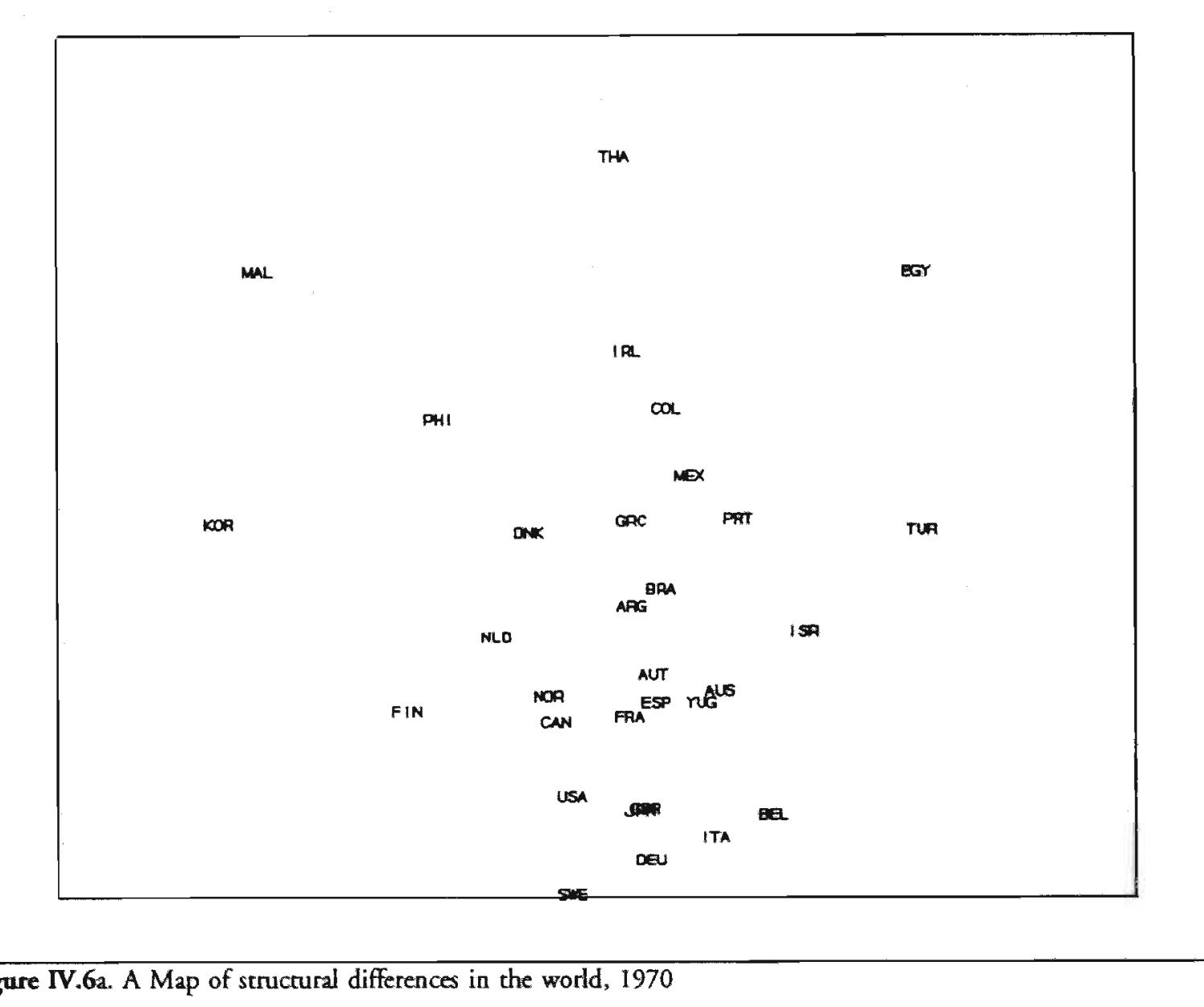




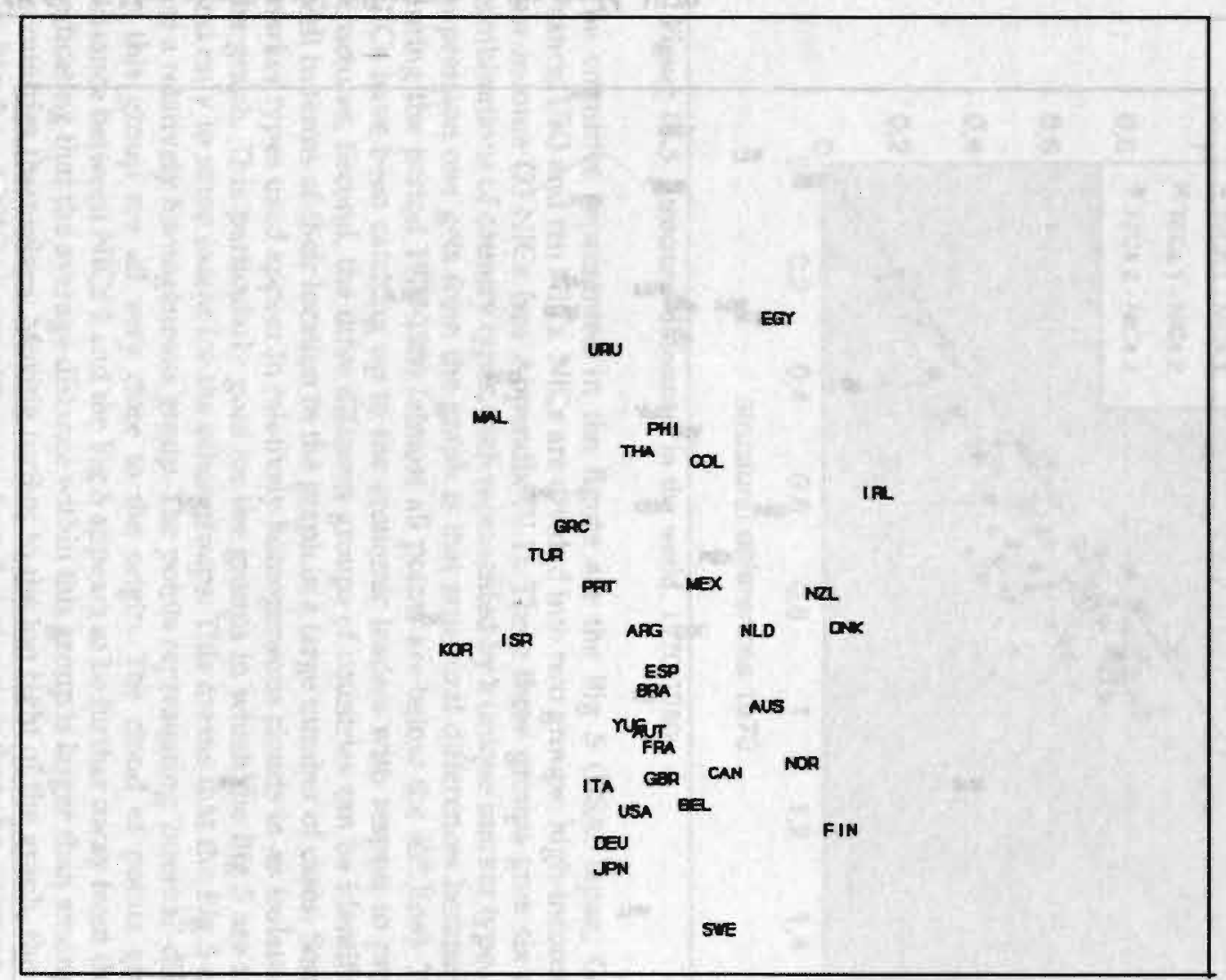

Figure IV.6b. A map of structural differences in the world, 1980 
These conclusions can also be drawn from a different way of graphing the structural distances between countries (now for a larger sample than Figure IV.5). In Figures IV.6a and IV.6b, the technique of nonmetric multidimensional scaling is applied to the case. This technique is further introduced and discussed in Appendix IV.3. The figures have to be interpreted as follows. The configuration of the points is chosen such that the rank order of the distances between (the centre of the points in the graph is as close as possible to the rank order of the distances found in the (half) matrix of distances between the countries in the graph as measured in the way introduced above. The two dimensions (or axes) themselves have no meaning at all. Their only purpose is to provide enough degrees of freedom in order to be able to find a 'close enough' configuration of points. In fact, one could increase the accuracy of the configuration by introducing another dimension, which has not, however, been done because this would make the graphical presentation more difficult. The scales of both dimensions are kept identical, in order to allow for comparison between the two graphs.

In terms of economic grouping, the graphs reflect to a large extent intuitive expectations. It seems as if there are a number of layers of groups of countries. The Asian NICs (Korea, Malaysia, Thailand and the Philippines), often highly specialized (see also Chapter 9), are at the outside of the configuration, after which one finds mixed layers of Southern American NICs (Argentina, Brazil, Colombia), the less developed from the DMEs (Turkey, Portugal, Greece) and the smaller DMEs (The Netherlands, Scandinavian countries). Then there is a core consisting mainly of the Big 5 countries plus Italy and Belgium ${ }^{8}$. The position of Yugoslavia among the 'inner layers' is surprising.

To conclude, one might say that besides differences in growth performance, there are also considerable differences in production structure between countries. Moreover, these differences are subject to changes over time.

\footnotetext{
In the first figure, the two countries appearing on top of each other are Japan and Great Britain.
} 


\section{c. Sectoral Growth Patterns}

Coming back to the issue of growth, Figure IV.7 presents sectoral growth rates of production over the period 1963-1989. The growth trends are calculated by estimating each country's growth trend by an OLS-regression, and weighting the results by the country's production share in 1980. This procedure is necessary because missing values in the data do not allow for the precise 'world' growth rate to be estimated. Note that for most countries, data for the last few years are absent, and that for a smaller number of countries data for the beginning of the period are absent.

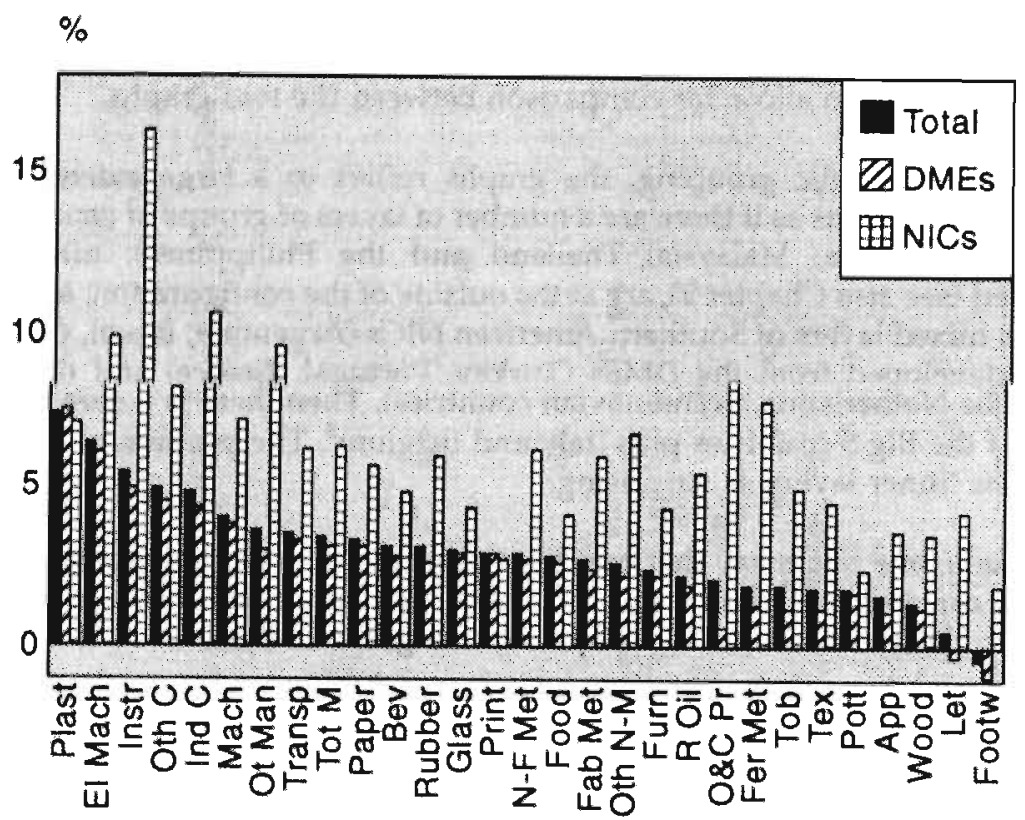

Figure IV.7. Growth of production in 28 manufacturing sectors, 35 countries 1963-1989

It is immediately clear that there is a strongly positive relation between the degree of technology intensity and the growth rate of production. The three high-tech sectors are ranked in places 2-5, most low-tech sectors have grown slower than average (as represented by total manufacturing), and most medium-tech sectors rank above average. This correspondence is an important finding because it confirms the economic importance of high-tech sectors at a more general world level. This illustrates the importance of the point made in Chapter 3 about income elasticities and major technological innovations.

With regard to the differences between blocks, it is worth stressing that the NICs' performance is higher than the rest of the world in almost every sector (with the exception of printing and publishing). In order to see the influence of this on 
market shares in world production, Figure IV. 8 looks at the market share in total production of NICs and DMEs in 1970 (left bar) and 1980 (right bar). Results for NICs are only given for ten NICs, because no data for the early periods are available for two countries. Total production is the production of DMEs plus ten NICs.

The figure shows that the share of DMEs in total production is still very large, although decreasing (for total manufacturing) with about $2.5 \%$ points over 1970 1980. Looking at individual sectors, observe that the loss of market shares of the DMEs to the NICs is a general phenomenon across sectors during the period 1970 1980 , and almost every sector (for which data are available) during 1980-1985 (1985 results not documented). Only for transport equipment (a medium-tech, large sector) and electrical machinery (high-tech), the NICs' gain in market share in 1970-1980 was partly lost again during 1980-1985. Sectors in which DMEs are relatively strong are mainly wood, furniture, paper, printing, industrial chemicals, plastic products and metal-related sectors. NICs are relatively strong in food and related sectors, textiles and related sectors and miscellaneous coal and petroleum products. All in all, the figure indicates that market shares are subject to a considerable degree of change, even at the level of aggregation of only two different blocks. The conclusion to be drawn from this is that besides aggregate differences, there are also considerable differences in growth patterns at the sectoral level.

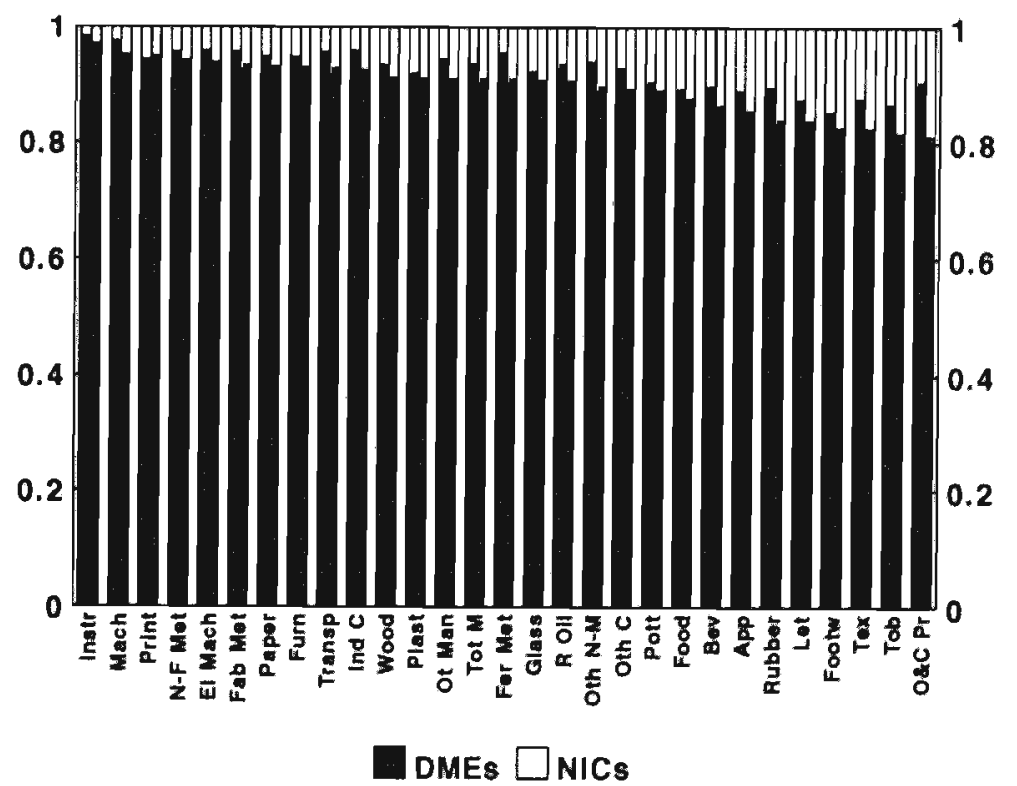

Figure IV.8. Marker shares in world manufacturing production, 1970-1980 


\subsection{Technology \\ a. How Exogenous is Solow's Residual?}

Chapter 2 presented some theories on the relation between technological change and economic growth. The older theories (Kaldor's model being an exception) assumed that technological change is exogenous, i.e., not systematically related to economic variables. The newer theories tend to look at innovation as an endogenous phenomenon. This section will address the question of endogenous or exogenous technological change by means of a preliminary empirical analysis. The approach followed is to relate numbers on the contribution of technological change to economic growth (as measured by TFP) by means of regression analysis to data on R\&D activities, investment and initial technology gaps. This will be done for a sample of 23 OECD countries.

As explained in Chapter 2, Solow's residual (TFP) measures the contribution of technological change to economic growth. Although the procedure is fraught with difficulties (such as the strict assumption of competitive market equilibrium and neglecting of sources of growth such as institutional change), it will be assumed here that TFP measures this contribution at least to an extent which allows one to make some inference about the relations between technological progress and economic variables from the empirical macroeconomic data. Usually, calculations of TFP assume that technological progress is neutral (as in the formula for TFP introduced in Chapter 2). It is, however, possible to assume that technological change has a bias and calculate the according rate of TFP growth associated with the observed movements in aggregate inputs and output. In this case, however, it is necessary to assume a specific functional form of the production function. Therefore, assume that the production function is Cobb-Douglas with CRS and labour-augmenting technical progress, as is the case in Solow's growth model from Chapter 2. Then, TFP growth can be calculated as follows.

$$
\hat{A}_{s}=\frac{1}{\sigma_{l}} Q-\hat{L}-\frac{1-\sigma_{1}}{\sigma_{l}} \hat{R}
$$

The usual TFP formula, under the assumption that technical progress is neutral, is reproduced from Chapter 2 and looks as follows.

$$
\hat{A}_{n}=Q-\sigma L-\left(1-\sigma_{1}\right) R
$$

The subscripts $n$ and $s$ denote neutral and labour-augmenting, respectively.

The value of $A_{n}$ and $A_{s}$ is calculated using aggregate data from the OECD ISDB databank. The capital stock ( $K$ in the formulas for TFP) is obtained from gross investment by a perpetual inventory method'. Labour input is measured as the number of labourers (not hours worked), while labour's share in income is calculated from the employee's total compensation (multiplied by the ratio of total employment to employees). The explanatory variables used in the equation for TFP are gross investment as a fraction of the capital stock $(I / K)$ or as a fraction of output $(I / Q)$ (taken from the OECD ISDB databank), business enterprise R\&D

\footnotetext{
The initial capital stock is calculated as $1 / 0.06$, the depreciation rate is assumed to be 0.02 . It is assumed that there is a one-year gestation lag for investment.
} 
expenditures as fraction of output (R\&D intensity, or RDI) (source: OECD/STIID), and 1963 per capita GDP in 1980 purchasing power parities (source: OECD/STIID).

There are two reasons why the analysis will be restricted to cross-country analysis rather than time series analysis. First, in the process of technological change, there are clearly lags involved between innovation inputs (measured by gross. investment or R\&D expenditures) and innovation outputs in the form of growth in TFP. The size of this lag is not clear, and moreover, probably not constant, so that time series analysis would be difficult. Second, the series used show trends in the period under consideration. R\&D intensity rises steadily in most countries, while the investment ratio falls. These trends are probably due to systematic changes of production mode in the countries under consideration, switching from a fixed capital-intensive way of production towards a more knowledge-intensive production mode ${ }^{10}$. While these trends can, and probably will be, related to productivity performance, a time series regression analysis is not likely to capture this phenomenon of a more secular nature than the short term regression would be fitting.

Therefore, the variables (except initial income per capita) used in the regression are averages over the period" 1960-1989 (TFP and investment) or 1967-1989 (R\&D). As in Dosi, Pavitt and Soete (1990), it is assumed that this provides a reasonable way to capture the lag structure of the relation (see also Chapter 8 below). Of course, this method does not take into account that the period in question was one of uneven distribution of productivity (and output) growth over time. It is well known now that productivity and output growth was remarkably slow from 1973 to the early $1980 \mathrm{~s}$. This phenomenon was particularly strong in the USA, and to a lesser extent elsewhere. Some countries (the lower income countries and Scandinavia), however, barely experienced this productivity slowdown. This heterogeneity over time is not taken into account in the regression analysis. Therefore, the only purpose of the regressions can be to explain the average productivity performance in the post-1960 period. The productivity slowdown cannot be explained.

The results are documented in Table IV.1. The two R\&D intensities reflect total Business Enterprise R\&D (including government subsidies, RDI1), and Business Enterprise R\&D privately financed (RDI2). What stands out in the results, is the importance of initial income as an explanation for the variance in TFP, measured either way. In fact, initial income and the constant are the only variables yielding significant results ${ }^{12}$. This shows that the catching-up phenomenon seems to be of great importance. Countries with low initial income tend to yield high TFP growth.

\footnotetext{
${ }^{10}$ The importance of this trend should not be overestimated, since gross investment in fixed capital is still about ten times more important than R\&D.

"Individual countries may have different periodization due to missing values in the data.

${ }^{12}$ Besides the variables in the table, regressions were also calculated with the difference between start and end period RDI and (I/Q) or (I/K) (scaled by the number of years between them). These yielded only insignificant results, with often the wrong sign, and have therefore been left out of the table.
} 
R\&D and investment seem to be much less important. The signs of the regression coefficients are almost always correct (i.e., positive), but also insignificant. Intuitively, one would expect the level of investment and $R \& D$ intensity to be correlated with initial income, so that the $t$-values in the table are probably underestimated due to some degree of multicollinearity. However, as the analysis in Appendix IV.4 shows, the effects of this are negligible.

The weakness of these results might be caused by the fact that, as already indicated above, the measure for TFP includes other variables than just technological change. Due, to its 'residual-nature', TFP measures all effects other than those of increases on capital and labour, implying that things such as measurement errors, institutional change, misspecification, etc., are all included (see also Nelson 1981). This may well lead to a low 'signal-to-noise' ratio, causing the low significance of the estimated coefficients. Moreover, the measurement errors might be correlated to the explanatory variables themselves (for example, high investment and a high degree of institutional change might go together), leading to additional problems with the estimations in the table. However, given the rough character of the test, no attempt will be made to correct for this.

The two last columns of Table IV.1 present F-statistics for tests of structural change of the parameters for different subsamples of countries. Separate regressions are calculated for high- and low-tech countries (as identified by RDI1), and for countries with high and low initial income gaps. The results show that in case of labour-augmenting technical progress (equations IV.5-IV.8), splitting the sample adds significantly to the $R^{2}$. However, the parameter estimates (not presented) show that in this case the $t$-values are in the same order of magnitude, and the parameters have the same sign. Thus, the conclusion of the regression is that the cross-country variation in Solow's residual can be explained for a large part by differences in initial income. The influence of $R \& D$ and investment is only weak ${ }^{13}$.

To conclude, one might say that the evidence for endogenous movements of TFP is quite weak. This preliminary result does not provide much support for theories of endogenous technological change, such as the new growth theory and Kaldor's model. If anything, the catching-up potential is an important explanatory variable, while variables that one would expect to explain TFP movements ( $R \& D$, investment) are generally insignificant. Of course, the tests undertaken are quite rough, and should not be taken as definite answers to the question of exogenous vs endogenous technological change. However, what stands out is the importance of catching up ${ }^{14}$ for TFP growth.

\footnotetext{
${ }^{13}$ A number of other studies have investigated the productivity - R\&D relation. Patel and Soete (1987) have found positive, but not very strong, relations between TFP and R\&D at the aggregate level. Mohnen (1990) gives an overview, and Mairesse and Sassenou give an overview of studies at the firm level. For a general overview of the relation between technical change and TFP, see Nelson (1981).
}

"Dowrick and Nguyen (1989) also find this. 
Table IV.1. Cross-country regressions explaining Solow's Residual, 1960-1989*

\begin{tabular}{|c|c|c|c|c|c|c|c|c|c|c|c|}
\hline Eq. \# & $\begin{array}{l}\text { Dep. } \\
\text { var. }\end{array}$ & Constant & INIT & $\mathrm{I} / \mathrm{K}$ & $I / Q$ & RDI1 & RDI2 & $n$ & adj. $R^{2}$ & $F_{1}$ & $\mathrm{~F}_{2}$ \\
\hline 1 & $A_{n}$ & 0,0330 & $\begin{array}{l}-0.0015 \\
* * *\end{array}$ & 0.0310 & & 0.1474 & & 23 & 0.62 & 1.80 & 1.68 \\
\hline 2 & $A_{n}$ & 0.0292 & $=0.0015$ & & 0.0251 & 0.1670 & & 23 & 0.64 & 0.69 & 1.47 \\
\hline 3 & $A_{n}$ & $\begin{array}{l}0.0321 \\
+*\end{array}$ & -0.0015 & 0.0624 & & & 0.0421 & 20 & 0.64 & 1.34 & 1.93 \\
\hline 4 & $A_{n}$ & $\begin{array}{l}0.0326 \\
* * 4\end{array}$ & -0.0015 & & 0.0168 & & 0.0539 & 20 & 0.64 & 0.65 & 1.55 \\
\hline 5 & A & 0.0567 & -0.0021 & -0.0761 & & 0.1941 & & 23 & 0.57 & 2.76 & 3.06 \\
\hline 6 & $A_{s}$ & 0.0335 & 0.0019 & & 0.0648 & 0.2391 & & 23 & 0.62 & 2.14 & $\begin{array}{l}3.11 \\
n\end{array}$ \\
\hline 7 & As & $\begin{array}{l}0.0552 \\
* * *\end{array}$ & -0.0021 & -0.0298 & & & 0.0847 & 20 & 0.60 & 2.12 & 3.81 \\
\hline 8 & $A_{1}$ & $\begin{array}{l}0.03399 \\
* * *\end{array}$ & -0.0018 & & 0.0659 & & 0.0909 & 20 & 0.65 & 0.97 & 2.44 \\
\hline
\end{tabular}

"One, two and three stars point to significance at the $10 \%, 5 \%$ and $1 \%$ level (one sided $t$ - and F-tests). A test for heteroscedasticity was performed, which resulted in non-rejection of the homoscedasticity assumption. Columns $F_{1}$ and $F_{2}$ point to $F$-tests for structural differences between two subsamples. In the case of $F_{1}$, the sample is split into two groups on the basis of R\&D intensity (RDD. The grouping is as follows: Turkey, Greece, Iceland, Portugal, New Zealand, Spain, Australia, Ireland, Italy (low-tech); Denmark, Finland, Austria, Canada, Norway, Belgiurn, Netherlands, France, Japan, Sweden, FR Germany, UK, USA, Switzerland (high-tech). In the case of $F_{2}$, the sample is split as follows: Turkey, Portugal, Greece, Japan, Ireland, Spain, Finland, Austria, Italy, FR Germany, France, Belgium (low initial income); Denmark, UK, Norway, Sweden, Iceland, Netherlands, Australia, Switzerland, New Zealand, Canada, USA (high intitial income). 


\section{b. Sectoral Trends in Technological Change}

Another useful question is whether the rate of technological change varies across sectors. To test for this, technological change is again measured by TFP. Using the Solow formula which is familiar by now (this time only with neutral technological change), an index of technological change is constructed for a number of sectors. The source of the data is the OECD ISDB database, which allows for construction of TFP indices at the 1-digit ISIC level for six OECD countries: the USA, Canada, Japan, FR Germany, Australia and Finland. At the 2-digit ISIC level, TFP indices can only be constructed for manufacturing in the USA and Japan. The period under consideration is 1970-1986. For this period, a 'cross-country average' sectoral rate of technological change is calculated by taking the weighted average of country level TFP growth per year, with country shares in total production used as weights. Setting the index of technological change at one for the starting year (1970), a shift factor ( $A$ in the production function) for each subsequent year can be calculated.

In order to test whether the rate of technological change is equal among sectors, an equation can be estimated which relates this index to time. Pooling the data together in one large sample, the model can be estimated for the whole sample, and for subsamples consisting of data for one sector only. A Chow F-test of the type used above can then be applied to test whether the split into subsamples (i.e., sectors) improves the fit of the equation. In the actual estimation, two different equations are used. One assumes a linear time trend (i.e., decreasing rates of technological change), and one assumes an exponential trend (i.e., constant proportionate rates of technological progress) ${ }^{15}$.

First, these equations are estimated for the 1-digit ISIC sectors agriculture, mining and quarrying, manufacturing, electricity-gas-water, construction, transport storage and communications, for the averages of the six OECD countries above. In this case, the F-statistics for the hypothesis of equal rates of technological change are 115 (linear trend) and 162 (exponential trend), which means that the null hypothesis is rejected at all normal levels of significance. Second, for the 2-digit ISIC manufacturing sectors food-beverages-tobacco, textiles, paper-printingpublishing, chemicals, non-metallic mineral products, basic metal products, and machinery and equipment, the F-statistics are 32 (linear time trend) and 24 (exponential trend), which are also highly significant. These results show that over the whole economy as well as within manufacturing, rates of technological change differ from sector to sector. Table IV.2 lists these differences ${ }^{16}$.

\footnotetext{
is An alternative specification, which has become fashionable recently, is the assumption of a stochastic trend or random walk (see, for example, Stock and Watson 1988). However, while this assumption provides ample opportunities for sophisticated econometric analysis, it does not start from the intuitive notion that the (long-term) direction of technological change is towards higher productivity and better products.
}

${ }^{16}$ Note that the restricted case represents an unweighted average rate of technological progress. Therefore, the coefficient here might tum up insignificant, while one would find a significant coefficient if one looked at aggregate data. 
Table IV.2. Sectoral rates of technological change, 1970-1986

\begin{tabular}{|c|c|c|}
\hline Sector & $\begin{array}{l}\text { Linear rate of tech } \\
\text { change }\end{array}$ & $\begin{array}{l}\text { Exp rate of tech } \\
\text { change }\end{array}$ \\
\hline Agriculture & $0.014 *$ & 0.012 **** \\
\hline Mining and Quarrying & $-0.031=$ & $-0.040 * *$ \\
\hline Manufacturing & $0.024 * *$ & $0.020 * * 4$ \\
\hline Electricity, Gas and Water & $0.0020 *$ & $0.0019 *$ \\
\hline Construction & $-0.015=*$ & $-0.018=*$ \\
\hline Transport, Storage and Communications & $0.016 * *$ & $0.014^{n * *}$ \\
\hline Total economy (restricted model) & 0.0015 & -0.0017 \\
\hline Food, Beverages and Tobacco & -0.0003 & $-0,0004$ \\
\hline Textiles & $0.044^{* *}$ & $0.034^{\text {s.⿲丿丨乚 }}$ \\
\hline Paper, Printing and Publishing & $0.0039 * *$ & $0.0037^{* *}$ \\
\hline Chemicals & $0.012 * * *$ & $0.011 * *$ \\
\hline Non-metallic mineral products & $0.0056 *$ & $0.0057 * *$ \\
\hline Basic metal products & -0.0003 & -0.0002 \\
\hline Machinery and Equipment & $0.047^{* * *}$ & 0.035 \\
\hline Total manufacturing (restricted model) & 0.017 *** & $0.013 * *$ \\
\hline
\end{tabular}

By and large, the table confirms the intuitive ideas about sectoral rates of technological change. It is largest and positive in manufacturing, but smaller in sectors as agriculture and banking. Negative values are found in mining and construction, which can be explained by the (growing) scarcity of land and natural resources. Within manufacturing, it is largest in textiles and machinery. In order to test in a more exact way in which sectors the rates of technological change actually differ ${ }^{17}, t$-tests on the parameter values in Table IV. 2 can be performed. In this case, the hypothesis that the rate of technological change is equal in two sectors must be tested by two t-tests, which yields the possibility for an inconclusive result. Applying this method (the exact results are not documented) to the 1-digit sectors, it is found that all estimated rates of technological change differ from each other, except the ones for agriculture and transport, storage and communications. For manufacturing, it turns out that the rates of technological change are not significantly different from each other in the (typically low-tech) sectors food-beverages-tobacco, paper-printing-publishing, non-metallic mineral products and basic metal products.

In a larger sample of countries, indicators of TFP growth in different sectors are

\footnotetext{
${ }^{1}$ Note that the F-tests above do not exclude the possibility that the rates of technological change are equal in a limited number of sectors.
} 
not available. However, one can look at the growth rate of labour productivity as an indicator of technological change ${ }^{18}$. Figure IV. 9 ranks the 28 manufacturing sectors used before by the rate of labour productivity growth over the period 19631989. The method of calculation is the same as the one used in Figure IV.7. The results in Figure IV.9 confirm the earlier impression of varying rates of technological change across sectors. As in the above regressions, the high-tech sectors rank among the highest rates. However, there are also some typically lowtech sectors where the growth rate of labour productivity has been quite high (iron and steel and textiles-related sectors are the most outstanding examples). This, as well as the high rate of TFP growth found above, stresses the importance of learning effects and productivity change outside the area of high-tech production.

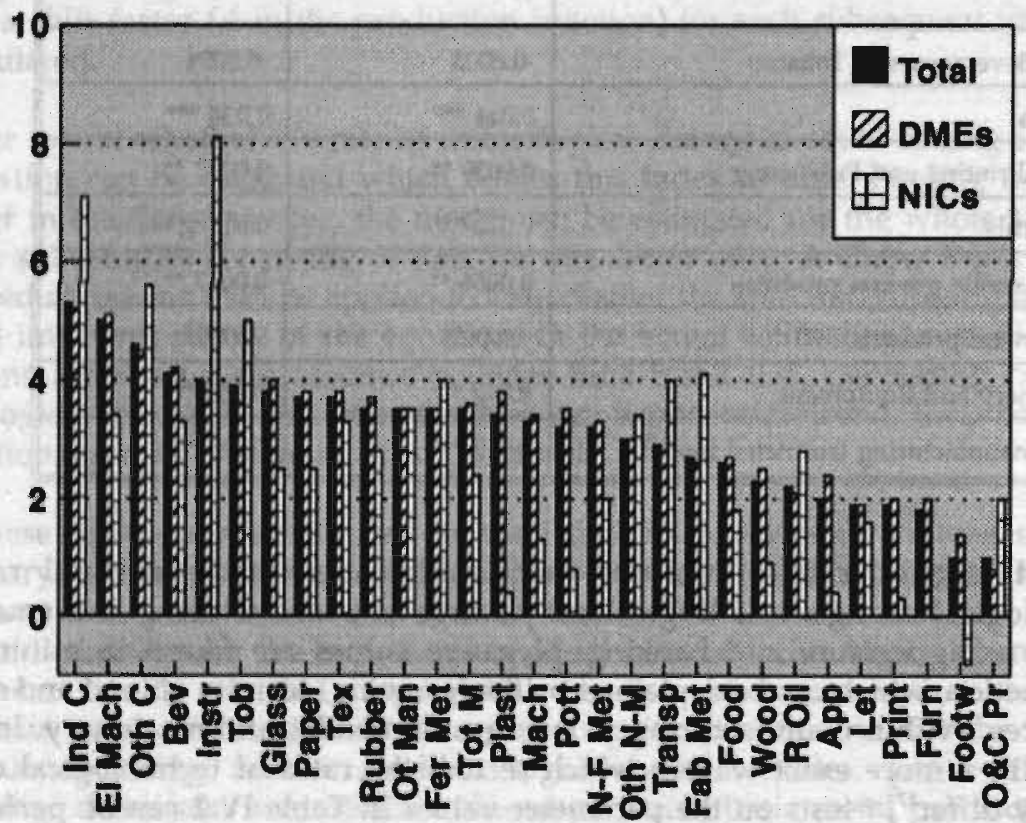

Figure IV.9. Average growth rate of labour productivity in manufacturing sectors, 1963-1989, NICs, DMEs and total

With regard to the distinction between NICs and DMEs, it appears that contrary to the picture for growth performance, the NICs have not achieved the fastest growth in labour productivity (note that the trend for total manufacturing represents the average for all sectors). Thus, although labour productivity has grown at a slower rate in the NICs than in the rest of the world, these countries have still been able to increase their production at a higher rate than the rest of the

\footnotetext{
1" For some comments with regard to the usefulness of labour productivity as an indicator of technology, see Chapter 8.
} 
world. This indicates that the growth performance of the NICs is a case of 'width' (arising out of the growth of the labour force) rather than 'depth' (arising out of increased productivity).

\subsection{Technology and Growth: Catching Up or Falling Behind? A Global Issue}

As a first way of getting some feeling of the relation between growth rates and technology in the world, this section will summarize the available evidence by trying to detect some regularities in growth performance across countries. The results in section $4.2 \mathrm{a}$ raise the question whether the relation between initial income and growth is also valid for a larger set of countries. This question is particularly acute if one realizes that most countries outside the sample considered above face an income gap much larger than the countries in the above regressions. Is the growth potential of these countries proportional to this income gap?

In order to answer this question, the dynamics of real per capita GDP (used as a rough indicator of technological level), denoted by $Q^{\text {opp }}$, for a larger sample of countries $(n=114)$ will now be investigated. Besides enlarging the sample, the method of calculating growth performance and the period under consideration have also been changed. The data used are taken from Summers and Heston (1987) (RCHGDP, as above). The value of per capita GDP for the United States is taken as the productivity of the technological leader in the definition of the technology gap. In order to take into account the long-term movement of per capita income, the period considered is 1960-1986. In order to take into account not only the beginning and end year of this period, the following method is used to measure the growth performance of a country. Define the relative per capita income gap (denoted by $G$ ) between country $i$ and the USA as follows.

$$
G_{i}=\ln \left(\frac{Q_{U S A}^{c a p}}{Q_{i}^{c a p}}\right)
$$

The logarithmic specification is used to obtain the convenient property that for equal values of per capita income levels, the income gap is zero. In order to measure the growth performance of a country, the average motion of $G$ over time can be measured by estimating the following equation for the period 1960-1985 ( $\varepsilon$ is an error term with the usual properties).

$$
G_{i t}=\alpha_{i} t+\beta+\varepsilon_{i t}
$$

Figure IV.10 presents the relation between the initial level of the per capita income gap and the motion over time of the gap, measured by the estimated value of $\alpha$ in equation (IV.5). Note that, by definition, a negative value of the growth rate indicates a relatively good performance. The lines drawn indicate the estimated (linear) regression lines for different subsamples. 
motion of G (\%) 1960-1986

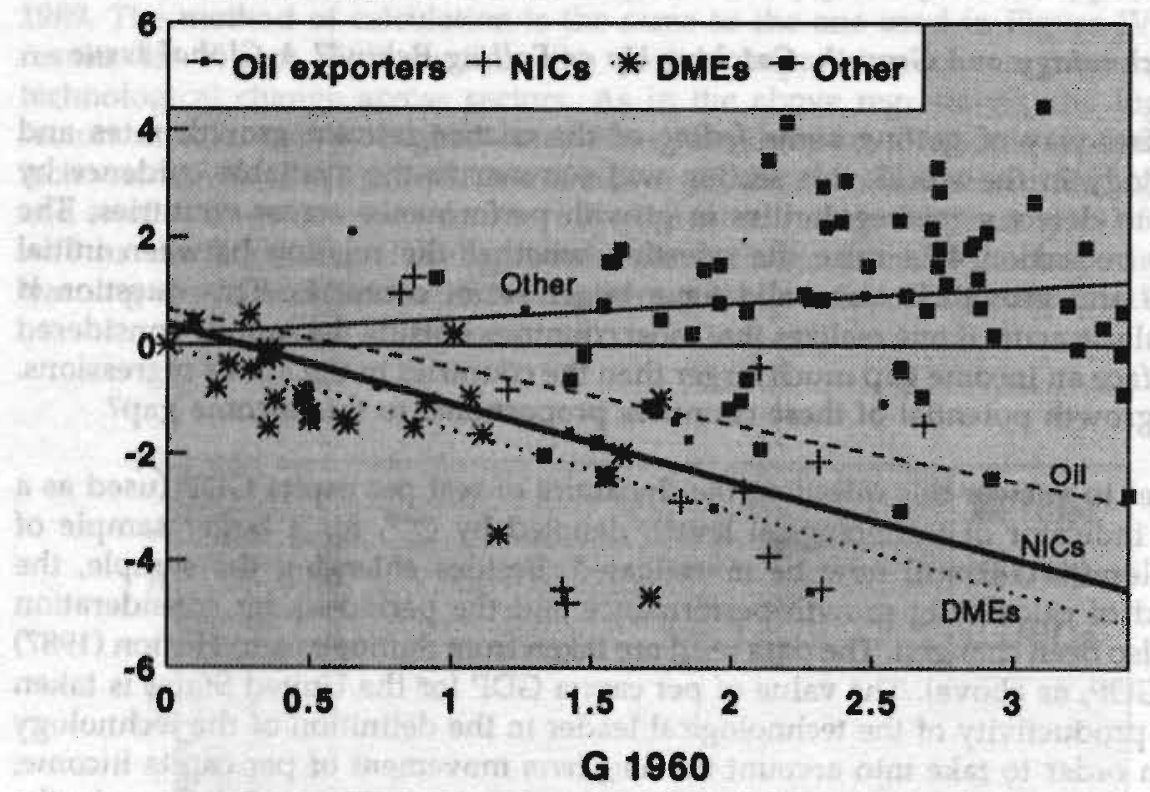

Figure IV.10. Convergence and divergence in the world economy, 1960-1985

If there is a systematic pattern in the total cloud of points in the graph, it is the variance, which grows bigger as the per capita income gap becomes larger. Thus, the countries close to the world economic and technological frontier (as measured by the performance of the USA) show smaller (absolute) growth rate differentials relative to this frontier than those further away from it. The results in Figure IV.10 indicate that there is a dichotomy between catching up and falling behind at the world level. Part of the countries facing the largest gaps (the developing countries) have also experienced the largest increases in the gap, which is exactly opposite to what the catching-up hypothesis predicts. However, within one or more groups of countries, the catching-up hypothesis seems to make some sense. To see this, one should realize that the catching-up hypothesis predicts that the regression using the variables in the graph yields a line with a negative slope crossing the vertical axis somewhere near the origin (so that most of the line is below the zeroline). Obviously, this makes sense for the group of DMEs, NICs and oil exporters. Thus, in terms of the results found, there seems to be some indication that catching up is a relevant phenomenon only for these groups. This is confirmed by a more formal analysis. The lines drawn are the regression lines for subsamples of the total of 114 countries. Running a regression for the total sample, and applying a Chow F-test for the hypothesis that this regression fits the data as well as the four separate regressions, yields an F-statistic of 7.59 , which rejects the null hypothesis at the $1 \%$ level. This is also in line with the result of empirical studies briefly reviewed in section 2.5 . 
In order to investigate whether the catching-up trend, which has now been shown to be 'local' over the most recent period, is also relevant in a longer time period, data from Maddison (1991) are used ${ }^{19}$. Define the convergence coefficient (C) as the mean value across countries of the percentual deviation from the frontier (which is defined as the sample maximum of per capita GDP, which is equal to the USA value for most of the period). Thus, a decreasing value of $C$ indicates convergence (catching up), while an increasing value points to divergence. Next, the inverse of the Thell Entropy coefficient for GDP (denoted by $E$ ) is an indicator of concentration. Large (smali) values of the indicator go together with high (low) concentration. At a given point in time, $E$ only gives an indication of the (spatial) division of some variable across the country sample. However, it is the time path of $E$ that is of interest for the analysis here, where a decreasing (increasing) trend indicates convergence (divergence).

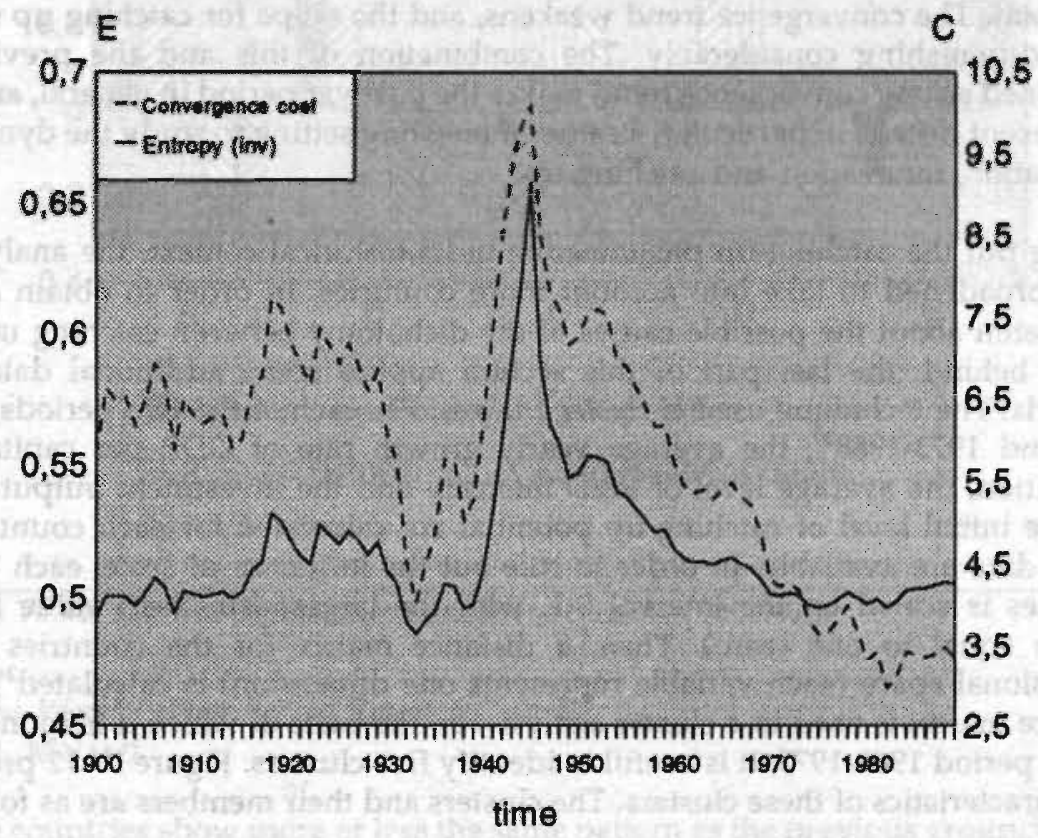

Figure IV.11. Convergence and divergence trends in the 20 th century

Figure IV.11 gives the time path of $C$ and $E$ for Maddison's long-run data over the 20 th century. An impressionist view of the time series seems to suggest that there are four main periods which differ with regard to convergence / divergence

10 Note that Maddison's long-run data are only available for a limited set of countries: Australia, Austria, Belgium, Denmark, Finland, France, Germany, Italy, Japan, Netherlands, Norway, Sweden, Switzerland, UK, USA. GDP is taken directly from Maddison, which means it is corrected for territorial changes, and population (also from Maddison) has been corrected for territorial changes by using Maddison's explanation for the GDP case. 
patterns. In the first period (1900-1920), there is no real trend in either of the series. As argued in Maddison (1991), this is the period in which the USA slowly begins to take over technological (i.e., productivity) and economic leadership from Great Britain. The second period corresponds to the 1920 s, in which some (very) weak signs of convergence are visible. This period is follows by the Great Depression of the 1930s and the second World War, which have a dramatic impact on both indicators. The period 1930-1950 is therefore not useful from an analytical point of view. Around 1950, the dispersion in (per capita) GDP seems to have settled back again at levels more or less comparable with the pre-1930 period, although the war seems to have created a gap between the USA and Europe (see Maddison 1991). From that point on, a very strong trend of convergence sets in. The figure shows that this period has indeed been an exceptional one from a historical point of view, and that a large part of the growth in the lagging countries must be explained by a catching-up effect. The last part of the time series in the graph seems to suggest that from the mid 1970s onwards, the catching-up effect is becoming less important. The convergence trend weakens, and the scope for catching up seems to be diminishing considerably. The combination of this and the previously mentioned strong convergence trend makes the postwar period in general, and the most recent decade in particular, a rather interesting setting to study the dynamics of imitation, innovation and catching up.

Having put the catching-up phenomenon in its historical context, the analysis is again broadened to take into account more countries. In order to obtain a first impression about the possible causes of the dichotomy between catching up and falling behind, the last part of this section applies some additional data and methods. The technique used is cluster analysis. For each of the two periods 19601973 and 1973-198820 the average yearly growth rate of GDP per capita and population, the average level of $R \& D$ intensity and the investment output ratio, and the initial level of catching-up potential are calculated for each country for which data are available. In order to rule out the influence of scale, each of the variables is scaled on the interval 0-1, with the largest (smallest) value in the sample equal to one (zero). Then, a distance matrix for the countries in 5dimensional space (each variable represents one dimension) is calculated ${ }^{21}$. This distance matrix is used in a cluster analysis, on the basis of which it is found that for the period 1960-1973, it is useful to identify five clusters. Figure IV.12 presents the characteristics of these clusters. The clusters and their members are as follows.

\section{A. "The Falling Behind Countries" ( $n=24$ )}

Central African Republic, Madagascar, Mauritius, Nigeria, Senegal, Sudan, Guatemala, Mexico, Trinidad \& Tobago, Argentina, Colombia, Ecuador, Peru, Uruguay, Venezuela, India, Iran, Jordan, Pakistan, Philippines, Sri Lanka, Thailand, Turkey, New Zealand.

This is the group of developing countries (ranging from the poorest African

* The periodization is chosen arbitrarily, although the break in 1973, of course, is not coincidental.

${ }^{2}$ Euclidean distances were used. For some details on distance measures, see Appendix IV.3. 
countries to some of the Southern American and Asian countries). These countries: faced an above average initial catching-up potential, but were not able to reap the benefits of it. They realized the lowest growth rates. Investment and R\&D intensity are usually low in these countries, while population growth is very high. Note the presence of New Zealand (1), Mexico, Turkey and Thailand in this group.

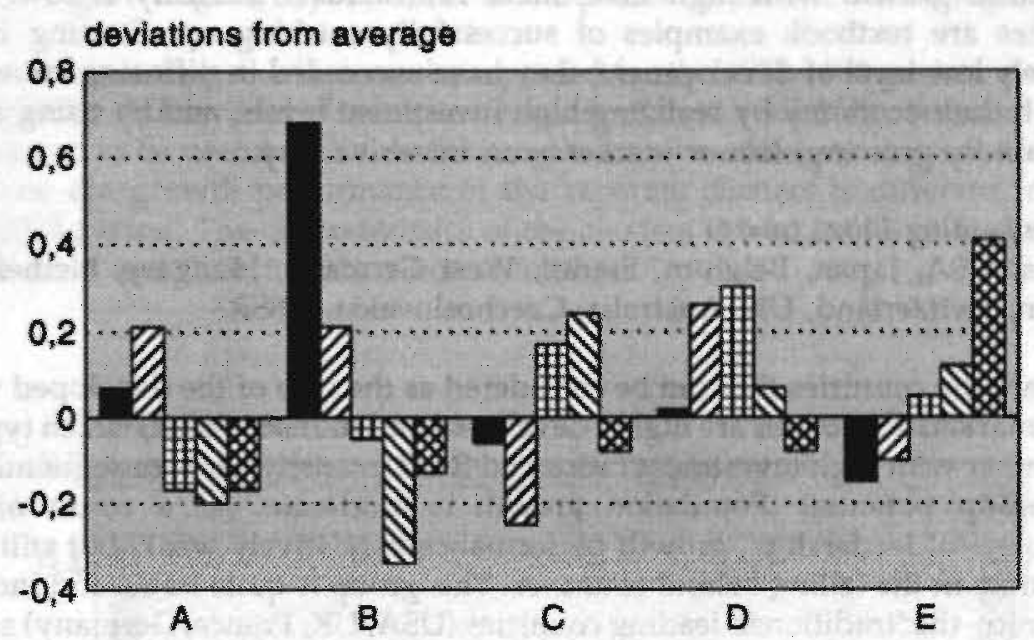
U Catching Up Potential $\square$ Population Growth 贯 Income Growth Ninvestment quote R\&D Intensity

Figure IV.12. Growth performance in different clusters, 1960-1973

B. "The Worst Falling Behind Countries" ( $n=2)$

Egypt, Malawi.

These countries show more or less the same pattern as the previous group, but just a few degrees worse. They can be considered the worst cases of the falling behind group. Note in particular the presence of Egypt.

C. "The Catching-Up Countries" ( $n=15)$

Jamaica, Austria, Cyprus, Denmark, Finland, Greece, Iceland, Ireland, Italy, Malta, Norway, Portugal, Spain, Yugoslavia, Bulgaria.

These are the countries which have been able to use their catching-up potential, which was, however, relatively small as compared to the falling behind countries. They combine low population growth with high investment ratios, but relatively low R\&D intensities. Thus, they appear to rely on the diffusion of knowledge rather than on the creation of knowledge. Most of these countries can be called 
D. "The Strongly Catching-Up Countries" ( $n=3)$

Israel, Korea, Singapore.

These countries have realized the highest growth rates. Clearly they had a certain ("critical?") level of catching-up potential, which they used combining high population growth with high investment ratios. $R \& D$ intensity is low. These countries are textbook examples of successfully catching up. Starting from a relatively low level of development, they have succeeded in diffusing knowledge through their economy by realizing high investment levels, and by using a large (and rapidly growing) labour market in an intensive way.

E. "The Leading Elite" ( $n=14)$

Canada, USA, Japan, Belgium, France, West Germany, Hungary, Netherlands, Sweden, Switzerland, UK, Australia, Czechoslovakia, USSR.

These are the countries that can be considered as the core of the developed world. Their (market) economies are highly developed and industrialized, which typically go together with high investment ratios and R\&D intensity, and consequently, low catching-up potential. Population growth is moderate. As a result of their 'technological leadership', growth performance is relatively weak, but still much better than in the falling behind countries. This group is quite large, and includes, apart from the 'traditional' leading countries (USA, UK, France, Germany) smaller but highly developed economies such as the Netherlands and Sweden. Japan, a country which is usually considered as having gone through the development phase during this period, is also present in this group. As a last 'peculiarity', note the presence of the USSR, Hungary and Czechoslovakia, as the 'leading' elite among the centrally planned economies.

Thus, the 1960-1973 world can neatly be divided into three major groups: falling behind, catching-up and leading countries. With regard to the question of catching up or falling behind, it seems that investment intensity is a crucial factor. Countries that have (not) been able to catch up are characterized by high (low) investment ratios. R\&D intensity seems to be less important for catching up, since both the catching-up groups are not characterized by high R\&D intensities. The role of population is not very clear. One (small) group has realized high growth rates with high population growth, while there is otherwise (especially outside the catching-up group) a negative relation between population growth and economic growth. There seems to be also a complex relation between the size of the catching-up potential and the capability to catch up, suggesting a 'critical' value of the catching-up potential.

In theoretical terms, the observed patterns in this period do not support one theory of growth (discussed in Chapter 2) in particular. The results for the investment variable can be explained by most of the models, although in the Solow case one has to assume that the equilibrium growth path $(k)$ has not been reached yet. The bad performance of the falling behind countries, as well as the performance of the catching-up countries, fit these investment-based predictions quite well (see also 
Romer 1989 for an empirical test of the new growth theories in this vein, Mankiw et al. 1990 for a test of the Solow model, and Durlauf and Johnson 1992 for a critique of the latter). For R\&D, however, the results do not (exactly) correspond with the theories. The high R\&D-intensive countries have not grown at the fastest rate. Instead, the diffusion of technological change (as indicated by the catching-up potential and the way in which it has been used) seems be much more important. All this indicates that the complex way in which science and technology influence economic growth goes beyond most of the presently known modelling efforts.

The same clustering exercise can be repeated for the 1973-1988 period, now with a marginally different set of countries (because of data availability reasons). Again, it appeared to be useful to divide the sample into five different clusters. However, this time the growth performance of the separate clusters is different from the 1960-1973 period. The characteristics of the clusters can be found in Figure IV.13. The clusters and their members are as follows.

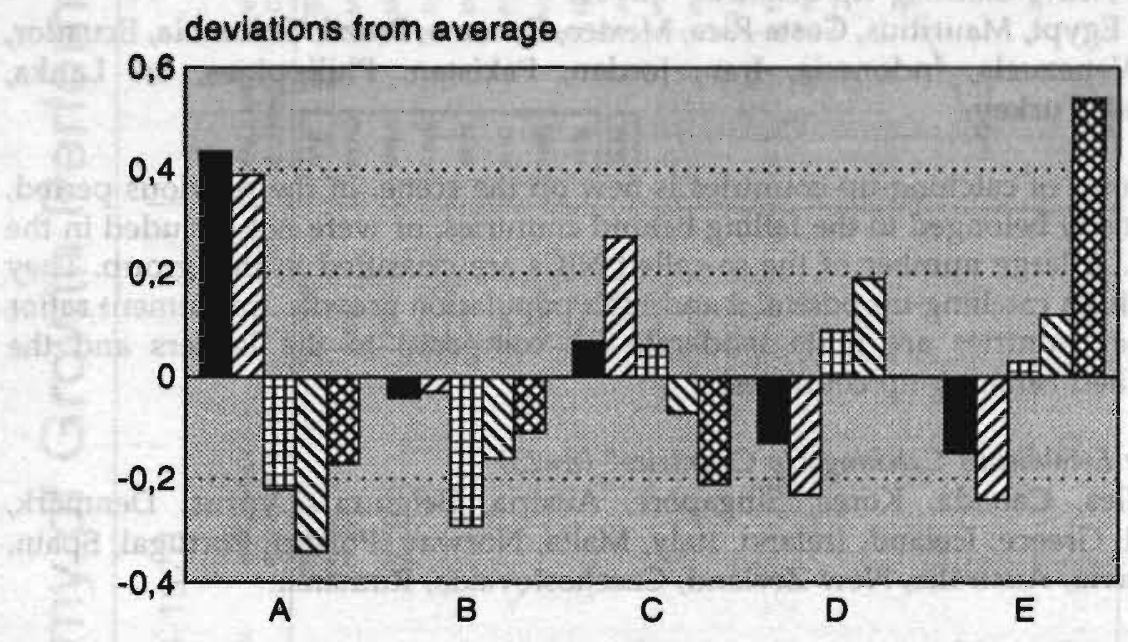

Catching Up Potential
Income Growth
R\&D Intensity

Figure IV.13. Growth performance in different clusters, 1973-1988

A. "The Established Falling Behind Countries" ( $n=9$ )

Central African Republic, Madagascar, Malawi, Nigeria, Rwanda, Senegal, Sudan, Guatemala, India.

Again, this is the group of developing countries (mostly the poorest African countries). As in the previous period, these countries faced a high initial catching- 
up potential, but were not able to reap the benefits of it. They realized low growth. Investment and $R \& D$ intensity are typically low in these countries, while population growth is very high. Compared to the previous period, this group is much smaller, and as a result, more homogeneous.

\section{B. "The Missed Opportunities Falling Behind Countries" ( $n=6)$ Guyana, Chili, Argentina, Trinidad \& Tobago, Jamaica, El Salvador.}

These countries form a second falling behind group, which mainly distinguishes itself from the first by the lower catching-up potential. As was clear from the catching-up examples in the previous period, this lower catching-up potential might have been a positive factor (large catching-up potentials seem to remain unrealized in the previous period) and therefore, these countries seem to have missed an opportunity. Some of them (Jamaica, Trinidad \& Tobago) belonged to the catching-up countries in the previous period. They have relatively low investment ratios and low R\&D intensity. Growth of population is moderate.

\section{C. "The Newly Catching-Up Countries" ( $n=19$ )}

Congo, Egypt, Mauritius, Costa Rica, Mexico, Panama, Brazil, Colombia, Ecuador, Peru, Venezuela, Indonesia, Iran, Jordan, Pakistan, Philippines, Sri Lanka, Thailand, Turkey.

This group of catching-up countries is new on the scene. In the previous period, they mostly belonged to the falling behind countries, or were not included in the sample. A large number of the so-called NICs are classified in this group. They have a high catching-up potential and high population growth. Investment ratios in these countries are quite moderate (as compared to the leaders and the established catching-up countries).

\section{D. "The Established Catching-Up Countries" ( $n=23$ )}

Seychelles, Canada, Korea, Singapore, Austria, Belgium, Cyprus, Denmark, Finland, Greece, Iceland, Ireland, Italy, Malta, Norway, Poland, Portugal, Spain, Yugoslavia, Australia, New Zealand, Czechoslovakia, Rumania.

These are the catching-up countries known from the previous period, including developed market economies as well as some of the (older) NICs. Thus, they more or less consist of the two catching-up groups from the previous period. Vehicles for catching up seem to be moderate population growth, high investment ratios and increased, but still moderate, $R \& D$ intensity.

\section{E. "The Leading Elite" ( $n=12)$}

St. Lucia, USA, Israel, Japan, France, West Germany, Hungary, Netherlands, Sweden, Switzerland, UK, USSR.

Here, one finds the highly developed market economies. They are mostly the same as in the previous period, and have the same characteristics. 


\section{A Taxonomy of Growth Performance, 1960-1988}

\begin{tabular}{|c|c|c|c|c|c|c|c|}
\hline & 1960 & 973 & & & & -1988 & \\
\hline $\begin{array}{l}\text { FALLIN } \\
\text { BEHIND } \\
\text { B. }\end{array}$ & $\begin{array}{l}\text { CATCHING } \\
\text { UP }\end{array}$ & $\begin{array}{l}\text { STRONGLY } \\
\text { CATCHING UP }\end{array}$ & LEADERS & $\begin{array}{l}\text { FALLING } \\
\text { BEHIND }\end{array}$ & $\begin{array}{l}\text { NEW } \\
\text { CATCMING UP }\end{array}$ & $\begin{array}{l}\text { OLD } \\
\text { CATCHING UP }\end{array}$ & LEAOEAS \\
\hline MWA & JAM & $\begin{array}{ll}\text { ISF } \\
\end{array}$ & CAN & CAF & EGY & 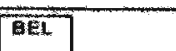 & [is9] \\
\hline EGY & |AUT & KOF & BEL & MOQ & mus & aus & जSA \\
\hline MDG & erp & SNG & Aus & mowa & MEX & GAN & JPP \\
\hline NQA & DNK & & CZA & naA & $\infty$ - & CZE & OEU \\
\hline SEN & FIN & & FRA & SEN & ECU & BNA & NLO \\
\hline sud & GRC & & DEU & suo & PEA & KOA & swe \\
\hline ARQ & ISL & & HUN & ABO & VEN & aur & $\mathrm{CHE}$ \\
\hline пто & IRL & & NLD & Tro & IRN & crp & aBA \\
\hline MUS & ITA & & SWE & JAM & JOR & ONK & FAA \\
\hline MEX & MLT & & $\mathrm{CHE}$ & & PAK & FiN & Hund \\
\hline CAF & NOR & & JPN & & PHL & GAC & USB \\
\hline $\mathrm{COL}$ & PPT & & USA & & LKA & ist. & \\
\hline ECU & ESP & & GBA & & THA & tra & \\
\hline PER & Yug & & USR & & TUR & $\mathrm{TA}$ & \\
\hline VEN & & & & & & met & \\
\hline $\begin{array}{l}\text { IFN } \\
\text { JOR }\end{array}$ & & & & & & NOF & \\
\hline PAK & & & & & & ESP & \\
\hline PHL & & & & & & nus & \\
\hline LKA & & & & & & N21 & \\
\hline $\begin{array}{l}\text { THA } \\
\text { TUR }\end{array}$ & & & & & & & \\
\hline $\mathrm{NzZ}$ & & & & & & & \\
\hline
\end{tabular}


A number of interesting differences with the previous period can be observed. First, some of the countries have switched from one group to another. These are summarized in Diagram IV.1. Groups of countries which appear together under the same heading on both sides of the diagram are presented in boxes. Most distinct is the switch of a number of falling behind countries in the first period to one of the catching-up groups in the second, including many NICs (for example Egypt, Thailand and most of the Southern American countries). They have been able to realize an industrialization process which resulted (among other things) in high investment levels and high growth rates. On the other hand, there are a limited number of countries which have degraded (from catching up to falling behind: Jamaica, Trinidad and Tobago; from leading to catching up: Czechoslovakia, Australia, Belgium, Canada). Thus, although the starting conditions were more or less the same in different countries, some of them were able to catch up, while others were not. This seems to suggest that there is some scope for influencing growth performance, either by governmental policies, or by differences in cultural or entrepreneurial variables. The dichotomy between successfully switching from falling behind to catching up and staying in a falling behind situation is illustrative.

A second difference is the distinction between catching-up groups. In the previous period, there were two catching-up groups, which were quite similar with regard to the variabies in the analysis, except 1or population growut. ilt ulis perivis, uleie is one group (the established catching-up), which is characterized by the 'classic' (previous period) characteristic of catching up (high investment). The other (newly catching-up) countries seem to have much lower investment levels. Note also that the scope for catching up has decreased considerably, since the growth rate differences between leaders and catching-up countries have diminished quite a bit.

\subsection{Summary and Conclusions}

A number of conclusions can be drawn from the above, which can be summarized into the following stylized facts.

1. Growth rates differ between countries and between groups of countries. This is true at the aggregate level and at the sectoral (manufacturing) level.

2. Rates of technological change differ between sectors. Evidence from a selected group of six OECD countries shows that there is a significant degree of heterogeneity in technological change at the 1-digit ISIC level. Evidence from the USA and Japan shows the same for the 2-digit ISIC level in manufacturing. At the 3-digit ISIC level in manufacturing, evidence on labour productivity for all DMEs and all NICs points to the same phenomenon.

3. Production structure differs between countries and time. However, within groups of countries, production structures can be quite similar. Applied to the relation DMEs - NICs this points to a catching-up phenomenon not only in growth rates but also in production structures. 
4. The macroeconomic rate of tedunological change is related to initial nabour) productivity lewels. In sample of $O E C D$ countries, low initial levels of productivity lead to high rates of TFP growth (catching up). The influence of other economic variables such as investment and $R \& D$ expenditures explains less of the cross-country macroeconomic variation in TFP.

5. In the world as a whole, falling behind is more relevant for the poorest countries than catching up. In general, the high-and middle-income countries grow fastest, while most low-income countries grow only at a slow rate. However, some of the lower income countries do seem to succeed in catching up (NICs and oil exporters). Within the catching-up group of countries, convergence of per capita income levels is a phenomenon that seems to be typical of the postwar period. Moreover, the convergence tendency seems to have come to a standstill during the most recent 15 years.

What are the possible explanations for these 'stylized facts'? An attempt will be made in the rest of this thesis to answer this question. In order to give the reader aste of what is in store in the following chapters, the different stylized facts will now be linked in a preliminary way, thus setting out the first lines of the explanation offered below.

First, the differences in performance across subgroups of countries (stylized fact 1) in combination with the importance of structural change (stylized fact 2-3) suggest that there is a structural explanation. Growth rates differ because economies differ with regard to their production, consumption and institutional structures. One useful way of modelling structural differences stems from the Keynesian tradition, and stresses (sectoral) differences in income elasticities of demand (Pasinetti 1981, see Chapter 3). Combined with specialization patterns, these differences will induce growth rate differentials between economies with different production mixes.

The second explanation stresses the interdependence of economies through trade. In this way, and by keeping in mind the previous chapter, the process of international economic growth can be seen as a selection process, with complex interdependencies between the different actors, influencing each other's performance and competitiveness on world product markets which act as the selection environment. An explanation based on these two principles will be further developed in Part Three below.

Stylized fact 4 seems to support the catching-up hypothesis found in the literature (see section 2.5). However, for one specific group of countries (the poorest developing countries), the catching-up hypothesis does not seem to hold. Therefore, one might argue that a more general catching-up model would have to take into account some additional factors present only in the poorest countries in order to be able to explain their bad performance. A model which does this will be developed in Part Two. 
Economic welfare is not distributed equally over the world. The amount of economic data available is generally positively correlated with welfare. Therefore, any study that tries to look at growth rates at the world level will necessarily have to work with a data set that is not a representative selection of what has been going on in the world. This also holds for this chapter, and the ones to follow. Therefore, it is useful to look at the representativeness of the different samples of countries used in this and subsequent chapters. To do so, this section will present some data on the world distribution of income drawn from the World Development Report 1990 (WDR), published by the World Bank. The samples of countries used will be evaluated with regard to their representativeness.

The World Bank divides its 121 reporting members into several categories, based on GNP per capita. Thus, the WDR makes a distinction between low-income, lower-middle-income, higher-middle-income and high-income countries. Columns (1) and (2) of Table IV.A1 give an impression of the relative importance of each of these groups. The well-known, yet shocking, conclusion from these columns is that world income is distributed in a tremendously unequal way.

The World Bank categorization is illuminating in the sense that it gives a clear picture of the relative per capita income position of countries. However, it does not give an exact indication of the development stage or perspective which the country faces. Within the group of high-income countries (largely OECD countries), there is a large homogeneity in this respect. All countries (excluding perhaps a few oilexporting countries) in this group have achieved a high degree of industrialization and economic development. Within the other groups of countries, the differences are more significant. These groups include the poorest developing countries, with almost no industrialization, and where agriculture has reached only a modest degree of development. But, they also include countries which have reached some stage of industrialization, even up to a level close to the OECD countries.

Columns (2) and (3) of the table show how well the sample of countries used in this chapter covers the total WDR sample. All over, the coverage is quite good, both in terms of numbers of countries and in terms of GDP. The relatively low coverage in the lowest income group is due to the fact that China, as a centrally planned economy and responsible for about half of the total GDP in this group, is left out of the analysis.

To do justice to the phenomenon of different stages of development, a distinction is often made between different types of countries. Usually, one finds industrialized countries, oil-exporting countries, Newly Industrialized Countries (NICs) and Less (or Least) Developed Countries (LDCs). It is not clear which countries are to be included in which categories; in addition one will find that a categorization of this type closely corresponds to the categorization in Table IV.A1. Here, a categorization based on that proposed in the United Nations (UNIDO) publication Industry in a Changing world (1983) will be used. The 114 countries used in this (and subsequent) chapter(s) are classified as follows. 
Table IV.A1. World income distribution (as measured by World Bank figures)"

\begin{tabular}{||l|l|l|l|l|l|l|}
\hline Group of countries & $\begin{array}{l}\text { (1) } \\
\text { n in WDR } \\
\text { sample }\end{array}$ & $\begin{array}{l}\text { (2) } \\
\text { Share in } \\
\text { 1980 total } \\
\text { GDP for } \\
\text { WDR } \\
\text { sample }\end{array}$ & $\begin{array}{l}\text { (3) } \\
\text { n in current } \\
\text { sample }\end{array}$ & $\begin{array}{l}\text { (4) } \\
\text { Share of 1980 } \\
\text { WDR GDP } \\
\text { covered by I.1 } \\
\text { sample }\end{array}$ & $\begin{array}{l}\text { (5) in II.1 } \\
\text { sample }\end{array}$ & $\begin{array}{l}\text { Share of 1980 } \\
\text { WDR GDP } \\
\text { covered by I.1 } \\
\text { sample }\end{array}$ \\
\hline $\begin{array}{l}\text { Low-income } \\
\text { countries }\end{array}$ & 42 & 0.05 & 33 & 0.58 & 0 & 0 \\
\hline $\begin{array}{l}\text { Lower-middle- } \\
\text { income countries }\end{array}$ & 37 & 0.06 & 34 & 0.99 & 8 & 0.73 \\
\hline $\begin{array}{l}\text { Higher-middle- } \\
\text { income countries }\end{array}$ & 18 & 0.07 & 12 & 0.92 & 6 & 0.35 \\
\hline $\begin{array}{l}\text { High-income } \\
\text { countries }\end{array}$ & 26 & 0.81 & 23 & 0.99 & 22 & 0.99 \\
\hline \begin{tabular}{l} 
All countries \\
\hline
\end{tabular}
\end{tabular}

"Calculations based on World Development Report 1990, World Development Indicators, Table 3, Technical Notes, table 1.

+ Twelve countries in this sample are not documented in the WDR. 


\section{A. Developed Market Economies (DMEs):}

Iceland, Greece, FR Germany, Italy, Ireland, Luxembourg, Cyprus, Belgium, Austria, France, Finland, Denmark, Malta, Canada, United Kingdom, Turkey, New Zealand, Australia, United States, Portugal, Norway, Netherlands, Switzerland, Sweden, Spain, Japan, Israel, South Africa.

Mostly, these are the 'Leading Elite' countries and '(Established) Catching Up' countries from the analysis above. The presence of Turkey is perhaps a bit strange in this respect, but serves to keep all the OECD countries under this heading.

\section{B. Newly Industrialized Countries (NICs):}

Malaysia, Hong Kong, Rep. of Korea, Brazil, Argentina, Uruguay, Colombia, Mexico, Singapore, Philippines, Thailand, Taiwan, Egypt.

For Taiwan, no sectoral (ISIC-2) data are available, so that all sectoral analyses exclude this country ('NICs-12'). The group called NICs-10 excludes Hong Kong and Uruguay for data availability reasons. NICs-10 have been subdivided into NICs-1 (high income: Argentina, Brazil, Rep. of Korea, Mexico, Singapore) and NICs-2 (low income: Colombia, Egypt, Malaysia, Philippines).

These are mainly countries that belonged to the 'Strongly' or 'Newly Catching Up' countries in terms of the cluster analysis above (with the exception of Argentina). These countries started from a low level of GDP per capita, but were (mostly) able to catch up by means of an active industrialization process.

\section{Less Developed Oil-Exporting Countries:}

Gabon, PR Congo, Iraq, Saudi Arabia, Syrian Arab Rep, Trinidad \& Tobago, Nigeria, Venezuela, Ecuador, Iran, Algeria.

These countries are a special type of catching-up countries. They owe their relatively high growth mainly to one of their natural resources: oil.

\section{Other (less developed) countries:}

Sierra Leone, Jamaica, Honduras, Nicaragua, Senegal, Chad, Panama, Haiti, Somalia, Barbados, Papua New Guinea, Costa Rica, Guatemala, El Salvador, Dominican Rep, Central Afr Rep, Surinam, Peru, Paraguay, Botswana, Fiji, Rwanda, Benin, Guyana, Bolivia, Angola, Niger, Cameroon, Burundi, Chile, Sudan, Guinea, Ghana, Ivory Coast, Sri Lanka, Jordan, Gambia, Ethiopia, Madagascar, Nepal, Mali, Malawi, Lesotho, Kenya, Liberia, Pakistan, Zaire, Uganda, Zimbabwe, Zambia, Tanzania, Swaziland, Tunesia, Togo, India, Morocco, Mauritania, Mauritius, Mozambique, Afghanistan, Burma, Bangladesh.

Most of these countries belong to the 'Falling Behind' group(s) above. 
Appendix IV.2. The 3-Digit ISIC Sector Classification (Revision 2)

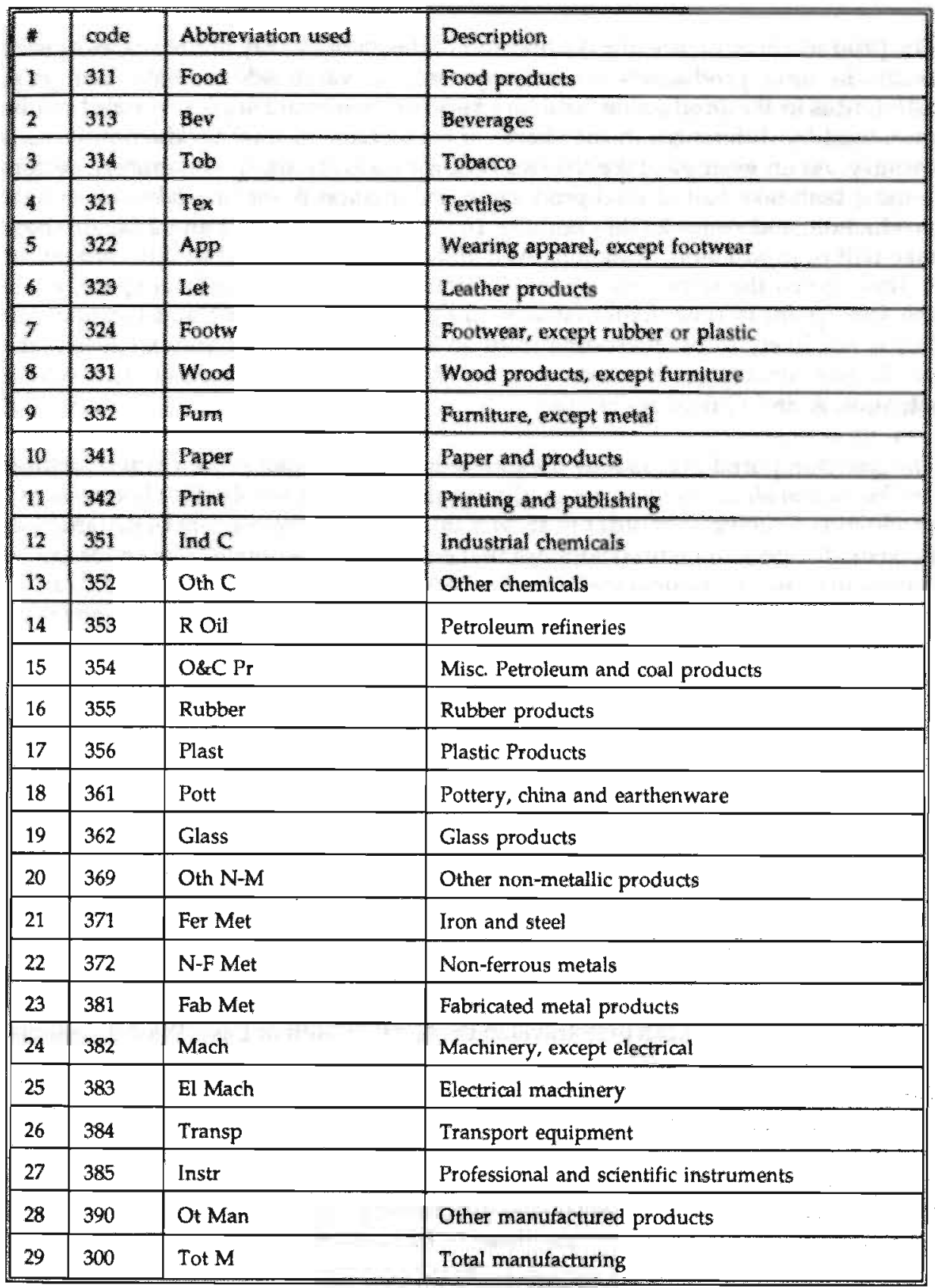



Countries $^{22}$

The production structure of a country can be described by way of the shares of each sector in total production (or employment, or value added, etc.). Similarly, differences in the production structure between two countries (or in time) can be measured by differences in the shares of each sector in total production in each country. As an example, take the two following situations. In situation A, sectors 1 and 2 both take half of total production. In situation $B$, sector 1 takes all of total production, and sector 2 takes nothing. In situation $C$, sectors 1 and 2 (again) both take half of production. Situations A, B and C may correspond to different points in time, given the same country, or different points in geographical space, given the same point in time. (Alternatively, one may vary both time and location, but this is not likely to be interesting from an analytical point of view). Clearly, the production structures in situation $A$ and $B$ and $B$ and $C$ are different, while in situation $\mathrm{A}$ and $\mathrm{C}$ they are similar.

The question posed here is how the difference between two production structures can be measured, i.e., how one can give an indication of the distance between two production structures. In order to answer this question, the concept of distance has to be made operational first. Suppose that points in an $n$-dimensional space can be represented by scores on a (ratio) scale. Then the score of item $i$ on scale $k$ can be denoted by $x_{i k}$. The Minkowski p-metric, measuring the distance between items $i$ and $j$, is then defined by

$$
d_{i j}(p)=\left(\sum_{k=1}^{n}\left|x_{i k}-x_{j k}\right|^{p}\right)^{\mu / p},
$$

In this definition, $p$ can take any (positive) value. Note that for the special case of $p=2$, calculating the Minkowski $p$-metric results in the most commonly used concept of distance: Euclidean distance. This can easily be verified by taking $n=p=2$, in which case the Minkowski $p$-metric results in the theorem of Pythagoras. Another special case results for $p=1$, where one has the city block distance measure, or the Manhattan metric. In two-dimensional space, the city block distance measures the distance that must be travelled to reach point $j$ starting from $i$, under the restriction that one can only travel in the North/South or East/West directions.

Two observations on the Minkowski $p$-metric can be made. First, note that the case of $p=1$ is the only case where differences in distance in one dimension $(k)$ are weighted equally. In general, differences in one dimension are weighted by their own size, raised to the power $p$-1. In the case of Euclidean distance, this means that each distance in one dimension is weighted by its own size. Second, note that for different values of $p$, the iso-distance lines from one particular point take different forms. In the case of Euclidean distance in the two-dimensional space, the

This section draws heavily on Green et al. (1989), section 1. 
iso-distance line is well known: it is a circle. In case of the city block distance measure, the iso-distance line is diamond shaped.

In economics, 'distance' is not a common concept (Linneman 1966 is one notable exception). Perhaps this is the reason why economists, in the cases they have applied distance measures, have not (always) conformed their measures to the commonly used Euclidean measure. In the case considered here - the measuring of distance between production structures - economists have most often used city block distance measures. Typically, one finds a measure of structural differences between situations $i$ and $j$ in the case of $n$ dimensions (sectors) to be defined as follows.

$$
d_{i j}=\sum_{k=1}^{*}\left|x_{i k}-x_{i j}\right|
$$

Note that this definition is the special case for $p=1$ of the above definition of the Minkowski p-metric. On a priori (economic) grounds, there is no reason at all why the city block measure should be preferred to any other measure, including the Euclidean one. Therefore, the following preliminary conclusion can be drawn: To measure the distances between each out of $[n \times(n-1)] / 2$ possible pairs from $n$ different situations, one could construct a (symmetric, zero-diagonal) matrix in which cell $i j$ (and $j i$ ) holds the resulting value of the Minkowski $p$-metric for $i$ and $j$. One could construct a different matrix for each separate value of $p$.

The next question posed here is whether the data in such a matrix can be graphed in such a way that one single figure illustrates how the different situations relate to each other. Obviously, while the matrix itself enables one to quickly look up the precise distance between any two situations, it does not allow for an easy and quick interpretation of the whole structure. To find an answer to this question, imagine a situation in which there are only three sectors and $n$ points. Note first that while there are three sectors, only two of the shares of these sectors are independent: The third can be found by applying the fact that the sum of the shares equals one. Thus, each situation can be represented by a point in twodimensional space. Measuring the distance in the usual way (for example by simply using a ruler) results in the distance matrix for $p=2$ (Euclidean distance). The graph of this two-dimensional space would indeed give a quick and precise impression of the distance relations in the whole set of situations.

Now imagine what happens if the number of dimensions (sectors) is increased. If $n$ becomes four, the (Euclidian) distances can be represented in the threedimensional space, if $n$ becomes five, a four-dimensional space is needed. In general, to represent the distances in an n-dimensional system, an (n-1)dimensional space is needed. Clearly, for cases relevant in reality, where for example at the 2-digit ISIC level nine different sectors are found in manufacturing alone, the number of dimensions is too high to use this precise Euclidean framework. Therefore, another method must be chosen. This method can be found in multidimensional scaling techniques. In general, this technique is applied in cases where (a ranking of) distances between pairs of situations can be given. In the 
present case, imagine that the distances in production structures between three situations $\mathrm{A}, \mathrm{B}$ and $\mathrm{C}$ are given, or can be ranked in descending (ascending) order. Clearly, this is the case for a distance matrix as described above. Note that it does not matter which value of $p$ is used in the construction of such a matrix.

Basically, the technique of multidimensional scaling works as follows. In an $n$ dimensional space, points are arranged in such a way that the interpoint distances have the same ranking (in the case of nonmetric scaling), or are exactly the same (in the case of metric scaling) as the input data. In general (applying the above logic), it can be shown that for $n-1$ dimensions it is always possible to find a configuration that represents the original ranking precisely. However, in practice, one can trade off the number of dimensions for the objective of a perfect representation of the original ranking. The smaller the number of dimensions, the farther the resulting configuration will be from the original distances. Thus, one would typically try to find the lowest dimension for which the representation is still fairly close.

Essentially, the technique used to find such a configuration is the following. First, one finds an (arbitrary) initial configuration, followed by a calculation of a measure of the 'badness of fit', usually called stress, of this configuration relative to the original distance matrix. Then, one tries to change the configuration in such a way that stress is decreased. Then the procedure starts again. This process is repeated until a satisfactory value of stress is found (or not found). In the figures presented in this chapter, the points were scaled using a nonmetric method, both because of the simpler calculation procedure and because the number of dimensions underlying the data (i.e., the sectors) is too large for fully metric methods to yield adequate results. 
Table IV.A2 shows the partial correlation coefficients between the variables used in the regression. It appears that both investment and $R \& D$ are strongly correlated with initial income, which confirms the impression of multicollinearity affecting the results in Table IV.1.

Table IV.A2. Partial correlation coefficients of the variables used in the regressions in Table IV.1.

\begin{tabular}{|l|l|l|l|l|l|l|}
\hline & $A_{n}$ & $A_{s}$ & INIT & I/K & I/Q & RDI1 \\
\hline$A_{n}$ & & & & & & \\
\hline$A_{s}$ & 0.95 & & & & & \\
\hline INIT & -0.83 & -0.81 & & & & \\
\hline I/K & 0.45 & 0.35 & -0.46 & & & \\
\hline I/Q & 0.49 & 0.60 & -0.52 & 0.35 & & \\
\hline RDI1 & -0.37 & -0.37 & 0.45 & -0.17 & -0.34 & \\
\hline RDI2 & -0.25 & -0.24 & 0.32 & -0.10 & -0.18 & 0.97 \\
\hline
\end{tabular}

Table IV.A3 gives the $R^{2} s$ of regressions of each explanatory variable (except the constant) on the other explanatory variables (including the constant) for the different equations. As shown in Johnston (1984: 245-249), the sampling variance of a parameter estimate grows increasingly for larger values of these $R^{2} s$, with critical values around 0.9. Table IV.A3 shows that the $R^{2} s$ found are well below this critical value, so that the effect of multicollinearity is not likely to affect the results too much. In addition, it is shown that the parameter estimate for INIT, which is the only one turning out significantly, is affected most by the multicollinearity problem.

This result is confirmed by another procedure to detect the influence of multicollinearity, described in Belsley et al. (1980). This procedure looks at the ratio of the square root of the largest eigenvalue of the squared matrix of independent variables (which are scaled to one) and the individual eigenvalues. Ratios above 20 point to serious multicollinearity problems. In the regressions in Table IV.1, the highest ratio does not exceed seven. In order to assess the influence of multicollinearity on the individual variances of the parameter estimates, one can then perform a decomposition of the regression variance in order to find the part of the variance attributable to excessively low eigenvalues. Although there are no excessively low eigenvalues in the regressions here, this variance decomposition was still performed, indicating that the coefficient of INIT (and, to a lesser extent, investment and the constant) is most seriously affected. This is in line with the analysis of the individual $R^{2}$. 
Table IV.A3. R $^{2} s$ of regressions of the dependent variables in table IV.1 on each other

\begin{tabular}{||l|l|l|}
\hline Eq. \# & Dep. var & $R^{2}$ \\
\hline 1 and 5 & INIT & 0.41 \\
\hline 1 and 5 & RDI1 & 0.20 \\
\hline 1 and 5 & I/K & 0.30 \\
\hline 2 and 6 & INIT & 0.23 \\
\hline 2 and 6 & RDI1 & 0.21 \\
\hline 2 and 6 & I/Q & 0.08 \\
\hline 3 and 7 & INIT & 0.29 \\
\hline 3 and 7 & RDI2 & 0.11 \\
\hline 3 and 7 & I/K & 0.21 \\
\hline 4 and 8 & INIT & 0.33 \\
\hline 4 and 8 & RDI2 & 0.11 \\
\hline 4 and 8 & I/Q & 0.27 \\
\hline
\end{tabular}




\section{PART TWO}

\section{Technology Spillovers in Interdependent Economies: Catching Up or Falling Behind?}





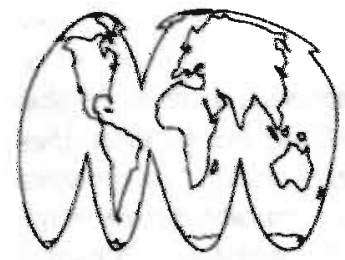

\section{CHAPTER 5. A Model of Catching Up or Falling Behind"}

The first stylized facts to be explained are the two last ones (4 and 5), indicating that the rate of productivity growth is inversely related to per capita income for countries in the middle- or higher-income range, but that the poorest countries grow slowest. These stylized facts stress the importance of knowledge spillovers. The two key conclusions from the discussion in Chapter 3 with regard to the theoretical nature of useful models (dynamic, and stressing differences between agents, in this case countries) will serve as guidelines while constructing the equations of a model which describes the working of international knowledge spillovers and their influence on the domestic economy. The dynamic character of the model is mainly related to its specification in terms of time derivatives. What is being modelled is not the level of some variable, but its motion over time (using differential equations). The full selection logic that was proposed in Chapter 3 will not be applied yet (this will be done in Part Three below). The idea of differences between countries with regard to technological capabilities will, however, be fully applied. On the one hand, the levels of the 'knowledge stock' are assumed to be different between countries (so that there are opportunities for spillovers), as in the so-called catching-up models. On the other hand, following from the discussion on Lamarckian evolution concepts in Chapter 3, it will also be assumed that learning capabilities differ between countries. Thus, the model describes the effect of technological interdependencies between countries upon growth rate differentials.

The main economic content from the model will be taken from the neo-Keynesian Dixon and Thirlwall model, as described briefly in Chapter 2. This approach to explaining growth rate differentials, taking into account endogenous technological change, was found to be a promising one. However, the economic interdependencies in the model will be of less importance than the technological ones. Therefore, this part is primarily aimed at modelling technological relations in an interdependent world. Part Three will delve more deeply into the influence of economic interdependencies.

\footnotetext{
'Parts of this chapter draw on Verspagen (1991).
} 


\subsection{Description of the Model}

The model developed here rests on the assumptions that individual (i.e., in this model, country-specific) technological capabilities differ (see Chapter 3). This does not only mean that countries differ with regard to their ability to produce technological knowledge, but also that the capability to imitate knowledge developed elsewhere differs. The latter idea has been put forward in literature from quite different branches in economics. For example, at the microeconomic firm level, this consideration led Cohen and Levinthal (1989) to formulate a model in which the degree to which a firm can use spillovers from knowledge generated by other firms (inside as well as outside the industry) is dependent on the R\&D outlays of the firm itself. At the macroeconomic level of (inter)national economic growth, Kristensen (1974), Rostow (1980: 259-288) and Baumol et al. (1989) have pointed to the fact that the extent to which a country can apply the backlog of unused knowledge crucially depends upon its capabilities to assimilate this knowledge. Kristensen (1974: 24) argues that technology spillovers will not take place when the capability of the receiving country is too low: "(...) The most rapid economic growth should be expected to take place in countries that have reached a stage at which they can begin to apply a great deal more of the existing knowledge. This requires capital for investment". Support for the hypothesis that the capability to assimilate technological knowledge is crucial in the process of international diffusion can also be found in the results from case studies in economic development and technology transfer. For example, Westphal et al. (1985: 168-169), in a case study of South Korea's economic development, observe that

"(...) assimilation [of forcign technology] often seems to be characterized as being automatic and without cost. If this were correct, assimilation would not merit much attention. But it is not accomplished by passively receiving technology from overseas. It requires investments in understanding the principles and use of technology, investments reflected in increased human and institutional capiral".

A model that tries to explain the patterns of international diffusion of knowledge should pay attention to these considerations.

The cumulative character of technological change is included in the model by means of the technological distance. More precisely, it is assumed that the larger the distance between the current level of technological knowledge and the technology to be imitated, the more difficult the process of imitation will be. The general idea captured by this is that technological knowledge is a highly heterogeneous good that is (generally) embodied in highly heterogeneous capital goods. Imagine the range of goods that embody technology as a range that can be ordered according to technological (or productivity) level. Given that an entrepreneur (or in more general terms, a country) is using a capital good from the lower part of this range, it will be easier to move to a slightly more sophisticated capital good than to move to a highly sophisticated type of capital.

As a stylized description of these aspects of technology gaps and imitation, the model considers the case of two countries, one of which is technologically advanced (called the North) and the other technologically backward (called the 
South). Technological knowledge is considered to be the only determinant of growth, although its effect can be both direct and indirect. The direct effect is through the value of the knowledge stock, denoted by $T$, which has a positive effect upon the country's growth rate. The indirect effect is through the effect of technological knowledge upon exports, which in turn has an effect upon growth. The argument of export-based growth is borrowed from the neo-Keynesian models. Dixon and Thirlwall (1975) argue that, in the long run, exports are the only form of exogenous effective demand and, therefore, are the factor which determines whether or not a situation of (Keynesian) full employment is reached. In an economy operating at full employment and with a stable population (both in the long run), export growth would not be a stimulus for economic growth. However, reality seems to prove that full employment is not usually the prevailing state for all periods in economic history.

Using subscripts $n$ and $s$ for denoting North and South respectively, the equation for the growth rate of a country's production can be represented as follows.

$$
\begin{gathered}
Q_{i}=\alpha T_{i}+\varepsilon \hat{X}_{i} \\
i=n s
\end{gathered}
$$

In this equation, $X$ denotes exports. Following the evolutionary logic introduced in Chapter 3 , the dynamics of exports can be described by the principle of economic selection. As a first approximation ${ }^{2}$, the selection process is represented by a linear relation between a country's competitiveness and the sum of the growth rate of its market share in total world markets. Then, the growth rate of total exports is equal to the growth rate of this market share and the growth rate of the volume of the market. The following equations take the relative knowledge stock as an indicator of competitiveness in this process.

$$
\begin{aligned}
& \hat{X}_{n}=\eta \ln \left(\frac{T_{n}}{T_{s}}\right)+\hat{Z} \\
& \hat{X}_{s}=\eta \ln \left(\frac{T_{s}}{T_{n}}\right)+\hat{Z}
\end{aligned}
$$

The logarithmic specification has the convenient property that for equal levels of $T$, the first term on the rhs is zero. These equations say that when knowledge stock levels in the two countries are equal, market shares will remain stable, and the growth rate of exports in the two countries will just be equal to the growth rate of the market volume. For differences in productivity levels, the advanced country will win market share (and thus have higher growth rates), while the backward country will loose market share (and thus have lower growth rates).

Of course, these equations capture only some of the real-world dynamics of export growth. For example, the wage rate is a factor that is likely to play a much more

${ }^{2}$ A more realistic model of economic selection is the replicator equation (III.1) - (III.2), which will be introduced in Part Three. The approach used here closely links up with Dixon and Thirlwall (1975). 
important role than accounted for here. To the extent that high knowledge levels are reflected in high productivity, the competitive advantage stemming from this might be offset by high wages, or the other way around. For now, this effect will not be taken into account, in order to keep the model simple and solvable. In Part Three, wage rate dynamics will be included in a model.

Following this, the advance in technological knowledge is modelled. First, define the knowledge gap (technology gap) between North and South (denoted by $G$ ) as follows.

$$
G=\ln \left(\frac{T_{n}}{T_{s}}\right)
$$

This is the same term as the one in equations (V.2) and (V.3), so that export performance is directly related to the technology gap. Growth of the knowledge stock results from an exogenous part (conveniently called the research sector output) and from dynamic learning effects, as in the Verdoorn law. The Verdoorn effect is represented by a (linear) relation between the growth rate of technological change and the growth rate of output (as in Dixon and Thirlwall 1975). No explicit, formal micro foundation for this relation will be given here. However, Verdoorn's law provides a reasonable way of formalizing some of the notions on technological change which have been discussed in Chapter 3 above, such as cumulativeness, and the absence of strict optimalization procedures. An additional source of growth of the knowledge stock in South are technology spillovers (as in Gomulka 1971). Preferably, the research sector should be endogenized in a more satisfactory way, but this is not done to keep the model as simple as possible. Thus, the endogenous sources for knowledge growth will be limited to learning effects and spillovers.

The final step in setting up the equation for knowledge production in North and South is to specify the spillover term. On the basis of the observations on technology (spillovers) above, a distinction is made between potential spillovers and actual spillovers. The concept which links the two is the learning capability of a country. To pick up the discussion about the Lamarckian view of evolution, the learning capability of a country is assumed to depend on an intrinsic part, and to use the idea of cumulative technological knowledge expressed above, the technological distance from the leading country is assumed to be the other factor influencing the learning capability. For a given technological distance, a country's learning capability varies with its intrinsic learning capability, which is determined by a mixture of social factors (Abramovitz 1986), education of the workforce (Baumol et al. 1989), the quality of the infrastructure, the level of capitalization (mechanization) of the economy, the correspondence of the sectoral mix of production in the leading and following country (Pasinetti 1981), and other factors. For a given intrinsic capability to assimilate spillovers, the overall capability will diminish with the technological distance.

Spillovers are modelled as net spillovers. It is assumed that net spillovers flow in the direction of the backward country at all times. If, at some point in time, the gap is closed $(G=0)$, no spillovers will occur. Thus, the value of $G$ itself is a 
measure for potential spillovers. Then, since the actual spillovers cannot be bigger than the potential spillovers, the capability factor must take some value between zero and one. For large technological distance, the capability should go to zero. If the technology gap is closed, the capability should be at its maximum value, one. An assumption that satisfies these requirements is the one that the capability to assimilate technological spillovers decreases with the size of the (relative) technology gap at a constant rate, say $1 / \delta$.

However, this rate of decrease in the capability to assimilate spillovers cannot be assumed to be given exogenously. It should be a function of the above-mentioned variables determining the intrinsic capability to assimilate spillovers. Here, these variables will be treated as policy variables, i.e., it is assumed that the government can decrease the rate of decline of the capability to assinnilate spillovers by means of an active policy in education, investment in infrastructure, etc. In other words, the parameter $\delta$ is a policy parameter.

Taking the value of the technology gap $G$ itself as a measure of the technological distance, the term $e^{-6 / 8}$ represents the capability to assimilate knowledge spillovers according to these principles. In that case, the equations for the rate of growth of the knowledge stocks are as follows.

$$
\begin{gathered}
\hat{T}_{n}=\beta_{n}+\lambda Q_{n} \\
\hat{T}_{s}=\beta_{s}+\lambda Q_{s}+a G e^{-G / \delta}
\end{gathered}
$$

The exogenous rates of knowledge growth are denoted by $\beta, \lambda$ is the Verdoorn learning rate $^{3}$, and $a G$ measures the potential spillover. The combination of the Verdoorn effect and the export-based growth link gives the model its strong neoKeynesian flavour.

Given the linear (monotonically increasing in $G$ ) specification of the potential spillovers, it can be easily verified that different functional forms of the capability term can give the total spillovers function three possible forms: monotonically increasing, monotonically decreasing, or a specification with one (or more) extreme value(s). The specification here obviously has the latter characteristic (one maximum for the spillovers function). One might argue that this is an ad hoc specification. On the basis of intuition and the evidence considered in Chapter 4, however, one might safely rule out the second possibility of a monotonically decreasing amount of spillovers for larger initial technology gaps. This still leaves open the possibility of a monotonically increasing spillovers function. As will be shown below, the model used here contains this assumption as a special case, so that it can be relaxed and tested empirically. The latter exercise will be undertaken in Chapter 6. Now, the model will be solved.

\footnotetext{
${ }^{3}$ For simplicity, it is assumed that $\lambda_{n}=\lambda_{3}=\lambda$. This assumption will be relaxed in Chapter 7 below.
} 


\subsection{Solving the Model}

First, the equations for the growth rates of the two countries are obtained by combining equations (V.1) - (V.6).

$$
\begin{gathered}
Q_{n}=\frac{\alpha \beta_{n}}{1-\alpha \lambda}+\frac{\varepsilon \eta}{1-\alpha \lambda} G+\frac{\varepsilon}{1-\alpha \lambda} Z \\
Q_{0}=\frac{\alpha \beta_{s}}{1-\alpha \lambda}-\frac{\varepsilon \eta}{1-\alpha \lambda} G+\frac{\varepsilon}{1-\alpha \lambda} Z+\frac{a \alpha}{1-\alpha \lambda} G e^{-G / \delta}
\end{gathered}
$$

At this stage, the assumption $\alpha \lambda<1$ proves to be useful, since otherwise the rhs of (V.7) - (V.8) would be negative ( $\alpha \lambda>1)$ or nonexisting $(\alpha \lambda=1)$. The economic meaning of this assumption is that the self-reinforcing effect coming from spirals of the Verdoorn $(\lambda)$ and technology $(\alpha)$ parameters cannot be so large as to cause an 'explosion' of the system. Dixon and Thirlwall (1975) apply a similar assumption".

The equations show that the growth rate of output is (among other factors) a positive function of the technology gap for the North, and a mixed positive / negative function of the technology gap for the South. Combining equations (V.7) (V.8) in one equation for the difference between the growth rates of output gives the following.

$$
\hat{Q}_{n}-Q_{s}=\frac{\alpha}{1-\alpha \lambda}\left(\beta_{n}-\beta_{s}\right)+\frac{2 \varepsilon \eta}{1-\alpha \lambda} G-\frac{a \alpha}{1-\alpha \lambda} G e^{-G / 8}
$$

This equation shows that the difference between the growth rates of output is a function of the technology gap between the two countries, and the difference in output of the research sector.

The next step is determining the dynamics of the technology gap. Equations (V.4) (V.6) and (V.9) allow for an analysis of these dynamics. Differentiating (V.4) with respect to time, and substituting equations (V.5) - (V.6) and (V.9) yields the following.

$$
G=\hat{T}_{n}-\hat{T}_{s}=\frac{1}{1-\alpha \lambda}\left(\beta_{n}-\beta_{s}\right)+\frac{2 \varepsilon \eta \lambda}{1-\alpha \lambda} G-\frac{a}{1-\alpha \lambda} G e^{-G / \delta}
$$

Equation (V.10) enables one to search for equilibrium values of the technology gap (in the sense that the size of the gap does not change). Equation (V.9) shows that for such an equilibrium value of the technology gap and a constant difference between outputs in the research sector, the growth rate differential does not change either. Thus, assuming that the difference between the output in the research sector is constant, the dynamics in this model of growth rate differentials are determined by the technology gap alone. Searching for equilibrium values of the technology gap, equation (V.10) is set to zero. This yields the following.

\footnotetext{
- An alternative specification of the Verdoorn effect that does not require this assumption will be presented in Chapter 7.
} 


$$
2 E \eta \lambda G+\beta_{n}-\beta_{s}=a G e^{-G / 8}
$$

Equation (V.11) can be easily analyzed by means of a figure which looks at the rhs and lihs of the equation separately (a so-called phase diagram). On the nonnegative part of the $G$-axis, the rhs has one intersection point with that axis at $G=0$. The slope of the function at this intersection point is greater than zero. The function has a maximum equal to $\mathrm{G} a / e$ at the point where $G=\delta$. For $G$ going to infinity, the value of the rhs goes to zero. The lhs of equation (V.11) is a straight line, which is always above the $G$-axis for nonnegative values of $G$ (assuming that the output in the research sector in the backward country is smaller than that in the advanced country). Depending on the values of the parameters, the graphs of the left and the rhs parts of equation (V.11) have either zero, one or two intersection points, which means that there are either zero, one or two equilibrium values for the technology gap.

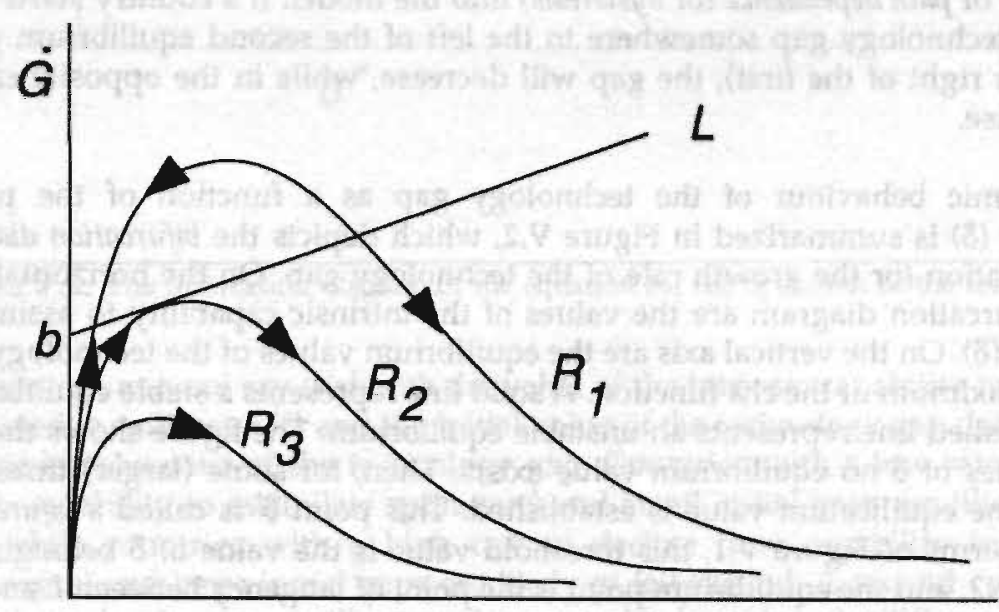

G

Figure V.1. The dynamics of the technology gap

Figure V.1 depicts the three possible situations for the dynamics of the technology gap. The curves denoted by $R$ represent the rhs of equation (V.11), while the curve labelled $L$ corresponds to the lis of the equation. The curves $R 1, R 2$ and $R 3$ correspond to different values of the rate of decline of the capability to assimilate knowledge spillovers for larger gaps, 1/ $\delta$. R1 represents a low rate of decline (a high intrinsic capability to assimilate, $\delta$ ), while $R 3$ represents a high rate of decline. The difference between the exogenous rates of knowledge growth in North and South is denoted by $b\left(=\beta_{n}-\beta_{\theta}\right)$. Wherever the $R$ curve is below the $L$ curve, the 
technology gap grows, since the amount of spillovers flowing to South is smaller than the increase in the technology gap determined by the other factors in the model (i.e., the difference between outputs in the research sector and the Verdoorn effect). Wherever the $R$ curve is above the $L$ curve, the technology gap becomes smaller.

Thus, in the case of $R 3$, the technology gap will always grow ${ }^{6}$, because the spillovers are too small for the whole range of $G$. In the case of $R 2$, there is one equilibrium value for the technology gap at the point of tangency between $R 2$ and $L$. A small deviation from this equilibrium point to the left will result in a growth of the technology gap, and thus take the system back to the initial equilibrium again. A small deviation to the right, however, will lead the system away from the equilibrium. Thus, the equilibrium point is stable from the left and unstable from the right. For R1, there are two equilibrium points. The rightmost point is unstable (a deviation to the left leads the system towards the leftmost equilibrium point, a deviation to the right leads to infinity). The leftmost point is stable from both sides. This situation is indeed the most interesting one, since it brings the possibility of path dependence (or hysteresis) into the model. If a country starts with an initial technology gap somewhere to the left of the second equilibrium point (but to the right of the first), the gap will decrease, while in the opposite case it will increase.

The dynamic behaviour of the technology gap as a function of the policy parameter $(\delta)$ is summarized in Figure V.2, which depicts the bifurcation diagram of the equation for the growth rate of the technology gap. On the horizontal axis of the bifurcation diagram are the values of the intrinsic capability to assimilate spillovers $(8)$. On the vertical axis are the equilibrium values of the technology gap and the maximum of the rhs function. A solid line represents a stable equilibrium, while a dashed line represents an unstable equilibrium. The figure shows that for small values of $\delta$ no equilibrium value exists. Then, for some (larger) threshold value $\delta^{*}$ one equilibrium value is established. This point $\delta^{*}$ is called a bifurcation point'. In terms of Figure V.1, this threshold value is the value of $\delta$ belonging to the curve $R 2$, and the equilibrium point is the point of tangency between $L$ and $R 2$. The exact value of this point is not solved for, but since the curve $L$ is upward sloping, it is clear that it will be to the left of the value of $G$ which gives the maximum of the spillovers function. For values of $\delta$ larger than the threshold level, two equilibria exist, as described by the curves in the bifurcation diagram.

\footnotetext{
S One must realize that the equation (V.11) was constructed by multiplying both sides of (V.10) by 1- $\infty$. Therefore, the curves no longer represent the exact values of the different terms in (V.10). To arrive at these expressions, one should multiply the curves by $1 /(1-\alpha \lambda)$. This will not, however, change the conclusions about the distinction between catching up or falling behind. The same argument applies to the various curves in Figure V.3 below.

- This, and the other possibilities for the motion of $G$, is depicted by the arrows in the figure.

'In this context, a bifurcation can be defined as a point where the qualitative behaviour (in the sense of existence of equilibria) of the system changes.
} 


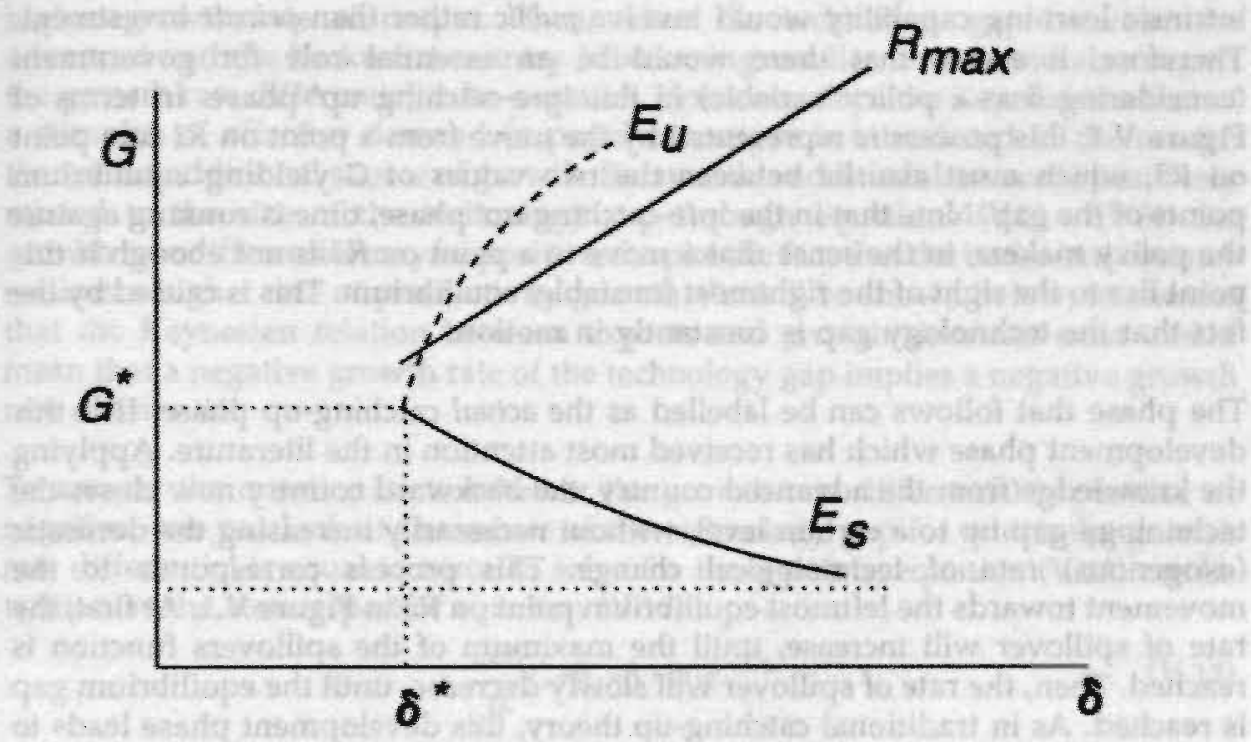

Figure V.2. The bifurcation diagram of the equation for the dynamics of the technology gap

To sum up, one can say that both the value of the intrinsic capability to assimilate knowledge spillovers $(\delta)$ and the initial value of the technology gap determine the dynamic behaviour of the technology gap. Countries with a low rate of decline (high capability to assimilate spillovers) and small initial gaps are likely to catch up, while countries with a high rate of decline (low capability to assimilate spillovers) and large initial gaps are likely to fall behind. A second conclusion is that the technology gap will never close completely, unless the difference between the (exogenous) rates of growth of the knowledge stocks vanishes. This conclusion must be understood as establishing the intuitive result that a technology gap can never be closed completely by imitation alone.

The model has some interesting implications for economic development policy ${ }^{8}$. These can be derived from the two conclusions drawn from the model. Starting from the first of these conclusions, one can easily see that countries which have a 'very high' level of backwardness cannot automatically assume that catching up will occur. The reason is that their capability to apply the knowledge from the more advanced country is inadequate. Thus, before catching up can become a relevant process in very backward countries, there must be a phase in which the country builds up its intrinsic learning capability ('pre-catching up'). In terms of the model, this building up of the intrinsic learning capability would consist of trying

\footnotetext{
${ }^{3}$ Compare Rostow $(1960,1980)$.
} 
to achieve a better education of the labour force, a better infrastructure, and other measures. Most of the measures one could imagine as contributing to a better intrinsic learning capability would involve public rather than prioate investment. Therefore, it seems that there would be an essential role for government (considering $\delta$ as a policy variable) in this 'pre-catching up' phase. In terms of Figure V.1, this process is represented by the move from a point on $R 1$ to a point on $R 3$, which must also lie between the two values of $G$ yielding equilibrium points of the gap. Note that in the 'pre-catching up' phase, time is running against the policy makers, in the sense that a move to a point on $R 3$ is not enough if this point lies to the right of the rightmost (unstable) equilibrium. This is caused by the fact that the technology gap is constantly in motion.

The phase that follows can be labelled as the actual catching-up phase. It is this development phase which has received most attention in the literature. Applying the knowledge from the advanced country, the backward country now closes the technology gap up to a certain level, without necessarily increasing the domestic (exogenous) rate of technological change. This process corresponds to the movement towards the leftmost equilibrium point on $R 3$ in Figure V.1. At first, the rate of spillover will increase, until the maximum of the spillovers function is reached. Then, the rate of spillover will slowly decrease, until the equilibrium gap is reached. As in traditional catching up theory, this development phase leads to (some) convergence of technological (productivity) levels.

Total convergence of technological levels will not, however, be reached by means of catching up alone. In order to close the gap completely, the backward country will have to go through one more phase. The relevant feature of this phase is the expansion of domestic research efforts up to a level comparable with the advanced country. More specifically, given the positive slope of the $L$ curve, the backward country will have to generate a higher rate of exogenous knowledge growth than the advanced country for some time in order to be able to catch up completely. This 'post-catching up' phase, in which the tendency of growth rates to converge halts, might be a more or less adequate description of the most recent trend in the long-run picture of convergence and divergence in Chapter 4 (Figure IV.11).

Note that the model also has an (although admitted very stylized) explanation for overtaking. One could imagine the situation in which the South successfully applies a development policy along the lines set out above, and indeed manages to close the gap completely. From that point on, the negative difference between the exogenous rates of knowledge growth would place the South in a position in which it becomes the technological leader. In that case, the model would collapse, with the North becoming the backward country, and the South the advanced one. The process would start over again, and the North would be able (or unable) to catch up. In a multicountry context, the model could thus generate patterns as observed in the economic history of the modern world (briefly described in Chapter 1).

Turning to the equation for the growth rate differential, the question arises as to whether or not it is possible that negative growth rate differentials exist (i.e., the backward country achieves higher growth rates than the advanced country). As 
noted above, one would expect that, in a long-term situation of full employment, a country that realizes a higher growth rate of productivity would also realize a higher growth rate of output. Thus, when the technology gap between the advanced and the backward country is becoming smaller, one would also expect the growth rate differential to be negative. However, since the Keynesian effect of a stimulus of effective demand (exports) on output is introduced in the model, there is an additional source of growth. Because this additional source is positively related to the size of the technology gap through equations (V.2) - (V.3), the growth rate differential may be positive, despite the fact that the backward country realizes a higher rate of productivity growth. As will be shown below, to assume that the Keynesian relation between exports and growth does not exist would mean that a negative growth rate of the technology gap implies a negative growth rate differential.

To answer the question as to whether the growth rate differential is positive or negative, one can look at the values of the technology gap for which the growth rate differential is equal to zero. To solve for these points, equation (V.12) can be written as the counterpart of equation (V.11).

$$
\frac{2 E \eta}{\alpha} G+\beta_{n}-\beta_{s}=a G e^{-\sigma / 8}
$$

The result is (again) that depending on parameter values, two, one or zero points exist for which the growth rate differential is equal to zero.

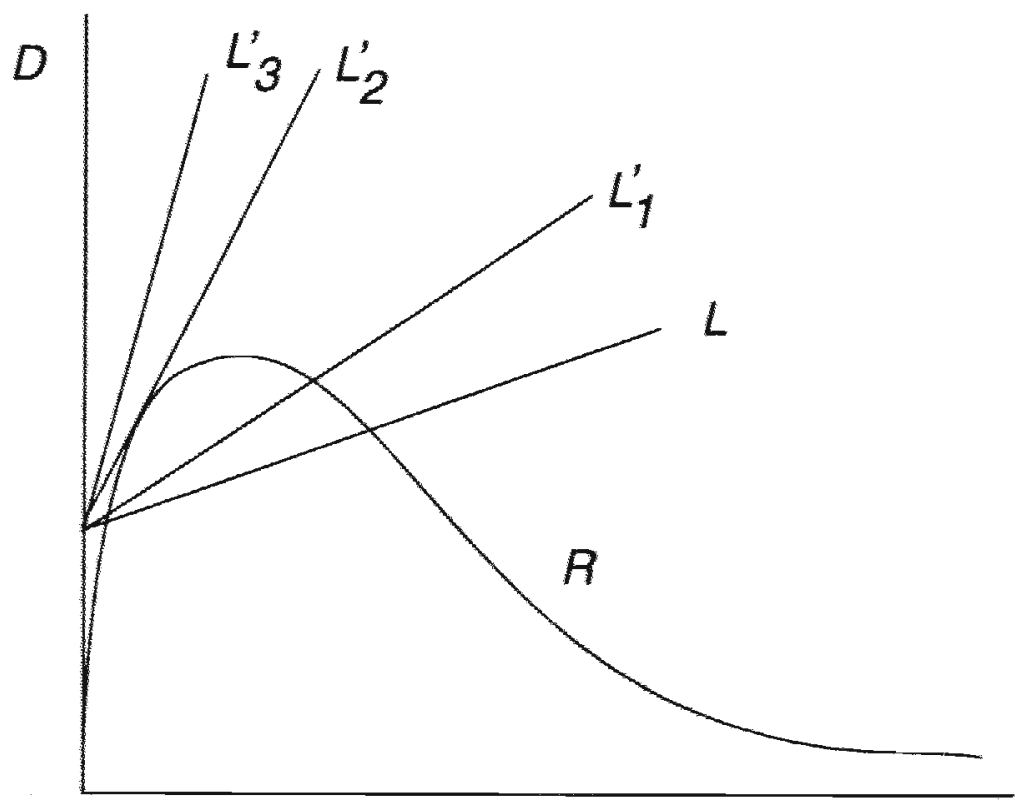

Figure V.3. The dynamics of the growth rate differential 
Equation (V.9) shows that for an increasing technology gap, the growth rate differential also moves towards infinity. Thus, if a country is falling behind in a technological sense, it will also fall behind in a growth sense. To analyze the opposite case, assume for a moment that the initial value of the gap is such that convergence towards the stable equilibrium point takes place. By looking at equations (V.11) and (V.12), it can be easily seen that for the values of $\alpha$ and $\lambda$ assumed above $(\alpha \lambda<1)$, the slope of the line on the lhs of (V.12) is always larger than the one on the lhs of (V.11). Figure V.3 graphs the lits and rhs of (V.12), similar to Figure V.1. The $L^{\prime}$ curves represent the lhs of (V.12) for different parameter values. The $R$-curve is the same as $R 1$ from Figure V.1, and the $L$-curve from Figure V.1 is reproduced for clarity. The growth rate differential is denoted by $D$.

Assuming that a country starts just a little bit to the left of the rightmost equilibrium point of the technology gap (i.e., the rightmost intersection point between the $L$-and $R$-curves in the figure), it is clear that initially the growth rate differential $D$ is positive (the $R$ curve is below the $L^{\prime}$ curve). At this stage, the backward country lags behind to such an extent that its disadvantage through trade is dominating. It depends on the size of $\alpha$ and $\lambda$ (the combined effect of the Verdoorn effect and the direct link between technology and growth) whether or not a negative growth rate differential arises at some stage. If the curve $L^{\prime}$ is not too steep (such as $L_{1}^{\prime}$ ), it will have two intersection points with the $R$-curve. Passing the rightmost of these, the growth rate differential will become negative. At this stage, the direct effect of knowledge growth dominates the export-based effect, and the technologically catching-up country also catches up in growth. However, since the knowledge spillovers are nonlinear, their size will decrease at some point (after passing the maximum of the $R$-curve). Eventually, the exportbased effect will dominate again, and the growth rate differential becomes positive. However, if the export-based effect is too strong, the $L^{\prime}$-curve will have no intersection points with the $R$-curve, e.g., $L_{3}^{\prime}$. The borderline case is $L_{2}^{\prime}$, with a point of tangency between the two curves. In case there are no intersection points, the export-based effect will dominate along the total catching-up process, and the catching-up country will not be able to generate higher growth, despite the faster growth of the knowledge stock. (Note, however, that the growth rate differential does have a minimum). In the borderline case, the growth rate differential will just 'touch' on the zero-level at the point where the spillovers are maximal.

It is not assumed that the parameters $\alpha$ and $\lambda$ can be influenced by policy. Therefore, a country cannot change the position of the $L^{\prime}$-curves. However, by moving the $R$-curve through the policy parameter $\delta$, the country can go from a situation of no intersection points (and slower growth) to a situation of rapid growth. This means that the policy of increasing the intrinsic capability to assimilate knowledge spillovers does not only apply to catching up in a technological sense, but also to catching up in growth. Thus, the conclusion is that if a country is catching up in a technological sense, this does not automatically imply catching up in a growth sense. In order for growth catching up to take place (at some stage), the level effect of the technology gap (modelled through trade) must not be too strong. 


\subsection{The Outcomes of the Model Under Varying Parameter Restrictions}

The model considered above yields some basic conclusions. The technology gap may either be increasing or decreasing over time, depending on the value of the initial technology gap, and the intrinsic capability to assimilate spillovers (8). In case of a decreasing technology gap, the growth rate of the technologically advanced country may either be higher than the backward country's growth rate for the whole period, or it may be smaller for some limited period of time, during which the backward country has an 'absolute' catching-up advantage.

Do these outcomes of the model still hold if one reduces the number of dynamic links between variables in the model? This section tries to answer this question. Subsequently, the following assumptions will be dealt with: no relevance of the $\delta$ parameter ( $\delta$ to infinity), no direct relation between output growth and productivity growth $(\alpha=0)$, no direct relation between export growth and output growth $(\varepsilon=0)$, and no relation between productivity growth and output growth $(\lambda=0)$.

\section{a. Infinitely Large Intrinsic Capabilty to Assimilate Knowledge Spillovers}

Assume that there is no relation between the technological distance and the backward country's capability to assimilate technology spillovers from the advanced country (the intrinsic capability to assimilate technology spillovers is infinitely large). To allow $\delta$ to go to infinity would mean that equations (V.9) and (V.10) reduce to

$$
\begin{gathered}
Q_{n}-Q_{s}=\frac{\alpha}{1-\alpha \lambda}\left(\beta_{n}-\beta_{s}\right)-\frac{2 \varepsilon \eta-\alpha \alpha}{1-\alpha \lambda} G \\
G=\frac{1}{1-\alpha \lambda}\left(\beta_{n}-\beta_{s}\right)+\frac{2 \varepsilon \eta \lambda-a}{1-\alpha \lambda} G
\end{gathered}
$$

In order for a catching-up relation to take place at all in this case, one must assume that the feedback of the gap to knowledge spillovers is larger than the (oppositely signed) feedback from the gap to trade. In mathematical terms, this means $2 \mathrm{E} \eta \lambda<a$. If this assumption is not satisfied, the conclusions of the model are more or less the same as in the neo-Keynesian Dixon and Thirlwall case.

Assuming that catching up is relevant, equation (V.14) shows that in this case the technology gap will always converge to an equilibrium. The equilibrium point of the technology gap is stable for the whole range of G. In terms of Figure V.1, this means that the curve $R$ becomes a straight line with a positive slope, and the curve $L$ becomes a horizontal line. The value of the technology gap (starting on either side) will move towards the intersection point of these lines. Equation (V.13) then shows that in this case the growth rate differential also converges to a fixed value.

Thus, in the event that $\delta$ is infinitely large, the dynamics of the model change

\footnotetext{
'This is similar to the case of no relation between productivity growth and export growth, as the reader can easily verify.
} 
considerably. The possibility of falling behind in the long run no longer exists, and the country is certain to catch up. Although this case may be less interesting from an empirical point of view (see Chapter 4), this approach has been followed in of the catching-up literature (Baumol 1986, Abramovitz 1986 and Gomulka 1971). In all the models used there, the intrinsic capability to assimilate knowledge spillovers is implicitly assumed to be infinitely large. Thus, these models can be considered to be special cases of the model used here. The next chapter will develop some formal tests to check this assumption.

\section{b. No Direct Link Between Technological Knowledge and Growth}

The next assumption made is that there is no direct link between the growth of the level of technological knowledge and the growth rate of output $(\alpha=0)$. This means that the link between technology and growth is made completely through the demand side of the economy. One could label this case as the fully Keynesian case. Here, equations (V.9) and (V.12) reduce to the following.

$$
\begin{gathered}
Q_{n}-\hat{Q}_{s}=2 \varepsilon \eta G \\
G=\beta_{n}-\beta_{s}+2 \varepsilon \eta \lambda G-a G e^{-G / \delta}
\end{gathered}
$$

The structure of equation (V.16) is basically the same as that of equation (V.10). Therefore, the essential dynamics of the technology gap do not change. What is different in this case is the relation between the technology gap and the growth rate differential. This relation, which is described by equation (V.15), no longer allows for negative growth rate differentials, which means that the backward country will always grow slower, despite its state of technological catching up. Equation (V.15) is a straight line which is always above the G-axis for positive G. Thus, the dynamics of the model are changed to some extent in this case.

\section{c. No Link Between Exports and Growth}

Setting $\varepsilon$ to zero means assuming that the link between growth of export and the growth rate of output does not exist. This is the case in a world where Keynesian full employment is the prevailing state of affairs, and technological change through the supply side of the economy is the only source of output growth. In this case, the equations for the growth rate differential and the growth rate of the technology gap are as follows.

$$
\begin{gathered}
Q_{n}-Q_{s}=\frac{\alpha}{1-\alpha \lambda}\left(\beta_{n}-\beta_{s}\right)-\frac{\alpha \alpha}{1-\alpha \lambda} G e^{-\sigma / 8} \\
G=\frac{1}{1-\alpha \lambda}\left(\beta_{n}-\beta_{s}\right)-\frac{a}{1-\alpha \lambda} G e^{-\sigma / 8}
\end{gathered}
$$

The structure of equations (V.17) and (V.18) is more or less the same as that of equations (V.9) and (V.10), with the exception of the second term including G in the latter equations. It can be easily verified that this does not drastically change the dynamics of the technology gap. In terms of Figure V.1, the basic form of the $R$ curves remains the same, while the $L$ curve becomes a horizontal line. 
The dynamics of the growth rate differential do change, however. Since technological knowledge is the only source of output growth, a decreasing technology gap directly implies a negative growth rate differential (the growth rate differential is simply the motion of the technology gap, multiplied with $\alpha$ ). If the growth rate of the technology gap is negative, it follows directly that the growth rate differential is always negative. Thus, in this case, a country that starts a catching-up process immediately realizes higher growth rates than the advanced country. In the general case, the (gap level-related) export effect might outweigh the direct effect through $\alpha$, which no longer holds here.

\section{d. No Verdoom Effect}

Finally, it is assumed that the Verdoorn effect is not relevant. Setting $\lambda=0$ means that equations (V.9) and (V.10) become as follows.

$$
\begin{gathered}
Q_{n}-Q_{s}=\alpha\left(\beta_{n}-\beta_{s}\right)+2 m \eta G-a n G e^{-C / s} \\
G=\beta_{n}-\beta_{s}-a G e^{-G / t}
\end{gathered}
$$

The form of equation (V.19) is basically the same as that of equation (V.9), but equation (V.20) is a little different from equation (V.10). However, the dynamic properties of equation (V.20) are the same as those of equation (V.10). This can easily be seen by imagining what happens to the curves in Figure V.1 in the case of equation (V.20). The shape of the $R$ curves remains the same, while the $L$ curve becomes a horizontal line. Again, there exists a possibility of falling behind (no intersection points between the curves) and catching up (two intersection points). Note that, ceteris paribus, the rightmost intersection point of the curves (i.e., the threshold level of the initial technology gap) lies further to the right in this case. This means that without the Verdoorn effect, it is 'easier' to catch up, because an additional source of knowledge growth, which works against the backward country in the early catching-up phase (see above), is ruled out. 


\subsection{Conclusions of the Model}

Combining the neo-Keynesian Dixon and Thirlwall model of export-based growth on the basis of self-reinforcing growth with a catching-up model, and taking into account some of the observations from the literature on technology (spillovers), leads to the following outcomes. Under the assumption that technological distance is a factor in explaining the capability to assimilate technological spillovers, the combination of the size of the initial technological gap and the value of the intrinsic capability to assimilate knowledge spillovers ( $\delta$ ) determines whether a country can catch up relative to the technological leader, or whether it will fall behind. This outcome holds true irrespective of all the other assumptions in the model.

Depending on the size of various parameters, catching up in a technological sense might or might not imply catching up in a growth sense (i.e., realizing faster growth in the backward country). Raising the intrinsic capability to assimilate knowledge spillovers will increase the speed of technological catching up, and thereby realize a shift from slower growth to faster growth. If it is assumed that productivity growth is the only direct source of output growth (no export-based growth), faster growth rate in the backward country is the only possible outcome in the case of catching up. The Verdoorn effect is not a necessary condition for the outcomes of the model as described above.

Thus, the model can explain both stylized facts 4 and 5 from Chapter 4 . The first of these, that a low initial level of labour productivity favours the rate of technological progress, was already explained in earlier work on catching up. However, the second, that the lowest per capita income countries also grow at the slowest rate, has not yet been explained in a formal catching-up modelling context. Therefore, this model shows that the use of nonlinear dynamic models combined with insights from the nonformal part of the literature on international growth provides a much richer perspective than the existing catching-up models. However, in order to test the content of the model, a more rigorous test than just looking at stylized facts is needed. Therefore, the next chapter will undertake an econometric test of a simple version of the model proposed here. 


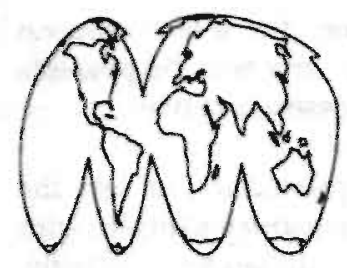

\section{CHAPTER 6. An Empirical Test of the Model $^{1}$}

In this chapter, the simplest variant of the model presented in Chapter 5, as well as some other models found in the literature on catching up, will be estimated using data on a maximum of 114 countries for the period 1960-1985. The aim of this exercise is to test whether the explanation for the dichotomy between catching up or falling behind (found in Chapter 4) can be explained in an empirical sense by the key concept introduced in the previous chapter: the intrinsic capability to assimilate knowledge spillovers.

\subsection{Testing Procedure and Data Sources}

The model developed in Chapter 5 is a dynamic model in the sense that it tries to explain a movernent of a variable over time. In the formulation, it was implicitly assumed that time is a continuous variable and that there are no time lags in the explanation of variables involved. Moreover, the notion of time was not specified very explicitly (i.e., it was not explicitly defined in months, years or days). All this was done because it proved to be 'easy' in the formulation of the model (it enables one to use simple differential equations). Now that the model is to be estimated explicitly, it is necessary to pay more attention to these issues. The movements which the model is trying to explain are not likely to reveal themselves in short periods. The model is not so refined that it can pretend to be able to explain the (productivity) growth path of an economy with all its short-run disturbances that are so well known from practice. It can only attempt to explain the long-run tendency of the growth path of the economy, i.e., whether a country will catch up to the technological frontier or rather fall behind, and how fast it will do this. Therefore, the model cannot be tested by using short-run data on productivity growth, but by using long-run trends in the underlying variables.

Additionally, the problem of time lags between variables becomes important if one attempts to estimate the model empirically. There is a lag between the 'invention' of knowledge and the moment this knowledge will be able to flow to the other country; there is a lag between 'investments' in intrinsic learning capability and the actual increase in this variable; there is a lag between the invention (or 'first spillover') of new knowledge and the diffusion of this knowledge; etc. While it would principally be desirable to develop an economic theory explaining these

\footnotetext{
'Most of the text in this chapter appeared as Verspagen (1991).
} 
lags, this is not possible in the current framework. Moreover, there is no reason to assume that the lags would be constant, or that it would in any way be possible to determine a satisfying empirical formulation of the processes involved.

Taking these problems into consideration, the following procedure to test the model will be applied. The model will be estimated in a cross-country sample, with the long-run movement of the technology (productivity) gap as the dependent variable. This implicitly means that the model is elaborated to a multi-follower - one leader context. Although time is assumed to be 'constant' in this cross-country approach, the dynamic character of the model is preserved in the sense that the movement of a variable over time is explained. This cross-country approach overcomes some of the problems involved in a time series approach mentioned above. Moreover, it closely links up to previous research in the field of catching up, as will become clear from the explicit formulation of the models to be estimated.

The following equations are used, which can be estimated for a cross-country sample using ordinary least squares (VI.1 and VI.2) or nonlinear least squares (VI.3).

$$
\begin{gathered}
G=c_{1}+a_{1} G_{0}+e_{1} \\
G=c_{2}+b P+a_{2} G_{0}+d E+e_{2} \\
G=\beta_{1}+\beta P+\alpha_{f} G_{0} e^{8 G_{0} / E}+e_{3}
\end{gathered}
$$

In these equations, $E$ is a (vector of) variable(s) influencing the intrinsic capability to assimilate knowledge spillovers, $P$ is a variable representing the exogenous rate of knowledge growth in the backward country, the subscript 0 denotes initial values, $c_{i}, a_{i}, b, d, \alpha, \beta_{1}, \delta$ are parameters to be estimated and $e_{i}$ are random disturbances with the normal characteristics. In order to avoid problems in the estimation procedure (i.e., when testing the assumption that the intrinsic capability to assimilate knowledge spillovers is infinitely large), $\delta$ now appears in the numerator of the $e$ power, instead of the denominator.

Equation (VI.1) specifies the simplest catching-up hypothesis, as been put forward and tested by among others Abramovitz (1979). It simply, and unconditionally, states that countries with a low initial level of productivity should grow faster. In terms of the analysis in the previous section, this model assumes that $\alpha, \lambda, \varepsilon=0$, and $\delta=\infty$ (assuming that $\delta$ is in the denominator). Equation (VI.2) adds two extra variables that have been proposed in Chapter $5(P, E)$, but is not specified in the nonlinear way as proposed in the model there. The extra terms are intended to measure the capability to catch up and the exogenous rate of growth of the knowledge stock. Such a linear equation (with the growth of population instead of the variable $P$ ) has been used by Baumol et al. (1989). It is applied here mainly to test whether or not the nonlinear specification of (VI.3) improves the goodness of fit.

Equation (VI.3) is the equation developed from the simplest model in Chapter 5. In fact, it assumes that $\alpha, \lambda, \varepsilon=0$ (this is done to keep the model to be estimated as simple as possible in order not to 'ask too much from the data'), but explicitly 
allows for $\delta<\infty$ (assuming it is in the denominator). The equation is aimed at taking into account the capability to assimilate knowledge spillovers in the nonlinear way as specified in Chapter 5. Its characteristics include the possibility of falling behind (path dependence) and the bifurcation described there.

On the basis of the theoretical exposure in Chapters 2 and 5 , it is to be expected that

and

$$
a_{i,} b, d, \beta_{b}, \alpha, \delta<0
$$

The constant $c_{i}$ might take on any sign.

$$
\beta_{1}>0 \text {. }
$$

Note that equation (VI.1) is nested in equations (VI.2) and (VI.3), so that specifications (VI.2) and (VI.3) can be tested against specification (VI.1) by a simple t-test with null hypothesis $b=0$ (in case of equation VI.2) or $\delta=0$ (in case of equation VI. $3, \delta$ appearing in the numerator as in the equation here).

Variables are measured as follows (for descriptive statistics and a correlation matrix, the reader is referred to Appendix VI.1). The level of the technology gap is measured in the way already applied in Chapter 4: namely by means of per capita GDP. This is an indirect way to measure what is supposed to be embodied in $T$. but it is the only measure available in a muntry samnle which is large enough to estimate the model from Chapter 5 . Thus, it is assumed that

$$
T_{i}=Q_{i}^{\text {cos }}
$$

The dependent variable is measured as the estimated (by OLS) time derivative of the gap, as in Chapter 4 above (for more details on the measurement of the motion of $G$ over time the reader is referred to that chapter). $G_{0}$ in equations (VI.1) to (VI.3) is measured as $\mathrm{G}_{1960}$.

Three different indicators for $E$ are used. The first two of these refer to education data (as a measure of the quality of the labour force), while the latter refers to the quality of the infrastructure as an indicator for the intrinsic capability to assimilate knowledge spillovers. The first indicator of education, EDUWB, is taken from the World Bank. This indicator is defined as the percentage of age group enroled in secondary education in 1965, and is the same as the one used in Baumol et al. (1989). The second indicator for education, denoted by EDUUN, is a weighted average of per capita enrolment in tertiary education over the years 1965 (weight 0.6) and 1975 (weight 0.4), using United Nations (UNESCO) data. The third indicator for the capability to assimilate knowledge spillovers is related to the quality of the infrastructure. It is defined as a weighted average (weights between brackets) of the per capita electricity-generating capacity for the years $1965(0.2), 1970$ $(0.2), 1975(0.3), 1980(0.2)$ and $1984(0.1)$. These data are taken from the United Nations, and the variable is denoted by INFRA.

The (exogenous) rate of productivity growth due to research activities in a follower country, $P$ in equation (VI.2) and (VI.3), is measured by the sum of the per capita number of patent grants in the U.S. over the period 1962-1985. This variable is denoted by PAT. The data are taken from the U.S. Patent Office. Patent data have 
also been used by Fagerberg (1988b) in an inquiry into 'why growth rates differ', but he uses the growth rate of the number of patents, and, moreover, takes his data from another source (the World Intellectual Property Organisation, WIPO). It should be noted that a patent proxy for the autonomous rate of innovation in a follower country has several disadvantages. Some of these more general disadvantages of patent data as an indicator of innovation are well known by now. In addition to this, the data applied here are external patents for all the follower countries in the sample, which means that the advantage of a comparable patent institution necessarily entails that the data used might just reflect a trend in the internationalization of an economy'.

\subsection{Results}

Using these different indicators, four different variants of equations (VI.2) and (VI.3), and one variant of equation (VI.1) are estimated. The four different variants of (VI.2) and (VI.3) relate to versions of the equations with each indicator for $E$ used separately, and one version with EDUWB and INFRA combined. The results of the estimation procedures are presented in Table VI.1, where estimations of parameters are denoted by hats above parameter names. Note also that in equation (VI.3), the estimated constant is to be interpreted as the estimation of $\beta_{1}$, while the estimations of $a_{i}$ in equations (VI.1) and (VI.2) are listed in the same column as the estimation of $\alpha$ in equation (VI:3).

Equation (VI.1) is reproduced from the analysis in Chapter 4 (although it was not explicitly documented there). Note that it was shown there that a version of this equation allowing for different parameter values for different subsamples fits the data better than the unrestricted version used here. The efforts made in the previous and current chapter must be understood as an attempt to explain these intercountry differences in a more satisfying way than just by means of exogenous parameter values.

According to the estimations in Table VI.1, the explanatory power of the equations, as measured by the (adjusted) $R^{2}$ statistic, varies from small to almost zero. The highest $R^{2}$ statistics are found in the estimation of equation (VI.3), while the two other equations have low $R^{2} s$. The majority of the estimated parameters has the expected sign and is significantly different from zero at the $5 \%$ level. However, these characteristics are not equally distributed over equations (VI.1) to (VI.3).

The estimation of $a$ in equations (VI.1) and (VI.2) takes on the wrong sign in four out of five cases, although it is only significant in two of these four cases. This points to the conclusion that the catching-up hypothesis is not valid in its most simple form in this big sample of countries. The significant and correctly signed parameters for the variable EDUWB in equations (VI.2.i) and (VI.2.iv) indicate that education is an important variable in explaining the growth pattern in this crosscountry sample, and thus seem to reject the most simple specification (VI.1). The same result has been found by Baumol et al. (1989). It should be noted, however,

\footnotetext{
${ }^{2}$ For these general drawbacks, as well as some specific problems with the data set used here, see the discussion in Chapter 8.
} 
Table VI.1 The estimation results for the three different models ${ }^{+}$

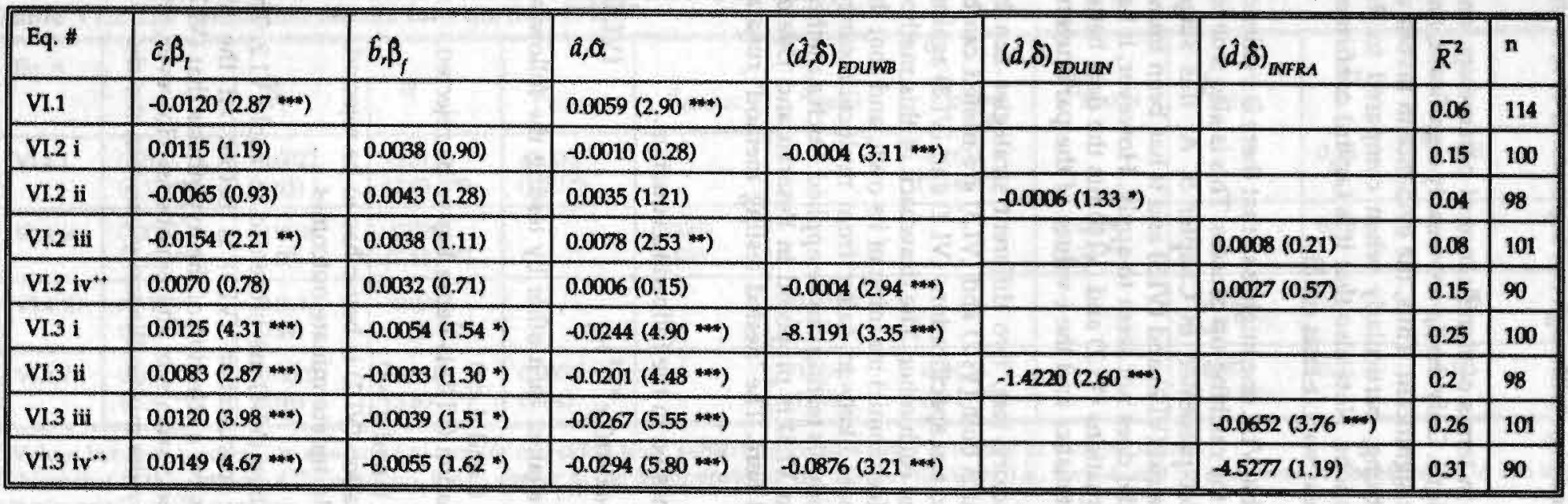

- Values between brackets are absolute $t$-values for one-sided tests, subscripts for parameters $\delta, b$ refer to variable names.

** Note that in this version of the equation, the \&s appear in the denominator of the exponential berm, i.e., they should be interpreted as being equal to $1 / 8$ in the other versions of the equation. 
that the parameter for EDUUN in equation (VI.2.ii) is not significant, which means that it does not support the 'education hypothesis'. Moreover, the only variant of equation (VI.2.ii) that gives the expected sign (although not significant) of $a$, is the variant including (only) EDUWB.

Equation (VI.3) gives the best results in terms of significance of parameters, and all the parameters have the expected signs. Only the $\beta_{s} s$ are weakly significant, and the $\delta_{\mathrm{INFRA}}$ in the variant (VI.3.iv) is not significant. Thus, the evidence in favour of the specification in (VI.3) is quite strong, particularly when compared to the evidence found for the other specifications. Note also that it is (again) confirmed that specification (VI.1) fits the data less well (t-tests on $\delta$ ).

Summarizing the conclusions from Table VI.1, one might say that there is evidence of a positive influence of education in the catching-up process. This is also true for the statistical evidence for the model presented in Chapter 5. At this stage, specification (VI.1) has been tested against (VI.2) and (VI.3) and it has been found that the most simple catching-up model does not seem to apply. However, it has not been tested as yet which of the equations (VI.2) and (VI.3) fits the data better otherwise than by looking at the $R^{2}$ statistics and the $t$-values of the parameters.

In trying to conduct a more satisfactory test, two different strategies can be followed. First, a new equation in which both (VI.2) and (VI.3) are nested can be estimated, and $t$-tests can be applied to test specifications (VI.2) and (VI.3) against this 'third' equation, and, thus, against each other. The drawback of this method is that such a 'third' equation has no (economic) meaning of its own, and that the estimation of such an equation is most likely to suffer from multicollinearity. Second, a method for non-nested hypothesis testing can be applied. Such a method for nonlinear equations (like equation VI.3) is proposed in Pesaran and Deaton (1978). Both methods will be applied here. The 'nested testing method' runs as follows.

Equations (VI.2) and (VI.3) are both nested in the following equation.

$$
G=c+\beta P_{f}+d E+\alpha G_{0} e^{8 G_{d} / E}+\varepsilon_{4}
$$

The two specifications can be tested against each other by testing the following hypotheses.

$$
\text { If } \delta=0 \text { and } d<0
$$

then the hypothesis that specification (VI.3) is better has to be rejected;

$$
\text { If } \delta<0 \text { and } d=0
$$

then the hypothesis that specification (VI.2) is better has to be rejected. Any other parameter occurrences yield indeterminate outcomes.

The results of the estimation of equation (VI.4) are presented in Table VI.2. The table provides some evidence that specification (VI.3) is better. At the $5 \%$ significance level, all the requirements for a rejection of the hypothesis that (VI.2) fits the data better are met in all the variants of the equations. However, the insignificance of $d$ might be caused by the multicollinearity between the rhs 
Table VI.2 The estimation results for equation (VI.4) ${ }^{*}$

\begin{tabular}{|c|c|c|c|c|c|c|c|c|c|c|c|}
\hline Eq. \# & $\hat{c}$ & $5=$ & $\alpha$ & $\hat{d}_{\text {EDUWB }}$ & $\hat{d}_{\text {EDUUN }}$ & $\hat{d}_{\text {INFRA }}$ & $\delta_{\text {EDUws }}$ & $\delta_{\text {toun }}$ & $\delta_{\text {DNFRA }}$ & $\bar{R}^{2}$ & n \\
\hline VI.4 I & $\begin{array}{l}0.0148 \\
\left(4.13^{~ * * *)}\right.\end{array}$ & $\begin{array}{l}-0.0022 \\
(0.53)\end{array}$ & $\begin{array}{l}-0.0176 \\
\left(2.93^{* *+}\right)\end{array}$ & $\begin{array}{l}-0.0002 \\
\left(1.50^{*}\right)\end{array}$ & & 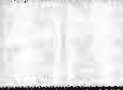 & $\begin{array}{l}-6.1611 \\
\left(2.14^{* *}\right)\end{array}$ & & & 0.26 & 100 \\
\hline VI.4 ii & $\begin{array}{l}0.0082 \\
(2.68 \text { **it) }\end{array}$ & $\begin{array}{l}-0.0034 \\
(1.00)\end{array}$ & $\begin{array}{l}-0.0204 \\
(3.44 * * 4)\end{array}$ & & $\begin{array}{l}0.0003 \\
(0.08)\end{array}$ & 98 & 7 & $\begin{array}{l}-1.4429 \\
(2.34 * *)\end{array}$ & & 0.20 & 98 \\
\hline VI.4 ìi & $\begin{array}{l}0.0138 \\
\left(4.25^{* * 1}\right)\end{array}$ & $\begin{array}{l}-0.0013 \\
(0.44)\end{array}$ & $\begin{array}{l}-0.0244 \\
(5.25 * 4)\end{array}$ & 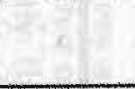 & & $\begin{array}{r}-0.0048 \\
\left(1.59^{*}\right)\end{array}$ & 63 & 73 & $\begin{array}{l}0.0529 \\
(3.42-\cdots)\end{array}$ & 0.27 & 101 \\
\hline Vl.4 iv & $\begin{array}{l}0.0187 \\
\left(4.30^{* * *}\right)\end{array}$ & $\begin{array}{l}-0.0002 \\
(0.05)\end{array}$ & $\begin{array}{l}-0.0188 \\
(3.50\end{array}$ & $\begin{array}{l}0.0002 \\
(1.04)\end{array}$ & & $\begin{array}{l}-0.0049 \\
(1.06)\end{array}$ & $\begin{array}{l}-0.2423 \\
(2.41-)\end{array}$ & 3 & $\begin{array}{l}5.0357 \\
(3.57 * *)\end{array}$ & 0.31 & 90 \\
\hline
\end{tabular}

* Values between brackets are absolute $t$-values for one-sided tests, subscripts for parameter $\delta, b$ refer to variable names.

** Note that in this version of the equation, the $\delta$ s appear in the denominator of the exponential term, i.e., they should be interpreted as being equal to $1 / 8$ in the other versions of the equation.

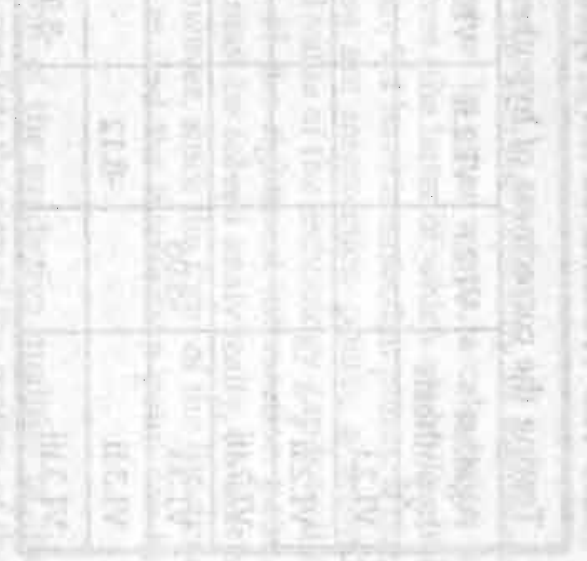


variables. At the $10 \%$ significance level, neither hypothesis can be rejected. The results in Table VI.2 thus point towards the conclusion that equation (VI.3) is the 'better' one, although the evidence is not altogether conclusive.

The second method makes use of techniques for nonnested hypothesis testing. In order to test two alternative models against each other, one can (in turn) maintain the hypothesis that one of these two models is correct. On the basis of this hypothesis a test statistic $N$ (the 'Cox'-statistic), which is (asymptotically) distributed as $N(0,1)$, can be calculated by a procedure which involves estimating four equations: the two models themselves, plus one more nonlinear regression and one more linear regression (see Pesaran and Deaton 1978 for more backgrounds on this method). Since the method to calculate the statistic makes use of maximum likelihood estimates of the variance of the regression, the best way to proceed is to estimate the equations by the maximum likelihood method. Appendix VI.2 describes the precise method that has been applied to estimate the statistic for these one-equation models. Table VI.3 gives the value of the statistic itself, for the variants (i), (ii) and (iii) of equations (VI.2) and (VI.3). Variant (iv), which yielded a less significant estimate in both cases, is no longer considered.

Table VI.3 A nonnested test of specifications (VI.2) and (VI.3) against each other

\begin{tabular}{|l|l|l|l|l|l|l||}
\hline \multicolumn{7}{||l}{ Testing the correctness of hypothesis } \\
\hline $\begin{array}{l}\text { Against } \\
\text { hypothesis }\end{array}$ & VI.2.i & VI.2.ii & VI.2.iii & VI.3.i & VI.3.ii & VI.3.iii \\
\hline VI.2.i & & & & -1.67 & & \\
\hline VI.2.ii & & & & & -0.20 & \\
\hline VI.2.iii & & & & & & -0.07 \\
\hline VI.3.i & -5.05 & & & & & \\
\hline VI.3.ii & & -8.12 & & & & \\
\hline VI.3.iii & & & -8.93 & & & \\
\hline
\end{tabular}

The evidence in Table VI.3 is quite strong, although again not altogether conclusive. For all three variants of equation (VI.2), the hypothesis that this model fits the data better than (VI.3) clearly has to be rejected, since the values of the statistics (the lower left corner of the table) are clearly significantly different from zero. The hypothesis that variant (i) of equation (VI.3) is the correct one has to be rejected (in a two-tailed test) only at the $10 \%$ level $^{3}$, so that this evidence is less strong. In the tests of variants (ii) and (iii) of equation (VI.3), the hypothesis that these equations fit the data less well than the corresponding variants of (VI.2) cannot be rejected. Summarizing the information in Table VI.3, it seems that there

\footnotetext{
The situation that in case of variant $i$ (at the 10\% level) both equation (VI.2) and (VI.3) have to be rejected might seem paradoxical, but is a quite 'normal' outcome of the testing procedure applied here. See Pesaran and Deaton (1978: 678-9) for a discussion of this feature of the procedure.
} 
is quite strong evidence in favour of specification (VI.3).

\subsection{Interpreting the Results}

The estimation results obtained in the previous section can be used to elaborate upon the dichotomy between catching up and falling behind. To do so, the estimated parameters and the variables will be used to calculate the exact form of the function for the motion of the technology gap for each country. Using this function, one can calculate the critical value (bifurcation value) of the intrinsic capability to assimilate knowledge spillovers. In the simple form of the model used in this chapter, this value is found at the point where the maximum of the $S$-curve (from Chapter 5) is equal to the level of the exogenous growth rate of the knowledge gap.

The function that will be used to make these calculations is the following.

$$
G_{i}=0.0149-0.0055 P_{i}-0.0294 G_{i 0^{2}} e^{C_{i} /\left(-0.0056 E D U W R_{i}-4.527 I N F R A\right)}
$$

This is the estimated form of equation (VI.3.iv), which gave the highest degree of explanatory power in the regressions in Table VI.1.

For each country, it is first tested whether the intrinsic capability to assimilate knowledge spillovers exceeds the critical value. In other words, a calculation is made to see whether or not the $S$ - and $L$-curves (the latter of which are horizontal in the simple version applied here) as in Figure V.1 have intersection points. If not, the country will be falling behind. If there are intersection points, a second calculation is made to see whether the initial value of the technology gap is to the right (falling behind) or left (catching up) of the rightmost intersection point. Unlike the previous calculation, this one cannot be solved analytically, so that a numerical solution must be searched for. However, since the form of the function to be solved is well-known, the procedure to find the intersection point can be carried out easily 4 .

This procedure also gives a good impression of the predictive qualities of the model. Looking at whether or not the model predicts the sign of the motion of the technology gap correctly (i.e., whether the country is catching up or falling behind), the prediction of this sign is correct in $72 \%$ of the cases.

Using the results of the calculations, the countries in the sample can be divided into three different groups. The first group consists of countries which are falling behind because their intrinsic capability to assimilate knowledge spillovers is so small that there is no intersection point between the $S$ - and $L$-curves. The second group is composed of countries for which equilibrium values of the technology exist, but which have an initial gap that is so big that they are falling behind. The third group includes the catching-up countries, for which equilibrium values of the

\footnotetext{
t One knows that the intersection point must lie to the right of the maximum of the S-curve. Thus, an iterative procedure starting at the maximum, and moving slowly to the right will at some point arrive at the solution (or very near to it).
} 
technology gap exist by definition.

Table VI.4. Catching up or falling behind according to the equation estimated Group 1. Falling behind without possibility to catch up

Algeria, Benin, Cameroon, Central African Republic, Chad, Peoples Republic of Congo, Ethiopia, Gabon, Ivory Coast, Kenya, Liberia, Madagascar, Malawi, Mali, Mauritania, Morocco, Mozambique, Niger, Nigeria, Rwanda, Senegal, Sudan, Tanzania, Togo, Uganda, Zaire, Bangladesh, Nepal, Pakistan, Guatemala, Haiti, Honduras, Papua New Guinea

Group 2. Falling behind with possibility to catch up

Ghana, Burma, Thailand

\section{Group 3. Catching up}

Egypt, Jamaica, Mexico, Nicaragua, Panama, Trinidad \& Tobago, Argentina, Bolivia, Brazil, Chile, Colombia, Ecuador, Paraguay, Peru, Uruguay, Venezuela, Australia, New Zealand, Mauritius, South Africa, Tunesia, Zambia, Hong Kong, India, Iran, Israel, Japan, South Korea, Malaysia, Philippines, Saudi Arabia, Singapore, Sri Lanka, Syrian Arab Republic, Austria, Belgıum, Lenmark, Finland, France, Greece, Ireland, Italy, Netherlands, Norway, Portugal, Spain, Sweden, Switzerland, Turkey, United Kingdom, Canada, Costa Rica, Dominican Republic, El Salvador

Table VI.4 gives an overview of the sample in these terms. One exceptional case is Switzerland, which has a value for $P$ which makes the $L$-curve lie below the horizontal G-axis in terms of Figure VI.1. This means that Switzerland is catching up, even though there are no formal intersection points between the two curves. Following the strict logic behind the formal definition of the model, one could say that Switzerland should be labelled as the technological leader because of these characteristics. Although Switzerland certainly is among the most advanced nations from a technological perspective, this is not done here. Instead, the Swiss case is seen as a peculiarity of the data and model.

The main feature that can be derived from the table is that the most powerful distinction between catching up or falling behind emerges from the possibility of no equilibrium points of the gap at all. With the exception of three, all fallingbehind countries have values of the intrinsic capability to assimilate knowledge spillovers that are too small to even yield the possibility to catch up. Another, more positive, way of saying the same thing is that almost all countries that have the possibility to catch up have succeeded in doing so. In terms of numbers, the largest part (60\%) of the sample is on the positive side of the catching-up / fallingbehind dichotomy. However, as much as $37 \%$ of the countries completely lacks the 
possibility to catch up. Individual countries seem to be ranked mostly in the intuitively correct categories (as already indicated by the $72 \%$ correct prediction of signs). A model taking into account more and better indicators of the intrinsic capability to assimilate knowledge spillovers would probably help explaining the few cases which seem to be placed wrongly, such as India. Almost all African countries are in Group 1, indicating the seriousness of the situation on that continent.

It is also worth noting that most of the oll-producing countries are classified in Group 3. This is somewhat surprising, because oil is not considered as a factor of development in the model nor the estimations. A possible explanation for this might be that even if these countries would not have had the richness of oil resources, they would have been catching up because of their high education level and infrastructure quality. However, it is also likely that part of the oil profits were used to increase efforts in these fields, so that causality is reverse. Probably, both explanations are relevant, with the mix of the two being specific to each country.

\subsection{Summary and Some Policy Conclusions}

In an econometric estimation for a cross-country sample of 114 countries, it was shown that the model proposed in Chapter 5 fits the data well, yielding (mostly highly significant) parameters with the expected sign. In the statistical procedure, it was shown that education is indeed an important factor in the catching-up process, which has also been shown by other research. The specific nonlinear model proposed in Chapter 5, with its features summarized there, is shown to fit the data better than linear models involving the same variables. This result is established by considering the common 'goodness of fit statistics, a procedure using nested equations to test different functional specifications against each other, and a procedure for testing (nonlinear) nonnested regression models.

These results point to the value of the arguments about the capability to catch up, which were put into the model in Chapter 5 . Thus, contrary to what the catchingup hypothesis assumes, being a following country does not automatically imply that catching up takes place. While technological change in the leading country is a factor spurring growth in the following country in the simple catching-up model, the results here show that in the real world, technological change is a mixed blessing. Only a limited number of countries are able to meet the requirements for being a successful catching-up country. Therefore, the model in Chapter 5 is shown to have empirical relevance for explaining stylized facts 4 and 5 in Chapter 4. In terms of the goals set out, attention can therefore be switched to the other stylized facts. Prior to this, however, the policy implications of the results in this chapter will briefly be discussed.

Although the development consequences of the model outlined in the previous chapter are very simple, there is an important lesson to be learned from the results. In order to change the economic relations in the world in a structural way, 
joint ${ }^{5}$ efforts from leading and backward countries ${ }^{6}$ should be directed towards increasing the elements of an imitation infrastructure. Education of the labour force in the poorest countries, often at the primary and secondary levels, investment in basic infrastructural projects like roads, airports and power supply are necessary to turn the falling-behind countries into catching-up countries.

In terms of the model, the governments of the falling behind countries should take the initiative in raising the intrinsic capability to assimilate knowledge spillovers. However, this often proves to be an unrealistic option. Governments in the third world usually do not have the funds to increase spending in the mentioned areas up to the degree necessary. And even if funds are available, the political priorities are often directed elsewhere. The World Development Report 1991 made a plea for reducing military spending, especially in the third world. Using funds which are now spent on weapons and war for increasing the quality of the knowledge spillover structure is an ideal that is in line with much of the sentiments found in Western aid projects. However, from an economic point of view, it would be desirable if international organizations like the IMF and the World Bank, as well as developed world governments would turn this economic logic into strong requirements accompanying investments in the third world aimed at increasing the education level, the infrastructure, etc., and make it as important in their recommendations as stabilization policies, public end external debt reduction, and financial stability?.

\footnotetext{
s It remains an open question whether it is in the North's interest to make these joint efforts. The setting of economic selection seems to suggest that it is not. However, there have been interpretations of evolution which stress cooperation and mutual aid (Kropotkin 1902, for a longer discussion in an economic context see Foster 1987 ).

-Although this phrase has become a cliche in 1992, the policy recommendations are also valid for the former centrally planned economies.

'A more detalled model than the one developed here could stress the interactions between these 'common' points of attention and the capability to assimilate knowledge spillovers.
} 
Table VI.A1. Correlation matrix of the variables used in section 4
G
$\mathrm{c}_{0}$
PAT
EDUWB
EDUUN

INFRA
G 1
$\begin{array}{lll}\mathrm{G}_{0} & 0.25 & 1\end{array}$
$\begin{array}{lll}\text { PAT } & -0.07 & -0.51\end{array}$
1
-0.51
-0.78
1
EDUWB $\quad-0.37$
$-0.78$
0.45
0.39
1
EDUUN $\quad-0.29$
$-0.69$
0.61
0.81
0.70
1
$0.62 \quad 1$

Table VI.A2. Descriptive statistics of the variables used in section 4

\section{MEAN STD DEV VARIANCE}

$\begin{array}{lrrr}G & -0.0025 & 0.0188 & 0.0004 \\ G_{0} & 1.7309 & 0.8931 & 0.7976 \\ \text { PAT } & 0.1963 & 0.5650 & 0.3192 \\ \text { EDUWB } & 25.5926 & 22.6262 & 511.9444 \\ \text { EDUUN } & 5.9552 & 5.8223 & 33.8996 \\ \text { INFRA } & 0.4202 & 0.6942 & 0.4819\end{array}$

\section{Appendix VI.2. The Calculation of the $\mathrm{N}$-statistic}

In this appendix, the procedure that was used to estimate the $N$-statistic (or 'Cox'statistic) will be explained. As has been noted above, this procedure is taken from Pesaran and Deaton (1978). For the derivation of the formulas used in this paper, and for the application of the procedure to a multi-equation model, the reader is referred to this original source.

The $N$-statistic applies in the case where two alternative (nonlinear and) nonnested equations, denoted by $f$ and $g$ are tested against each other.

$$
\begin{aligned}
& H_{0}: y=f\left(\beta_{0} x\right) \\
& H_{1}: y=g\left(\beta_{1} x\right)
\end{aligned}
$$

In this formulation, $y$ is the dependent variable, $x$ is a vector of independent variables, and $\beta_{i}$ are vectors of parameters to be estimated. Throughout, hats above variables will, as usual, denote estimations.

Here, the calculation of $N$ will be carried out for the maintained hypothesis that 
model $H_{0}$ is the correct one. The first step is then to estimate the two models (using the maximum likelihood method), and calculate the asymptotic (i.e., maximum likelihood) variance of the two regressions, denoted by $\sigma_{0}^{2}$ and $\sigma_{1}^{2}$, respectively. Step two is to calculate the predicted values of the estimated equation $H_{0}$, which is denoted by $f\left(\beta_{0}\right)$, and use these as the dependent variable in a regression estimation $H_{i}$. Then define

$$
\theta_{10}^{2}=\theta_{0}^{2}+\theta^{2}
$$

where $\sigma^{2}$ is the estimated variance of the regression $g$, using the predicted values of $f$ as dependent variables.

Now define

$$
T_{0}=\frac{n}{2} \ln \left(\frac{\sigma_{1}^{2}}{\sigma_{10}^{2}}\right)
$$

Now proceed estimating the variance of $T_{0}$, denoted by $\hat{\nabla}_{\theta}\left(T_{0}\right)$, as follows. Define the following function.

$$
\hat{F}=\frac{\partial f}{\partial \beta_{0}}
$$

Then run a regression of $\hat{F}_{\beta_{e}-\beta_{8}}$ on the residuals from the regression $g$ on the predicted values of $f$, and denote the residual sum of squares of this regression by $e^{2}$. Then calculate

$$
V_{0}\left(T_{0}\right)=\frac{\sigma_{0}^{2}}{\sigma_{10}^{4}} e^{2}
$$

Finally, define

$$
N_{0}=\frac{T_{0}}{\sqrt{\hat{V}_{0}\left(T_{0}\right)}} .
$$




\section{PART THREE}

\section{Technological Change, International Trade and Growth Rate Differentials}




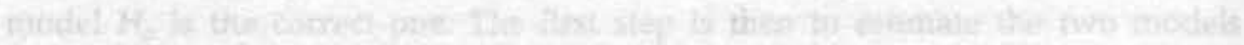

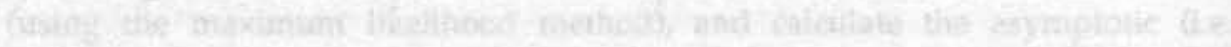

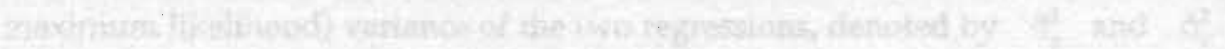

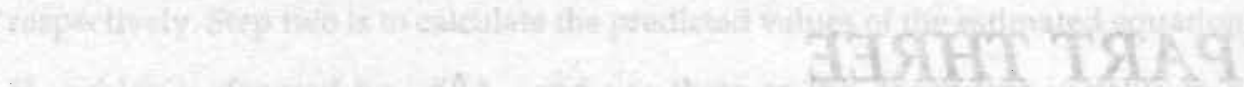

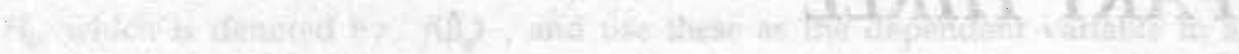

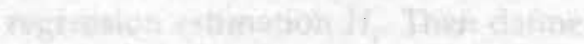

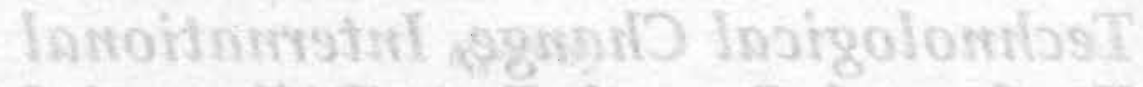

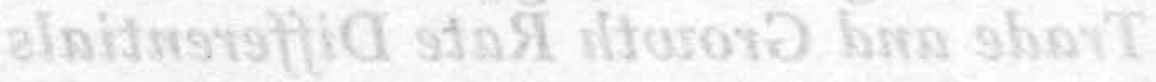

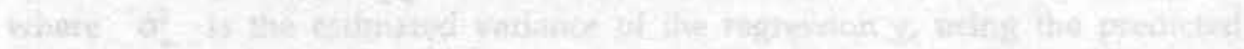

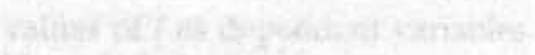

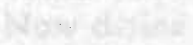

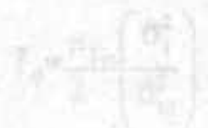

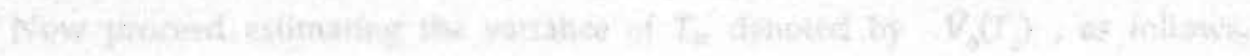

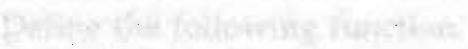

$$
\begin{aligned}
& x+y \\
& x+5
\end{aligned}
$$

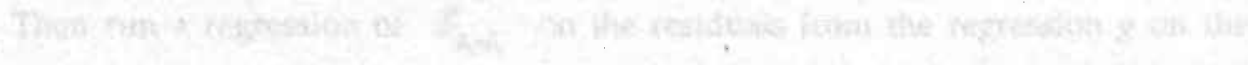

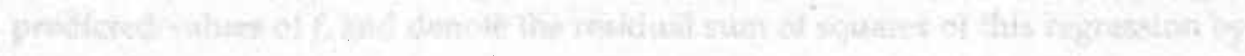

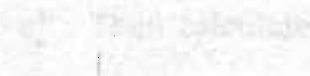

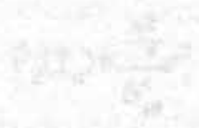

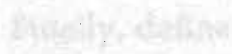

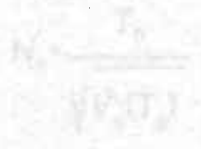




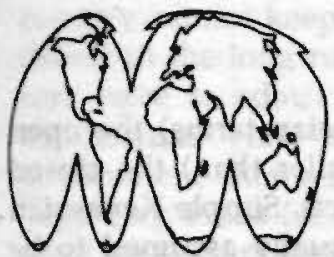

\section{CHAPTER 7. An Evolutionary Model of Technological Change, Specialization and Economic Growth'}

Part Two has explained the stylized fact of differential growth rates by searching in depth for an explanation for the dichotomy between catching up and falling behind at the global level (stylized facts 4 and 5 in Chapter 4). However, due to the aggregate nature of the analysis, the stylized facts describing the role of technological change at the sectoral level (2), and the role of the production structure (3) have not yet been treated. The model to be developed in this chapter aims at providing an explanation for growth rate differentials (stylized fact 1) from the point of view of sectoral differences in technological change and economic importance, and their relation to trade and growth. Thus, the model deals with specialization patterns and their influence on growth. A recent model concerned with the same issues and basically set up along the same (Keynesian) lines, but with a less explicit evolutionary character is in Cimoli (1990).

The model that will be presented in this chapter, can be viewed as an elaboration on the model in Chapter 5. Although the innovation part of the model no longer contains knowledge spillovers ${ }^{2}$, the specification of technological change in the form of intertemporal learning is richer than before, among other things allowing for differentials rates across countries and sectors (stylized facts!). The economic structure is also much richer than before, allowing for a more adequate representation of international trade, as well as the sectoral mix of production and consumption.

Consequently, the model primarily looks at economic links between countries, rather than technological interdependencies in the form of knowledge spillovers. In Part Two, these economic links were modelled only in a preliminary way. The aim of the current chapter is to specify a more satisfactory model. To do so, the relation between growth and technology will be linked by the concept of competitiveness. Setting up the specific evolutionary way of modelling proposed in Chapter 3, the equations will explain fluctuations in employment, production growth and productivity in an international context. The analysis will, however, be limited to the real (i.e., nonmonetary) sector of the economy.

${ }^{3}$ This chapter draws largely on Verspagen (1992b).

\footnotetext{
${ }^{2}$ Including knowledge spillovers between countries and an exogenous research sector, like in Chapter 5, does not change the conclusions drawn below. This is shown in Verspagen (1992c).
} 


\subsection{A Descriptive Interpretation a. Trade and Growth}

Simple national accounting identities show that (in Keynesian terms) the open economy income multiplier is different from (in fact, smaller than) the closed economy income multiplier, because of import leakage effects. Simple Keynesian (open economy) models also show that larger exports (usually assumed to be exogenous in the textbooks) increase national income. Realising that both export and import performance are dynamic, endogenous variables, this simple logic suffices to show that international trade is an important determinant of growth patterns, which is also the outcome of the open new neodassical growth models discussed in Chapter $2^{3}$.

An important question that arises in this respect is how the openness of the economy will affect countries: Will it be beneficial or harmful to them? Standard (neoclassical) trade theory argues that all countries benefit from trade (the wellknown Heckscher-Ohlin framework). However, interpreting the relation between trade and growth using the income accounting identity known from (Keynesian) macroeconomics, the 'Pareto efficient' trade effect is no longer obvious.

Using the above framework for assessing the relation between trade and growth basically gives two effects which play a role in the long run. First, the volume of exports has a positive effect on national income (growth), as in the model in Chapter 5. Second, there is the effect of import penetration. An increased import penetration has a negative effect on domestic income, through a smaller value of the multiplier. Combined, these two effects lead to the well-known prisoners' dilemma: While it is beneficial to all individual countries to increase their exports and discourage imports, the sum of these individual behaviour patterns leads to a clearly inefficient aggregate outcome. The 'logic' behind 'early' (i.e., original) mercantilism can be interpreted as playing this prisoners' dilemma game in an unrepeated context, yielding the least efficient outcome ${ }^{4}$. In purely mercantilistic terms, a country which cannot increase its exports to the extent of offsetting the effect of an increasing import penetration, is worse off in the long run. On the other hand, a country whose increased exports outweigh the increasing import penetration (or even better, add to the effect of decreasing import penetration) is better off in the long run. In terms of the trade balance, a surplus is a facilitator for economic growth, while a deficit is a brake.

This extreme mercantilistic point of view will not be defended here. Instead, the above (which was, basically, nothing else than accounting) will be applied in the so-called balance of payments approach to economic growth (Thirlwall 1979, Fagerberg 1988a), thus modifying the purely mercantilistic point of view. A

${ }^{3}$ However, in these models, the effect of trade is mainly through the reallocation of resources, and the resulting effect on relative prices. In the (Keynesian) model proposed here, the effect of trade mainly works through the level of macnoeconomic activity.

' See Axelrod (1984) for more details about prisoners' dilemma games in repeated and unrepeated contexts. 
country cannot keep on drawing on its international reserves to finance a trade deficit in the long run. Therefore, countries with a trade deficit will, in the long run, have to adjust to a rate of income growth consistent with trade balance equilibrium. How this adjustment comes about (by market mechanisms or government intervention) is not the primary concern here (see for exarnple Fagerberg $1988 \mathrm{a}$ for a discussion of this topic). The opposite (the case of a trade surplus) also applies. In the absence of capital flows, it does not make sense in the long run to spur export growth without increasing imports: this would only lead to accumulation of foreign currency reserves (or, in the setting of the mercantilist age, precious metals). Since no direct utility can be derived from these reserves, society's welfare is not increased by the constantly improving export position. Direct utility can be derived from consumption, and it therefore 'makes sense' to keep the demand for consumption in pace with the increasing export performance. Moreover, even if the countries with trade surpluses wanted to maintain this, they would not be able to do this because the countries in deficit would have to adjust to equilibrium in the long run.

\section{b. Trade and Technology}

To find out whether or not it is possible for all countries in the world to benefit from trade, it has to be investigated what determines the import and export performance of a country. This is where the attention switches to a second point, namely the relation between trade patterns and technological capabilities. The standard view on trade is that it is determined by comparative advantages, which can arise because of differences in factor endowments. In light of the discussion in Chapter 3, this approach can be seen as typically static. Following the argument from Chapter 3, a different view will be taken here: The process of international trade will essentially be treated as a dynamic process of competition.

Leaving out the characteristics of a good (such as the price and the quality) for a moment, the only difference between foreign and domestic producers is their location. It is natural to assume that a consumer is indifferent to the location of production of the product (abstracting from possible nationalistic feelings which have led to such campaigns as "Buy British", or international politically oriented boycotts such as recently against South Africa, Iraq, Libya or what is still left of Yugoslavia). Thus, if a good coming from a foreign supplier is cheaper or has a better quality (even after transportation), the consumer is likely to buy this good instead of the domestically supplied good. In other words, the import and export performance of an industry in a country is determined by the average competitive strength (or competitiveness) of the industry relative to the foreign producers. Then, it is easy to understand that the relation between trade and technological capabilities lies in the influence of technology on competitiveness. Making a distinction between price and product competition, one can say that process innovation is a main determinant of productivity and, therefore, of price competitiveness, while product innovation is a main determinant of quality competitiveness. The remainder of this chapter will only be concerned with price competitiveness, but this is only done for reasons of simplicity.

One major aspect of price competitiveness are factor costs. In the current model, 
these will be taken into account by introducing wage rate dynamics. This opens up the possibility that countries lagging behind in a technological sense are still being competitive because of their lower wage rate. The empirical relevance of this is obvious, and will be investigated in the context of the model in Chapter 8.

\section{c. The International Location of Innovation}

As argued in Chapter 3, there are important differences in technological capabilities between individual firms. At a higher level of aggregation, these differences are also present between countries (see for example Pavitt and Soete 1982). They consist of both aggregate differences (country A has a higher technological level than country B) and sectoral differences (sector $i$ in country A is relatively stronger than sector ii in country A). Following the above arguments, this means that different countries have different abilities to compete in different sectors, i.e., in different markets. In a dynamic context, one wonders whether these differences in competitiveness will vanish over time, or whether they are persistent, or maybe even self-reinforcing.

Part Two has already identified learning in the form of technology spillovers as a factor that may reduce technological differences over time. The spillover effect leads to a negative feedback (a low level of technological change leads to good performance). The model in Chapter 5 also had a positive technological feedback effect in the form of the Verdoorn learning process. The model in this chapter will stress the cumulativeness of the innovation process, and pay exclusive attention to the positive technological feedback effect. However, it will also contain a negative feedback effect in the form of wage rate dynamics, and a feedback effect with an unspecified a fixed sign in the form of income elasticities.

\section{d. Specialization Pattems and Economic Growth}

It has been argued that a main factor explaining a country's growth pattern is its trade performance, and, later, that the main determinant of a country's sectoral trade performance is its competitiveness. In turn, competitiveness is determined to a large extent by technological factors. So far, it has not been discussed in what way sectoral growth patterns (and trade patterns) translate into the aggregate growth path of the economy. The aggregate growth rate is just a weighted average of the sectoral growth rates, with shares in domestic production used as weights. The extent to which sectoral competitive advantages translate into aggregate production growth is therefore (in the short run) determined by the (fixed) share of the sector in total production.

The sectoral distribution of production at the global level will be determined by the sectoral distribution of consumption patterns. Due to specialization, however, consumption and production patterns may differ at the national level. Thus, the domestic consumption pattern (for the 'nonspecialized' part of production) and the foreign consumption pattern (for the 'specialized' part of production) will be decisive factors for the determination of the growth potential of an economy. As argued in Chapter 3 and Pasinetti (1981), income elasticities determine the sectoral mix of consumption. From the perspective of an exporting sector, the potential 
demand for its product consists of the consumption of the sector's product in all other countries. As explained above, the extent to which this potential demand can be reached depends upon competitiveness. The size of the potential demand, however, depends upon income elasticities of consumption. Therefore, the (sectoral) opportunities for export (and growth) also depend on these income elasticities. This means that a competitive advantage in some sector can only generate an important effect upon aggregate economic growth if the demand potential in the international markets for the product of this sector is high, and if the share of this sector in domestic production is substantial. The same argument holds true for importing sectors. This conclusion has been reached in various types of literature, such as evolutionary inspired treatments of trade and technology (Dosi et al. 1990), as well as the literature on strategic trade (Krugman 1990).

\subsection{The Model}

\section{a. The Selection Environment}

The first step in setting up the evolutionary model is to specify the selection environment. Starting point of the analysis is Thirlwall's (1979) formulation of the balance of payments restriction to economic growth. In a single good context, with $R$ denoting real income, one can write the following.

$$
R^{*}=\frac{\alpha}{\beta} z \text {. }
$$

In this equation, $\alpha$ denotes the elasticity of the country's exports with regard to world exports, and $\beta$ is the country's elasticity of imports with regard to national income. Assuming that, initially, the balance of payments of a country is in equilibrium, $R^{*}$ is the balance of payments restricted real income. The ratio of the elasticities of exports and imports determines whether the country's growth rate is above, below or equal to the growth rate of world income.

After having described this framework, Fagerberg (1988a: 358) concludes that "(...) it is not clear what meaning should be attached to the income elasticities of demand in" equation (VII.1). Furthermore, he says that non-price factors might be a factor explaining international differences in these elasticities. This suggestion is the basis for his further analysis: "However (...), it would be preferable to include these factors in the equations for exports and imports instead of relying on estimated proxies (which may be subject to different interpretation)" (p. 359).

Fagerberg's viewpoint that the use of income elasticities as in equation (VII.1) is not very enlightening is well taken here. However, a different way of specifying an alternative for equation (VII.1) is chosen. A different specification based on an evolutionary description of the world economy will be adopted. Define import penetration $(z)$ in sector $j$ in country $i$ by

$$
z_{i j}=\frac{M_{i j}}{C_{i j}} \text {. }
$$

$C_{i j}$ is the volume of the domestic market for the product of sector $j$, or domestic consumption (all goods are consumption goods) of sector $j$ goods, and $M$ denotes real imports. Assuming for the moment that $C$ and $z$ are fixed, the import demand 
for sector $j$ 's goods is determined by this equation. Using this equation for the 'rest of the world' (denoted by $w$ ) and taking into consideration that imports into the rest of the world are equal to country $i$ 's exports, one can write

$$
X_{i j}=C_{v o j} z_{v o j^{+}}
$$

The evolutionary content of the model is primarily achieved by specifying the motion of $z$ in discrete time using the evolutionary selection equation introduced as equations (III.1) - (III.2) in Chapter 3. These two equations are slightly modified in order to make them more suitable for the model here. First, average competitiveness is calculated by using previous period market shares $(z)$, which is necessary to let market shares count to one in each period. Second, percentage deviations from competitiveness are used on the rhs of the equation, in order to rule out influences of scale in the measurement of $E$. Appendix VII.2 gives more detailed mathematical information on the selection equation.

$$
\begin{gathered}
z_{i j i}=z_{i j l-1}+z_{i j-1} \phi_{i j}\left(E_{w i j} / \bar{E}_{i j t}-1\right) \\
\bar{E}_{i j t}=E_{i j t}\left(1-z_{i j l-1}\right)+z_{i j-1} E_{w j i}
\end{gathered}
$$

Thus, each country's $z$ is determined by an evolutionary market selection process with two groups of producers (domestic and foreign) $)^{5}$ competing with each other. Consumers tend to buy more of the product when competitiveness is higher. Each one of the producer groups gains or loses market share, depending on whether its competitiveness is above or below average market level. This constitutes the dynamic, evolutionary approach to trade discussed above.

As discussed already in Chapter 3, a crucial feature of equation (VII.4) is the definition of $E$. As a first approximation, assume that price competition is the only important mode of competition in international markets. With $P$ denoting price and $e$ denoting the exchange rate $(1$ unit of foreign currency $=e$ units of domestic currency), it can be written that ${ }^{6}$

$$
E_{i}=\frac{1}{e_{i} P_{i}}, \quad 0<\phi<1 .
$$

Note that it does not matter in what currency prices are expressed, since multiplying all prices with one exchange rate does not affect the part between brackets on the rhs of (VII.4). Note also that the restriction that $\phi$ is positive and smaller than unity rules out the theoretically impossible outcome that $z$ becomes negative (see Appendix VII.2).

\footnotetext{
${ }^{5}$ Note that for a model with $n>2$ countries, one would have $n-1 z$ s: one for each group of foreign producers (i.e., a country). This is indeed the approach used in the simulation experiments below. Note also that one could principally write out the equation for $p$ producers, of which $q(<p)$ are foreign, and arrive at the above equation for country aggregates by simply aggregating the equations, which indicates the intuitive way in which aggregates can be interpreted in the selection equation logic.
}

- From now on, superscripts are omitted in cases where period $t$ is referred to (obviously). 
In order to be able to write an expression for the balance of payments restricted growth rate, a number of national accounts identities have to be formulated. First, real consumption $C_{i j}$ can be identified by introducing the variable $S_{i j}$ which denotes the consumption share of good $j$ in domestic real income $R_{i}$.

$$
C_{i j}=R S_{i j}
$$

(VII.7)

Second, real income can be defined as being equal to nominal income divided by the price level that is relevant to the consumer, $P^{c}$.

$$
R_{i}=\frac{\sum_{i} Q_{i} P_{i}}{P_{i}^{i}}
$$

Third, the sectoral and overall consumer price levels are weighted averages of the different producer prices, with market shares and consumption shares as weights.

$$
\begin{gathered}
P_{i j}^{\varepsilon}=\left(1-z_{i j}\right) P_{i j}+z_{i j} P_{w i}{ }^{i} \\
P_{i}=\sum_{i} S_{i j} P_{i j}
\end{gathered}
$$

Fourth, it is assumed that production is equal to demand (domestic plus foreign), so that, using (VIL.2), one obtains

$$
Q_{i j}=\left(1-z_{i j}\right) C_{i j}+X_{i f}
$$

Now assume that domestic absorption is equal to domestic income, or that the $S_{i f} s$ sum to one in each country $i$. Then it follows from (VII.7) - (VII.11) that the current account is in equilibrium. This can be written as follows.

$$
\sum_{i} e_{i n w} P_{w i j} M_{i j}=\sum_{j} P_{i j} X_{i j}
$$

Substituting (VII.7) - (VII.11) into equation (VII.12), (logarithmically) differentiating and re-arranging terms, one arrives at the following equation for the difference between the balance of payments warranted growth rate for country $i$ 's real income and the rest of the world's real income growth rate.

$$
\hat{R}_{w}-\hat{R}_{i}=\left(\sum_{i} P_{w i} \frac{m_{i j}}{m_{i}}-\sum_{j} P_{i j} \frac{x_{i j}}{x_{i}}\right)+\left(\sum_{i} \hat{z}_{i i} \frac{m_{i j}}{m_{i}}-\sum_{j} \hat{z}_{w i} \frac{x_{i j}}{x_{i}}\right)+\left(\sum_{i} S_{i i} \frac{m_{i j}}{m_{i}}-\sum_{j} S_{w i j} \frac{x_{i j}}{x_{i}}\right) \text { (VII.13) }
$$

With initial condition $\sum_{j} P_{i j}^{0} X_{i j}^{0}=\sum_{j} e_{w j}^{0} P_{w j}^{0} M_{i j}^{0}$.

In this equation, $m$ and $x$ denote nominal imports and exports, respectively. This equation is the multi-sector counterpart of equation (VII.1). At the expense of simplicity, equation (VII.13) explains the elasticities $\alpha$ and $\beta$ in equation (VII.1) in terms of the factors on the rhs of (VII.13).

The first term between brackets reflects the direct effect of a change in the terms of trade over time. If world prices increase at a faster rate than domestic prices, the country can import less given the revenue of its exports. The growth rate consistent with this smaller value of imports will be smaller than the rest of the world's growth rate. This explains the (positive) sign of this term. The second term 
between brackets reflects the effect of a change in import penetration in country $i$ and the rest of the world. It reflects the effects of changes in sectoral trade positions. A lower import penetration in the country, and a higher import penetration in the rest of the world (i.e., a better export performance of country $i$ ) lead to a higher growth rate in $i$. Note that, via equations (VII.4) - (VII.6), this effect is closely linked, and indeed opposite, to the first effect. The third and last term between brackets is associated with changes in the consumption pattern over time. A positive sign of this term means that consumption patterns in country $i$ and the rest of the world have shifted in such a way that the pattern in the rest of the world is now closer to the strong points in the export position of $i$, while the patterns in $i$ itself have changed such that they are further away from the strong points of the export position of the rest of the world.

Exchange rate movements also add to the terms of trade effect. This is reflected by the presence of the growth rate of $e_{i w}$ on the rhs. A devaluation of the domestic currency (a positive growth rate of $e_{k w}$ ) thus increases the growth rate differential relative to the rest of the world, because it has a negative influence on the terms of trade. But this is not the only effect of a devaluation. Ceteris paribus, a devaluation will also have an effect upon competitiveness, and therefore on the growth rates of $z_{i j}$ and $z_{w i}$. Thus, there is also an effect upon the second term between brackets on the rhs of the equation for the growth rate differential. This effect can be called the competitiveness aspect of a devaluation. This effect cannot easily be quantified in an exact way. However, the following preliminary remarks apply. First, it can be easily seen and understood that the terms with $e_{i w}$ in them (either directly or indirectly), bear great similarity to the well-known MarshallLerner condition for assessing the effects of a devaluation on the current account. The effect of an increase in $e_{i t}$ on the growth rate of the penetration of domestic producers in foreign markets $\left(z_{t i p}\right)$ is positive, while the effect upon the penetration of foreign producers in domestic markets $\left(z_{i j}\right)$ is negative. This ensures that the competitiveness effect upon the growth rate differential is negative. However, it remains an open question whether this negative effect is larger, equal to or smaller (in absolute terms) than the effect of a decrease in the terms of trade.

Second, the exact elasticity of the value of the competitiveness effect with regard to the rate of change of the exchange rate cannot easily be calculated. What can be said is that the exact reaction of the growth rates of $z_{w j}$ and $z_{i j}$ to a one-percent change in the exchange rate depends upon the current producers' price differentials, the current exchange rate, and the current values of $z$ in a nonlinear way.

The different effects can be illustrated more clearly by writing and graphing the different terms separately for the case of two commodities (sectors). For the sake of simplicity, the exchange rate will be assumed to be fixed, thus reducing the number of effects to three. The symbols $I_{1}, I_{2}$ and $I_{3}$ represent the (direct) terms of trade effect (first term on the rhs of VII.13), the competitiveness effect (the second term on the rhs of VII.13) and the consumption pattern effect (the third term on the rhs of VII.13), respectively. Writing out (VII.13) for the 2-sector case, and substituting (VII.7) - (VII.9) in the second part on the rhs, one arrives at the following result. 


$$
I_{1}>0 \text { if } \hat{P}_{i 2}>a_{1} \hat{P}_{i 2}+b_{1}
$$

with $a_{1}=-\frac{x_{i 1}}{x_{i 2}}, \quad b_{1}=\frac{x_{i}}{m_{i}}\left(\hat{P}_{\mathrm{w} 1} \frac{m_{i 1}}{x_{i 2}}+\hat{P}_{\mathrm{w} 2} \frac{m_{i 2}}{x_{i 2}}\right)$

$$
I_{2}>0 \text { if } P_{i 2}-P_{\text {wi2 }} \geq-a_{2}\left(P_{i n}-P_{w 1}\right)
$$

with $a_{2}=\frac{\bar{P}_{w 21+1} \phi_{i 2}\left(1-z_{i 2}\right) \frac{m_{i 2}}{m_{i}}+\bar{P}_{i t i+1} \phi_{w 2}\left(1-z_{w 2}\right) \frac{x_{i 2}}{x_{i}}}{\bar{P}_{w 11+1} \phi_{i 1}\left(1-z_{i 1}\right) \frac{m_{i 1}}{m_{i}}+\bar{P}_{i n+1} \phi_{w 11}\left(1-z_{w 11}\right) \frac{x_{i 1}}{x_{i}}} \frac{\bar{P}_{w 11+1}}{\bar{P}_{i 2 t+1} \bar{P}_{w 12+1}}$

$$
\begin{gathered}
I_{3}<0 \text { if } S_{w 2}<-a_{3} S_{i 2} \\
\text { with } a_{3}=-\frac{x_{i}}{m_{i}} \frac{\left.R S_{i 2} S_{i 2} S_{w 2}-z_{i 2}\right)}{\left.R_{w 2}-z_{w 12}\right)}
\end{gathered}
$$

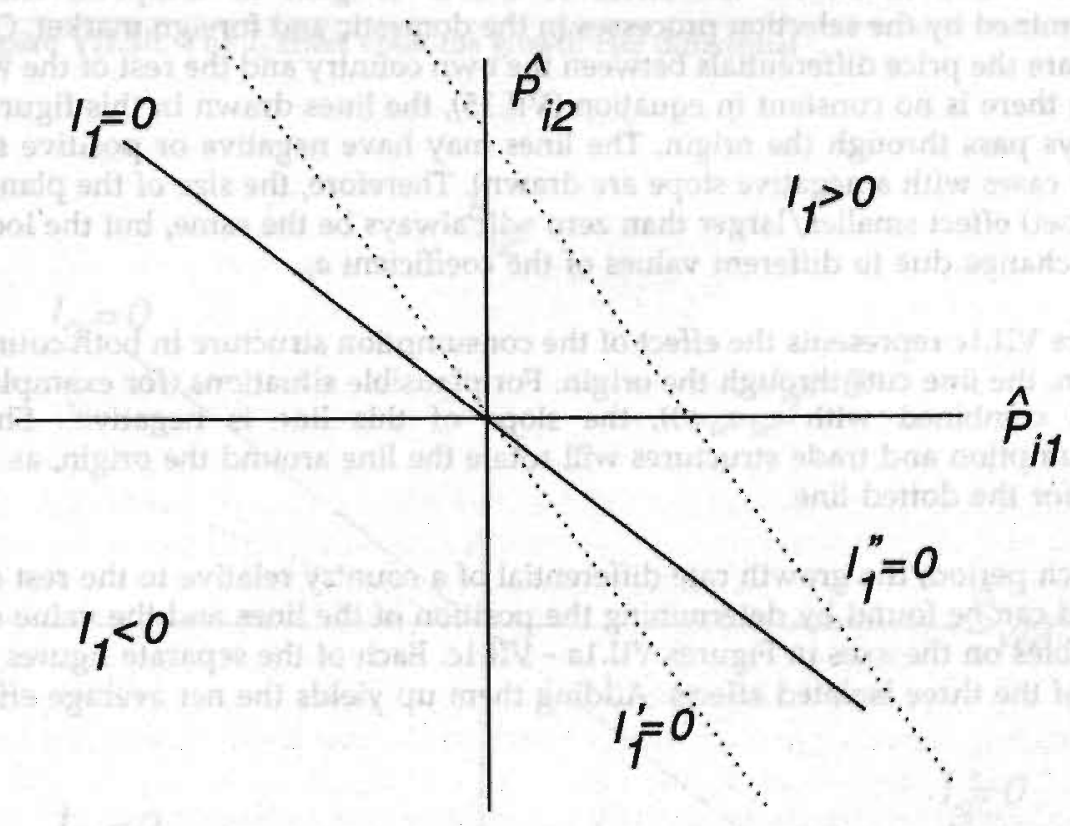

Figure VII.1a. The $I_{1}$ effect on the growth rate differential 
These inequalities are represented by Figures VII.1a - VII.1c. The lines in the figures divide the plane into two parts, one for which the (net) effect represented in the graph is smaller than zero and another one for which it is larger than zero. Note that for changes in the trade and consumption structure (and therefore in the production structure) the dividing lines between those planes will be changing over time.

In Figure VII.1a, the (instant) effect of the rate of change of prices is drawn. The variables on the axes are the growth rates of the domestic producer prices. The solid line is drawn under the assumption that the price changes in the rest of the world as a whole (the term $b_{1}$ in VII.14) are equal to zero (or just cancel each other out). In general, this will of course not be true. A positive (negative) term $b_{1}$ will reduce the size of the plane for which combinations of the country's own growth rates of producers prices will yield a positive (negative) influence upon the growth rate differential. An example of such an influence is given by the line for which $I_{1}{ }^{\prime \prime}=0$. Changes in the own export structure, as reflected in $a_{1}$, will not change the size of the two planes, but will change the location by rotating the line around its intersection point with the vertical axis. Note that the negative slope will always remain. An example of a rotation of the line due to a different export structure is given by the line for which $I_{1}{ }^{\prime}=0$.

Figure VII.1b illustrates the effect of a loss or gain in competitiveness as determined by the selection processes in the domestic and foreign market. On the axes are the price differentials between the own country and the rest of the world. Since there is no constant in equation (VII.15), the lines drawn in this figure will always pass through the origin. The lines may have negative or positive slopes (only cases with a negative slope are drawn). Therefore, the size of the planes for the (net) effect smaller/larger than zero will always be the same, but the location may change due to different values of the coefficient $a_{2}$.

Figure VII.1c represents the effect of the consumption structure in both countries. Again, the line cuts through the origin. For plausible situations (for example, $z_{w 2}$ $z_{\mathrm{re} 1}>0$ combined with $\left.z_{i 2}-z_{i 1}<0\right)$, the slope of this line is negative 7 . Shifting consumption and trade structures will rotate the line around the origin, as is the case for the dotted line.

In each period, the growth rate differential of a country relative to the rest of the world can be found by determining the position of the lines and the value of the variables on the axes in Figures VII.1a - VII.1c. Each of the separate figures gives one of the three isolated effects. Adding them up yields the net average effect.

\footnotetext{
'Note that for some implausible, but by no means impossible, values of the $z$ 's the slope of the line can be positive. However, this does not change the argument.
} 


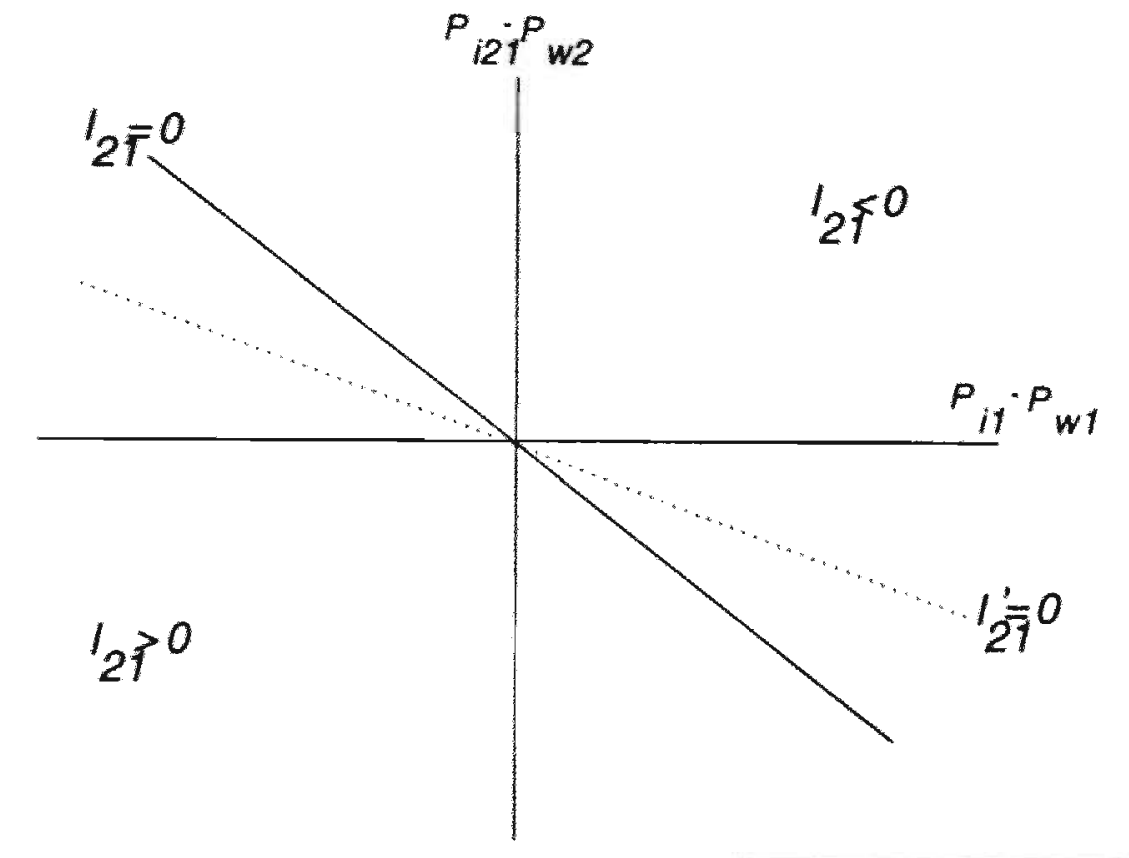

Figure VII.1b. The $I_{2}$ effect upon the growth nate differential

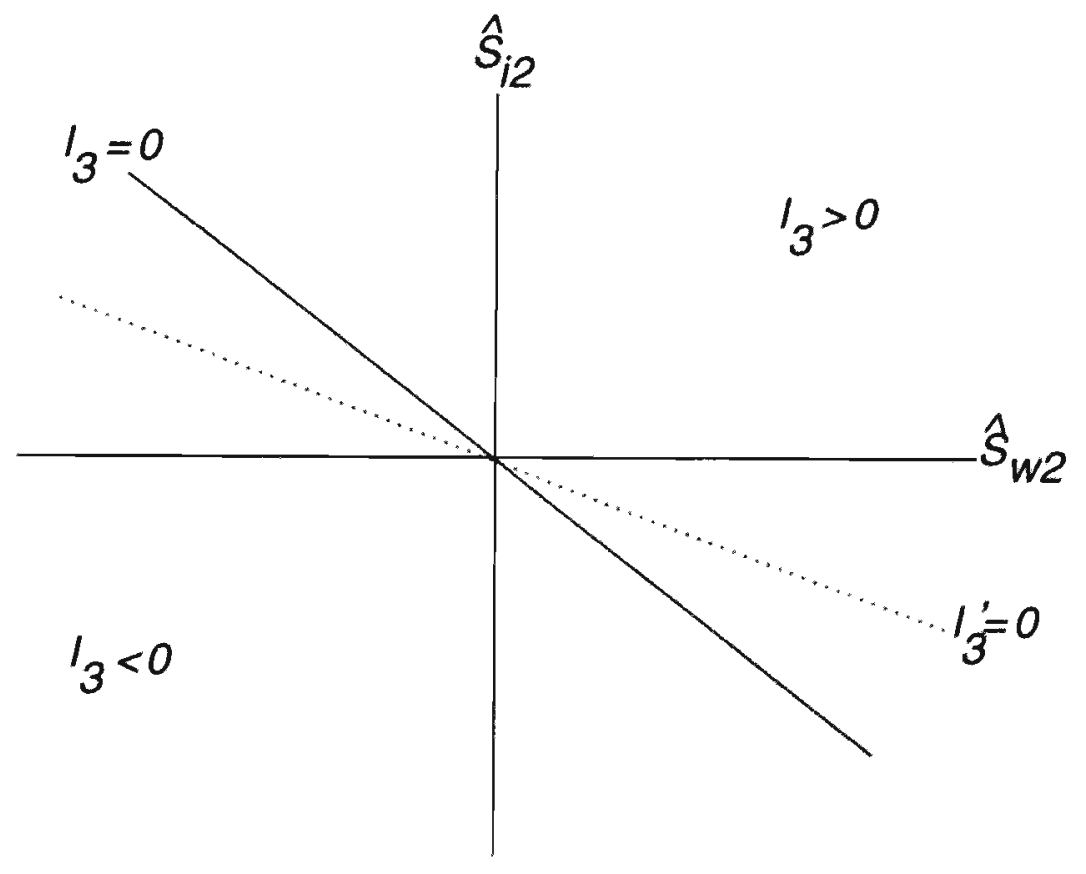

Figure VII.1c. The $I_{3}$ effect upon the growth rate differential

145 


\section{b. Endogenizing Competitiveness: Leaming. Wage Rate Dynamics and Income Elasticities}

After having modelled (and analyzed in a preliminary way) the selection environment, the way in which Lamarckian style feedbacks shape the learning and adaptation process of countries will now be specified. This is necessary because, at this stage, not having specified the motion of some key variables in equation (VII.13), one cannot say much about the long-run values of growth rate differentials.

First, the equation for $P$ is specified. The approach chosen is highly stylized, but can serve as a means of illustrating some of the mechanisms associated with the evolutionary approach adopted. For the sake of simplicity, assume that all goods are produced with labour alone and that profits are equal to zero ${ }^{8}$. One can then write the following identity.

$$
P_{i j}=\frac{W_{i}}{G_{i j}}
$$

$W$ stands for the nominal wage rate and $G$ is (labour) productivity.

Endogenizing these two variables, the movement of the latter is specified using an equation which combines principles already applied in Parts One and Two: the Verdoorn relation and Kaldor's technical progress function (Kaldor 1957). Both effects capture the notion of dynamic scale effects linked to the cumulative character of technological change. Although this is only a very stylized description of technological change which does not involve endogenous investment in $R \& D$, it still takes into account the basic cumulative characteristics (see Chapter 3 ) that are the focus of this model. The following equation is used.

$$
\hat{G}_{i j i}=\lambda_{i j} Q_{i j l-1}^{1 / \gamma_{i}} \quad \lambda_{i j}>0, \gamma_{i j}>1
$$

In this equation, $\gamma$ and $\lambda$ are country and sector-specific learning parameters reflecting differences between sectors and countries in the rate of (dynamic) learning. These differences may be related to differences in the sectoral technology opportunities and to institutional differences. The equation says that the current period growth rate of labour productivity is a nonlinear function (passing through the origin) of the previous period growth rate of output. Thus, this equation brings a positive feedback into the system (high growth leads to high growth), with a 'learning lag' of one period. The function is specified in such a way that the marginal increases in productivity growth become smaller and smaller (but remain positive) for larger growth rates of production (decreasing marginal learning rates).

The behaviour of a system in which production growth is equal to productivity growth (i.e., in which there are no influences from the demand side, like the neoclassical growth model), and productivity growth is described by equation

\footnotetext{
- Alternatively, one could specify some mark-up pricing rule and a fixed capital output ratio, as has been done for example in (respectively) Silverberg et al. (1988) and Cantwell (1989). This would not change the conclusions in a qualitative way.
} 
(VII.18) can be easily analyzed. Similar to the analysis in Kaldor (1957: 265-270), the equilibrium growth rate of the system is found at the intersection point of the curve describing (VII.18) and the $\mathbf{4 5}$ degrees line. This is depicted in Figure VII.2. For values to the right (left) of this intersection point, the rate of productivity growth is below (above) the rate of output growth, and hence the rate of output growth will fall (increase), leading the system to the intersection point.

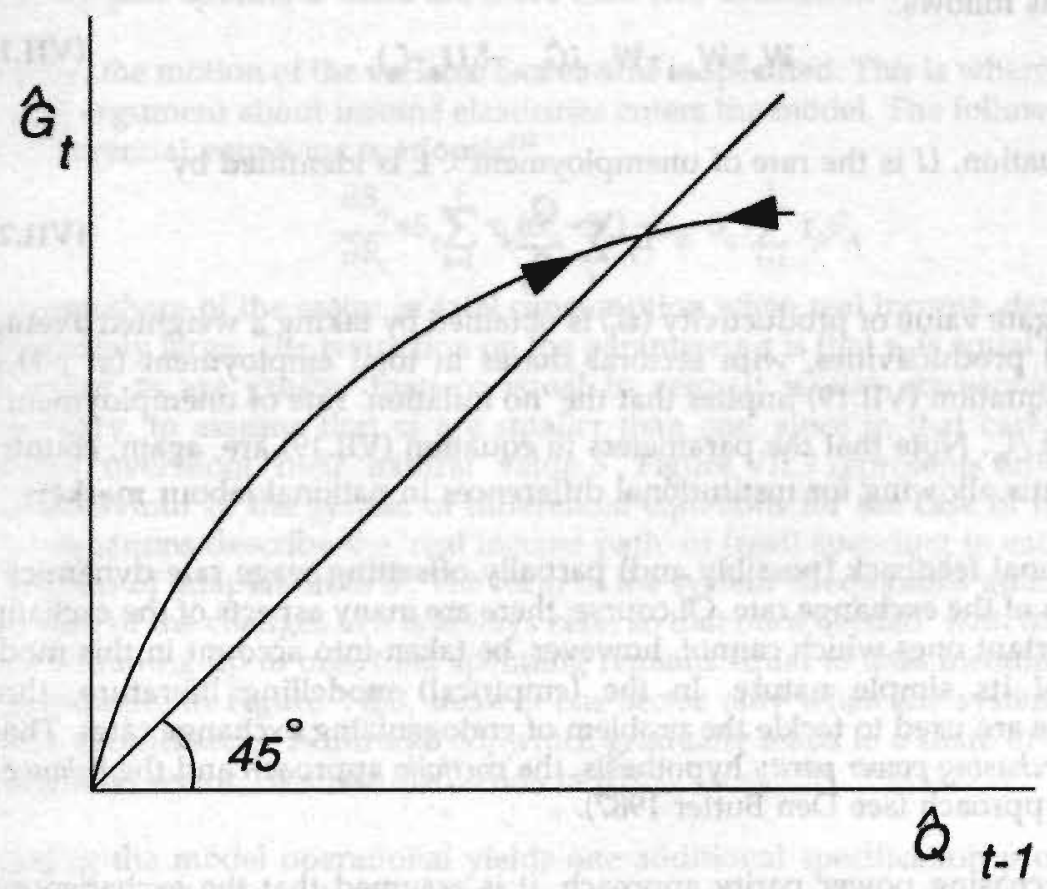

Figure VII.2. The technical progress function

Thus, in the short run, the rate of learning is either larger or smaller than the rate of output growth. This means that in the short run, dynamic returns to scale at both increasing and decreasing rates can occur. In the long run, the system will, provided that no other shocks or tendencies occur", tend to a rate at which output and productivity will grow equally fast. This 'natural rate' is equal to $(1 / \lambda)^{y / 1 / n}$. Note that, in general, due to technological and institutional differences, one would expect $\gamma$ and $\lambda$, and hence the natural rates of growth, to differ between countries.

A negatioe feedback results from wage rate dynamics. It is assumed that the motion of this variable is influenced by two sources. The first is the rate of productivity

- It might be useful to point out that in the present model there are a number of tendencies and shocks which might prevent the system from settling down at the equilibrium growth rate. These are the evolutionary selection equation, exchange rate movements, consumption share movements, foreign demand and wage rate movements. 
growth. The second is the state of the labour market. In 'normal' situations, wages increase as fast as productivity. However, if unemployment is above a certain threshold, workers are prepared to work for lower wages, in order to increase their chance of employment. If unemployment is above that same threshold level, workers will demand a growth rate of wages which is higher than productivity growth, because there is relatively little chance of becoming unemployed. Thus, only when unemployment is exactly at the threshold level (the 'no inflation rate of unemployment') will wages grow as fast as productivity ${ }^{10}$. This can be specified as follows.

$$
W_{i t}=W_{i t-1}+W_{i t-1}\left(G_{i t-1}-\delta_{i} U_{i t}+\zeta_{i}\right)
$$

In this equation, $U$ is the rate of unemployment ${ }^{11} . L$ is identified by

$$
L_{i}=\sum_{i} \frac{Q_{i j}}{G_{i j}}
$$

The aggregate value of productivity $\left(G_{i}\right)$ is obtained by taking a weighted average of sectoral productivities, with sectoral shares in total employment (at $t-1$ ) as weights. Equation (VII.19) implies that the 'no inflation' rate of unemployment is found at $\delta_{i} / \zeta_{j}$. Note that the parameters in equation (VII.19) are, again, countryspecific, thus allowing for institutional differences in national labour markets.

An additional feedback (possibly and) partially offsetting wage rate dynamics is the motion of the exchange rate. Of course, there are many aspects of the exchange rate, important ones which cannot, however, be taken into account in this model because of its simple nature. In the (empirical) modelling literature, three approaches are used to tackle the problem of endogenizing exchange rates. These are the purchasing power parity hypothesis, the portfolio approach and the balance of payments approach (see Den Butter 1987).

In the purchasing power parity approach, it is assumed that the exchange rate moves in such a way as to guarantee (a tendency towards) equality of (consumer) price levels in the two countries. This hypothesis is highly suitable in the present model, since the consumer price level has already been given a prominent role in the selection mechanism. Marking the exchange rate consistent with complete ppp by an asterisk, it can be specified as follows.

$$
e_{i w}^{*}=\frac{P_{i}}{P_{w}^{i}}
$$

Assume that in each period, the exchange rate adjusts partially to a level that would have been consistent with complete equality of ppp power parities in the

10 This specification is a simpler way of representing the bargaining process as in the wellknown 'Goodwin model' (Goodwin 1967). Introducing a mark-up pricing rule in the model would allow for the inclusion of the full Coodwin effect.

"Define $U$ as $(N-L) / N$, where $N$ is labour supply and $L$ is labour dernand. $N$ is assumed to be constant, thus ruling out a common source of economic growth found in most growth models. 
previous period. This can be put in mathematical terms as follows.

$$
\ln _{\text {ind }}=\rho\left(\ln P_{i t-1}^{s}-\ln P_{-1-1}^{c}\right)+(1-\rho) \ln e_{\text {int }-1}
$$

In this equation, $\rho$ is an adjustment parameter. Normally, one would assume $\rho<1$, in which case the actual exchange rate smoothly adjusts to the ppp warranted rate (which might be a moving target). Assuming $p>1$ would imply overshooting. The logarithmic specification is necessary for the equations for $e_{i k}$ and $e_{k i}$ to yield consistent results. This is also the reason why $p$ cannot be country-specific (or even country-pair-specific if there are more than two countries).

Finally, the motion of the variable S over time is specified. This is where Pasinetti's (1981) argument about income elasticities enters the model. The following system of differential equations is adopted ${ }^{12}$.

$$
\frac{\partial S_{i j}}{\partial R_{i}}=S_{i j} \sum_{k=1}^{1} \tau_{k j}\left(S_{i k}-S_{i k}^{*}\right)-\left(S_{i j}-S_{i j}^{*}\right) \sum_{k=1}^{1} \tau_{j k} S_{i k}
$$

$S^{*}$ is the share of the sector in total consumption when real income, denoted by $R$, is infinitely large. The restriction on the parameters $\tau$ is that $\tau_{h}$ is equal to zero and all other is are greater than or equal to zero. It is also convenient, but not necessary, to assume that $\tau$ are smaller than one, since in that case the shares cannot 'overshoot their 'natural' value $S$ '. Figure VII.3 represents an example of the behaviour of the system of differential equations for the case of two sectors. The equations describe the 'real income path' of (real) spending in each sector as a process of adaptation to $S^{*}$. The form of the system of equations guarantees that the sum of the changes in $S$ is always zero, so that once 'feeded' with initial values of $S$ summing up to one, total spending remains equal to total income. In case of the example in Figure VII.3, there is one sector only when the system starts. At $t=0$, a second sector is introduced, which gradually tends to a share of 0.5 in total. Naturally, sector 1's share also tends to 0.5 .

Making the model operational yields one additional specification problem. This problem results from the fact that for $n$ endogenous countries, the model specified so far is underdetermined because there are only $n-1$ independent balance of payment restrictions. Therefore, a country called the rest of the world (denoted by $w$ as before) will be specified. The growth rate in this country is such that full employment (at the 'natural' level) is assured ${ }^{13}$, or

\footnotetext{
${ }^{32}$ Note that while this system of differential equations is largely consistent with Pasineti's view, he does not narrow his model to any specific functional form. It should be realized that the behaviour of this equation, which is specified in continuous time, is different in discrete time (as it is used here). If the same form is kept, but discrete time changes are used instead of continuous time changes, the movement of the $S^{\prime} \mathrm{s}$ will still be consistent in the sense that they always add up to one, but each prediction of $S$ will only be a linear approximation to the true value according to equation (VII.23). However, this is acceptable for small steps, and non-negative changes in real income.
}

${ }^{13}$ Note that this rules out the unemployment term in the equation for this country's wage rate. 


$$
\sum_{j} \frac{Q_{w j}}{G_{w i}}=N_{w} \frac{\zeta_{w}}{\delta_{w}}
$$

This equation must be regarded as an extra restriction on the growth rate of country $w$.

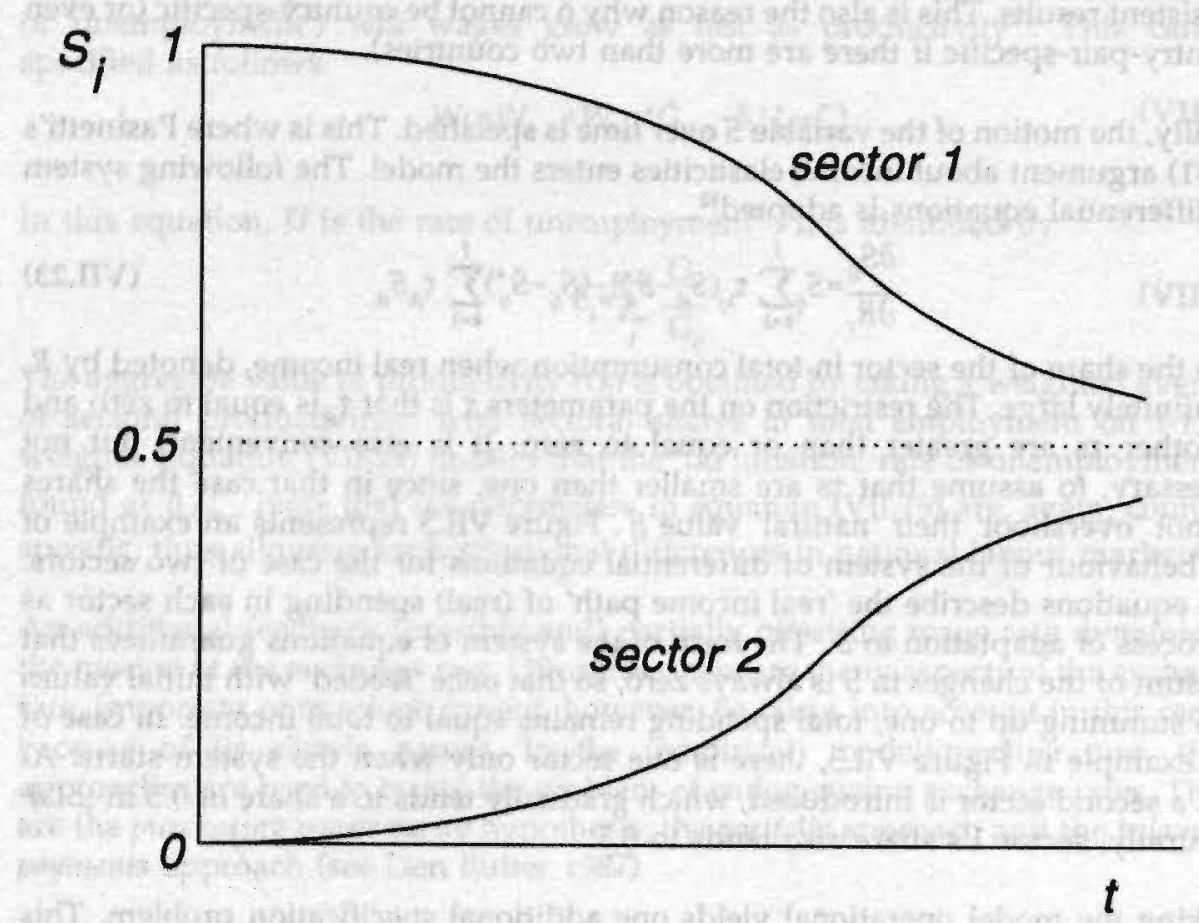

Figure VII.3. The dynamies of sectoral shares in consumption 


\section{Simulation Results}

Given the complexity of some of the dynamics defined by the equations above, the analysis will be limited to simulation experiments". The case considered is a three-country / two-sector case. There are two countries (called 1 and 2) in which the growth rate is determined by balance of payments equilibrium, and one country ( $w$, or 'the rest of the world') where output is always at the full employment level. Initially, the value of all variables is equal in all three countries. Each sector occupies half of the labour resources in the country (and thus accounts for half of the production and income). $S$ is equal to 0.5 in each sector. Trade occurs, although none of the countries has a competitive (or comparative) advantage in either one sector. Import penetration is equal in the two sectors and countries, so that trade between $i$ and the rest of the world is balanced (both in a nominal and real sense) even at the sectoral level. All countries start with a growth rate of production (in both sectors) of slightly above $2 \%$. The initial values of all variables are given in Appendix VII.2. The time span simulated is 98 periods, while two periods of initial data have to be specified.

To assess the simulation results, two indicators are used which capture the basic results in a number or sign. First, the growth rate differential $D$ is defined as

$$
D=\hat{R}_{1}-\hat{R}_{2} \text {. }
$$

Second, a specialization index, denoted by $F$, is defined as

$$
F=\frac{Q_{11}}{Q_{11}+Q_{12}}-\frac{Q_{21}}{Q_{21}+Q_{22}}
$$

First, some simulation runs will very briefly be analyzed by looking at the resulting signs of $D$ and $F$. After that, the two most interesting runs will be used to look at some outcomes of the model in more depth. To start with, some experiments which yield zero growth rate differentials will be conducted (run 1-4). After that, experiments which yield uneven growth will be explained (run 5-9). Although the first group of simulation runs may not be empirically relevant in this extreme form, they might indicate why growth rate differentials are closer to zero in some groups of countries (OECD, see Chapter 4 ) than in others. Results of the simulations are summarized in Table VII.1.

14 The simulation method used is a simultaneous solution to the discrete time model, through a compiler generating a program using the Gauss-Seidel algorithm. The software is developed at MERIT (thanks to Adriaan van Zon), and will be available on the market soon. For reasons of space, it is impossible to give the results for all variables in each run. The complete results are, however, available on a separate floppy disk (refer to Appendix VII 3 for more details). In order to get some feeling for the basic dynamics of the model, simulations with a one-sector model were also carried out. These revealed that for some parameter values (small $\phi$, large $\delta$ ) the model yields adjustment paths with exploding cyclical behaviour of key variables like $z, u$ and $W$. However, the analysis of the two-sector model is limited to parameter values yielding damping cyclical behaviour. 
Table VII.1. A description of the parameters and the results in some simulation runs $^{+}$

\begin{tabular}{|l|l|l|l|l|l|l|l|l|l|l||}
\hline & Main feature affected & 1 & 2 & 3 & 4 & 5 & 6 & 7 & 8 & 9 \\
\hline$\gamma_{11}$ & learning rate & 2 & & & & & & & 2.1 & 2.1 \\
\hline$\gamma_{12}$ & idem & 2 & & & & & & & 1.9 & 1.9 \\
\hline$\gamma_{21}$ & idem & 2 & & & & & & & 2.05 & 2.05 \\
\hline$\gamma_{22}$ & idem & 2 & & & & & & & 1.98 & 1.98 \\
\hline$\gamma_{w 1}$ & idem & 2 & & & & & & & 2.01 & 2.01 \\
\hline$\gamma_{w 2}$ & idem & 2 & & & & & & & 2.02 & 2.02 \\
\hline$\lambda_{11}$ & idem & 0.15 & & & 0.1 & & & 0.1 & 0.16 & 0.16 \\
\hline$\lambda_{12}$ & idem & 0.15 & & & 0.2 & & & 0.2 & 0.14 & 0.14 \\
\hline$\lambda_{21}$ & idem & 0.15 & & & 0.2 & 0.1 & & 0.3 & 0.12 & 0.12 \\
\hline$\lambda_{22}$ & idem & 0.15 & & & 0.1 & 0.1 & & 0.1 & 0.18 & 0.18 \\
\hline$\lambda_{w 1}$ & idem & 0.15 & & & & & & & 0.14 & 0.14 \\
\hline$\lambda_{w 2}$ & idem & 0.15 & & & & & & & 0.15 & 0.15 \\
\hline$\tau_{112}$ & income elastictity & 0.15 & & & & & 0.05 & & 0.14 & 0.14 \\
\hline$\tau_{121}$ & idem & 0.15 & & & & & 0.05 & & 0.12 & 0.12 \\
\hline$\tau_{212}$ & idem & 0.15 & & & & & & & 0.17 & 0.17 \\
\hline$\tau_{221}$ & idem & 0.15 & & & & & & & 0.12 & 0.12 \\
\hline$\tau_{w 12}$ & idem & 0.15 & & & & & & & 0.15 & 0.15 \\
\hline$\tau_{w 21}$ & idem & 0.15 & & & & & & & 0.11 & 0.11 \\
\hline$\phi$ & exports / imports & 0.2 & & & & & & & & \\
\hline$\delta$ & wage rate & 0.5 & & & & & & & & \\
\hline$\zeta$ & wage rate & 0.025 & & & & & & & & \\
\hline$\rho$ & exchange rate & 0.25 & & & & & & & & 0 \\
\hline$S_{i 1}^{*}$ & income elasticity & 0.5 & 0.2 & 0.2 & & & 0.2 & 0.2 & 0.31 & 0.31 \\
\hline$S_{21}^{*}$ & idem & 0.5 & 0.2 & 0.8 & & & 0.2 & 0.2 & 0.62 & 0.62 \\
\hline$S_{t w 1}^{*}$ & idem & 0 & 0 & 0 & 0 & + & +- & -+ & + & + \\
\hline$F$ & specialization & 0.2 & & & & 0.2 & 0.2 & 0.5 & 0.5 \\
\hline$D$ & growth rate differential|| & 0 & 0 & - & - & 0 & + & - & + & + \\
\hline
\end{tabular}

+ Empty cells have to be read as containing a value equal to the basic run. 
Run 1 represents the basic variant of the model. All parameters are equal across countries, and since all countries start from the same situation, they will all grow equally fast. Market shares will not change and specialization will not occur. Runs $2-4$ represent slight variations to this basic variant, all leading to zero growth rate differentials.

Run 2 is the so-called nonspecialization-induced scale effects run. In this experiment, the value of $S_{i 1}^{*}$ is decreased for all countries. As expected, this has no result for the growth rate differential or the specialization pattern, since the change affects all countries equally. However, because of increased learning effects at the national level, caused by higher growth rates in the 'larger' sector 2, world income is higher in this case. Thus, the system is characterized by dynamic increasing returns, like in many of the new neoclassical growth models.

The next two runs are illustrations of cases where scale effects are a result of specialization. Run 3 illustrates structure-induced scale effects. This run shows that in the case of oppositely directed national changes in domestic consumption patterns, there is an incentive for specialization. The changes in $S_{n}^{*}$ compared to the basic run are of opposite sign for the two countries. Then each country specializes in the good with the largest $S_{i j}^{*}$. Since the learning rates are equal in the two sectors and $S_{a}$ is equal to 0.5 in the rest of the world, this specialization pattern has no influence upon the growth rate differential, but again it leads to higher growth, even in the country which does not specialize ("consumer surplus'). Typically, differentials in consumption structure cause dynamic returns to scale.

Next, there is the technology-induced scale effects case in run 4 . Here, the learning rates are varied in a 'symmetric way'. $S_{\text {"il }}$ is equal to 0.5 again, and each country has a learning advantage in one (different) sector (in the sense that the intersection point of its learning equation with the 45 degrees line lies further to the right). Specialization occurs in the sector where the country has a learning advantage, but because of the symmetry in the consumption structure, no growth rate differential occurs. Thus, in this case, the scale effects are caused by technological differences between countries.

The remaining experiments are cases in which the variations in parameters are less symmetric, such that the different counter effects do not cancel each other out any longer. These experiments lead to more interesting conclusions. First, consider the case in which a country has a learning advantage in both sectors, which can be labelled technology-induced uneven growth. This is the case in run 5 . Since country 1 's advantage is proportional between the sectors (i.e., there is no comparative advantage), no specialization occurs. Obviously, the technologically more advanced country continues to grow faster for a long time (the total simulation period).

Run 6 shows structure-induced uneven growth. Learning rates are equal among sectors and countries, but in country $1 S_{n 1}^{*}$ adjusts slower ( $\tau$ ) to its (lower) equilibrium value. Thus, during the transition period, $S_{11}$ is higher (compared to the other countries). Initially, this leads to a minor negative growth rate differential, because the country specializes in a sector which is becoming less important internationally. This does, however, lead to increased specialization in 
this sector. Country 2, like the rest of the world, specializes in sector 2 , and has to fight a severe competitive struggle in this sector ('the rest of the world' is a large producer). Thus, country 1 finds a 'niche' to specialize in and generates positive growth rate differentials in the long run.

Run 7 is a mixed structural / technology-induced uneven growth case. At first, the growth rate differential is negative, later it becomes positive. The negative trend that occurs initially is obvious. Country 2 has a learning advantage in sector 1 , which is (becoming) less important in terms of total world consumption, because of the $S_{n}$ s being less than 0.5 . Therefore, country 1 specializes in a product which has a smaller market. However, the dynamics are such that the initial advantage of country 2 lays a heavy burden on the growth rate of its wage rate. At some point (early in the second half of the simulation period), this leads to cost-inflation and a declining market share in the rest of the world, and to a declining growth rate of the market share in country 1 . Country 1 , being in a situation with a less tight labour market, is therefore able to catch up, and, quite suddenly, generate a positive growth rate differential. In the period for which the simulation was carried out, this was followed by another regression in country 1 , because of the resulting tension on its labour market. An important role in this process of successful catching up is played by the self-reinforcing learning effects that country 1 captures again when it gains competitiveness. This experiment shows that the nonlinear dynamics of the model can indeed generate results in which different effects offset each other to different degrees over time. Thus, the results are unpredictable in a precise sense by intuition alone.

In run 8 and 9 , the parameters have been changed in such a way that almost all symmetries vanish. This is a mixed uneven growth case, which is most likely to be found in actual practice. In run 8, exchange rates are (as before) flexible, while run 9 examines the effect of a fixed exchange rate regime.

These last two runs will be analyzed in more detail. Figures VII.4 and VII.5 give the basic results for this case. The specialization pattern (Figure VII.4) shows a regular pattern leading to a complete specialization of country 1 in sector 1 and country 2 in sector 2 . On the other hand, Figure VII.5 shows that the pattern of the growth rate differential is far from regular. The different lines in the figures represent the two different cases: one with flexible exchange rates (dashed lines, $\rho=0.25$ ) and one with fixed exchange rates (solid lines, $\rho=0$ ). In case of $F$, the two lines are on top of each other.

First, the case of flexible exchange rates (dashed lines) is discussed. The explanation of the specialization pattern that appears is as follows. In country 1 , the sectoral consumption share of sector 1 tends to a value smaller than 0.5 (which is the starting value), while in country 2 , it tends (although slower for a given increase in income) to a value larger than 0.5 . Thus, one would expect country 1 to specialize in sector 2 goods, and country 2 to specialize in sector 1 goods (compare run 3 in Table VII.1). This does not happen because the 'comparative technology advantages' are the other way around: Country 1 (2) has a higher (natural) rate of learning in sector 1 (2), so that the selection mechanism in international markets drives country 1 (2) towards specialization sector 1 (2). 
Because the learning rates do not change along the simulation period, this specialization tendency drives the two countries towards complete specialization.

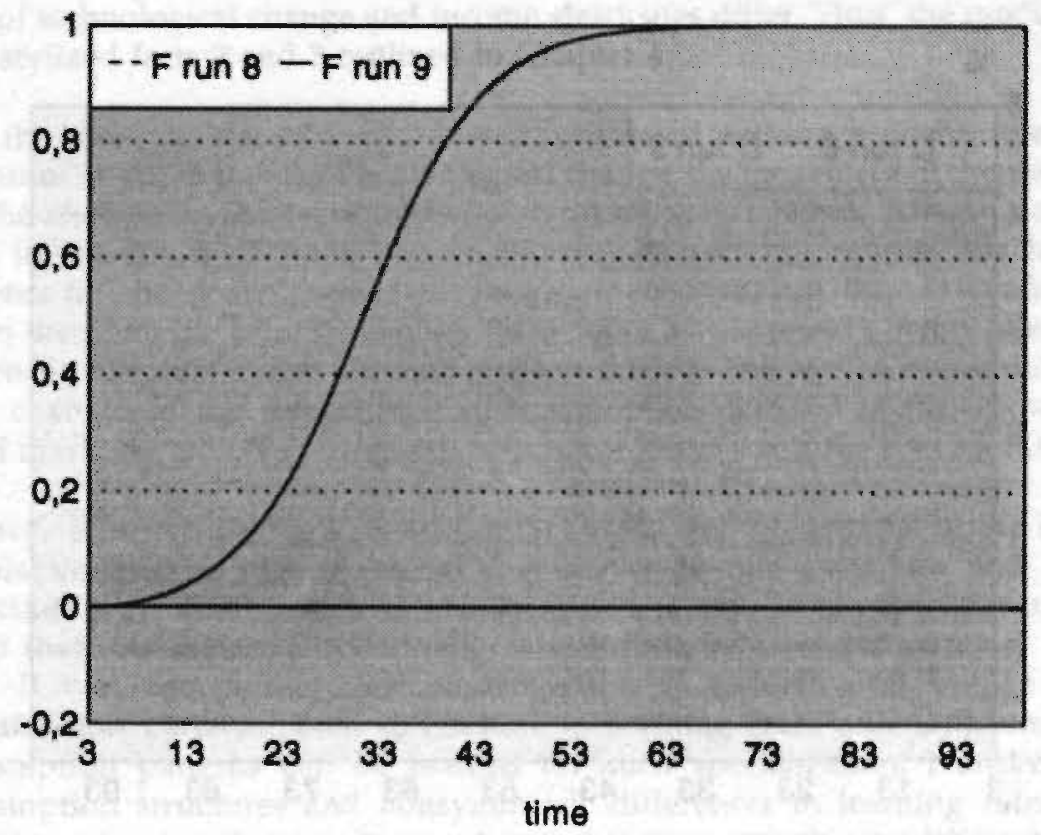

Figure VI.4. The specialization index in runs 8 and 9

The growth rate differential can be explained as follows. In the beginning, there is a (very) weak cyclical pattern, which can be explained by wage reactions to unemployment changes, which are in turn caused by the differences in competitiveness. These reactions are largely the same as those found in the Goodwin model (Goodwin 1967). No large differentials arise, because the markets for both goods are by and large of equal size. Therefore, the real income of the countries 1 and 2 settles roughly on the same level until around period 35. From that period on, the situation on the labour market and sectoral productivity growth rates in the two countries become different to such an extent that a substantive growth rate differential arises. The higher level of specialization of country 1 in sector 1 and the wage dynamics turn out to be such that the growth rate of country 1 is much higher. However, a devaluation of country 2's currency (compared to currencies in both 1 and $w$ ) sets in immediately. This improves the competitiveness of country 2 bit by bit, and eventually, leads to a situation in which the growth rate differential drops again.

Thus, run 8 shows the (combined) effects of technological differences, labour market elasticities, consumption patterns and exchange rate movements leading to complex dynamics. Run 9 cancels out one of these effects: exchange rate flexibility. In the picture for the specialization pattern (solid lines), one can see that 
exchange rate (in)flexibility does not influence the specialization pattern between 1 and 2 . The reason for this is that the comparative advantages are not reversed by flexible exchange rates.

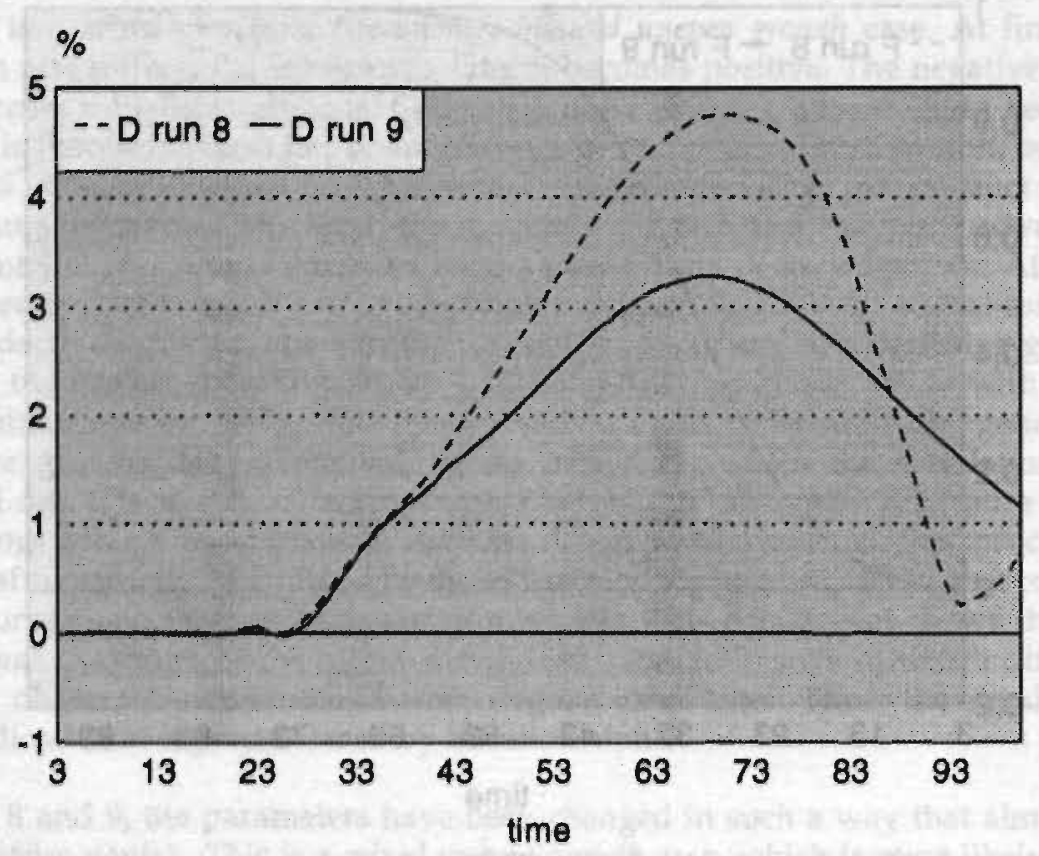

Figure VII.5. The growth rate differential in runs 8 and 9

There is a more substantive difference for the growth rate differential. In the beginning, the alternating pattern from the first run is re-produced. Later, the (absolute value of) the differential is much smoother. However, with regard to unemployment (not shown), the pattern is smoother in the case of flexible exchange rates, because price differentials (i.e., differences in competitiveness) are to some extent 'polished away' by exchange rate movements. Therefore, employment will react more strongly, with wages following when exchange rates are fixed. This effect is very strong towards the end of the simulation period. In the case of flexible exchange rates, unemployment in both 1 and 2 boosts to very high levels.

This concludes the analysis of the model. Although a lot more experiments could be carried out (and indeed have been), the ones presented here suffice to indicate the basic characteristics of the model. These will now be summarized briefly. 


\subsection{Summary and Conclusions}

This chapter presented a dynamic, evolutionary model developed along the lines set out in Chapter 3 and starting from the assumptions that sectoral and national rates of technological change and income elasticities differ. Thus, the model starts from stylized facts 2 and 3 outlined in Chapter 4.

First, the consequences of a model were considered without explicitly specifying the (cumulative) character of technological change, the movement of the wage rate and the changes in the composition of consumption demand. It was found that gains in the terms of trade and changes in its sectoral composition have an influence on (the) growth rate (differentials). In the short run, there is an effect that allows the domestic country to grow faster when its export prices increase, but in the longer run, this causes a negative effect through the loss of competitiveness. Also, changes in the composition of consumption demand in the domestic or world markets can have a negative or positive effect upon the growth rate.

This was followed by the introduction of evolutionary feedbacks in the form of cumulative learning (technological change), wage rate dynamics and income elasticities of (sectoral) consumption. By means of simulation experiments, it was found that this causes 'Goodwin-like' adjustment paths of the national growth rates. It was shown that the cumulativeness of technological change causes specialization patterns. Both differences in learning rates and (adjustment of) consumption patterns can be reasons for such specialization. Nonsymmetric consumption structures and nonsymmetric differences in learning rates cause differences in growth rates. It was shown that zero growth rate differentials are found only in limited number of cases of more or less complete symmetry between countries. Interpreting the evidence in Chapter 4 , these symmetries might present a more adequate description of differences between some countries (mostly the relatively homogeneous group of OECD countries) than others. In other (more realistic) simulation experiments, nonzero differences in economic growth between countries were found. 

Case

Table VII.A1. Initial values used ${ }^{+}$

\begin{tabular}{|c|c|c|c|}
\hline \multicolumn{2}{|c|}{$\begin{array}{l}\text { Initial values } \\
\text { arbitrarily set }\end{array}$} & Results & \\
\hline$G_{i j}$ & 0.8 & $P_{i j}$ & 1 \\
\hline$W_{i}$ & 0.8 & $p_{i j}^{c}$ & 1 \\
\hline$z_{i i j}$ & 0.2 & $S_{i j}$ & 0.5 \\
\hline$C_{i j}$ & 1.1875 & $Q_{i j}$ & 1.1875 \\
\hline$N_{i}$ & 3.125 & $R_{i}$ & 2.375 \\
\hline
\end{tabular}

" Column indicator "results" points to values which follow from the values set arbitrarily and the fact that an initial value must be a (static) solution to the model. $z_{i j}$ indicates the market share of producer $l$ on the market in $i$ in sector $j$ goods.

\section{Appendix VII.2. Some Mathematical Details of the Selection Equation in Discrete} Time

In a general' rorm, witn $n$ agents and $m$ cenoting market snares, write the seiection equation as follows.

$$
\begin{gathered}
m_{i t}-m_{i t-1}=m_{i t-1} \phi\left(E_{i} / \bar{E}-1\right) \\
\bar{E}=\sum_{i} m_{i t-1} E_{i}
\end{gathered}
$$

If one adds up over all $h$ agents, the total market share should always remain one. Suppose that, initially, this condition is met. Then, by adding (VII.A1) up over all $h$ agents and substituting (VII.A2), one can see that this is always met.

$$
\sum_{i}\left(m_{i t}-m_{i t-1}\right)=\sum_{i} \phi\left(E_{i} m_{i t-1} / \bar{E}-m_{i t-1}\right)=\phi \sum_{i} E_{i} m_{i t-1} / \bar{E}-\phi \sum_{i} m_{i t-1}=0
$$

The selection equation used in this chapter is of the type (VII.A1) - (VII.A2), so it is correct to calculate the market share of domestic producers as the residual of all the foreign producers' market share, which is equal to the total import penetration.

Another condition is that one cannot allow negative market shares to occur. In order to see whether negative market shares may occur at some time, one can write the following inequality. 


$$
m_{i}=m_{i t-1}+m_{i-1} \phi\left(E_{i} / \bar{E}-1\right)>0
$$

In our case, where $\phi>0$, the solution to this can be written as follows.

$$
E_{i} / \bar{E}>\frac{\phi-1}{\phi}
$$

Note that for negative values of $\phi$, the $>$ collapses to a $<$. Note that if $\phi<1$, as was assumed in the text, the rhs of (VII.A5) is negative, so that the inequality always holds ( $E$ is positive).

\section{Appendix VII.3. Accessing the Complete Simulation Results on Floppy Disk ${ }^{15}$}

The floppy disk that comes with this thesis contains nine databases with the results from each of the simulation runs in Table VII.1 above. A program (VIEW.EXE) on the disk enables one to put these data into graphs on the screen of an MSDOS-compatible PC with at least $512 \mathrm{~KB}$ memory and a graphics card. These graphs can then be saved in a diskfile which can be printed using any program that supports the Lotus 123 PIC format.

The program VIEW.EXE is a part of the MADMAN program developed by Menhir Software, and was programmed by Huub Meijers. The fact that it is distributed with this thesis does not mean that the program is public domain or shareware. In fact, it is copyrighted, and making copies for other than backup purposes is illegal. Moreover, although due care has been given to putting the program together, the author of this thesis nor Menhir software can be held responsible for any damage the program may cause.

The program is started by inserting the floppy disk in the drive, switching to the current program directory (usually $B: \backslash$ or $A: \backslash$, refer to your MSDOS manual for more details), and typing VIEW followed by return. Then, press a number (1-9) in order to see the corresponding results, or press 0 to return to MSDOS. Once you have accessed a database, you will see a screen showing the variables in the current page. A Page is a set of variables beginning with the same character. The program provides online help on how to switch pages, how to display variables, or how to make graphic files. You can also customize the program to your system defaults, although in most cases, the program will detect your hardware automatically.

The variable names used in the program differ somewhat from these used in the text. Table VII.A2 contains the equivalence.

${ }^{15}$ MSDOS and Lotus 123 are trademarks. 
Table VII.A2. Concordance between variable names in the text and variable names in the program.

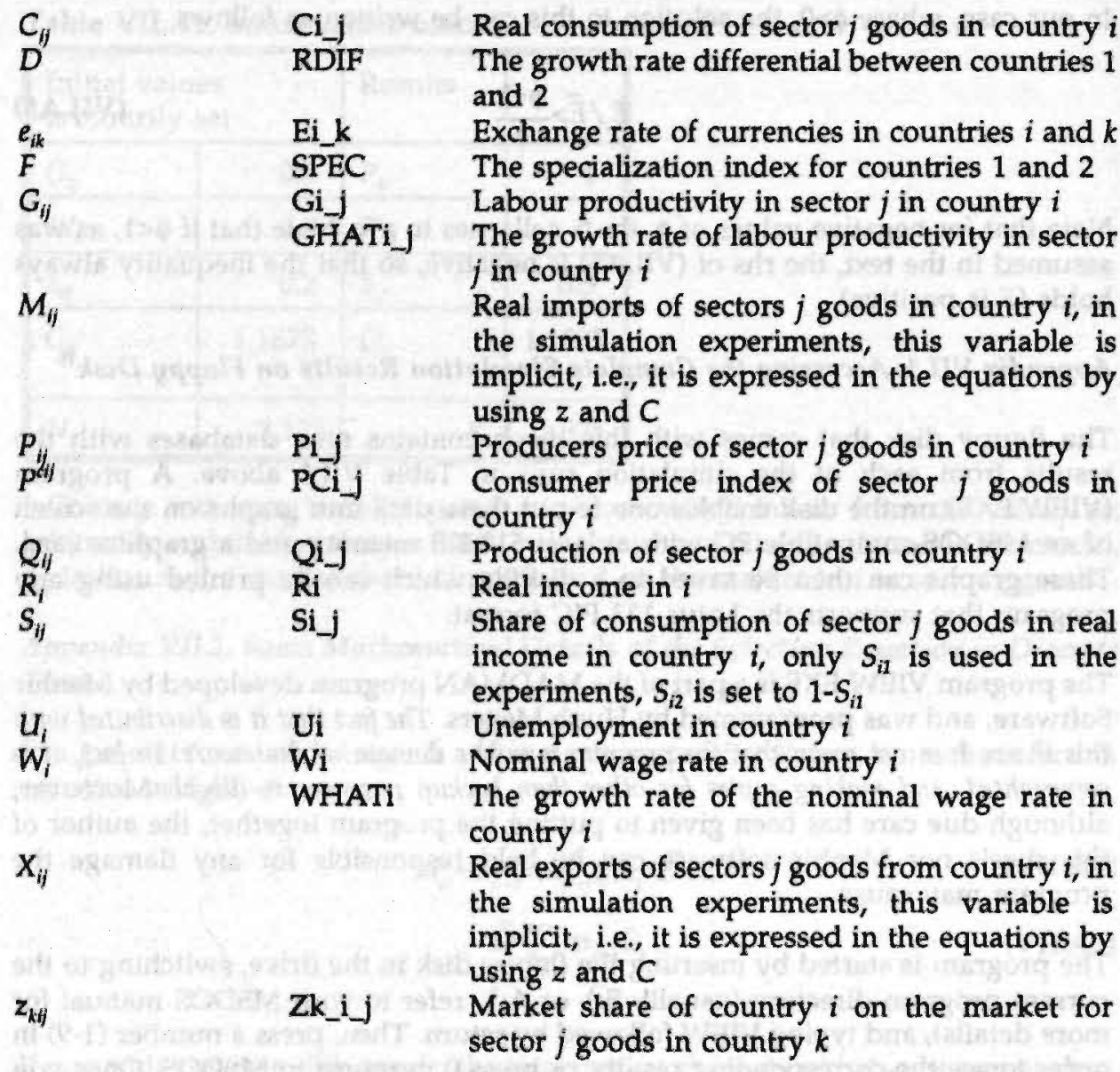




\section{CHAPTER 8. An Empirical View on the Evolution of Trade and Technology}

This chapter investigates the relation between technology and trade. This relation has been subject to earlier research, as for example by Soete $(1981,1987)$, Hughes (1987) and Dosi et al. (1990) (which will be referred to as DPS from now on). The difference between this chapter and earlier research lies in the specific aim of the statistical analysis undertaken. The aim here is to investigate whether the functional specification of the evolutionary selection equation used in the previous chapter can survive a confrontation with the data. This means that the analysis in this chapter will not test the implications of the model in Chapter 7 as a whole, but will only address a limited part of it. Chapter 9 is aimed at testing the broader implications of the model in Chapter 7, and will make use of the results obtained in the current chapter. A second aim of the present analysis is to find out which aspects of competitiveness play a role in the selection process. To do so, a large data set will be applied in regressions explaining market shares for 28 manufacturing sectors.

The results of these regressions will be compared to the results obtained in other research (DPS). To do this, the DPS-type regressions will be 'reproduced' ${ }^{\prime}$ for the current sample of countries and years. However, it is not the aim to test the specific evolutionary specification against these other specifications, both because they are not necessarily conflicting and because the statistical techniques applied do not allow for such a sharp test.

'Due to data limitations, a complete reproduction of the results is not possible. 


\subsection{Patents as Indicators of Innovation}

As technology is the main factor explaining growth in this thesis, the current chapter will have to take it into account in explaining trade patterns. So far, two sorts of data, R\&D expenditures and patents, have been used as indicators for innovative activities. In the sectoral setting of the previous and current chapter, R\&D data are not available in a country sample larger than the core OECD countries. Therefore, patents will be used as an indicator of technological change. However, as already indicated above several times, there are a number of disadvantages to using patents in this way. These will be discussed before the actual empirical analysis is carried out.

The underlying idea of using patents as innovation statistics is that the number of patents is a good indicator of the innovative strength of the applicant. However, some aspects pertaining to patents should lead one to using them only with caution. Some of these drawbacks are well known by now (Pavitt 1985, Basberg 1987, Griliches 1990). First, the value of one patent to another may differ, even if one uses data from one patent issuing-institution like the US Patent Office. The reason for this is that a patent office only requires minimum levels of novelty, which are generally exceeded by individual patents. Moreover, the real (economic) value of a patent cannot be known in advance, i.e., at the time of application. Some work on patent renewal rates (Schankerman 1989) has been undertaken to correct patent statistics for these differences, but as yet this research has not yet reached the stage at which its results can be used widely in empirical research.

Second, the propensity to patent might differ among sectors, as a result of which the value of patents as indicators of innovation varies between sectors. The reason for this is that there might be other sources of protection for an innovation besides patenting. The possibilities of these other sources, like secrecy, lead times, etc., are likely to differ between different technologies, and hence, sectors (for an empirical analysis of different ways of appropriating technologies, see Levin et al. 1987). For example, in pharmaceuticals patents are very important, while they are much less useful in the computer industry?

There is, however, another - seldom mentioned - reason for considering patents to be bad indicators of innovation. By linking innovation to the concept of countrywise competitiveness as in the previous chapter, one aims at giving an indication of the general (average) level of technological capability of a (sector in a) country. Thus, one would ideally like to consider all sources of technological knowledge of the firms in the country. Of course, there are sources of knowledge that are much more important (in a quantitative way) than invention (as measured by patents). Diffusion of knowledge (from abroad as in Part Two, or from other domestic firms) is such a source. The majority of firms will not rely (completely) on the development of in-house knowledge, but instead imitate innovations from

${ }^{2}$ This example highlights another aspect of patenting: the patent lifetime. Due to severe development and testing requirements, patent life time is generally considered to be too short in pharmaceuticals, while in computing (hardware), the economic life time of an innovation is much shorter than normal patent duration. 
elsewhere, or, even simpler, just buy new equipment and recruit skilled labour on the market. Thus, the problem is that patent statistics only measure innovation activities of the inventing firms, and do not consider what can be put under the general heading of 'diffusion of innovation through the economic system'. Viewed in this way, one can even go one step further and state that patents, being primarily a way of appropriating technology, are a barrier to diffusion (compare the new neoclassical models reviewed in Chapter 2). Consequently, they have a partially negative effect on the general technological level of a country.

In an international context, the appropriation aspect of patents has an additional dimension. As will be discussed in more detail below, the international system of intellectual property rights (i.e., patents) has been under severe pressure in the past decades. Part of the success of some countries (especially NICs) can be attributed to their successful imitation of foreign technologies, often through 'violation ${ }^{3}$ of international agreements on property rights. Moreover, the internationalization of the world economy has made patents less useful as an indicator of technologies appropriated on a national level. Due to the presence of multinational firms, technologies can easily be used in countries where they have not been developed.

Yet another reason for considering patents as bad indicators of innovation lies in the fact that patents might be indicators of economic aspects rather than being related to technology aspects. Bosworth (1984) has argued that looking at external patents might reflect the openness of an economy rather than its technological level. The reason for this is that firms will only patent their inventions abroad if there exists an incentive for this in the form of exports. This 'reverse causality' would lead to a strong correlation between exports and patenting, but would not necessarily indicate that technology is important in the determination of trade.

A last drawback of patents as innovation indicators is the obvious relation between the number of patents and country size. Large countries, ceteris paribus innovativeness, are likely to have more patents than small countries. Therefore, it is necessary to correct for size differentials. However, if one does not know the exact shape of the relation between size and patenting, the exact form of the correction is hard to find.

To illustrate some of these points, a simple regression involving some of the above-mentioned correlations will be performed. Consider the following unrestricted Cobb-Douglas patenting function.

$$
P_{i}=\left(1+\delta_{i}\right) A R_{i}^{\alpha} N_{i}^{\alpha} O_{i}^{\alpha}
$$

In this equation, $P$ stands for the number of patents, $R$ is R\&D intensity, $N$ is population, $O$ is the openness of the economy, $A$ is a scale parameter, the $\delta s$ reflect country-specific factors, subscripts $i$ denote countries, and the as are elasticities. The equation is estimated in a pooled cross-country time series data set. The

\footnotetext{
${ }^{3}$ In many cases, one cannot really speak about violation, because the countries in question did not sign the international agreements on intellectual property.
} 
sample consists of the 24 OECD countries plus 13 NICs$^{4}$. Estimating this equation ${ }^{5}$ gives the following results.

$$
\begin{aligned}
& \ln A=-9.70^{\circ} \\
& \alpha_{r}=1.84^{\prime \prime} \\
& \alpha_{n}=0.98^{m *} \\
& \alpha_{0}=1.28^{m *} \\
& \text { adj. } R^{2}=0.85 \\
& \delta_{\text {vas }}=11.14^{--} \\
& \delta_{\text {pn }}=3.41^{m-} \\
& \delta_{\mathrm{can}}=3.71^{\mathrm{Na}} \\
& \mathrm{n}=233
\end{aligned}
$$

A country dummy is introduced in the equation for the USA, Japan and Canada (i.e., $\delta$ is estimated for these countries, and set to zero for all other countries). The reasoning behind the dummy for the USA is obvious, because for this country the patent market considered is the home market. Therefore, one would expect the USA (ceteris paribus) to have more patents. It is generally known that Canada has very close relations with the USA. Thus, one could expect Canada to patent relatively more in the USA than other countries. Japanese patenting in the USA has been observed to be very high, especially for the period under consideration. This points to some important Japan-specific factors which are not considered here in detail (such as differences in managers' attitude towards patenting or the sectoral mix of the economy)?

The parameter estimates are all highly significant (despite the multicollinearity between openness and size) and all the signs are correct. Thus, the performance of the equation can considered to be good, and all explaining factors play a significant role. A Chow-test for structural change of the parameters between the periods 1975-1981 and 1982-1987 points to an absence of structural change. With regard to the estimated elasticities, it is important to note that the $R \& D$ elasticity

- Thus, there are 37 countries. In the regressions in the next sections, the same countries are used, with the exclusion of Switzerland and Iceland, because no price indices are available for these countries. Also, The Philippines were excluded because inspection of the raw data on exports for this countries revealed very high (100-200\%) increases in export volumes over the (late) 1980 s. The 34 countries used in all regressions are Japan, USA, Canada, Belgium, Denmark, France, West Germany, Greece, Ireland, Italy, The Netherlands, Portugal, Spain, United Kingdom, Australia, New Zealand, Austria, Finland, Norway, Sweden, Turkey, Yugoslavia, Israel, Mexico, Colombia, Brazil, Argentina, Uruguay, Egypt, Thailand, Malaysia, Singapore, South Korea, Hong Kong.

\footnotetext{
"The period of estimation is 1975-1987. P is measured by the number of patents granted in the USA, measured by date of application (source: US Patent Office). $R$ is measured by R\&D intensity, which is defined as total R\&D expenditure (public and private, source: UNESCO/OECD) over GDP (source: Summers and Heston 1991). $N$ is measured by the number of people in thousands (source: Summers and Heston 1991), $O$ is measured by the sum of exports and imports over GDP (source: Summers and Heston 1991). The sample that is considered is a pooled cross-country time series sample (13 years, 37 countries). The equation is estimated by taking natural logarithms on both sides, which requires nonlinear least squares.

- It would be preferable to construct an openness indicator which takes into account the direction of trade. This will be done below.

It must be admitted that the Japanese dummy is inspired by the data rather than by theory. The results of the estimations, as other estimations with a Japanese dummy below, are only changed marginally when leaving it out.
} 
is well above unity, which points to increasing returns to R\&D intensity. The other elasticities are both around one ${ }^{8}$. This shows that it is reasonable to correct for size and openness by assuming a linear relation between patenting and these variables.

But even if one corrects patent statistics for these two influences, it is desirable to use other innovation indicators to check for the possible effects of the other deficiencies of patent statistics as discussed above. Thus, one would like to have an indicator that measures the degree of diffusion of new technologies through the economic system of a country. Unfortunately, indicators of diffusion are only available at the case study level, and certainly not at the mesoeconomic level in a sample of countries as broad as the one used here. Therefore, an indirect indicator is to be used. One such indicator, the one that will be used here, is labour productivity. The idea behind this is that in general, the application of new knowledge will raise the level of labour productivity, by enabling a firm to produce more given its labour input. Neoclassical growth theory has argued that there is another source of labour productivity growth: substitution (induced by factor price differences). According to this theory, it would therefore be better to use multi-factor productivity as an indicator of technological change. However, as argued in Chapter 3, substitution (moving along the isoquant) cannot be seen as being independent of technological change (moving the isoquant). In this view, technological development goes hand in hand with mechanization of the production process and scale economies (or dynamic learning effects), and increases of production per hour of labour input.

Labour productivity is related to unit wage costs (through identity VII.17). Therefore, if one is using it as an indicator of technological change, one should not use unit wage costs as an indicator of price competitiveness. But, rather than posing a problem, this gives the issue of price competition a clearer dimension. Obviously, there are two sources for competitive prices. The first one is low wages (the labour market aspect), and the second one is high productivity (the technology aspect). Separating these two aspects, as in the simulation experiments in Chapter 7 , can only improve the insight into the way global competition works. This implies that there are now two different aspects of technology in the analysis. First, the usual technological aspect of competition, which is related mostly to product quality (this is the one most widely used). Second, the cost aspect of technology explained above. By using patents and labour productivity separately, one can try to capture both aspects.

Taking these considerations into account, the next sections will apply both patents and labour productivity variables in the regressions explaining the sectoral trade patterns in NICs and OECD countries.

s Although a t-test for difference of the openness elasticity from unity would be significant at reasonable levels. However, this nonlinearity is so small on the relevant range for the variables, that it is safe to assume a linear relation. 


\subsection{Summarizing Some Known Correlations}

The purpose of this section is to test the present data set for some relations that have been well established elsewhere in the literature on trade and technological innovation. The main reference to which comparisons will be made is DPS.

Chapter 6 of that book explored the empirical relation between patenting (as an indicator of technological development) and trade. Two main tests were performed ${ }^{9}$. The first one involves running a regression with export market shares as the dependent variable and the share in patenting, the capital labour ratio, population and a distance (relative to some assumed centre of the world) variable as the explaining variables. The second one is a regression explaining per capita exports, and using patents per head, investment per employee and wages on value added as explaining variables. Both tests explain export performance for 1977, and use cumulated (USA) patents over the 1963-1977 period. The regressions are performed for 40 groups of manufacturing products. The data are cross-country data. Countries in the regression are OECD countries only.

The first test explains the relation between technology and exports mainly by relating shares in exports to shares in patenting. However, DPS do not rely solely on patent statistics as indicators of innovation, but assume that the capital labour ratio also picks up some aspects of technological change. This is in accordance with the suggestions made about patents and labour productivity above. To control for size differences between countries (which could explain both patent shares and export shares), the population variable is present in the regression. The outcome of the test is that the patenting variable is significant in many sectors, especially the ones that one would characterize as not based on natural resources. The influence of population, however, is much less clear. Only in a few sectors is the population variable significant, which is interpreted by DPS as pointing to the existence of scale economies.

In the second test in DPS, both the dependent variable (in this case export values, not shares) and the explaining patent variable are divided by population. Moreover, this test also includes a variable that measures the influence of wage costs (wages over value added) and investment per employee (a proxy to the capital labour ratio). Once again, the outcome of this exercise is that the patenting variable turns out to be highly significant in most sectors. The results for the investment/employment and wage cost variables are much less significant, and the wage variable has a wrong sign (i.e., positive) in some cases. The conclusion of this exercise is that the performance of the technology variable is robust when controlled for the influence of wage differentials.

To investigate whether these results can be reproduced in the data set used here, the relation between patenting and export performance is estimated in a different way. The data used can be described as follows. As in DPS, but contrary to most

\footnotetext{
- Actually, DPS have two more tests of the relation between trade and technological change. However, since the variables used in these tests (revealed comparative advantage and net exports) are not so suitable to the setting of the model in Chapter 7, these will not be considered here.
} 
other studies dealing with trade (for example, Fagerberg 1991), the sectoral classification used is ISIC (revision 2). The common classification used for trade data is SITC (revisions 1-3). Therefore, if one wants to relate trade and production (related) data, a conversion in either direction is necessary. DPS convert the SITC variables to (I)SIC, using a self-developed conversion table. They are able to maintain a large number of sectors, mainly because they concentrate on the most developed countries.

However, the data construction procedure used here is similar to the one in DPS only with regard to the sort of classification scheme used (ISIC). The available SITC-1 data (source: OECD, UNSO) are converted to ISIC. This conversion is necessary because the independent variables are only available in 3-digit ISIC form. Contrary to most trade studies, price indices are used to control for the influence of price changes. While most trade studies use either 'real' volumes (tons, numbers) or values, the present analysis uses volumes expressed in some common price unit (like in most production-related statistics). The price indices used are the implicit domestic producer price indices from the UNIDO Industrial Statistics Database. This means that it is implicitly asscumed that there is no (price) segmentation between export and home markets. The data for wages and labour productivity are also taken from the UNIDO industrial statistics database. Patent statistics are taken from the US Patent Office.

In order to bring the data together in the ISIC-2 scheme, both trade and patent statistics had to be converted from their original classification schemes. The concordance tables used for trade data are self-developed on the basis of tables used at the OECD and UNIDO, and are documented in Appendix VIII.1. Patents are classified by the US Patent Office by SICs (not ISICs). Details about this procedure and on the conversion between SIC and ISIC can also be found in Appendix VIII.1.

Contrary to DPS, the analysis does not concentrate on one specific year, but instead uses a panel of pooled cross-country time series data. While this method drastically increases the number of observations, and thus the power of the statistical methods applied, it also introduces some specific problems like the possibility of structural change over time and autocorrelation of residuals for separate countries. These problems will not be addressed explicitly in this section, since the aim is only to do a rough test of some results obtained before. The period for which data is available is 1964-1987.

In a first regression, export market shares are correlated with the wage rate, labour productivity, patenting shares and a constant. The variables are defined as follows. 


$$
\begin{gathered}
z_{i j}=X_{i j} / \sum_{i} X_{i j} \\
w_{i j}=\left(W_{i j} / L_{i j}\right) /\left(\sum_{i} W_{i j} / \sum_{i} L_{i j}\right) \\
g_{i j}=\left(Q_{i j} / L_{i j}\right) /\left(\sum_{i} Q_{i j} / \sum_{i} L_{i j}\right) \\
T_{i j}=\left(P_{i j} / \sum_{i} P_{i j}\right)\left(z_{i j} / z_{i j}^{\text {us }}\right)
\end{gathered}
$$

with

$$
\begin{aligned}
& \text { P: stock of patents }{ }^{10} \\
& \text { T: a technology indicator, } \\
& \text { w: a wage rate indicator, } \\
& \text { g: a labour productivity indicator, } \\
& \text { W: wage sum, }
\end{aligned}
$$

and $i$ and $j$ denoting countries and sectors, respectively ${ }^{11}$.

Note that the wage and productivity variables are defined as the ratio of the country value and the average world value. In the construction of the technology variable, the share of patenting is divided by a direction coefficient of exports, which has a value higher (lower) than one for countries having 'above (below) normal' trade intensity with the USA. This is meant to control for any influences of trade direction connected to the patent variable.

The technology variable is essentially the share in patenting, and can therefore be expected to be correlated to the export market share if only because of size differentials. Therefore, this regression in itself is not intended to provide a test of the influence of technology-related variables on export performance. Instead, the estimated parameters will be used to deduce some conclusions on the influence of technology on exports.

The actual equation used is a simple linear form, and includes two additional (multiplicative) dummy variables ( $d$, defined as $D_{i} T_{i j}$, with $D$ being equal to one for $i$, and zero for others) for the USA and Japan. The reasons for this are the same as in the estimation of the patenting function. The dummy for Canada is no longer included, because this effect is assumed to be captured by the more appropriate direction of trade correction used here. Thus, the equation looks as follows.

$$
z_{i j}=a_{w} w_{i j}+a_{g i j} g_{i j}+a_{i} T_{i j}+d_{\mathrm{vsa}}+d_{j \mathrm{pm}}+c_{j}+e_{i j}
$$

In this equation, $e$ is an error term with the usual assumptions, $c$ is a constant, and $a_{u}$ and $a_{t}$ are parameters. The results of this regression are presented in Table VIII.1.

10 The use of a stock variable is meant primarily to account for some of the time lags involved in the relation between innovation (patents) and performance. The stock is calculated using a perpetual inventory method with a yearly depreciation rate of $15 \%$. For calculating the initial value of the stock, it was assumed that its growth rate in the period 1962-1963 was 5\%. Regressions with the number of patents instead of the stock in general produce the same results, although the value of the elasticities varies, and the t-vahues are generally less significant

"A superscript US indicates market shares of exports to the USA. 
Table VIIL.1. Relation between market share, wage rate, labour productivity and patenting share.

\begin{tabular}{|c|c|c|c|c|c|c|c|}
\hline SECTOR & $-(\omega)$ & $a(g)$ & $e(t)$ & d/usal & dijn & c & $n / R^{2}$ \\
\hline \multirow[t]{2}{*}{ Foed } & - a.tons & 0.035632 & 0.2918 & 422140 & -0.3279 & 0,000259 & 32 \\
\hline & $281-$ & $736-$ & $9.85-$ & $7.51=$ & $1.94-$ & o.t. & 0.5 \\
\hline \multirow[t]{2}{*}{ Textiles } & $-0,0344$ & 0.021768 & 046063 & -0.41231 & 0.7411 & $0.620 \times$ & 323 \\
\hline & $7 \pi=$ & $257=$ & 140 & $12.2=$ & $460-$ & 6050 & 0.7 \\
\hline \multirow[t]{2}{*}{ Appare? } & -0.0354 & 0.016109 & 0,030677 & tocusest & .0 .3194 & 0.059227 & 323 \\
\hline & 6.40 & $258-$ & 486 & $205-$ & 1.17 & $7.38=$ & 0.16 \\
\hline \multirow[t]{2}{*}{ lnd chem: } & 0.009919 & 0.00041 & 1309 & -1.1418 & $0 . x 057$ & -0.0124 & 579 \\
\hline & 0.26 & $6.41 \%$ & $4048-$ & $36,16=$ & $3.26=$ & $3.93=$ & 0.82 \\
\hline \multirow[t]{2}{*}{ Oth chem } & 0.00584 & 0,030099 & 1.485 & -1.3678 & $1.0 \%$ & .000726 & 47 \\
\hline & $164^{*}$ & 5.40 & $36.47=$ & $34.62 \cdots$ & $5.03 * *$ & $190^{\circ}$ & 0.80 \\
\hline \multirow[t]{2}{*}{ Ref all } & 0.007654 & 0.010159 & -0.01391 & 0.031328 & 0.074 & 0.012155 & 257 \\
\hline & 0.69 & $1.64^{\circ}$ & $161^{*}$ & $1.75^{\circ}$ & 1.24 & $3.07=$ & 0.02 \\
\hline \multirow[t]{2}{*}{ Rubler } & -0.00355 & 0.005893 & 0.88409 & 0.7575 & 1.0382 & $0.014 \% 7$ & 501 \\
\hline & 0.83 & 1.51 & $18.03-$ & $1699=$ & $6.42=$ & $291=$ & 049 \\
\hline \multirow[t]{2}{*}{ Plastice } & $-0,00818$ & 0.008372 & 0.52452 & $04+924$ & 0,0514 & 0.01722 & 486 \\
\hline & $206 \cdots$ & $186 *$ & 23.76 at4 & $20.08 \cdots$ & 0.26 & 3.68 & 0.56 \\
\hline \multirow[t]{2}{*}{ Pottery } & 0.00913 & 0.01836 & 0.14516 & -0.1184 & 4.4293 & 0,061132 & 41) \\
\hline & 5.45 & 3.18 & $3.41 * *$ & $2.78 \cdots$ & 12.40 & 7.57 ate & 0.30 \\
\hline \multirow[t]{2}{*}{ Glass } & 0.01493 & 0.020896 & 1.266 & $-1,1619$ & -0.95251 & 0,016909 & 41 \\
\hline & $2.29 *$ & $2.51 \cdots$ & 13,87 & 1304 w** & $3,94 \cdots$ & $2.23 *$ & 0.35 \\
\hline \multirow[t]{2}{*}{ Oth min } & .0 .02249 & 0,030082 & 0.25533 & $-0,19764$ & 0.40932 & 0.023232 & 446 \\
\hline & $3.59=$ & $3.33=$ & $8.28 \%$ & $6.35 *$ & $204 *$ & $3.10 \cdots$ & 0.16 \\
\hline \multirow[t]{2}{*}{ tron, steel } & -0.02317 & 0,093885 & 0.9079 & -0.88426 & 0,29406 & -0.04416 & 348 \\
\hline & $2.85 \cdots$ & 10.23 & $13,99 *$ & 13.75 & 200 & 3.96 & 0.54 \\
\hline \multirow[t]{2}{*}{ Non-fert } & 0.040956 & -0.00537 & 0.45699 & -0.43483 & -0.27544 & -0.0039 & 345 \\
\hline & $7.20 \ldots$ & 0.86 & $12.19 \cdots$ & 11.97 **** & $2,81 \cdots$ & 0.70 & 0.44 \\
\hline \multirow[t]{2}{*}{ Fab met } & 0.02326 & 0.040289 & 1.2222 & -1.0868 & 1,6604 & -0.00093 & 557 \\
\hline & $6.29=$ & $8.35 \cdots$ & 34.23 m. & $31.40^{\circ}=$ & $5.39 \cdots$ & 0.30 & 0.76 \\
\hline \multirow[t]{2}{*}{ Non-el mach } & -0.01468 & 0.011821 & 2.0137 & .1 .7531 & 0.65662 & 0.005418 & 621 \\
\hline & 3.95 & $3,99 \cdots$ & $39.36 \cdots$ & $35.38 \cdots$ & $3.31 \cdots$ & $2,05 \%$ & 0.81 \\
\hline \multirow[t]{2}{*}{ Dl mach } & $-0,01713$ & 0.019477 & 0.6926 & -0.5226 & 2.2842 & 0.006062 & 576 \\
\hline & $4.68-$ & $3,74-$ & $29.27-$ & $22.58 \cdots$ & 22.29 & $2.16 \%$ & 0.78 \\
\hline \multirow[t]{2}{*}{ Transport } & -0.02426 & 0.066691 & 1.0257 & -0.84079 & 0,89938 & -0.02145 & 499 \\
\hline & $4.04=$ & 11.87 & $21.52 \ldots$ & $18.42 \ldots$ & $6.21-$ & 5.05 & 0.71 \\
\hline \multirow[t]{2}{*}{ Instruments } & -0.01664 & 0.012695 & 2.17 & -1.9195 & 0.48745 & 0.001879 & 525 \\
\hline & $4.12=$ & $3.47=$ & 35,21 & $31,84^{\circ-4 *}$ & $3.87=$ & 0,56 & $O B 1$ \\
\hline
\end{tabular}


The degree of explanation, as measured by the $R^{2}$ statistics and overall significance of the $t$-values, is high. Regarding individual variables, the wage variable turns out to be significant and correctly signed in almost all sectors. Rubber has a correct, but insignificant, sign. Industrial chemicals, refined oil (not significant) and nonferrous metals (significant) are the sectors with a wrong sign. The labour productivity variable, which measures the other aspect of unit wage costs, has the correct sign in all but one sector (non-ferrous metal, insignificant). In all other cases it is positive, and, except for rubber, significant. The rubber sector has a correct, but insignificant sign. This indicates in a preliminary way, stronger than in DPS, the importance of the wage rate in competitiveness.

As could be expected, the patent variable is highly significant and has the correct sign in almost all cases. The exception is refined oil (wrong sign, but significant), a highly natural resource-based sector. The same holds for the USA dummy variable. The Japanese dummy variable more often has a positive than a negative sign, indicating the weakness of the argument that Japanese patenting is 'above normal' for all sectors. However, even though it was expected that there is a positive correlation between patenting shares and export market shares due to size differentials alone, the estimated parameters $\left(a_{1}\right)$ are generally different from each other. If one assumes that the influence of size is equal among sectors, this implies that there are also other aspects of patenting that are important. Therefore, it is useful to compare the estimated elasticities by ranking the sectors in order of increasing magnitude of the estimated parameters. Table VIII.2 does this for the three variables in the regression.

The results of this ranking procedure closely correspond to the intuitive ranking that one would make for the relative importance of innovation and price competitiveness. In the wage column, it are the typically low- (high-) tech sectors that rank among the highest (lowest) parameters. Sectors that have a slightly unexpected position are food (low) and transport (high). In the productivity column, the order is more diffuse. This is probably a reflection of the fact that the labour productivity coefficient both captures quality and price competition aspects of technology (more on this below).

In the patents column, the order is quite close to intuition again. Exceptions are the electrical machinery sector (low) and glass (high). On the basis of the 'image' of the electrical machinery sector, one would expect it to rank as a high-tech sector. However, this is probably caused by the time and ISIC aggregations. The broad definition of this sector at the ISIC 3-digit level includes both high-tech products such as digital recording equipment, and products for which price competition is important and technological content low (for example electric can openers) ${ }^{12}$. Moreover, because the importance of the high-tech elements in this sector has only become significant in the 1980s, this equation most probably suffers from pooling over time.

${ }^{12}$ Note that the ISIC-2 logic classifies most computer-related products under office machinery, which is a part of nonelectrical machinery. Another sector which suffers from severe aggregation problems is the transport equipment sector, in which both bicycles and airplanes are classified. 
Table VIII.2. Ranking of sectors according to the value of the estimated parameters in Table VII. $1^{*}$.

Sequence number wage rate

Productivity

Patents

\begin{tabular}{llll}
\hline 1 & [Nonferrous metals] & ([Nonferrous metals]) & [Refined oil] \\
2 & [Refined oil] & (Rubber) & Apparel \\
3 & ([Industrial chemicals]) & Plastic & Pottery, etc \\
4 & (Rubber) & Refined oil & Other minerals \\
5 & Other chemicals & Nonelectrical machinery & Food \\
6 & Plastic & Instruments & Nonferrous metals \\
7 & Food & Apparel & Textiles \\
8 & Nonelectrical machinery & Pottery, etc. & Plastic \\
9 & Glass & Electrical machinery & Electrical machinery \\
10 & Instruments & Glass & Rubber \\
11 & Electrical machinery & Textiles & Iron and steel \\
12 & Other minerals & Industrial chemicals & Transport \\
13 & Iron and steel & Other minerals & Fabricated metal \\
14 & Fabricated metal & Other chemicals & Glass \\
15 & Transport & Food & Industrial chemicals \\
16 & Apparel & Fabricated metal & Other chemicals \\
17 & Pottery, etc. & Transport & Nonelectrical machinery \\
18 & Textiles & Iron and steel & Instruments \\
\hline
\end{tabular}

- For the wage variable, sectors are ranked in order of decreasing magnitude (i.e., large positive values first and large negative values last); for the other variables, the order is reverse. Round brackets 0 indicate nonsignificance, straight brackets [] indicate a wrong sign. 
The next equation explains the market share of individual countries. This time, however, the patents indicator used is not biased by size. It is defined as follows.

$$
T_{i j}=\left[\left(P_{i j} / \sum_{i} P_{i j}\right) /\left(N_{i j} / \sum_{i} N_{i j}\right)\right]\left[\left(Q_{i j} / \sum_{i} Q_{i j}\right) / z_{i j}^{u s}\right]
$$

Essentially, this indicator is a normalized patents per head indicator, with the average number of patents per head in the sector as the normalization variable. Moreover, the indicator is corrected for the direction of trade, and the openness of the economy by multiplying it with the ratio of the shares in production and exports to the USA (multiplying by a number larger (smaller) than one if a country is closed (open) towards the USA).

Another variable that is included in the regression at this stage is the share in total population. This is done for two reasons. First, on the lhs of the equation is now a variable that is highly dependent on country size, while the variables on the rhs are all independent of size. Therefore, an equation without the size variable suffers from misspecification due to left-out variables. Second, following DPS, the influence of scale economies is tested. The share in total population is assumed to capture these two effects. The other variables (including the definition of the dummies) are the same as in the previous equation.

The results of this estimation can be found in Table VIII.3. Overall, the $\mathbf{R}^{2}$ statistics are somewhat lower than in the previous equation. Still, they are in most cases acceptable. The wage cost variable performs less well than in the previous equation. Now, in most cases the sign is wrong (positive), and the $t$-values are low. Thus, the influence of wage rate differentials in this equation is, if anything, reverse. This result corresponds more or less to the results in DPS. A possible explanation for this might be the differences in quality of labour, corresponding to differences in wages, in broad accordance with the efficiency wage hypothesis.

The performance of the labour productivity variable is more or less the same as in the previous equation. Only in the nonferrous metals sector is the sign wrong (although the $t$-value is not significant). In industrial chemicals, rubber and glass, the correct sign is not significant. In an (undocumented) regression with a more restrictive form (standardized unit wage costs instead of the two separate terms $g$ and $w$ ), the net result of these two results was that the unit wage variable is in most cases significant with the correct sign. This shows the dominance of the labour productivity results in this equation.

The patent variable also performs less well than in the first equation. Still, some plausible results arise. First, in ten sectors, the sign of the patent variable is correct and significant, as well as the sign of the USA dummy. Most of these sectors (chemicals, plastic, fabricated metal, machinery, instruments) are high-or mediumtech sectors. The textiles and apparel sectors also belong to this group, which is perhaps surprising, given their low-tech image (compare, however, the results for this sector in Chapter 4). The absence of transport in this group is notable, but might be explained by its very crude aggregation. Significantly negative signs are found in food, refined oil, rubber, glass, and other minerals, all of them sectors in which there natural resources play a major role, which might explain part of their bad performance, as in DPS. Once again, the Japanese dummy is mostly positive, 
Table VIII.3. Relation between market share, wage rate, labour productivity and patents per capita.

\begin{tabular}{|c|c|c|c|c|c|c|c|c|}
\hline SECTOR & $d(w)$ & $a(g)$ & ait) & $d(x)$ & dipe & $\alpha(s)$ & $E$ & $n / R^{*}$ \\
\hline Food & -0.00006 & 0.065161 & -0.0031 & $0.0004 \%$ & -0.0068 & 0.40085 & -0.03067 & 363 \\
\hline - & 0.00 & $11 . n-$ & $4.55-$ & Q.4B & $3.19=$ & $7.15=$ & $6.30=$ & a.53 \\
\hline Texiles & -0.0192 & $0.002890^{\prime}$ & 0.011561 & 0.01946 & -0.02197 & $1.02 x$ & 0.000165 & 323 \\
\hline & $3.46=$ & $3.95=$ & $177-$ & $8.39=$ & 2280 & $1305-$ & 0.02 & 0.48 \\
\hline Apperw1 & -0.01801 & 0.013492 & 0000029 & 0,0004 & -0.01924 & 0.7920 & 0.0219 & 323 \\
\hline & $321=$ & $230=$ & $201-$ & $7.13=$ & $5.17=$ & $893=$ & $2.65-$ & 0.30 \\
\hline Ind chem & 0.054614 & 0.000069 & 0.0167 & $0.0 x a c 0$ & -0.05853 & 1.1205 & 0.06201 & 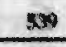 \\
\hline & $9.39=$ & 1.04 & $8.18=$ & $12 \times 9 \cdots$ & $6.39 \cdots$ & $1571-$ & $9.73=$ & 0.54 \\
\hline Oth chem & 0.023164 & 0.036324 & 0.026831 & -0.003701 & -0.10866 & 0.96248 & $0.04 \%$ & 470 \\
\hline E & $4.12=$ & $441=$ & $8.19 m$ & $112)^{\circ}$ & $10.12 \mathrm{~m}$ & $13.10=$ & B.18 m & 0,49 \\
\hline Rel oll & 0.006189 & 0.012124 & -0.0004 & 0.001693 & 0.0004 & -0.17426 & actors? & 25 \\
\hline & 0.57 & $201-$ & $3.32=$ & $1.69^{\circ}$ & 0.82 & 1.27 & $3.37=$ & 0.05 \\
\hline Rubber & 0.041836 & 0.003866 & -0.00166 & 0.01035 & 0.0139 & 1.1462 & $+0.032 n 2$ & 501 \\
\hline & $9.38=$ & 0.95 & $2.62 \mathrm{~m}$ & $8.96 \cdots$ & 0.94 & $15.82=$ & $5.45=$ & 0.4 \\
\hline Puntic & 0.023134 & 0.012072 & 0.007619 & 0.01841 & $-0,02055$ & $1.002 \times$ & -0.03011 & 4 \\
\hline & $4.69=$ & $2.21 *$ & $5.52=$ & $11.55=$ & $8.13=$ & $13.87=$ & $4.43=$ & 0.36 \\
\hline Pottery & 0.002524 & 0.01507 & -0.00052 & 0.00712 & 0.16759 & 1.5847 & -0.01597 & 41 \\
\hline 2 & 0.42 & $300 *$ & 1.15 & $9.34 \cdots$ & $4.47=$ & $14.93=$ & $1.82^{*}$ & 0.48 \\
\hline Glass & 0.030697 & 0.003121 & -0.00291 & -0.00973 & 0.0477 & 1.1222 & 0.01348 & 41 \\
\hline $2=$ & $4.03 \cdots$ & 0.33 & $1.68^{\circ}$ & $4.08 \cdots$ & $5.32 \cdots$ & $10.60 \cdots$ & $1.61^{\circ}$ & 0.27 \\
\hline Oth min & 0,003625 & 0.039157 & -0.00053 & -0.01278 & -0.03395 & 1.2647 & $-0,03203$ & 446 \\
\hline & 0.65 & $4.90 \cdots$ & 1.06 & $9.67 \cdots$ & $4.72=$ & $14.08 *$ & $4.10=$ & 0.34 \\
\hline Iron, steel & 0.025197 & 0.094556 & 0,009557 & -0.01988 & -0.00902 & 1.2722 & -0.10761 & 348 \\
\hline 3 & 275 & $9.32 \cdots$ & 4.84 & $8.36=$ & 0.74 & $11.25-$ & $7.22 \%$ & 0.45 \\
\hline Non-ferr & 0.065405 & $-0,00102$ & -0.00123 & -0.00585 & -0.0159 & 0.67825 & -0.02997 & 345 \\
\hline & $10.70^{40 *}$ & 0.15 & 1.05 & $4.16=$ & $5.24=$ & $9.25=$ & $4.21=$ & 0,36 \\
\hline Fab met & 0,017142 & 0.038682 & 0.013944 & -0.00255 & -0.06953 & 1.0115 & 0.0451 & 557 \\
\hline 01 & $3.04 \cdots$ & 5.600 & $5.09=$ & $8.33=$ & $3.51 \cdots$ & $16.71 \cdots$ & $9.28=$ & 0.51 \\
\hline Non-l mach & 0.028212 & 0.01774 & 0.021701 & 0.029 & -0.04345 & 1.1252 & -0.01257 & 621 \\
\hline 2 & $4.42 \cdots$ & $3.70 \cdots$ & $6.17 \ldots$ & $7.73 \cdots$ & $2.25{ }^{\circ}$ & $14.95=0$ & $8.62 \mathrm{mo}$ & 0.51 \\
\hline El mach & 0.010018 & 0.0231 & 0.012833 & $-0,01814$ & 0.14906 & 0.86756 & -0.03058 & 576 \\
\hline & $2.03^{-}$ & $3.48 \cdots$ & $8.89=$ & $10.99 \cdots$ & $1271=$ & $14.92-$ & $5.92=$ & 0,65 \\
\hline Transport & 0.052198 & 0.031617 & -0.00035 & -0.01556 & 0.024302 & 1.1827 & -0.05821 & 499 \\
\hline$=$ & $7.58 \cdots$ & $4.83=$ & 0.65 & $8.20=$ & 151 & $16.08=$ & 10.73 & 0.63 \\
\hline Instruments & 0.016479 & 0.028643 & 0.037025 & -0.04195 & 0.0775 & 1.161 & $-0,04571$ & 525 \\
\hline 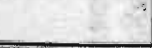 & $254 \mathrm{~m}$ & $4.94 \cdots$ & $6.98 \cdots$ & $7.97 \%$ & $3.60=0$ & $12.86=$ & $7.66-$ & 0.54 \\
\hline
\end{tabular}


Table VIIL4. Ranking of sectors according to the value of the estimated parameters in Table VIII.3.

\section{Sequence}

number

Productivity

Patents

Population

\begin{tabular}{llll}
\hline 1 & ([Nonferrous metals]) & [Food] & Refined oil \\
2 & (Glass) & [Glass] & Food \\
3 & (Rubber) & [Rubber] & Nonferrous metals \\
4 & (Industrial chemicals) & ([Nonferrous metals]) & Apparel \\
5 & Plastic & ([Other minerals]) & Electrical machinery \\
6 & Refined oil & ([Pottery, etc.]) & Other chemicals \\
7 & Apparel & [Refined oil] & Fabricated metal \\
8 & Pottery, etc. & ([Transport]) & Plastic \\
9 & Nonelectrical mach & Apparel & Textiles \\
10 & Electrical machinery & Plastic & Glass \\
11 & Instruments & Iron and steel & Nonelectrical machinery \\
12 & Transport & Textiles & Industrial chemicals \\
13 & Textiles & Electrical machinery & Rubber \\
14 & Other chemicals & Fabricated metal & Instruments \\
15 & Fabricated metal & Industrial chemicals & Transport \\
16 & Other minerals & Nonelectrical machinery & Other minerals \\
17 & Food & Other chemicals & Iron and steel \\
18 & Iron and steel & Instruments & Pottery, etc. \\
\hline
\end{tabular}

- For the wage variable, sectors are ranked in order of decreasing magnitude (i.e., large positive values first and large negative values last); for the other variables, the order is reverse. Round brackets () indicate nonsignificance, straight brackets [] indicate a wrong sign. Numbers following sector names indicate shifts in rank relative to Table VIII.2. 
indicating a better Japanese performance than can be predicted just by patents.

The population variable is significant in all but one sector (refined oil), which indicates the influence of size and economies of scale. These two influences can be separated out by looking at the magnitude of the estimated coefficient and their rank order. Table VIII.4 ranks the sectors by magnitude of the estimated parameters. The wage rate estimates are excluded from this, because the results cannot directly be interpreted. In the productivity column, food and other minerals rank among the high elasticities, while otherwise one finds the high-tech sectors in the lower part of the table. In the patents column, the result of the low-tech, partly natural resource-based sectors ranking low (with wrong signs), and the typical high-tech sectors ranking high is now very clear. With regard to the population variable, the switch from coefficients smaller than unity to larger than unity lies between other chemicals and fabricated metal (positions 6 and 7). Thus, most sectors have an estimated elasticity with regard to size that is larger than one, which might point to the existence of scale economies in these sectors.

Summarizing Tables VIII.1 - VIII.4, there seems to be evidence in this data set for the importance of technology in the static explanation of trade patterns, as found before by DPS. Mostly, sectors in which technology plays a major role (according to the results) are also the sectors that one would intuitively label as high- or medium-tech. The results with regard to the importance of low wage rates also correspond to those in DPS, indicating that low wage rates do not ceteris paribus go together with good export performance.

\subsection{Trade and Technology: A Dynamic Evolutionary Framework}

The aim of this thesis is to provide a dynamic, evolutionary perspective on the relation between trade, growth and technology. In light of the interpretation of these concepts that has been used until now, the analysis by DPS (and the previous section) can be characterized as essentially taking a static, structural, point of view. What is being estimated is the relation between the structure of technological capabilities (mainly as measured by patents), and the structure of trade relations. The regressions performed relate the trade structure to the innovation structure, assuming that the relation between the two does not change over time (this is even the case in the pooled data set in the previous section).

In Chapter 7, the replicator equation was used to describe the relation between technological performance and trade from a specific dynamic and evolutionary perspective. The rest of this chapter will be aimed at testing the empirical value of this explicit way of modelling the evolutionary dynamics of trade and technology. The assumption behind the replicator equation is that differences in competitiveness induce changes in the trade structure, as opposed to the more commonly used notion that differences in competitiveness correspond to differences in the trade structure. The replicator equation can be rewritten, so that it only has the current period market share on the lhs, as follows. 


$$
z_{i j p}=\left(1-\sum_{k} \phi_{j k}\right) z_{i p-1}+\sum_{k} \phi_{j k} \frac{E_{i j k t}}{\bar{E}_{i j k}} t z_{i j p-1}
$$

This form of the equation contains a number of restrictions, which can be tested in a regression analysis. The form of the equation that will be used for this is the following.

$$
z_{i j,}=\Psi z_{i j}^{i-1}+\sum_{k} \phi_{j k} \frac{E_{i j k}^{l} z_{i j}^{l-1}+c_{j}+e_{i}}{\bar{E}_{j k}^{\prime}}
$$

The 'evolutionary restrictions' that would give equation (VIII.9) the same form as equation (VIII.8) are $\Psi=1-\sum \phi_{k}, c_{j}=0$, and $e_{i}$ being a usual error term. These restrictions will be tested by the appropriate tests below. The last restriction (about the error term) is quite special here. Note that in the complete replicator system with equations for each country in the sample, the error terms sum to one by definition (see also Appendix VII.2). Thus, the assumption about a zero mean of the error term is satisfied by definition. However, this also introduces interdependent error terms, which should ideally be taken into account in the estimation procedure. However, since one does not generally have observations for $E$ for each country in the sample, it is possible that the error term does not have mean zero, and the interdependencies are more complex than in the case of a full system of equations. In fact, the mean of the error terms would be exactly zero only if the average value of competitiveness of the left-out countries were equal to $\bar{E}$. In case this does not hold, the estimated constant will pick up the mean of the error term ${ }^{13}$. Thetefore, although the constant is assumed to be zero in theory, one should not be surprised if it turns out to be significant in practice.

Moreover, the combination of the lagged dependent variable and the error term in equation (VIII.9) introduces the concept of a stochastic trend into the model. Stochastic trends have been the key concept in a recent discussion about permanent and transitory components in macroeconomics (the unit root debate), which had a large influence on the estimation of equations with a stochastic trend $^{14}$. The conclusions from this debate are not, however, directly applicable to the model used here, because of the complicated error structure discussed above, and the variable $z$ being bounded between zero and one. Thus, while the point about the error structure is well taken, the analysis will proceed by using simple OLS methods.

The question that has been raised above a few times and that has to be faced here ultimately, is how to define the different aspects of competitiveness, or how to

${ }^{13}$ To be precise, the above reasoning about the interpretation of the constant term only holds for observations belonging to one time period, and not for the whole pooled data set. In the estimations, year-specific additive dummies were estimated, but these proved to be insignificant in general. Therefore, it seems that the error resulting from this source can be picked up by a single constant term.

"For overviews of this discussion, see Stock and Watson (1988) and Campbell and Perron (1991). For an original contribution from the point of view of evolutionary theory, see Lippi (1989). 
measure $E_{k}$. The approach taken is basically the same as that in the previous section. The same variables will be used, although they will be slightly transformed to make them more consistent with the replicator equation approach. Thus, there will be wage rate, labour productivity and patent variables as different aspects of competitiveness. Using the wage rate and productivity variables, it is possible to deduce the importance of both aspects of technology introduced above (cost competition and quality competition) by looking at the parameter estimates of $\phi_{k}$, with $k=$ (wage rate, labour productivity). To grasp this, consider the case in which (the absolute values of) the estimates of the partial $\phi s$ of the wage rate and labour productivity are equal to each other. This means that if a country has unit wage costs exactly equal to the world level, its market share will not change. The same situation, but with the partial $\phi$ for labour productivity now being larger than the one for the wage rate, means that even if unit wage costs are equal to the average, the market share will change (the direction depends on the 'source' of averagely competitive unit wage costs). Obviously, in this case there is more to technology than just the price competitiveness aspect. Thus, the extent to which (the absolute value of the partial $\phi$ for labour productivity is larger than its wage rate counterpart is a measure for the importance of the 'non-price-competitionrelated' aspects of technological change.

\subsection{Estimation of the Replicator Equation}

In the construction of the independent variables in the estimations of the replicator equation, one should be aware that the term $E / \bar{E}$ has an average value of one for countries with competitiveness exactly equal to average. In the theoretical logic of the equation, this is assured by the definition of $\bar{E}$. However, because the exact construction of $\bar{E}$ in this way is somewhat misleading in the case of missing values, a different approach is taken here. Like in the estimations above, the independent variables are standardized by the sample mean, so that an average value of one results. In addition, one should realize that according to equation (VIII.9), this value must be multiplied by the previous period market share. Thus, the following definition for the wage rate variable arises.

$$
w_{i j t}=z_{i j+1}\left(E_{i j t} / \bar{E}_{j i t-1}\right)=z_{i j-1}\left(W_{i j} / L_{i j p}\right) /\left(\sum_{i} W_{i j} / \sum_{i} L_{i j t}\right)
$$

The labour productivity indicator is defined in a similar way.

$$
g_{i j t}=z_{i j-1}\left(E_{i j 2 t} / \bar{E}_{j 2 t}\right)=z_{i j-1}\left(Q_{i j t} / L_{i j t}\right) /\left(\sum_{i} Q_{i j t} / \sum_{i} L_{i j}\right)
$$

The scale variable included in the regression is now scaled to the value one, which it obtains for a country that is exactly as large as the simple mean of all countries.

$$
s_{i t}=z_{i j-1}\left(E_{i j k} / \bar{E}_{j a t}\right)=z_{i j-1}\left(N_{i t} / \sum_{i} N_{i t}\right) /\left[(1 / n) \sum_{i}\left(N_{i t} / \sum_{i} N_{i t}\right)\right]
$$

Note that the effects that are due to size differences are included in the lagged dependent variable, so that the size variable is mainly related to economies of scale now. 
The first patent indicator used is the one in the regression in Table VIII.1 and VIII.2, but normalized by the market share $z^{\text {us }}$. This means that the indicator is now free of influences of size differentials between countries, and has a 'natural' average of one. In mathematical terms, it looks as follows.

$$
T_{i j t}=z_{i j-1}\left(E_{i j k t} / \bar{E}_{j \mu t}\right)=z_{i j t-1}\left(P_{i j t} / \sum_{i} P_{i j p}\right)\left(1 / z_{i j t}^{\text {us }}\right)
$$

The estimated equation looks as follows.

$$
z_{i j}=\Psi_{i j} z_{i j}^{t-1}+\phi_{j 1} w_{i j}+\phi_{j 2} z_{i j}+\phi_{j s} s_{i}+\phi_{j k} T_{i j 1}+d_{u s o n}+d_{j p m}+e_{i}
$$

In first instance, this equation is estimated for the whole sample of pooled observations (1964-1987). The results are shown in Table VIII.5. The $\mathrm{R}^{2}$ statistics in this table are generally blurred, because market shares change only very slowly, so that the autoregressive term has a large explanatory power. Therefore, the partial $\mathbf{R}^{2}$ of the variables of interest (technology-related, population and wages) are generally lower. The $t$-statistics in the column for the autoregressive term are constructed under the hypothesis that $\Psi=1-\Sigma \phi_{\mathrm{k}}$. Thus, they test one of the two restrictions that result from the evolutionary logic, so that an insignificant value indicates a 'good' result. The results show that in many cases (exactly half), rejection of this hypothesis is indeed the result, which shows the limits of the evolutionary logic. Nevertheless, the value of most of the parameters for $z_{t \cdot 1}$ still has the correct sign (i.e., it is on the correct side of one), and one must keep in mind that the values used in the $t$-test are estimates for the other parameters, which are subject to variation, as shown by their standard errors.

The wage rate variable gives good results. A correct significant sign is found 15 out of 18 times, which is nine times significant. A significant, but wrong sign is found twice (glass, nonferrous metals). More or less the same result is found for the labour productivity estimates. In 10 out of 18 cases, the parameters have a significant and correct sign, and one time (other minerals) a significant, but wrong sign is found. This indicates that the evolutionary specification of the competition process makes sense, and that these two variables are indeed strongly related to the evolutionary performance of countries.

The results are less clear for the patent-related variable. Only six times is it significant, and four out of these six times, it has a negative sign. Particularly in the chemically related sectors the negative signs are remarkable. The two patent dummy variables also show insignificant or significantly wrong signs in many cases.

The population variable is often (12 times) significant and has a positive sign, particularly in high-tech sectors. The presence of economies of scale seems to be indicated by this result (see also Fagerberg 1991). With regard to the constant, it is worth noting that the 'predicted' violation of the second evolutionary restriction (the constant is equal to zero) is indeed taking place in many cases, although the estimated value is generally small, and in many cases only weakly significant. 
Table VIII.5. Results for the replicator equation, wage rate, labour productivity, patents over export and population as dependent variables

\begin{tabular}{|c|c|c|c|c|c|c|c|c|c|}
\hline SECTOR & 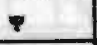 & (a) & $(2)$ & (N) & dinsen & atipus & 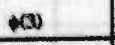 & $\varepsilon$ & $\omega / R^{n}$ \\
\hline Food & 0.9088 & 0.0214 & 0,06004 & $0.0015 s$ & $-0,0125$ & a.x617 & 0.002458 & 600044 & 342 \\
\hline & 154 & 1.38 & $3.48-$ & 0.21 & $1.90^{\circ}$ & $211-$ & $2.62=$ & $1.68^{\circ}$ & 6.0 \\
\hline Tealle & 0.92172 & -0.00391 & 0.00207 & 0.0201 & - Moesrs & a)1245 & $0,001 \% 3$ & ac0114 & 34 \\
\hline$y=$ & 0.94 & $331=$ & $298=$ & $264=$ & $3 . x^{m}$ & 4. & 260 & $22 n=$ & 0,90 \\
\hline Apparel & 0.9578 & -0.0441 & 0.04169 & acoisen & $0.000 \mathrm{~ns}$ & $-0,0 \operatorname{sen}$ & -90017 & 0,00004 & 32 \\
\hline & 1.13 & $2.23=$ & $1.74^{\circ}$ & 1.42 & 0.24 & $1.70^{\circ}$ & $1.3 \%$ & $1,83 *$ & ass \\
\hline lnd chem & 0.9727 & -0.02513 & 0,035009 & -0.0048 & 0.026511 & -0.07448 & $0.000 \times 4$ & 0.000404 & 50 \\
\hline & 1.00 & $1.7^{\circ}$ & $1.61^{\circ}$ & 240 & $189^{\circ}$ & $2.62=$ & 1.6 & $1.61^{\circ}$ & $\$$ \\
\hline Oth chem & 1.0086 & -0.00044 & 0.03549 & $-0,04123$ & 0,03612 & $-0,0025$ & 0.000324 & 0.00036 & 47 \\
\hline t & 1.12 & $251=0$ & 1.15 & $2.42=$ & $246=$ & 0.05 & 0.33 & 1.25 & 0.90 \\
\hline Ret all & 0.09316 & 0.0168 & 0.002026 & $-0,0002$ & 0.000740 & $0.001 \mathrm{~m}$ & 0.00101 & 0.00158 & 257 \\
\hline & 0.75 & 0.52 & 3.49 & 0.46 & 0.12 & 0.43 & 0.7 & 1.4 & 0.97 \\
\hline Rubber & 0.80502 & -0.00403 & $0.062 \mathrm{~m}$ & 0.00231 & 0.004401 & -0.1405 & 0.00346 & $0.00126 ?$ & 501 \\
\hline$x=$ & $24=$ & 0.24 & $2.53-$ & $2.07 \%$ & 0.39 & $4.15=$ & $3.17=$ & $3.42=$ & 0.9 \\
\hline Puntic & 0.92513 & 0.01449 & 0.00817 & 0.014107 & 401156 & $\cos x$ & -0.00074 & 0.000649 & 48 \\
\hline ar & 0.22 & 0.58 & 1.0 & 1.8 & 1.25 & $2.10=$ & 0.63 & 1.32 & $0.9 n$ \\
\hline Poltery & 1.0146 & -0.04651 & 0.009181 & $-0,00001$ & 0.000068 & $-0.150 m$ & 0.60004 & 0.001197 & 41 \\
\hline 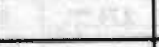 & 0.74 & $251 \cdots$ & 0.92 & 0.01 & 0.01 & $2.77^{m}$ & 0.06 & $2.68 m$ & 0.99 \\
\hline Glass & 0.90633 & 0.008737 & 0.008669 & $-0,00975$ & -0.01006 & -0.06641 & 0.003002 & 0.001028 & 441 \\
\hline 25 & $2.61=$ & $2.95=$ & 0.27 & 0.71 & 0.75 & $2.20 *$ & $3.58=0$ & 2.850 & 0.99 \\
\hline Oth min & 1.048 & 0.019216 & -0.08576 & -0.002 & -0.00443 & -0.06423 & 0.001596 & 0,000749 & 446 \\
\hline & 0.74 & 1.20 & $29 n$ & 0.45 & 0.81 & $2.49 *$ & $1.77^{*}$ & $1.90^{*}$ & 0,99 \\
\hline Iron, steel & 0.89993 & 0.021103 & -0.01532 & -0.01988 & -0.0059 & -0.18702 & 0.006713 & 0,002504 & 348 \\
\hline & $2.46=$ & 0.70 & 0.66 & 1.01 & 0.31 & $4.19=$ & $8.28=$ & $3.34 *$ & 0.98 \\
\hline Non-fer & 0.74804 & 0.046574 & 0.09900 & -0.00914 & -0.01971 & -0.11131 & 0.01058 & 0.003527 & 345 \\
\hline 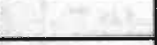 & $3.23=$ & $1.87^{*}$ & $2.58 \cdots$ & $2.76=$ & $1.7{ }^{\circ}$ & $4.14 \cdots$ & $6.22 \cdots$ & $5.14^{-\infty}$ & 0.96 \\
\hline Fab mat & 0.86891 & $-0,00302$ & 0.071846 & -0.02184 & -0.00636 & 0.36023 & 0.004007 & 0.001145 & 557 \\
\hline & $236=$ & 0.19 & $2.24 \%$ & 1.22 & 0.36 & $5.65 \cdots$ & $490=$ & $3.80 \cdots$ & 0.99 \\
\hline Nonel mach & 0.95319 & -0.04119 & 0.000378 & 0.001827 & $-0,0094$ & 0.048829 & 0.002151 & 0.000706 & 621 \\
\hline 65 & $1.64^{*}$ & $3.14 \cdots$ & 1.10 & 0.09 & 0,43 & 1.20 & $2.16 \%$ & $3.33 \cdots$ & 1.00 \\
\hline Fl mach & 0.84957 & -0.0654 & 0.1038 & 0,00009 & -0.03245 & -0.21126 & 0,005291 & 0.001191 & 576 \\
\hline$x_{0}$ & $3.28-$ & $3.26 \mathrm{mon}$ & $3.52 \mathrm{~m}$ & 0.01 & $3.28 \cdots$ & 4.200 & $7.68 \mathrm{~ms}$ & $4.21=$ & 0.90 \\
\hline Transport & 0.75232 & -0.0367 & 0.16181 & 0.029982 & -0.09727 & -0.31188 & 0.006506 & 0.001108 & 499 \\
\hline & $274^{m}$ & $1.93 *$ & $7.06=$ & $211 \%$ & $5.26 \cdots$ & $8.18 \cdots$ & $7.24=$ & $3.09=$ & 0.99 \\
\hline Instruments & 0.9598 & $-0,05681$ & -0.00494 & 0.025421 & 0.03168 & 0.10688 & 0.003095 & 0.001113 & 325 \\
\hline & $250=$ & $3.25 \mathrm{~m}$ & 0.22 & 0.98 & 1.14 & $3.05 \ldots$ & $2.85=$ & $399=$ & 0.99 \\
\hline
\end{tabular}


Table VIIL.6. Results for the replicator equation, wage rate, labour productivity and patents per head as dependent variables

\begin{tabular}{|c|c|c|c|c|c|c|c|c|c|}
\hline SECTOR & $\Psi$ & (it) & 42 & (4) & (1usen) & $d(j p m)$ & (3) & $c$ & $\pi / R^{2}$ \\
\hline Food & 0.50945 & -0.02123 & 0.058816 & 0.001767 & $-0.66 \mathrm{an}$ & -0.06088 & 0.000511 & 0.003854 & 362 \\
\hline t & 1.58 & 1.34 & $3.17=$ & 0.38 & $202=$ & $215^{*}$ & $2.87=$ & $1.92 *$ & 0.98 \\
\hline Textles & 0.91996 & -0.07423 & 0,055189 & 0.01623 & consas & -0.00928 & 0.00024 & 0.001204 & 323 \\
\hline$=$ & 124 & $3.44=$ & $3.04=$ & $2.87=$ & $3,62=$ & $5.10=$ & $2.73 \cdots$ & $234^{-0}$ & 0.99 \\
\hline Appurel & 0.9725 & 40.65060 & 0.0439 & 0.001687 & 0.000235 & $-0.0 \times 07$ & 0.0019 & 0.00093 & 32 \\
\hline 21 & 1.13 & $250=$ & $1.55^{*}$ & $1.99 *$ & 0.14 & $1.64^{\circ}$ & 1.58 & $1.82^{\circ}$ & 0.98 \\
\hline Ind chem & 0.57252 & -0.00298 & 0.0479 & -0.0121 & 0.005446 & -0.06284 & 0.001196 & 0,000034 & 509 \\
\hline & 0.41 & $160^{\circ}$ & $2.17 *$ & $188 *$ & 0.82 & $3.50=$ & $1.71^{\circ}$ & 1.36 & 0.99 \\
\hline Oth chem & 0.98836 & -0.0000 & 0.00005 & -0.0123 & 0.0091 & -0.02068 & 0.000768 & 0.008413 & 478 \\
\hline & 0.51 & $2.44=$ & 1.31 & $204=$ & $1.62 *$ & 0.70 & 0.91 & 1.44 & 0.99 \\
\hline Rel ofl & $0 \sin 26$ & .0 .01654 & 0.093994 & $-0,0012$ & 0.001064 & $-0,60249$ & $-0,001$ & 0.00161 & 257 \\
\hline & 0.74 & 0.50 & $352=$ & 0.73 & 0.30 & 0.35 & 0.69 & 1.49 & 0.97 \\
\hline Rubber & 0.88496 & -0.00432 & 0.06945 & 0.01097 & 0.00047 & 0,0989 & 0.000138 & 0.00106 & 501 \\
\hline & $1.83^{*}$ & 0.20 & $311=$ & $190^{\circ}$ & 000 & $4.14=$ & $2.85=$ & $2.85 \cdots$ & 0.99 \\
\hline Mastic & 0.91765 & 0.015002 & 0.03685 & $0.00 \mathrm{~m} / \mathrm{s}$ & $-0,00057$ & 0,0405 & 0,00006 & 0.0009 & 486 \\
\hline & 0.60 & 0.66 & 1.46 & $1.70^{*}$ & 1.47 & $247 *$ & 0.34 & $1 \% 8^{*}$ & 0.98 \\
\hline Pottery & 1,0196 & -0.04976 & 0.009233 & 0,000006 & 0.00044 & -0.07912 & $-0,00011$ & 0.001395 & 41 \\
\hline & 0.68 & $2.68 \cdots$ & 0.93 & 0.00 & 0.11 & $2.55=$ & 0.14 & $2.74 * *$ & 0.99 \\
\hline Ginat & 0.90516 & 0,025919 & 0.006366 & 0.001604 & 0.01364 & -0.05508 & 0.000016 & 0.000974 & 441 \\
\hline 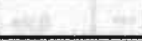 & $2.22 *$ & $2.63=$ & 0.31 & 0.19 & $1.68^{\circ}$ & $2.66 * 0$ & 3.57 & $2.78 \cdots$ & 0.99 \\
\hline Oh min & 1.0478 & 0.018533 & -0.08315 & -0.00134 & -0.00329 & $-0,03111$ & 0.001465 & 0.00072 & 446 \\
\hline 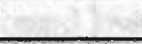 & 0.65 & 1.16 & $2.87 \cdots$ & 0.48 & 0.88 & $241 *$ & $1.62^{*}$ & $1.85^{*}$ & 0.99 \\
\hline Iron, steel & 0.90027 & 0.000071 & 0.00637 & 0.001883 & -0.01687 & -0.07134 & 0.006308 & $0.002 a 15$ & 348 \\
\hline & $2.21 *$ & 0,00 & 0.28 & 0.19 & $1,74^{*}$ & $4.10=0$. & $8.00=$ & 3.16 - & $0.9 \%$ \\
\hline Non-for & 079845 & 0.037186 & 0,08696 & -0.00527 & -0.01317 & -0.04642 & 0.006156 & 0.002805 & 345 \\
\hline$y=$ & 190 & 1.45 & $2.04^{\circ}$ & 0.81 & $2.25 *$ & 3.15 t* & $4.38 \cdots$ & $4.14=$ & 0.98 \\
\hline \multirow[t]{2}{*}{ Fah mat } & 0.86816 & -0.0119 & 0.07527 & $0.005 \%$ & $-0,0 \mathrm{~m}$ & -0.21277 & 0.0003766 & 0,001134 & 557 \\
\hline & 1.90 & on & $246=$ & 0.70 & 0.92 & $5.38 \cdots$ & $4.64 \cdots 0$ & $3.74 \cdots$ & 0.99 \\
\hline \multirow[t]{2}{*}{ Nenel mueh } & 0.9246 & $-0,0358$ & 0.03535 & 0,002262 & -0.0128 & -0.0006 & 0.002055 & 0.000848 & 621 \\
\hline & $2.244^{\circ}$ & $274=$ & 1.30 & 0.31 & 1.50 & 0.04 & $3.78 \mathrm{~m}$ & $3.94 \cdots$ & 1.00 \\
\hline Bi mach & $0.810 \% 1$ & $-0.0 \mathrm{~m} 15$ & 0.1734 & -0.00218 & -0.01454 & 0.08091 & 0.005167 & 0.001059 & 576 \\
\hline+ & $2.71 \cdots$ & 360 & $5.62 \cdots$ & 0.49 & $3,30 \cdots$ & $6.21 \%$ & $7.17 m$ & $3.2 \cdots$ & 0.99 \\
\hline Trempoxt & 0.80014 & $-0,00016$ & 0.17283 & 0.023751 & -0.00673 & 0.13318 & 0,004166 & 0.000985 & 49 \\
\hline$=$ & $2.22=$ & $111 \cdots$ & 7.600 & $340 \mathrm{~m}$ & $4.45 \cdots$ & $6.37 \div$ & $456^{-6}$ & $2.60=0$ & 0.99 \\
\hline \multirow[t]{2}{*}{ lnatruments } & 1,0000 & $-0,0 \times 341$ & $0.001 \%$ & 0,049 & 0.048113 & 0.064916 & a.0n461 & 0.00046 & 52 \\
\hline & $2.19 *$ & $1.91^{\circ}$ & $1.62^{\circ}$ & $2.91=$ & $2.76 \mathrm{~m}$ & $3.64=$ & 1.33 & $2.86-$ & 09 \\
\hline
\end{tabular}


Table VIII.7. Results for the replicator equation, wage rate, labour productivity and population as dependent variables

\begin{tabular}{|c|c|c|c|c|c|c|}
\hline SECTOR & $\Psi$ & (1) & (a) & (13) & G & s/ $/ R^{3}$ \\
\hline Food & 091229 & -0.0029 & $0,4 / 2316$ & 0.0065 & o.onocis & 69 \\
\hline & 250 & $254 \cdots$ & $502=$ & 1.95 * & $3.26-$ & as \\
\hline Beverstze & a.srast & -0.0349 & Q.147es & -0.0000 & 0.00018 & 699 \\
\hline & 0.40 & 476 & $6.18=$ & 0.70 & $2.02=$ & 0.9 \\
\hline Tobanos & 1.0005 & -0.02906 & 0.009 & $-0,00001$ & 0.000001 & 67 \\
\hline & 0.75 & $2.79=$ & 150 & 005 & 0.66 & 0.9 \\
\hline Textiles & 0.95318 & -0.064 & $0.009 a 13$ & acomis & $0.000 \times 5$ & 609 \\
\hline & 1.16 & $4.40=$ & 3.55 m & 1.22 & $2.73=$ & 009 \\
\hline Apparel & 1.027 & 0.00752 & 0.001628 & -0.00192 & $0.00063 \%$ & 604 \\
\hline & 0.88 & $2.65=$ & 0.10 & $3.27=$ & $255=$ & 0.98 \\
\hline Lewher & 0.96824 & -0.06058 & 0.051561 & 0.001234 & 0000740 & 687 \\
\hline & $1.61^{*}$ & $4.85=$ & $3.32=$ & $236-$ & 250 & 0.84 \\
\hline Footwe:ar & 0.97107 & -0.158078 & 0.12002 & -0.00038 & 0.001225 & 689 \\
\hline & 2.29 & $9.04=$ & $6.78-$ & 0.27 & $37 x=$ & 0.0 \\
\hline Weod & 0.8746 & 0.059230 & 0,01294 & o.00004s & 0.001016 & 608 \\
\hline & $210^{\circ}$ & $6.04=$ & $a 73$ & 0.12 & 2870 & 0.97 \\
\hline Wood fum & 1.034 & -0.00551 & 00004 & 0.00169 & 0.000103 & 682 \\
\hline$x^{2}$ & 0.42 & $2.85 \cdots$ & 0.54 & $2.85-$ & 0.36 & 0.9 \\
\hline Paper & 1.0863 & -0.03082 & -0.05983 & 0.000796 & 0.000178 & 699 \\
\hline haing & 0.16 & $3.75 \cdots$ & $4.57 \cdots$ & $4.24 \cdots$ & 0.87 & 0.99 \\
\hline Print/Publ & 0.99535 & $-0,02055$ & 0.022544 & 0,000119 & 0,000078 & 670 \\
\hline & 0.15 & $1.68^{\circ}$ & 1.21 & 0.54 & 0.45 & 0.99 \\
\hline Ind chem & 0.95391 & $-0,02733$ & 0.031956 & 0.000484 & 0.000267 & 694 \\
\hline & 0.67 & $2.77 \cdots$ & $2.21=$ & $1.911^{*}$ & 1.52 & 0.99 \\
\hline Oth chem & 0.99083 & 0,03459 & 0.036245 & $0.00028 s$ & 0.0001329 & 697 \\
\hline & 0.35 & $4.08 \cdots$ & $1.26^{\circ}$ & 1.04 & $1.89^{*}$ & 0.99 \\
\hline Ref oil & 0.94446 & 0.009535 & -0.00069 & -0.0011 & 0.000655 & 673 \\
\hline & 0.71 & $1.95 \%$ & 0.00 & $2.29 \cdots$ & 2.16 & 0.97 \\
\hline Mise CseO & 0.94523 & -0.02905 & -0.00035 & 0.000758 & 0.001124 & 571 \\
\hline 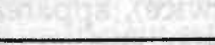 & $2.31=$ & $2.33-$ & 0.22 & 3.16 & $1.61^{\circ}$ & 0.99 \\
\hline Rubber & 0.97342 & -0.04204 & 0.053742 & 0,000024 & 0,000534 & 689 \\
\hline-1 & 0.80 & $3,80=$ & 3.05 & $0.0 \%$ & $2.29-$ & 0,99 \\
\hline Plastic & 0.92966 & 0.03523 & 0.030113 & $-0,00093$ & 0.000455 & 652 \\
\hline 20695 & 0.23 & $2.54=$ & 1.45 & $1.86 *$ & 1.36 & 0.98 \\
\hline Pothery & 1.054 & -0.0717 & 0.012506 & -0.00123 & 0.000041 & 682 \\
\hline$\sqrt{12}$ & 0.31 & $6.59 m$ & 1.53 & $254=$ & $3.42=$ & 0.99 \\
\hline
\end{tabular}




\begin{tabular}{|c|c|c|c|c|c|c|}
\hline Glas: & 0.92248 & 0.018301 & 0.04208 & 0.00026 & 0.000466 & 684 \\
\hline & 0.96 & $1.81 *$ & $2.86-$ & 0.76 & $2.22=$ & 0.99 \\
\hline Oh miln & 1.0537 & 0.010063 & $-0,06802$ & 0.00013 & 0.000281 & 692 \\
\hline 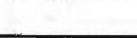 & 0.16 & 0.92 & $288 *$ & 0.30 & 1.22 & 0.99 \\
\hline \multirow[t]{2}{*}{ Iron, weel } & 1.046 & -0.07883 & -0.0523 & 0.000427 & 0.000571 & 691 \\
\hline & $2.96=$ & $4.70=*$ & $4.94=$ & $7.67=$ & $2.17 *$ & 0.98 \\
\hline \multirow[t]{2}{*}{ Non-ler } & 0.09231 & 0.098952 & 0.032296 & 0.000232 & 0.000971 & 687 \\
\hline & $1,61^{*}$ & $3.30=$ & $3.14^{m}$ & 0.54 & $3,41=$ & 0.98 \\
\hline \multirow[t]{2}{*}{ Pab mot } & 0.95198 & -0.0402 & 0.057181 & 0,00022 & 0.00049 & 690 \\
\hline & 0.85 & $3.63=$ & $239=$ & $0 \pi 2$ & $2.28 *$ & 0.99 \\
\hline \multirow[t]{2}{*}{ Nen-el much } & 096042 & -0.0977 & $0.0430 \%$ & 0.001264 & 0,000595 & 685 \\
\hline & 1.81 & $5.35=$ & $1.77^{\circ}$ & $4.57 \div$ & $3.45 \cdots$ & 1.00 \\
\hline \multirow[t]{2}{*}{ III mach } & 0.59634 & .000211 & 0.03574 & 0,002211 & 0.000642 & 692 \\
\hline & $3.21 \cdots$ & $9.44=$ & $2.55=$ & $7.62 * 4$ & $2.48 \cdots$ & 0.99 \\
\hline \multirow[t]{2}{*}{ Trunsport } & 0.93672 & -005818 & $0.00010 \mathrm{~s}$ & 0,000802 & 0.000482 & 688 \\
\hline & $200-$ & $4.83 \cdots$ & $5.81 \cdots$ & $2.60=$ & $1.08 *$ & 0.99 \\
\hline \multirow[t]{2}{*}{ Inouruments } & 0.99131 & $-0,06681$ & 0.002212 & 0.000202 & 0.000878 & 645 \\
\hline & 4.BA - & $5.54=$ & 0.13 & $7.04 \cdots$ & $4,02=$ & 0.99 \\
\hline Oh man: & 0.92023 & 0.01053 & 0.035302 & $-0,00137$ & 0.001066 & 656 \\
\hline & 1.31 & 0.4 & 1.56 & 2.09 & $2.22-$ & $0 . \%$ \\
\hline
\end{tabular}

Before discussing these results in a more detailed way, a regression with another patent variable is carried out. This variable is basically the same as that used in the static estimates, and is defined as follows.

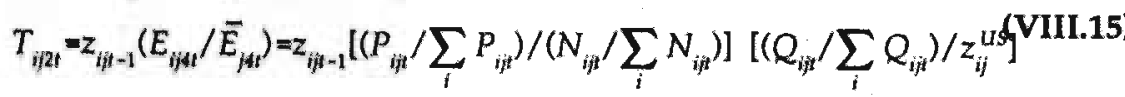

The results of this estimation are in Table VIII.6. Overall, the results closely resemble those in the previous table. The qualitative results (significance and signs) in the columns for the autoregressive term, the wage rate, labour productivity and size are almost exactly the same. The results for the patent variable are slightly more significant overall (eight significant estimates). However, the sign is negative in half of these cases. Summarizing the significant results for the patent variables gives significantly positive coefficients in textiles and transport (twice), apparel, plastic (once), and significantly negative coefficients in industrial and other chemicals, rubber (twice) and nonferrous metals and instruments (once).

Given the performance of the patent-related variables, it makes sense to run the same regressions without a patent variable at all. The results of this procedure are presented in Table VIII.7. This table also includes the sectors for which no patent data are available. In the first column of the table (the parameters for $z_{k-1}$ ), it now appears that the first evolutionary restriction is violated in fewer cases (total 11, and seven times for the sectors already in Table VIII.5 and VIII.6). Excluding patents from the analysis seems to improve the equation in this respect. The wage 
rate variable still performs well, although there are now five (out of 28) sectors with a significant, but wrong sign: wood, refined oil, plastic, glass and nonferrous metals. In the labour productivity column, only one new significant, but wrong parameter is found (in paper). Overall, the results are still quite strong: 21 out of 28 correct and significant signs for the wage rate variable, and 15 out of 28 for the labour productivity variable.

Thus, the evolutionary dynamics with regard to wage rate and labour productivity competition seem to work with the data applied. Most parameters estimated are significant, have the correct sign and a reasonable magnitude, but the two evolutionary restrictions are not always satisfied. The specific results with regard to the patent variables will be discussed in more detail below.

\subsection{Some Further Tests on the Robustness of the Replicator Estimates}

In this section, some tests are carried out to find out whether the estimates in the previous section suffer from some common problems in the regression model. All the tests will be carried out for the equation estimated in Table VIII.7.

First, the possibility of autocorrelation of the error terms in the equation estimated is investigated. Since the model is not a pure time series model, the assumption of autocorrelated errors only makes sense for groups of observations in the sample that can be sequenced in time in a meaningful way. In other words, one only has to look at autocorrelation between error terms of the time series of one country at a time, repeating this procedure for all countries in the sample. Because there are lagged dependent variables in the equation, the normal Durbin-Watson statistic cannot be used, and because it is not possible to say whether or not Durbin's $h$ statistic can be computed (see Johnston, 1982: 318), the following testing procedure is applied. For each country in the sample, the residuals are computed, and used as the dependent variable in a regression with the lagged residual and all the other variables in Table VIII.7 as explaining variables. A t-test on the parameter for the lagged residual is then an asymptotically equivalent ${ }^{15}$ procedure to using Durbin's $h$ statistic (Johnston, 1982: 318).

Table VIII.8 displays the results of this testing procedure. It appears that the problem of autocorrelated residuals is present in the regressions, but not to an overwhelming degree in most sectors. Nevertheless, Table VIII. 8 raises the question as to what extent the results in Table VIII.7 are affected by this. To answer this question, one should keep in mind that OLS estimation under autocorrelation leads to inefficient estimates, possibly overestimation of $t$-values on individual parameter estimates, although the estimates themselves are still unbiased. However, to answer the question of the consequences of autocorrelation for the results obtained, it is not a 'statistical' way of correcting for its presence that is followed. Instead, some theoretical reflections on the possible causes will be given.

\footnotetext{
${ }^{15}$ Note, however, that there are 23 observations at the most for each of these regressions.
} 
Table VIII.8. The degree of autocorrelation in the estimate of the replicator equation

A. By sectors

\begin{tabular}{|c|c|}
\hline $\begin{array}{l}\text { Sector } \\
\text { Food }\end{array}$ & $\begin{array}{l}\text { Autocorrelated countries } \\
\text { Denmark }\left(++^{* *}\right) \text {, Italy }\left(+^{*}\right) \text {, Netherlands }(+*) \text {, Sweden }(+*) \text {, Mexico }(+*) \text {, South } \\
\text { Korea }\left(-+^{*}\right)\end{array}$ \\
\hline Beverages & $\begin{array}{l}\text { USA }(-*) \text {, Canada }(-* *) \text {, Belgium }\left(+^{* * *}\right) \text {, Germany }\left(+^{* * *}\right) \text {, Ireland }\left(+^{*}\right) \text {, Turkey }\left(-^{+*}\right) \text {, } \\
\text { Argentina }\left(-^{* *}\right)\end{array}$ \\
\hline Tobacco & Belgium $(+* *)$, Germany $(+* *)$, Austria $\left(-^{* *}\right)$, Malaysia $(+* *)$ \\
\hline Textiles & USÄ (+ "), Greece (- *"), Finland (- "), Malaysia $\left(-*^{*}\right)$ \\
\hline Apparel & $\begin{array}{l}\text { Netherlands }\left(++^{* *}\right) \text {, New Zealand }\left(+^{* *}\right) \text {, Austria }\left(+^{* *}\right) \text {, Yugoslavia }\left(++^{* *}\right) \text {, Uruguay }(+ \\
\left.*^{*}\right) \text {, Singapore }\left(+^{* * *)}\right)\end{array}$ \\
\hline $\begin{array}{l}\text { Leather } \\
\text { Footwear } \\
\text { Wood }\end{array}$ & 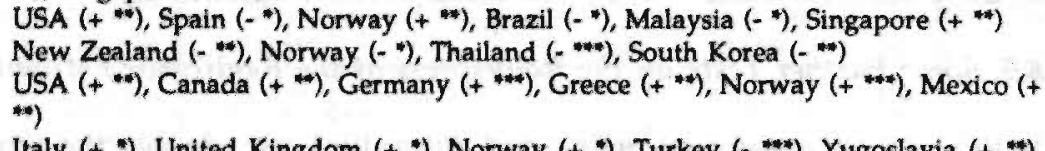 \\
\hline Wood furn & $\begin{array}{l}\text { Italy }\left(++^{*}\right) \text {, United Kingdom }\left(++^{*}\right) \text {, Norway }(+*) \text {, Turkey }\left({ }^{* *}\right) \text {, Yugoslavia }(+*) \text {, } \\
\text { Malaysia }\left(++^{* *}\right)\end{array}$ \\
\hline ap & **), Denmark (+ "), Hong Kong (- **), Colombia (+ **), Thailand (+ *) \\
\hline Print & 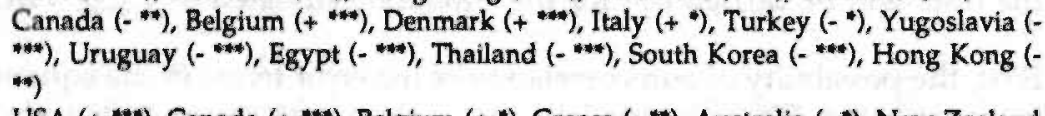 \\
\hline Ind chem & $\begin{array}{l}\text { USA }\left(++^{* *}\right) \text {, Canada }\left(++^{* *}\right) \text {, Belgium }(+*) \text {, Greece }\left(-{ }^{*}\right) \text {, Australia }(-") \text {, New Zealand } \\
\left(*^{*}\right) \text {, Yugoslavia }\left(++^{*}\right) \text {, Mexico }(+*) \text {, Singapore }(+*)\end{array}$ \\
\hline Oth o & $(+*)$, Italy $(+*)$, New Zealand $(+*)$, Yugoslavia $(+*)$, Colombia $\left(\left(^{* *}\right)\right.$, Malaysia \\
\hline Refined oll & $\begin{array}{l}\left(+^{* *}\right) \text {, Brazil }\left(-^{* *}\right) \text {, Egypt }\left(-{ }^{* *}\right) \text {, } \\
\text { South Korea }\left(+^{*}\right)\end{array}$ \\
\hline lis & $\left.*^{* *}\right)$, Austria $\left(+^{* * *}\right)$, Colombia $(-*)$ \\
\hline Rubber & ece $\left(+{ }^{* *}\right)$, Finland $(-*)$, Sweden $(+* *)$, Mexico $(+*)_{1}$ \\
\hline last & USA $(+*)$, Canada $(+*)$, Australia $(-* *)$, Norwa \\
\hline Sotte & 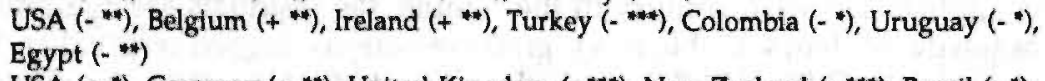 \\
\hline Slass & $\begin{array}{l}\text { USA }(+*) \text {, Germany }\left(++^{* *}\right) \text {, United Kingdom }\left(-^{* * *}\right) \text {, New Zealand }\left(-{ }^{* *}\right) \text {, Brazill }\left(-{ }^{*}\right) \\
\text { Canada }(+*) \text {, Denmark }\left(+^{*}\right) \text {, Germany }\left(+^{* * *}\right) \text {, Australia }(+* * *) \text {, Austria }\left(+^{* *}\right) \text {, Mexico } \\
\left(+^{* * *}\right) \text {, Egypt }\left(-^{* * *}\right)\end{array}$ \\
\hline Iron, steel & $\begin{array}{l}\text { Denmark }\left(++^{* *}\right) \text {, Netherlands }(+*) \text {, Spain }\left(-{ }^{*}\right) \text {, Yugoslavia }\left(-{ }^{* *}\right) \text {, Mexico }\left(++^{* *}\right) \text {, } \\
\text { Singapore }\left(-{ }^{*}\right) \text {, South Korea }\left(-{ }^{*}\right)\end{array}$ \\
\hline met & USA (- *) \\
\hline abr met & USA $\left(+^{* *}\right)$, Germany $\left(+^{* * *}\right)$, Italy $\left(++^{*}\right)$, Turkey $\left(-^{* *}\right)$, Israel $\left(-^{* * *}\right)$ \\
\hline Non-el mac & $\begin{array}{l}\text { USA }(+* *)_{1} \text {, Greece }\left(*^{* *}\right) \text {, Netherlands }(+* *) \text {, New Zealand (- "), Turkey }\left(-*^{* *}\right) \text {, } \\
\text { Yugoslavia }(+* *) \text {, South Korea }(-*)\end{array}$ \\
\hline El mach & 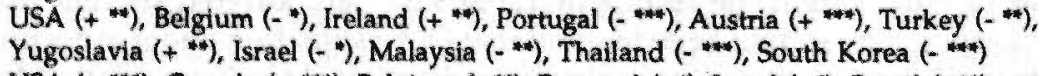 \\
\hline & USA (+***), Canada $\left(+^{* * *}\right)$, Belgium (-**), Portugal (- *), Israel (- "), Brazil (- **) \\
\hline & $\begin{array}{l}\text { fland }(+*) \text {, Yugoslavia }\left(*^{* *}\right) \text {, Colombia }\left(-{ }^{*}\right) \text {, Argentina }\left({ }^{*}\right) \text {, Singapore }\left(+^{*}\right. \\
\text { uth Korea }\left(-*^{*}\right)\end{array}$ \\
\hline & $\begin{array}{l}\text { USA }\left(++^{*}\right) \text {, Canada }\left(+^{*}\right) \text {, Greece }\left(+^{* *}\right) \text {, Netherlands }\left(-{ }^{*}\right) \text {, United Kingdom }\left(-{ }^{*}\right. \\
\text { Norway }\left(+^{*}\right) \text {, Turkey }\left(-^{* *}\right) \text {, Brazil }\left(-^{* *}\right) \text {, Argentina }\left(+^{* *}\right) \text { Egypt }\left(+^{*}\right)\end{array}$ \\
\hline
\end{tabular}

(continued on next page) 


\begin{tabular}{|c|c|c|c|c|}
\hline \multirow[t]{2}{*}{ Country } & \multicolumn{4}{|c|}{ Number of autocorrelated sectors } \\
\hline & $10 \%<c e>5 \%$ & $5 \%<\alpha>1 \%$ & $\alpha_{1}<1 \%$ & total \\
\hline Japan & 1 & 1 & & 2 \\
\hline USA & 5 & 6 & 4 & 15 \\
\hline Canada & 3 & 3 & 2 & 8 \\
\hline Belgium & 3 & 2 & 3 & 8 \\
\hline Denmark & 2 & & 4 & 6 \\
\hline France & 1 & & & 1 \\
\hline Germany & 1 & 2 & 3 & 6 \\
\hline Greece & & 5 & 2 & 7 \\
\hline Ireland & 2 & 2 & & 4 \\
\hline Italy & 3 & 2 & & 5 \\
\hline Netheriands & 2 & 2 & 1 & 5 \\
\hline Portugal & 1 & & 1 & 2 \\
\hline Spain & 2 & & & 2 \\
\hline United Kingdom & 1 & 1 & 1 & 3 \\
\hline Australia & 1 & & 2 & 3 \\
\hline New Zealand & 1 & 4 & 1 & 6 \\
\hline Austria & 1 & 2 & 2 & 5 \\
\hline Finland & 2 & 1 & & 3 \\
\hline Norway & 3 & 1 & 2 & 6 \\
\hline Sweden & 1 & 2 & & 3. \\
\hline Turkey & 2 & 2 & 4. & 8 \\
\hline Yugoslavia & 1 & 5 & 3 & 9 \\
\hline Israel & 2 & & 1 & 3 \\
\hline Mexico & 1 & 3 & 2 & 6 \\
\hline Colombia & 2 & 3 & 1 & 6 \\
\hline Brazil & 3 & 2 & & 5 \\
\hline Argentina & & 1 & 2 & 3 \\
\hline Uruguay & 1 & 1 & 1 & 3 \\
\hline Egypt & & 2 & 3 & 5 \\
\hline Thailand & 1 & & 4 & 5 \\
\hline Malaysia & 2 & 4 & 2 & 7 \\
\hline Singapore & 2 & 3 & 2 & 7 \\
\hline South Korea & 3 & 1 & 3 & 7 \\
\hline Hong Kong & & 1 & 1 & 2 \\
\hline Total & 55 & 64 & 57 & $176(18 \%)$ \\
\hline
\end{tabular}

In many cases, the presence of autocorrelation does not results from a deterministic relation between the error terms themselves, but instead from some degree of misspecification, which leads to serially correlated residuals. Most probably, this is also the case in this regression. To picture this, consider part $B$ of Table VIII.8. It appears that some countries are more seriously affected by the autocorrelation problem than others, in the sense that they have more sectors where it appears. The USA, Canada, Belgium, Turkey, and Yugoslavia are the countries where the problem is most serious. Therefore, the hypothesis that there are some variables left out of the regression, but explaining part of the performance of separate countries (especially the ones mentioned), seems to be plausible. Indeed, there are many variables influencing competitiveness that have necessarily been left out of the regressions here. These are investment, profit margins, trade barriers, distances and many others. Therefore, the results probably suffer from some degree of misspecification (left-out variables), which manifests 
itself partly through the presence of autocorrelated residuals. Unfortunately, the only way to solve this problem, i.e., to get data on the variables left out, is not within the reach of research.

The next test performed involves the detection of heteroscedastic error terms. It is a simple Glejser test (Johnston, 1982: 301-2), in which the absolute values of the estimated residuals are used as dependent variables in regressions with each of the explaining variables in Table VIII.7 and a constant as independent variables. A ttest for the estimated slope of the regression line is a test for heteroscedasticity, and was performed for the regressions in Table VIII.7. The results are not documented separately, but can be summarized briefly. All the estimated parameters in the Glejser test were significant, pointing indeed to a serious degree of heteroscedasticity in the results in Table VIII.7. In most (22 out of 28) cases, the estimated parameter for $z_{t-1}$ yielded the highest $t$-values in the Glejser tests.

The presence of heteroscedasticity mainly has the same consequences as autocorrelation: It makes the parameter estimates inefficient (i.e., more reliable estimates are possible), but leaves them unbiased. Estimation under heteroscedasticity is possible, and various methods are known. Here, the simplest of these methods, a simple weighted regression, will be used. The square root of the variable that seems to be the strongest source of the observed heteroscedasticity $\left(z_{t \cdot 1}\right)$ will be used as the weight. Weighted variants of the equations estimated in Tables VIII.5, VIII.6 and VIII.7 were performed, but only the equivalent of Table VIII.7 is documented here as Table VIII.9. The results in the two other tables did not vary much $^{16}$. The main conclusions from comparing the results in Table VIII.9 and Table VIII.7 are as follows. First, the value of the $t$-statistics is somewhat higher overall. Clearly, this results from the more efficient estimation method used. Second, there are no drastic shifts in the signs or values of the estimated parameters.

In order to evaluate the parameter estimates in another way than has been done previously, Table VIII.10 ranks the sectors with regard to the magnitude of the estimated coefficients. In the column for the wage rate, some of the high-tech sectors rank among the ones with a high evolutionary elasticity with regard to this variable. Electrical machinery is the best example. However, one also finds traditional low-tech products like apparel, footwear and pottery among the highranking sectors. In the labour productivity column, the high-tech sectors rank generally lower, with transport as an exception, which illustrates the importance of the cost aspects of technology. The next column ranks the difference between the wage rate and labour productivity elasticities. As explained above, this gives an indication of the noncost aspects of technology. In this column, the high-tech sectors rank higher than in the previous two, with instruments, transport, and machinery among the highest ones. The low classification of electrical machinery is surprising, as well as the presence of beverages at the bottom of this and the former column.

\footnotetext{
${ }^{16}$ In the interpretation of the constant in the weighted regressions, one should bear in mind that because we have weighted by $z_{\text {.1. }}$, it can no longer be interpreted as a constant. See Johnston (1982, Chapter 8).
} 
Table VIII.9. Results for the replicator equation, wage rate, labour productivity as dependent variables, weighted OLS with $z_{i-1}$ as the weight.

\begin{tabular}{|c|c|c|c|c|c|c|}
\hline SECTOR & $\Psi$ & (10) & (a) & $A(0)$ & $c$ & $n / R^{*}$ \\
\hline Food & 0.89011 & 400040 & 0.00054 & 0.0002 & D.0017s & 74 \\
\hline & $3.31=$ & $200^{\circ}$ & $536-$ & $1.95 *$ & $3.46=$ & a*s \\
\hline Beverages & 0.59252 & -0.06141 & 0.307 & 0.008962 & a.crous & 74 \\
\hline & $2.66-$ & $8.74 \cdots$ & $10.30=$ & $343=$ & $3.24 \cdots$ & nov \\
\hline Tobuees & 1.019 & -004062 & 0.006104 & $0.000422^{\prime}$ & oconas & 718 \\
\hline & 0.78 & $352=$ & 0.80 & 1.57 & $24=$ & 0.50 \\
\hline Teatile & 0.93206 & -0.05251 & $0.65 \pi 52$ & 0,000217 & 0.001393 & 743 \\
\hline & 1.42 & $1.26-$ & $363 \cdots$ & a.60 & $230-$ & 0.90 \\
\hline Appurel & 0.9005 & $-0,035$ & a.cossost & $-0,00120$ & 0.003834 & 738 \\
\hline+ & $2.94=$ & $5.43=$ & $3.53=$ & $5.95=$ & $5.04=$ & 0.68 \\
\hline Leather & 0.97231 & -0.04417 & 0.005102 & 0.00144 & 0.00244 & 731 \\
\hline & $2.03=$ & 4.96 & 2.36 & $2.20=$ & $3.08=$ & 0,98 \\
\hline Footwen & 0.86373 & -0.25109 & 0.2478 & 0.002036 & 0.00574 & 730 \\
\hline & $3.57=$ & $14.73=$ & $15.86=$ & 0.94 & $5.21=$ & 0.9 \\
\hline Wood & 0.7949 & 0.08467 & 0.035079 & -0.00003 & a.conms & 743 \\
\hline & $2.86=$ & 9.20 - & $216^{*}$ & 64 & $3.27=$ & 0.97 \\
\hline Wood furn & 1.0152 & -0.04842 & -0.01242 & 0.004472 & 0.000825 & 719 \\
\hline 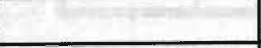 & 1.49 & $3.97 \cdots$ & 0.59 & $5.45=$ & 0.93 & 0.99 \\
\hline Paper & 1.0986 & -0.02363 & $-0.0 \% 033$ & 0,000499 & 0.002644 & 738 \\
\hline thests & 0.50 & $2.46 \%$ & 6.04 w* & $220 "$ & $3.33=$ & 0.99 \\
\hline Print/publ & 0.9956 & -0.02465 & 0.031388 & 0.000111 & -0.00043 & 73 \\
\hline & 0.16 & $2.39=$ & $1.88 *$ & 0.61 & 0.98 & 0.99 \\
\hline Ind chem & 0.98829 & $-0,03448$ & 0.027519 & 0.000564 & 0.001107 & 739 \\
\hline & 1.09 & $3.65=$ & $1.68 *$ & $2.04=$ & $1, n *$ & 0,99 \\
\hline Oth chem & 0.9006 & .0 .03994 & 0.038779 & 0.08021 & 0.0018391 & 742 \\
\hline & 0.89 & $5.15=$ & $1.73^{\circ}$ & 0.73 & $3.00 \approx$ & 0.99 \\
\hline Ref oil & 0.85988 & 0.073267 & 0.020088 & 0.00176 & 0.001127 & 718 \\
\hline & $1.74^{\circ}$ & $3.81 \cdots$ & $3.74 \cdots$ & 3.400 & $3.11-$ & 0.97 \\
\hline Mise CeO & 0.89248 & $-0,02085$ & 0,00005 & 0.011448 & 0.002281 & 604 \\
\hline 100 & $250 \cdots$ & $2.32 *$ & $1.82^{\circ}$ & 4.8600 & 0.61 & 0.99 \\
\hline Rubber & 0.96106 & $-0,04205$ & 0.061003 & -0.00034 & 0.001567 & 732 \\
\hline & 0.98 & $4.20=$ & $338=$ & 0.83 & $2.13^{\circ}$ & 0.9 \\
\hline Plastic & 0.87939 & 0,038361 & 0.074576 & 0.0016 & 0.00109 & 690 \\
\hline & 0.32 & $3.09-$ & $3.45=$ & 3.04 & 1.28 & 0,96 \\
\hline Pottery & 1.0432 & -0.10039 & 0.013524 & -0.0005 & 0.004729 & 726 \\
\hline 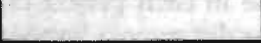 & $2.05 *$ & $9.14 \cdots$ & 1,41 & 0,96 & $4.26 \cdots$ & 0.99 \\
\hline
\end{tabular}




\begin{tabular}{|c|c|c|c|c|c|c|}
\hline Giass & 0.87965 & 0.091548 & 0.066168 & -0.00052 & 0,001209 & 729 \\
\hline & 1.51 & $3.55 \cdots$ & $4.86 \cdots$ & 159 & 1.83 & 0.99 \\
\hline Cals min & 1.0552 & 0.015809 & -0.06544 & 0.000184 & 0.000363 & 737 \\
\hline & 0.26 & 1.37 & $3.52=$ & 0.40 & 0.57 & 0.99 \\
\hline Iron, eteel & 1.0613 & -0.05027 & -0.06231 & 0.004367 & 0.003077 & 736 \\
\hline & $1.26 \cdots$ & 5.30 & 6.24 & 10.38 & $2.92=$ & 0.98 \\
\hline Nonferr mat & 0.639003 & 0.13751 & 0.1138 & -0.00002 & 0.006142 & 726 \\
\hline & $5.51=0$ & $9,00=0$ & $15.69=$ & $0.0 \mathrm{~B}$ & $5.04=$ & 096 \\
\hline Fab mat & 0.9663 & -0.03519 & $0.04 \times 651$ & 0,000141 & 0.000556 & 735 \\
\hline & 0.76 & $3.81 \cdots$ & 1.70 & 0.46 & 1.01 & 0.99 \\
\hline Non-el mach & 0,98174 & -0.04531 & 0.0006332 & 0.001458 & 0.002021 & 725 \\
\hline & $2.00=$ & $6.10=$ & 0.30 & $5.02 \cdots$ & $3.53 \mathrm{mot}$ & 0.99 \\
\hline PI mach & 1.0001 & -0.10974 & 0.029808 & 0.002503 & 0.002139 & 734 \\
\hline & $3.85=0$ & $10,35 \cdots$ & $2.08=$ & $7.95=$ & 2.79 & 0.99 \\
\hline Trannport & 0.92955 & -0.04476 & 0.000373 & 0.000439 & 0.001846 & 733 \\
\hline & 221 & $4.23 \cdots$ & $500 \cdots$ & 1.4 & $2.19 *$ & 0.99 \\
\hline Inalruments & 0.92726 & -0.07739 & 0.046404 & 0.00195 & 0.005001 & 681 \\
\hline & $5.85 \mathrm{mo}$ & $7.49=$ & 2,330 & 6.15 & $7.16 \cdots$ & 0,99 \\
\hline Oh man & 0.99417 & -0.01656 & 0.069912 & $-0,0019$ & 0.003402 & 700 \\
\hline & $1.90^{\circ}$ & 0.67 & 2.4 & 286 & $2.19 *$ & 0.95 \\
\hline
\end{tabular}

In the size column, it is interesting to note that the distinction between negative and positive coefficients lies between printing and publishing and fabricated metal (positions 10 and 11). Thus, in more than half of the sectors, the scale economies variable has a positive (and mostly significant) sign. The high-tech sectors have high, positive coefficients, although there are a few more traditional sectors at the very bottom of the list.

The last test performed is one for structural change in the parameters of the model over time ${ }^{17}$. Table VIII.11 documents Chow F-statistics for a 'trapped' hypothesis of structural change. The first statistic tests for changes between the period 19641972 and 1973-1987, while the second statistic divides the latter period into 19731979 and 1980-1987. The hypothesis used is that all parameters in the equation in Table VIII.7 (constant and two elasticities) change over time. The results in the table indicate that structural change is a relevant phenomenon for most of the sectors and periods. However, the results must be interpreted with caution, because in some cases, splitting up the sample into different periods leads to wrongly signed parameters, which constitutes a better fit, but yields parameters that are hard to interpret.

"Note that due to the restriction that market shares must count to one in each period (see Appendix VII.2), it does not make sense to estimate the model with parameter differences between countries. One can, however, introduce dummy variables to capture country specific effects. This has been done, although the results are not published. In general, the dummies were not significant in a systematic way. 
Table VIII.10. Ranking of sectors according to the value of the estimated parameters in Table VIII.10".

Sequence

Number

Wage rate

Labour productivity

Difference

Population

1
2
3
4
5
6
7
8
9
1
11
1
1
1
15
1
1
18
19
20
21
2
2
2
2
26
27
28

[Nonferrous metals]

[Wood]

[Refined Oil]

[Paper]

[Other minerals]

Pottery, etc

[Iron and steel]

Misc C\&O

[Plastic]

[Glass]

([Other minerals])

([Wood furn])

Apparel

Apparel

(Other manufacturing)

[Misc C\&O]

Wood furn

Other manufacturing

(Tobacco)

Leather

Food

(Nonelectrical machinery)

Paper"

Refined oil

Footwear

Iron and steel

Printing and publishing

Industrial chemicals

Electrical machinery

Misc C\&O

Electrical machinery

Printing and publishing

Fabricated metal

Wood

Other chemicals

Leather

Other chemicals

Tobacco

Instruments

Transport

Fabricated metal

Other minerals*

Printing and publishing

Other chemicals

Rubber

Refined oil*

Fabricated metal

Industrial chemicals

Textiles

machinery

Textiles

Glass

Other manufacturing

Wood

Apparel

Food

Food

Leather

Plastic

Instruments

Apparel

Iron and stee

Transport

Textiles

Pottery, etc

Nonferrous metals

Electrical machinery

Footwear

Beverages

Other manufacturing

Transport

Glass:

Instruments

Plastic

Nonelectrical machinery

Refined oil

Plastic

Glass

Pottery

Rubber

Wood

Nonferrous metals

Printing and publishing

Fabricated metal

Other minerals

Other chemicals

Textiles

Food

Tobacco

Transport

Paper

Industrial chemicals

Leather

Nonelectrical mach

Instruments

cootwea

Electrical machinery

Iron and steel

Wood fum

Nonferrous metals

Beverages

Misc C\&O

-For the wage variable, sectors are ranked in order of decreasing magnitude (i.e., large positive values first and large negative values last); for the other variables, the order is reverse. Round brackets 0 indicate nonsignificance, straight brackets $\|$ indicate a wrong sign. The third column ranks according to the difference between the labour productivity and wage rate parameters. In this calculation, parameter estimates with a wrong sign were set to zero. - In the calculation of this value, wrongly signed parameters were set to zero (see also under ). 


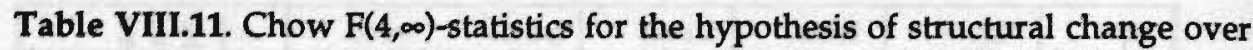
time

\begin{tabular}{|c|c|c|}
\hline SECTOR & $F_{1}$ & $\mathrm{~F}_{2}$ \\
\hline Food & 2.17 & $5.60 \cdots$ \\
\hline Beverages & $243 * *$ & 2.09 \\
\hline Tobacco & 5.74 *** & $7.45=$ \\
\hline Textiles & 3.58 & $7.79 * \cdots *$ \\
\hline Apparel & 5.02 & 2.11 \\
\hline Leather & 0.94 & 0.43 \\
\hline Footwear & 1.15 & $6.91 \ldots$ \\
\hline Wood & $2.55^{* * *}$ & 0.79 \\
\hline Wood furn & $2.67 \cdots$ & 20.97 *** \\
\hline Paper & 1.50 & 8.94 *n* \\
\hline Printing/publ & 2.67 *n. & $3.60^{* 4 *}$ \\
\hline Ind chem & 1.75 & 7.29 w. \\
\hline Oth chem & 1.23 & $14.22 * * *$ \\
\hline Ref oil & $3.97^{* * *}$ & $2.27 * *$ \\
\hline Misc C\&O & 7.25 **** & 1.82 \\
\hline Rubber & 1.24 & $5.30^{* * *}$ \\
\hline Plastic & 0.85 & 0.39 \\
\hline Pottery & $3.01 \cdots$ & $6.23 * * *$ \\
\hline Glass & $6.89 * *$ & $9.66 * * *$ \\
\hline Oth $\min$ & $3.33 \cdots$ & 1.75 \\
\hline Iron, steel & $11.87^{\text {n** }}$ & 1.59 \\
\hline Non-fer met & $4.05 * * *$ & 3.11 *** \\
\hline Fab met & $4.48^{n+4 *}$ & $7.60 \cdots$ \\
\hline Nonel mach & $2.99 * * *$ & $8.50^{\cdots *}$ \\
\hline El mach & 5.80 *** & $13.83 \cdots$ \\
\hline Transport & $8.05^{* * 4}$ & $2.96 * * *$ \\
\hline Instruments & $18.46^{* * 4}$ & $15.10^{* * *}$ \\
\hline Oth man & $5.38 * 1 *$ & 1.46 \\
\hline
\end{tabular}


The exact results of the parameter estimates are not documented here because of space considerations. A summary of the estimates is as follows. In textiles and leather-related branches, the parameters generally decline over time, particularly the one for productivity. This indicates that competition is becoming less intensive in these sectors. An exception to this is the change in the wage parameters of the two last periods (1973-1979 and 1980-1987) in the leather-related branches, which increase. In chemicals, the productivity parameter generally decreases, while the wage rate parameter increases. This points to increasing attention for cost aspects in the competition process in these industries. In basic metals and fabricated metals also, the productivity parameter is decreasing over time, which indicates that technology aspects are becoming less important here. In machinery, on the other hand, both the wage and productivity parameters are increasing.

\subsection{Explaining the Results for the Patent Variables}

As has already been indicated above, the 'dynamic equation' results with respect to patents are quite different from those obtained in the first (static) structural regressions. In the static regressions, the parameters estimated were significantly positive for those sectors in which one would expect technology to play a major role. In the dynamic regressions, significantly positive coefficients were obtained in some sectors, and negative estimates were found in others. What are the possible explanations for these, at first sight, contradictory results?

It must be noted that if the esumauon or a dynamic proceso indicatco that popitivo changes of some variable take place in cases where another variable has a low value, this would imply that at some point an equilibrium point could be reached in which a high value of the first variable is correlated with a low value of the second one. Obviously, such an equilibrium is not found in the static regressions. Instead, negative dynamic and positive static coefficients were found (particularly in chemicals). The only explanation for this is that the system started in a situation that was far from its (new) equilibrium state, and moved towards it only very slowly.

This seems to be an adequate description of the situation in the world in an era which witnessed the catching up of the NICs. Even if this points to an explanation for the 'strange' combination of positive static and negative dynamic correlations, it does not in itself provide an explanation for the negative dynamic correlations. However, there are some tendencies that are not captured in the previous analyses, which would lead to the results found if they were strong enough.

The first of these tendencies relates to a point mentioned in section 8.1 above. Due to the increasing complexity of technological developments, an increasing number of firms relies on diffusion rather than in-house development of knowledge. The number of high-tech firms developing knowledge largely by themselves is generally higher in countries that have a strong trade position, as shown by the static regressions. Due to the cumulativeness of technology, the core group of hightech firms (even at a world level) changes only gradually. The changes in trade positions, which are also slow (this emerges from the results, as well as from other evidence, for example in Amendola et al. 1991), are related to the total group of 
firms. If the technological performance of these firms is much more related to diffusion-like characteristics, the indicators related to the core high-tech group of firms are not very adequate, and one might find unclear results by using them. However, this still does not explicitly explain the negative coefficients found. Therefore, one would have to rely on other explanations.

Second, and building on the first point, the specific meaning of patents as a way of appropriating technologies might actually have a negative effect on the diffusion of technologies to other firms. In some sectors, like chemicals, patents are an important and effective way of protecting technology from flowing to other firms. Thus, in countries where firms have a high propensity to patent, diffusion to other domestic firms might be slower, eventually leading to bad performance. Even if this argument is intrinsically logical, one might be reluctant to believe it, because of limits to the diffusion-braking characteristics of patents. However, specifically addressing the international dimension makes the argument stronger.

This leads to the third argument. The usefulness of patent statistics for innovation can be questioned from the point of view of the working of the international system of intellectual property protection. There are at least two reasons why this system has been rather unsuccessful during the past decades. Primo, the rise of the NICs, especially the Asian economies, was often built on the 'undermining' of intellectual property. A major factor contributing to the success of the NICs has been the imitation of Western inventions. In some cases, this imitation took place by so-called 'inventing-around' a patent, which is in accordance with international agreements on intellectual property. But in other cases, the imitation violated these international agreements. Either way, imitating countries have not patented much, but they have grown very fast, so that one is likely to find a negative correlation between the two.

Secundo, the rise of multinational cooperations made it possible to easily relocate production in manufacturing sectors. Therefore, multinationals can easily spread the different activities (i.e., research and production) over different locations. In practice, this often led to research being undertaken in the 'home' country, and production being relocated to the so-called low-wage countries. This means that technology developed in the traditional (Western) countries was applied in other countries, i.e., the countries that are viewed as competitors in the above regressions.

Recently, a slightly different form of this phenomenon has taken place. In this case, the presence of trade barriers between economies (for example, between USA and Japan), has forced companies (mostly Japanese) to invest abroad. The idea was to build factories in the countries whose markets were protected by all sorts of trade barriers, so that the products made in these factories could be sold in a home market rather than being exported. It goes without saying that the technologies that were used in these investment flows were mainly developed domestically. Thus, these two phenomena lead to slow growth of countries that have high patent activity.

These points provide possible explanations for the results obtained in the 
regressions. However, there is no direct way of testing either of these possibilities in the present analysis other than by relating them to some general facts, as done above. Therefore, future research is necessary to investigate the merits of each of the points in depth.

\subsection{Summary and Conclusions}

This chapter has examined the relation between trade and technology from an empirical point of view. In a discussion on indicators, it was concluded that although patents are often used as innovation indicators, they have some specific drawbacks that make them inadequate for this purpose in some ways. Therefore, the regressions estimated used patents and labour productivity as indicators of technological capabilities.

The data set used included 28 manufacturing sectors (3-digit ISIC), 34 countries (OECD and NICs) and the period 1964-1987. In a panel of pooled cross-country time series data, equations for each sector were estimated. First, the (static) relations found in Dosi et al. (1990) were re-estimated. Although the sectoral aggregation is much higher than in DPS, and the data are panel instead of crosscountry, it was concluded that the qualitative results are much the same. For hightech sectors, there is a positive relation between patenting and export market shares. Other significant variables are the relative level of labour productivity, and country size (both controlling for size differences and economies of scale). The wage rate turned out to be not very significant in most sectors.

The main aim of the analysis was to test the empirical relevance of the specification of the relation between trade and technology developed in Chapter 7. Therefore, the replicator equation was used as a specific dynamic specification for the relation between trade and competitiveness in an OLS estimation. The results from these estimates were that the evolutionary specification finds some clear, but not entirely conclusive, support from the data. Moreover, the performance of the variables is quite different from the static regressions. First, the wage rate turned out to be significant in most cases. Second, the patent variables were only significant in a few sectors, and often had a negative sign. The results for the two other variables (labour productivity and country size) was more or less the same. In this case, the significance of country size points to economies of scale, because the influence of size differences had already been captured in another way by the evolutionary specification. Especially in high-tech sectors, the scale factor contributed significantly.

The (partly) negative signs for the patenting variables are in sharp contrast with the positive coefficients estimated in the initial, static, equations. Possible explanations for this might be related to the specific characteristics of patents as invention-appropriating-indicators. Moreover, the presence of multinational companies has led to a situation in which technologies are applied in countries where they were not invented, so that there might be a negative relation between patenting and exports. Further research is necessary to investigate these possibilities. 
The SITC-1 trade data were translated into ISIC-2 using the following concordance table, developed on the basis of similar tables used by OECD and UNIDO.

Table VIII.A1. Concordance between SITC-1 and ISIC-2* ISIC-2 SITC-1

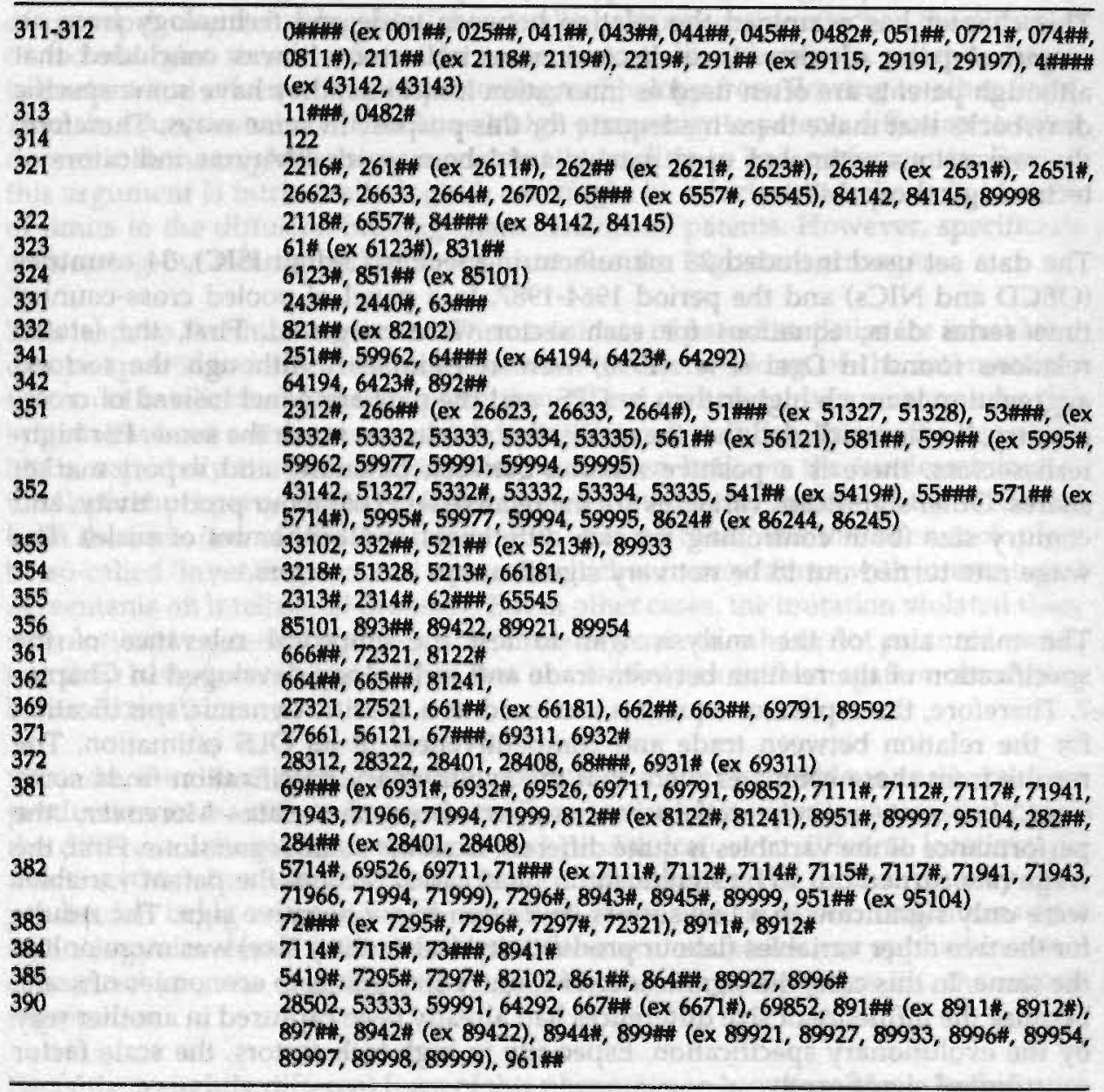

" points to a nonsignificant digit.

US patents are classified by the patent office in SIC classes on the basis of technological characteristics. However, one patent may be assigned to more than one SIC class. Therefore, one has to decide how to count the number of patents per SIC. The procedure used here is to count a patent that has been assigned to more than one (say $n$ ) SIC classes for $1 / n$ in each class (so-called fractional counting). The scheme to convert SIC classes to ISIC- 2 is the following. 
Table VIII.A2. Concordance between ISIC-2 and US Patent SIC

Sequence number ISIC-2 US Patent Office sequence number (SIC)

\begin{tabular}{|c|c|c|}
\hline & $311-312$ & 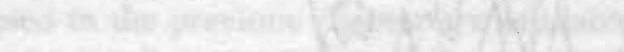 \\
\hline 2 & 313 & - \\
\hline 3 & 314 & - \\
\hline 4 & 321 & 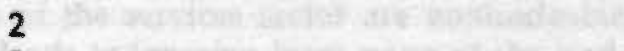 \\
\hline 5 & 322 & 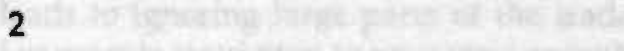 \\
\hline 6 & 323 & 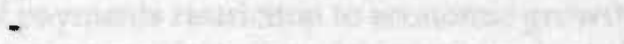 \\
\hline 7 & 324 & - \\
\hline 8 & 331 & - \\
\hline 9 & 332 & - \\
\hline 10 & 341 & $=$ \\
\hline 11 & 342 & -700 \\
\hline 12 & 351 & $6,7,8,9$ \\
\hline 13 & 352 & $11,12,13,14$ \\
\hline 14 & 353 & $15-15=$ \\
\hline 15 & 354 & Shlites \\
\hline 16 & 355 & 16 \\
\hline 17 & 356 & 16 \\
\hline 18 & 361 & 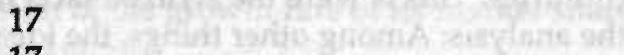 \\
\hline 19 & 362 & 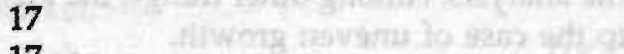 \\
\hline 20 & 369 & 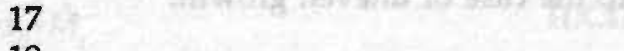 \\
\hline 21 & 371 & 19 \\
\hline 22 & 372 & 20 \\
\hline 23 & 381 & 21 \\
\hline 24 & 382 & $23,24,25,26,27,29,30,31,32$ \\
\hline 25 & 383 & $35,36,38,39,40,42,43$ \\
\hline 26 & 384 & $46,49,50,51,52,53,54$ \\
\hline 27 & 385 & 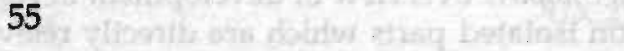 \\
\hline 28 & 390 & $x^{2}$ \\
\hline
\end{tabular}

Not all sequence numbers are used, because some classes are aggregates. 


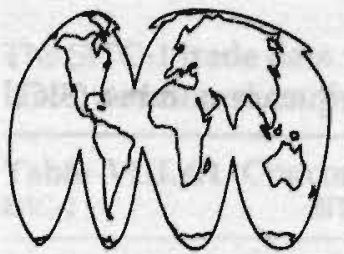

\section{CHAPTER 9. A Broader Empirical View on Trade, Technology and Growth}

This final chapter of Part Three is aimed at providing a more general test of the theoretical framework proposed in Chapter 7. However, since the model proposed there was very stylized, the procedure of testing it necessarily involves some 'creativity' by transforming the general consequences of the model into testable hypotheses. In order to do so, two different strategies will be used. First, some equations will be derived on the basis of the model, and these will be estimated using the data set and some of the results from the previous chapter. This provides a general approach to the subject, which pays no attention to results for specific countries. This is were the stylized facts from Chapter 4 will be brought back into the analysis: Among other things, the idea of structural differences will be applied to the case of uneven growth.

The second approach is more case study-oriented, and it concentrates on the Asian countries in the sample, which were shown to be 'prime' examples of catching up in Chapter 4. The current analysis tries to give an in-depth overview of the observed performance of these countries in light of the preceding analysis. However, the reader should keep in mind that it is not the aim of this part to give a complete overview of development in Asian NICs. Instead, the analysis will focus on isolated parts which are directly relevant to the preceding chapters.

\subsection{A General Test of the Relation Between Competitiveness, Structure and Growth Rate Differentials}

In applying the model from Chapter 7 to actual data, a number of problems arise. The first problem is concerned with the concepts used in the model. The main force determining the growth rate of a country was the balance of payments, which was assumed to be in equilibrium at all times. During the presentation of the model it has already been admitted that this assumption does not comply with the real-world facts. What one observes are balance of payments deficits and surpluses, and as a result, accumulation of debt in some countries. Nevertheless, Thirlwall (1979) and Fagerberg (1988a) have shown that the balance of payments restriction to growth rates does make sense in an empirical setting. Therefore, although balance of payments equilibrium is seldom achieved, growth rates seem to converge to the value that is consistent with external equilibrium, at least for the countries investigated by Thirlwall and Fagerberg. 
However, both Thirlwall and Fagerberg used aggregate data to test their models. As was shown in Chapter 7, the country-wise differences in elasticities observed by them can (at least theoretically) be explained by the production and consumption structure of the domestic economy. This is the main reason why the analysis in Chapters $\mathbf{7}$ and $\mathbf{8}$ was extended to include the sectoral level. However, this poses another problem: The data used in the previous chapter are available for the manufacturing sector only, and, as a result, many sectors of the economy, such as agriculture, mining, building, transport, and other forms of services, were ignored. And even though large parts of the services sector are nontradeable, concentrating on manufacturing alone leads to ignoring large parts of the trade balance. Therefore, even if the balance of payments restriction to economic growth is relevant, it cannot be used in the narrow manufacturing perspective adopted here.

Thus, it is imperative to develop another way of exploring the empirical consequences of the model proposed in Chapter 7. To do this, assume for the moment that there is only one market for each of the products of the industrial sectors identified in the previous chapter. In other words, the relevant market for each producer is the total world market, irrespective of its location. This means that the detailed specification of the relation between competitiveness and growth through the import and export sides of the trade balance will be 'skipped'. Then, using a simple definition, each country's rate of growth of production in a specific sector over a specific period will be the sum of the growth rate of its market share and the growth rate of volume of the market.

$$
Q_{i j}=z_{i j}+\hat{M}_{j}
$$

In this equation, the symbols are as defined in previous chapters, and $M$ is the size of the market. As before, it is assumed that the movement of the market share is determined by competitiveness, so that a country whose competitiveness is exactly equal to the average will grow as fast as the market volume. This country is denoted by *.

$$
\hat{Q}_{j}^{*}=\hat{M}_{j}
$$

The next step is to write an expression for the aggregate growth rate of countries. Obviously, the aggregate growth rate can be found by adding together the sectorwise growth rates, taking sector shares as weights. In mathematical form, this is written as follows.

$$
Q_{i}=\sum_{j} \sigma_{i j} Q_{i j}=\sum_{j} \sigma_{i j} \hat{z}_{i j}+\sum_{j} \sigma_{i j} \hat{M}_{i}
$$

Obviously, for the 'average competitive' country ("), the aggregate growth rate reduces to the following.

$$
Q^{\circ}=\sum_{j} \sigma_{j}^{*} \hat{M}_{j}
$$

Combining the last two equations, the growth rate differential between an individual country and the average country growth rate can be written as follows.

$$
\hat{Q}_{i}-\hat{Q}^{*}=\sum_{j} \sigma_{i j} \Sigma_{i j}+\sum_{j}\left(\sigma_{i j}-\sigma_{j}^{*}\right) \hat{M}_{i}
$$


This equation shows that the growth rate differential is the sum of two partial effects, the first can be attributed to competitiveness, and the second to the structure of production. Using the evolutionary equation used in the two preceding chapters, the last equation can be rewritten as follows.

$$
Q_{i}-Q^{*}=\sum_{j}\left(\sigma_{i j} \sum_{k} \phi_{j k}\left(E_{i j k} / \bar{E}_{j k}-1\right)\right)+\sum_{j}\left(\sigma_{i j}-\sigma_{i}^{*}\right) \hat{M}_{j}
$$

The first term on the rhs of equation (IX.6) is due to competitiveness, while the second one is due to the production structure.

However, the irrealistic assumption of one world market leads to the necessity of carefully interpreting this equation. First, the competitiveness part does not take into account all sorts of factors that might prohibit a successful transformation of high competitiveness into high growth. The most obvious of these factors is the existence of trade barriers in the form of protectionist measures, and the space dimension, which leads to trade flows from and to one specific country that are unequally distributed over the world. Second, the structural part of the equation models the structural problem from the supply side, while it seems to be more logical to model it from the demand side, as in Chapter 7. In other words, in the theoretically preferred approach from Chapter 7, the existence of a structural advantage or disadvantage was determined by the country's and the world's consumption structures, while here it are the production structures that matter. Obviously, at the total world level, the consumption and production structures must be equal, but as the simulation results in Chapter 7 showed, for separate countries that are trading with other countries, the two are likely to differ, due to specialization. Therefore, part of the equation is misspecified with regard to the impact of competitiveness on growth through the import (i.e., demand) side of the economy.

Nevertheless, equation (IX.6) can be tested using the data and results for $\phi$ estimated in the previous chapter. Before doing so, a regression relating growth rate differentials of manufacturing production and total GDP (denoted by $\eta$ is carried out. This equation gives an idea as to what extent the results for manufacturing have significance for the economy as a whole. The equation used is as follows'.

$$
\hat{Y}_{i}-\hat{Y}^{*}=\gamma_{0}+\alpha_{0}\left(\hat{Q}_{i}-\hat{Q}^{\prime}\right)
$$

The outcome of this regression is the following.

$$
\begin{aligned}
& \alpha_{0}=0.437(22.02) \\
& \gamma_{0}=0.001(0.88)
\end{aligned}
$$

\footnotetext{
1 The data set used in the regressions in this section is partly the same as that used in the previous chapter. Manufacturing variables not used there (such as the growth rate of output) are taken from the same source (UNIDO Industrial Statistics Database). Data for GDP in this chapter are taken from Summers and Heston (1991). Countries used and the period involved are also the same (1963-1987). Starred values refer to (weighted) sample averages.
} 


$$
\begin{aligned}
& n=652 \\
& \text { adj. } R^{2}=0.43
\end{aligned}
$$

A Chow-test for structural change between the periods before and after 1973 is not significant. These results show that there is a strong correlation between the growth rate differential with respect to total output and the growth rate differential of manufacturing output. Of course, this correlation is not surprising, since manufacturing output is a part of total output. Nevertheless, the value of the estimated coefficient, which is clearly smaller than one, shows that there is a general tendency in the data towards specialization between the manufacturing and nonmanufacturing countries. The reason for this is that the estimated value of $\alpha_{1}$ shows that large positive values of growth rate differentials in manufacturing tend to go hand in hand with below-average growth (i.e., negative growth rate differentials) in nonmanufacturing sectors of GDP. Large negative values of the growth rate differential in manufacturing tend to go together with above-average growth in nonmanufacturing sectors. As a result, the growth rate differential induced by the manufacturing sector is partly offset by the other sectors. In other words, the manufacturing sector has induced a tendency towards divergence, while this has been partly offset by a converging tendency in nonmanufacturing sectors.

Now that the relation between manufacturing and total growth rate differentials is clear, attention can be shifted towards explaining the growth rate differentials. In order to do so, define the following variables.

$$
\begin{gathered}
\Theta_{i}=\sum_{i}\left(\sigma_{i j} \sum_{k} \phi_{j k}\left(E_{i j k} / \bar{E}_{j k}-1\right)\right) \\
S_{i}=\sum_{j}\left(\sigma_{i j}-\sigma_{j}^{*}\right) \hat{M}_{j} \\
O_{i}=\left(X_{i}+M_{i}\right) / Y_{i} \\
H_{i}=\sum_{j}\left(\sigma_{i j}-\sigma_{j}^{*}\right)^{2} \\
k_{i}=I / Y_{i}
\end{gathered}
$$

$\Theta$ stands for competitiveness, and is defined according to equations (IX.5) - (IX.6). The $\phi s$ are taken from the empirical analysis in the previous chapter ${ }^{2} . S$ is the effect of the production structure, and is also defined as in the equations above. 0 measures the openness of the economy. This variable is used to correct the relations above for different degrees of openness. Several specifications will be used to do this, which will be discussed below in more detail. $H$ is a measure of the degree of specialization of the economy. It is defined as the variance of the sectoral shares in manufacturing output around the sample means, so that high

\footnotetext{
${ }^{2} \phi$ used are moving averages of those obtained in the estimations for Table VIII.11, so that competitiveness consists of the wage rate, labour productivity and a scale factor. For the exact values of the $\phi s$ used, the reader should refer to the floppy disk. The program that should be

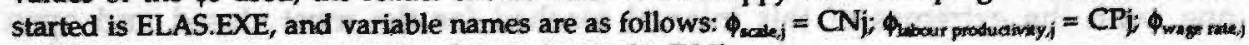
$=C W_{j}(j$ refers to a sequence number in Appendix IV.2).
} 
values correspond to a high degree of specialization. This variable is meant to pick up the effects of increasing returns to scale due to specialization, which were explained in the discussion of the simulation results of the model in Chapter 7. In principle, these scale effects are assumed to be included in the measures of competitiveness used, but in order to see if any of these effects are not captured through $\Theta$, the $H$ variable is included in the regressions. Although the definitions of $H$ and $S$ are alike, the correlation between the two is low $(-0.03)$. This illustrates that $H$ and $S$ measure two different things: $H$ is related to the static structure of the economy, which is assumed to provide opportunities for dynamic scale effects, while $S$ measures the dynamic structural advantages related to market demand. $k$ stands for the investment intensity, and is included to take into account some aspects of competitiveness that are not included in the definition of $\Theta$.

These variables will be used in a number of different equations. Since the basic equation derived above (IX.6) assumes that all economies are completely open, some additional specifications will be tested that relax this assumption. The basic idea behind these other forms is that the relation between competitiveness and growth rate differentials is stronger for economies that are more open. Thus, one can assume that in a regression of the type (IX.6), the estimated coefficient for competitiveness varies with openness. One way of taking this into account is by estimating an equation with competitiveness multiplied by openness $(O \cdot \Theta)$ as one of the independent variables. Another possibility is to specify a nonlinear (in the parameters) relation between openness, competitiveness and growth. Both approaches will be followed below.

First, some linear (in the parameters) equations will be estimated. The estimates will be done both for equations explaining the growth rate differential in manufacturing, and GDP. The results for the linear equations are in Tables IX.1 and IX.2. The tables show that the overall explanatory power of the regressions is rather weak. However, the coefficients are (highly) significant in most cases, which indicates that although the variance explained is low, there is a significant relationship of the kind assumed. Chow-tests for structural change between periods before and after 1973 are not significant.

Turning to the individual equations, the following can be said. In Table IX.1, equation (i) is the purest form of the hypothesis derived above (IX.6). The parameter estimate of $\Theta$ is smaller than one, indicating that there is indeed a factor which prohibits the differences in competitiveness to be transformed into differences in growth rates completely. This is probably a mixed effect of the competitiveness measures being less than perfect and of the omission of the openness effect. The estimated parameter of the structural term $S$ is larger than one, which is hard to explain from the point of view of the above equations.

Equation (ii) tries to correct for the openness by assuming that the slope of the basic equation (as in i) varies with openness. The minimum value of $O$ observed (around $4 \%$ ) corresponds to an estimated coefficient of around 0.015 , while the maximum $O$ value (around $245 \%$ ) yields a slope of around one. Thus, these results indicate that the slope of the competitiveness variable varies between zero and one, with the extremes of this interval reached for the most closed and open 
economies in the sample.

Equations (iii) and (iv) are basically the same, but introduce the specialization term. It is shown that higher specialization leads to higher growth. The coefficient of $\theta .0$ becomes snnaller and insignificant, while the (adjusted) $R^{2}$ in (iv) gets smaller by including the extra variable. This effect might be partially due to multicollinearity (the correlation between $\Theta . O$ and $H$ is close to 0.4). In any case, this shows that part of the effect of the openness variable in (ii) is due to specialization increasing with openness. The constant in (iii) - (iv) becomes smaller, while the other coefficients remain more or less the same.

Table IX.1. Estimation results for linear equations explaining growth rate differentials for manufacturing output $(n=652)$

\begin{tabular}{|c|c|c|c|c|c|c|c|}
\hline No & C & C.O & $S$ & $H$ & $K$ & c & $R^{2}$ \\
\hline $\mathbf{i}$ & $\begin{array}{l}0.27 \\
(2.94 * * *)\end{array}$ & & $\begin{array}{l}1.90 \\
\left(5.60^{\mathrm{**}}\right)\end{array}$ & & t & $\begin{array}{l}0.016 \\
\left(7.27^{\cdots *}\right)\end{array}$ & 0.06 \\
\hline ii & 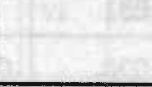 & $\begin{array}{l}0.42 \\
(3.09 * *)\end{array}$ & $\begin{array}{l}1.87 \\
(5.52 * * *)\end{array}$ & & & $\begin{array}{l}0.016 \\
\left(7.30^{m * n}\right)\end{array}$ & 0.06 \\
\hline iii & $\begin{array}{l}0.24 \\
(2.60 \text { ***) } \\
\end{array}$ & & $\begin{array}{l}1.96 \\
(5.89 * * *) \\
\end{array}$ & $\begin{array}{l}0.33 \\
(5.02 * * *) \\
\end{array}$ & & $\begin{array}{l}0.008 \\
\left(2.76^{\text {***})}\right.\end{array}$ & 0.09 \\
\hline iv & $f^{2} x^{2}$ & $\begin{array}{l}0.19 \\
(1.33)\end{array}$ & $\begin{array}{l}1.95 \\
\left(5.83^{* * *}\right)\end{array}$ & $\begin{array}{l}0.31 \\
(4.37 * * *)\end{array}$ & & $\begin{array}{l}0.009 \\
\left(3.28^{* * *}\right)\end{array}$ & 0.08 \\
\hline $\mathbf{v}$ & $\begin{array}{l}0.23 \\
(2.42 * *)\end{array}$ & & $\begin{array}{l}1.86 \\
(5.49 * * *) \\
\end{array}$ & & $\begin{array}{l}0.06 \\
(2.01 \cdots ")\end{array}$ & $\begin{array}{l}0.002 \\
(0.24)\end{array}$ & 0.06 \\
\hline vi & & $\begin{array}{l}0.38 \\
\left(2.78^{* * *}\right) \\
\end{array}$ & $\begin{array}{l}1.83 \\
\left(5.41^{* * *}\right)\end{array}$ & & $\begin{array}{l}(0.06 \\
\left.2.23^{* 4}\right)\end{array}$ & $\begin{array}{l}0.0003 \\
(0.04) \\
\end{array}$ & 0.06 \\
\hline vii & $\begin{array}{l}0.17 \\
(1.83 *)\end{array}$ & & $\begin{array}{l}1.91 \\
\left(5.76^{* * *}\right)\end{array}$ & $\begin{array}{l}0.37 \\
\left(5.49^{\text {***)}}\right.\end{array}$ & $\begin{array}{l}0.09 \\
\left(2.98^{\text {***)}}\right.\end{array}$ & $\begin{array}{l}-0.014 \\
\left(1.83^{*}\right)\end{array}$ & 0.10 \\
\hline viii & $4 \operatorname{tag} 20$ & $\begin{array}{l}0.10 \\
(0.65)\end{array}$ & $\begin{array}{l}1.90 \\
\left(5.73^{\text {***)}}\right.\end{array}$ & $\begin{array}{l}0.37 \\
(5.01 * * *)\end{array}$ & $\begin{array}{l}0.10 \\
\left(3.31^{\text {*n+1) }}\right.\end{array}$ & $\begin{array}{l}-0.016 \\
\left(1.99^{* 4 \prime}\right)\end{array}$ & 0.10 \\
\hline
\end{tabular}

Variants (v) and (vi) show that there is also a significant relation between investment intensity and growth rate differentials, and that the influence of $S$ and $\Theta$ is not affected by this. Finally, equations (vii) and (viii) include all the variables, and show the general significance.

Table IX.2 repeats the same relations, but explaining GDP growth rate differentials instead. As could be expected from the estimated relation between GDP and manufacturing growth, the coefficients in these equations are smaller than the ones in (i)-(iv), and so are the $R^{2}$ s. However, the coefficients are also significant, which indicates that the relations are strong enough to survive additional sources of disturbance caused by the relation between GDP and manufacturing output. 
Table IX.2. Estimation results for linear equations explaining growth rate differentials for GDP $(n=652)$

\begin{tabular}{|c|c|c|c|c|c|c|c|}
\hline No & $C$ & $\mathrm{CO}$ & $S$ & $H$ & $K$ & constant & $K^{2}$ \\
\hline 1 & $\begin{array}{l}0.16 \\
\left(2.55^{* * 4}\right)\end{array}$ & & $\begin{array}{l}0.52 \\
(2.25 * *)\end{array}$ & & & $\begin{array}{l}0.007 \\
\left(4.90^{* *}\right)\end{array}$ & 0.02 \\
\hline ii & & $\begin{array}{l}0.35 \\
\left(3.78^{* *}\right)\end{array}$ & $\begin{array}{l}0.49 \\
(2.14 *)\end{array}$ & & & $\begin{array}{l}0.007 \\
(4.65 \text { ***) }\end{array}$ & 0.03 \\
\hline iii & $\begin{array}{l}0.13 \\
\left(2.08^{* *}\right)\end{array}$ & & $\begin{array}{l}0.58 \\
\left(2.58^{* * *}\right)\end{array}$ & $\begin{array}{l}0.31 \\
(6.98 * *)\end{array}$ & & $\begin{array}{l}-0.001 \\
(0.28)\end{array}$ & 0.08 \\
\hline iv & & $\begin{array}{l}0.13 \\
(1.36)\end{array}$ & $\begin{array}{l}0.57 \\
\left(2.53^{* *}\right)\end{array}$ & $\begin{array}{l}0.30 \\
(6.16 *)\end{array}$ & & $\begin{array}{l}0.0002 \\
(0.10)\end{array}$ & 0.08 \\
\hline$v$ & $\begin{array}{l}0.13 \\
\left(1.94^{* *}\right)\end{array}$ & & $\begin{array}{l}0.49 \\
(2.12\end{array}$ & & $\begin{array}{l}0.05 \\
(2.53 * *)\end{array}$ & $\begin{array}{l}-0.005 \\
(0.97)\end{array}$ & 0.02 \\
\hline vi & & $\begin{array}{l}0.32 \\
\left(3.43^{* *}\right)\end{array}$ & $\begin{array}{l}0.46 \\
\left(2.01^{*}\right)\end{array}$ & & $\begin{array}{l}0.05 \\
\left(2.58^{* *}\right)\end{array}$ & $\begin{array}{l}-0.005 \\
(1.08)\end{array}$ & 0.04 \\
\hline vil & $\begin{array}{l}0.07 \\
(1.13)\end{array}$ & & $\begin{array}{l}0.53 \\
(2.42 *)\end{array}$ & $\begin{array}{l}0.34 \\
(7.60 * *)\end{array}$ & $\begin{array}{l}0.08 \\
\left(3.87^{*}\right)\end{array}$ & $\begin{array}{l}-0.020 \\
\left(3.73^{* *}\right)\end{array}$ & 0.10 \\
\hline vili & & $\begin{array}{l}0.05 \\
(0.54)\end{array}$ & $\begin{array}{l}0.53 \\
\left(2.40^{* *}\right)\end{array}$ & $\begin{array}{l}0.34 \\
\left(6.94^{* * *}\right)\end{array}$ & $\begin{array}{l}0.08 \\
\left(4.06^{* * 4}\right)\end{array}$ & $\begin{array}{l}-0.02 \\
\left(3.79^{* * *}\right)\end{array}$ & 0.10 \\
\hline
\end{tabular}

The influence of openness on the coefficient of $\Theta$ can also be estimated by means of nonlinear specifications. Various alternatives were tested, which are all nested in the following equation.

$$
D_{i}=\left(\mu+\alpha O_{i}^{B}\right) \Theta_{i}+\beta S_{i}+\gamma
$$

Estimating this equation in its least restrictive form (i.e., leaving all the parameters free) does not yield very good results, both in terms of convergence and in terms of $t$-values of the estimated parameters. Therelore, various special cases of the general equation were estimated, which, in general, produce quite good results.

Table IX,3 lists the resuls (Chow-tests for structural change are not significant). In equations (i) and (iv), one would expect $1 \geq \mu+O^{\AA} \geq 0$ (close to zero for closed economies, and close to one for open economies), which implies that $\mu<0$ and $\delta>0$. Note that this equation assumes that the relation between competitiveness and growth is zero fot an economy with a value of $O>0$. In other words, the point at which competitiveness becomes meaningless lies before the point of a completely closed economy. The performance of the equation for GDP growth is better than for the equation for manufacturing, at least in terms of significance of the coefficients. Although the relation may not be very strong, it is useful to calculate the boundaries of the range for the implied coefficient of $\theta$. These are as follows: for $D_{Q}: 0.45 \geq \mu+O^{3} \geq 0.10 ;$ for $D_{\gamma}: 0.50 \geq \mu+O^{\delta} \geq-0.10$. 
Table IX.3. Nonlinear specifications of the relation between growth, competitiveness, structure and openness $(n=652)$

\begin{tabular}{|c|c|c|c|c|c|c|c|}
\hline $\begin{array}{l}\text { Dep } \\
\text { var }\end{array}$ & No & $\alpha$ & $\mu$ & $\delta$ & $B$ & $\gamma$ & $R^{2}$ \\
\hline$D_{\mathrm{Q}}$ & $\mathfrak{i}$ & fixed to 1 & $\begin{array}{l}-0.65 \\
(4.72 \cdots *)\end{array}$ & $\begin{array}{l}0.08 \\
(0.68)\end{array}$ & $\begin{array}{l}1.88 \\
(5.54 * * *)\end{array}$ & $\begin{array}{l}0.016 \\
(7.20 \cdots \cdots)\end{array}$ & 0.06 \\
\hline$D_{Q}$ & ii & $\begin{array}{l}0.41 \\
(297 \cdots)\end{array}$ & fixed to 0 & $\begin{array}{l}0.72 \\
(1.31)\end{array}$ & $\begin{array}{l}1.87 \\
(5.52\end{array}$ & $\begin{array}{l}0.016 \\
(7.22)\end{array}$ & 0.06 \\
\hline$D_{Q}$ & iii & fixed to 1 & fixed to 0 & $\begin{array}{l}1.03 \\
(3.43\end{array}$ & $\begin{array}{l}1.80 \\
\left(5.24^{\cdots m}\right)\end{array}$ & $\begin{array}{l}0.014 \\
\left(6.30^{* * *}\right)\end{array}$ & 0.05 \\
\hline$D_{Y}$ & iv & fixed to 1 & $\begin{array}{l}-0.69 \\
(7.20\end{array}$ & $\begin{array}{l}0.18 \\
(1.78\end{array}$ & $\begin{array}{l}0.49 \\
(2.13 !)\end{array}$ & $\begin{array}{l}0.007 \\
\left(4.75^{* \cdots *}\right)\end{array}$ & 0.02 \\
\hline$D_{\gamma}$ & $v$ & $\begin{array}{l}0.25 \\
\left(2.77^{* *}\right)\end{array}$ & fixed to 0 & $\begin{array}{l}3.55 \\
(5.27 * *)\end{array}$ & $\begin{array}{l}0.52 \\
\left(2.25^{* *}\right)\end{array}$ & $\begin{array}{l}0.007 \\
(4.87 \text { *w* })\end{array}$ & 0.04 \\
\hline$D_{\mathrm{r}}$ & vi & fixed to 1 & fixed to 0 & $\begin{array}{l}1.42 \\
(5.68 * *)\end{array}$ & $\begin{array}{l}0.41 \\
\left(1.72{ }^{*}\right)\end{array}$ & $\begin{array}{l}0.004 \\
(2.93 * n *)\end{array}$ & 0.03 \\
\hline
\end{tabular}

Thus, the estimated coefficients for manufacturing yield values of the regression slope in the correct range, which holds to a lesser extent for total GDP. Although part of the estimated range is smaller than zero, keeping standard errors of the estimated coefficients in mind, these values are quite good.

The results of variants (ii) and (v) indicate that for GDP growth rate differentials, the linear (in the parameters) forms (vi) and (iix) in Table IX.2 are more restrictive than necessary. These equations yield significant parameters, which are different from those obtained in linear regressions. However, calculating the maximum value for the slope of the $\Theta$ term yields values around six for the GDP equation, and 0.8 for the manufacturing variant. The value for GDP is quite high from a theoretical point of view. Equations (iii) and (vi) bring the maximum values for the slopes of $\Theta$ closer to each other. For these equations, in which all parameters are significant, the values are 3.7 (GDP) and 2.5 (manufacturing). Still, this is quite high, so that one should interpret equations (ii), (iii), (vi) and (vii) as being not very relevant to the rightmost tail of the distribution of $O$.

The exact relationship between competitiveness, openness and growth as described by the first nonlinear equation is explained in Figures IX.1a and IX.1b. The other nonlinear equations, as well as variants (ii), (iv), (vi) and (viii) in the linear estimates, yield similar 'landscapes', but they are somewhat less steep (and nonlinear) in the $O$ dimension. In the figures, the 3-dimensional function described is projected on a 2-dimensional space, using the relevant ranges for the competitiveness and openness variable, and the estimated parameters for the manufacturing output growth variant of the equation. The structural part of the equation, as well as the constant, have been set to zero. 


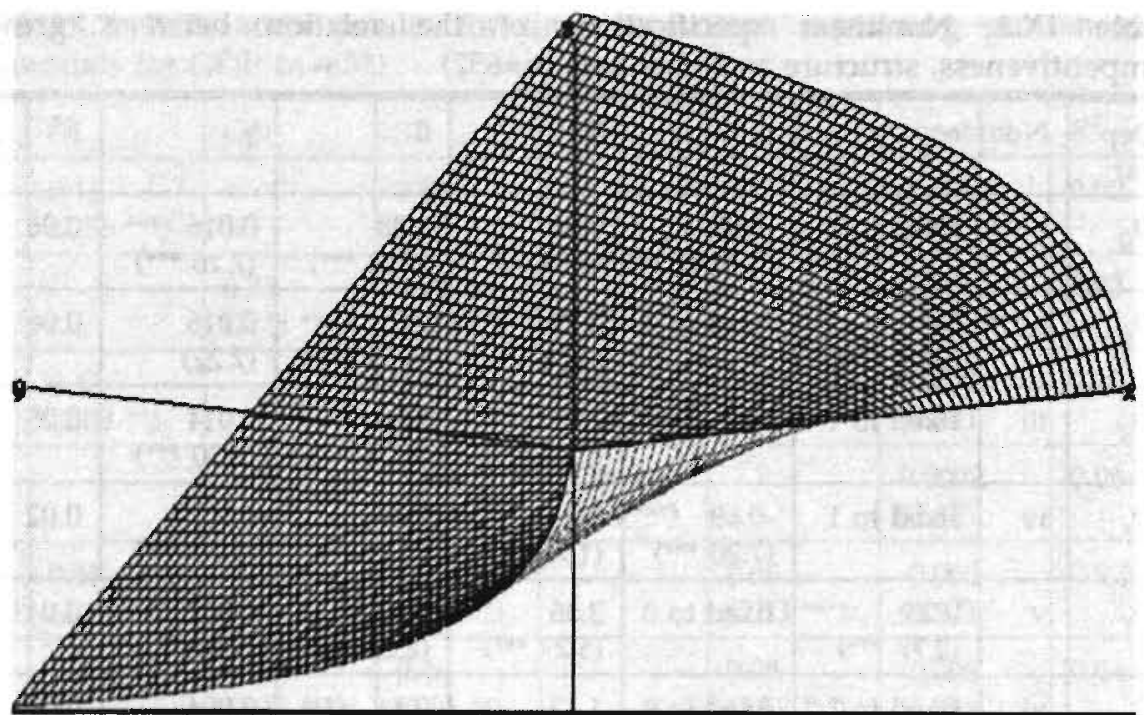

Figure IX.1a. The 3-dimensional relation berween openness, comperitiveness and growth, viewpoint 1

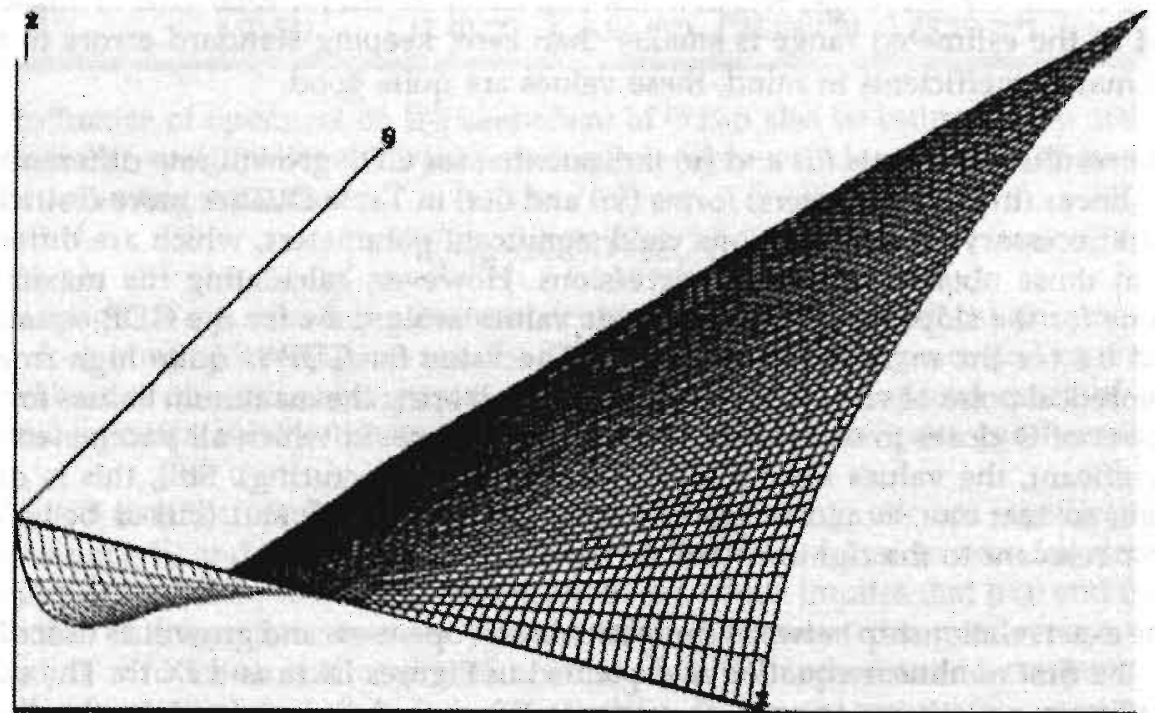

Figure IX.1b. The 3-dimensional relation between openness, competitiveness and growth, viewpoint 2 
The two different figures project the same function in the 2-dimensional space, each taking a different viewpoint. Growth rate differentials are measured on the $Z$-axis (vertical), the $X$-axis (stretching from the bottom-left to the top-right corner) measures competitiveness, and the $Y$-axis (stretching from top-left to bottom-right) measures openness. For growth and competitiveness, the middle of the respective axes represent the point zero. For the $\mathrm{Y}$-axis, the middle point corresponds with a value of the openness variable of around $125 \%$. Moving to the right on the $X$-axis means a higher value of competitiveness, while moving to the left on the $Y$-axis corresponds to higher openness. Dark-coloured surfaces represent the top of the projected plane, and light shades correspond to the bottom of the plane.

In order to interpret the form of the plane, it is useful to start by imagining a situation in which openness does not matter, and the relation between competitiveness and growth is linear. This is the case in equations (i) in Tables IX.1 and IX.2. Here, one could graph this relation in a 2-dimensional space. However, if a 3-dimensional space was used, there would be no variation along the third dimension, and the figure would simply look like an uphill road that can be crossed without gaining or losing height. Riding the road with a bicycle, however, would lead to gain/loss of height. At some point (halfway, at the point zero on the competitiveness axis), one would reach a point where the height corresponds to a zero growth rate differential.

Bearing this situation in mind, it is easy to see what would happen if the influence of openness is taken into account in as in the different variants of equation (IX.9). Now, each slice of the road (along its 'direction of the traffic') has a 'personal' steepness, which means that if one drives closer to one side of the road, the steepness varies. In fact, if one drives on the outer rightmost edge (corresponding to a closed economy), the road is completely flat. This slice of the road corresponds to the $\mathrm{X}$-axis. The more one moves to the left, the steeper the surface becomes. This interpretation is evident from Figure IX.1a.

Another way of saying the same thing is the following. At the maximum of openness (the farthest possible point on the Y-axis from the origin), the plane cuts the horizontal plane for which growth $(Z)$ is zero with a fairly large slope (close to 0.7 ). From that slice on, the slices closer to the origin are curled towards the $X$ axis. For negative values of competitiveness (X-axis), the plane curls to the $X$-axis from below (negative values on the $Z$-axis), and for positive competitiveness it curls to the $X$-axis from above. This interpretation is more evident from the viewpoint taken in Figure IX.1b.

The simple, but important, economic interpretation of these figures is that competitiveness only matters when the economy is open enough. Economies actively taking part in world trade are more sensitive to differences in competitiveness than less open economies. To put it another way, it is not beneficial to have an open economy unless the domestic economy is competitive. 


\subsection{Catching Up: A Detailed Look at the Asian NICs}

After this general interpretation of the relation between trade, competitiveness and growth, this section will take a closer look at some of the countries in the sample, in order to see to what extent their growth pattern can be explained by the approach taken. The aim of this is to go beyond the general nature of the regressions in the previous section, and explore the data used there, as well as some additional data, for the consequences of the general framework derived from the model in Chapter 7.

The empirical overview in Chapter 4 has indicated that the NICs are the countries which have achieved the most spectacular growth performance in the period under consideration. But even within this group, there are considerable differences. Although the data are not actually documented here, it is a well-known fact that the Asian $\mathrm{NICs}^{3}$ are most remarkable. As will become apparent below, these countries have achieved very high growth rates over the previous period, which is the reason why they are sometimes called the Dynamic Asian Economies (DAEs). Thus, these countries seem to be good candidates for the case study approach adopted in this section. The USA (representing the economic and technological leader at the outset of the period) and Japan (the early example of catching up, and by now an economic and technological leader, especially in the Asian region) will also be considered as benchmarks.

Table IX.4 summarizes the growth performance of these countries. The table shows that at the outset of the period, the USA, as the technological and economic leader, was realizing a small positive growth rate differential. In manufacturing, most of the Asian economies were still falling behind, with Japan as a clear and Korea and Malaysia as less clear exceptions. For GDP, the growth rate differentials for the Asian economies were more on the positive side. Thus, Japan emerged as a regional leader in terms of growth rates and per capita income (not documented) as early as the 1960 s. After 1965 , the USA economy slowed down, and mostly achieved negative growth rate differentials. The Asian catching-up process set off in this period, and only came to a standstill in Japan in the most recent period. The other Asian economies, especially Korea, continued to grow very rapidly, both with regard to GDP and manufacturing, with occasional exceptions.

\footnotetext{
${ }^{3}$ In this thesis: Hong Kong, (South) Korea, Malaysia, Singapore, Thailand, The Philippines.
} 
Table IX.4. Growth performance of Asian NICs and technological leaders, 19631987

\begin{tabular}{|l|l|l|l|l|l|l|}
\hline Country & $1963-1965$ & $1965-1970$ & $1970-1973$ & $1975-1980$ & $1980-1985$ & $1985-1987$ \\
\hline$D_{Q}$ & \multicolumn{5}{|l|}{$\mid$} \\
\hline Philippines & -2.95 & -1.43 & 5.07 & 7.24 & 14.97 & 10.61 \\
\hline Malaysia & 0.52 & 3.49 & 3.11 & 4.79 & 3.65 & 3.50 \\
\hline Thailand & -0.54 & 1.68 & 5.32 & 4.84 & 1.30 & -4.82 \\
\hline Korea & 1.17 & 16.40 & 14.48 & 14.31 & 7.04 & 11.91 \\
\hline Hong Kong & -1.33 & 3.12 & 4.37 & 6.42 & 4.04 & 6.48 \\
\hline Singapore & -2.19 & 6.27 & -3.63 & 1.28 & 0.77 & -1.01 \\
\hline Japan & 2.50 & 6.22 & 1.23 & 1.19 & 2.01 & -0.90 \\
\hline USA & 0.72 & -1.78 & -1.39 & 0.05 & -0.19 & 0.13 \\
\hline$D_{Y}$ & & & & & & \\
\hline Philippines & -2.08 & 0.54 & 2.43 & 2.23 & -1.72 & -1.99 \\
\hline Malaysia & 0.15 & 1.00 & 4.31 & 4.59 & 3.52 & -6.82 \\
\hline Thailand & 1.85 & 2.71 & 1.62 & 4.26 & 3.05 & 0.73 \\
\hline Korea & 0.10 & 5.91 & 5.77 & 2.85 & 2.25 & 5.64 \\
\hline Hong Kong & 6.44 & 3.33 & 3.28 & 6.69 & 4.49 & 4.89 \\
\hline Singapore & -5.66 & 6.35 & 6.32 & 4.03 & 4.69 & -1.18 \\
\hline Japan & 3.20 & 5.25 & 2.03 & 1.23 & 1.13 & 0.22 \\
\hline USA & 0.07 & -1.34 & -1.85 & -0.69 & 0.24 & 0.15 \\
\hline
\end{tabular}

How can this growth pattern be explained? Bearing the results of the regressions in the previous section in mind, the present section explores the trends for the USA and Asian economies in more detail. The first factor that will be examined is competitiveness $(\theta)$. In Figure IX.2a, the competitiveness profiles of the USA and Japan are presented. The figure gives the percentage point contribution of wage rate competitiveness to the total on the horizontal axis, and its productivity and scale counterpart on the vertical axis. The solid line going from the upper left corner to the bottom right corner makes the distinction between negative (left) and positive (right) total competitiveness. The dotted lines divide the 2-dimensional space in parts that correspond to different sources of competitiveness. Japan starts as a technologically backward country, which is still competitive due to its low wage rate. The USA starts as a highly competitive country with regard to technology, but lags behind in the wage rate dimension. Some of the reasons why the USA's total competitive lag did not materialize in a larger negative growth rate differential than that in Table IX.4 will become apparent below. The catching-up process of Japan is made visible through its constant upward movement in the diagram. However, at the same time, Japan moves slowly to the left, indicating its loss in the wage rate dimension of competitiveness. The USA shows a movement in the opposite direction. The catching-up process in the rest of the sample makes 
it lose part of its advantage on the vertical axis. Regarding the wage rate, however, the USA moves in the positive direction, making it more competitive overall, especially in the late 1970 s and 1980 s.

The movements in the horizontal direction of Figure DX.2a illustrates the influence of exchange rates on the wage rate competitiveness of the two leading economies in the world. The USA's swing in the horizontal direction corresponds exactly with the large amplitude of the exchange rate path of the US\$ over the 1970s and 1980s. The same holds for the Japanese pattern over the 1980s.

Figures $\mathrm{IX} .2 \mathrm{~b}$ and $\mathrm{IX} .2 \mathrm{c}$ show that exchange rate movements are not quite so dominant for the other Asian economies. Since the movements of these economies mainly take place in quadrant IV, the figure only gives the rightmost half of the total competitiveness diagram in Figure IX.2a. The Asian NICs' increasing competitiveness is in most cases due to wages, both in a static sense (the presence of most series in the top of quadrant IV) and in a dynamic sense (the movement to the right). At the same time, however, some of the series (especially Malaysia and Korea) also show a small upward movement (over the latest period), indicating the technological catching-up process.

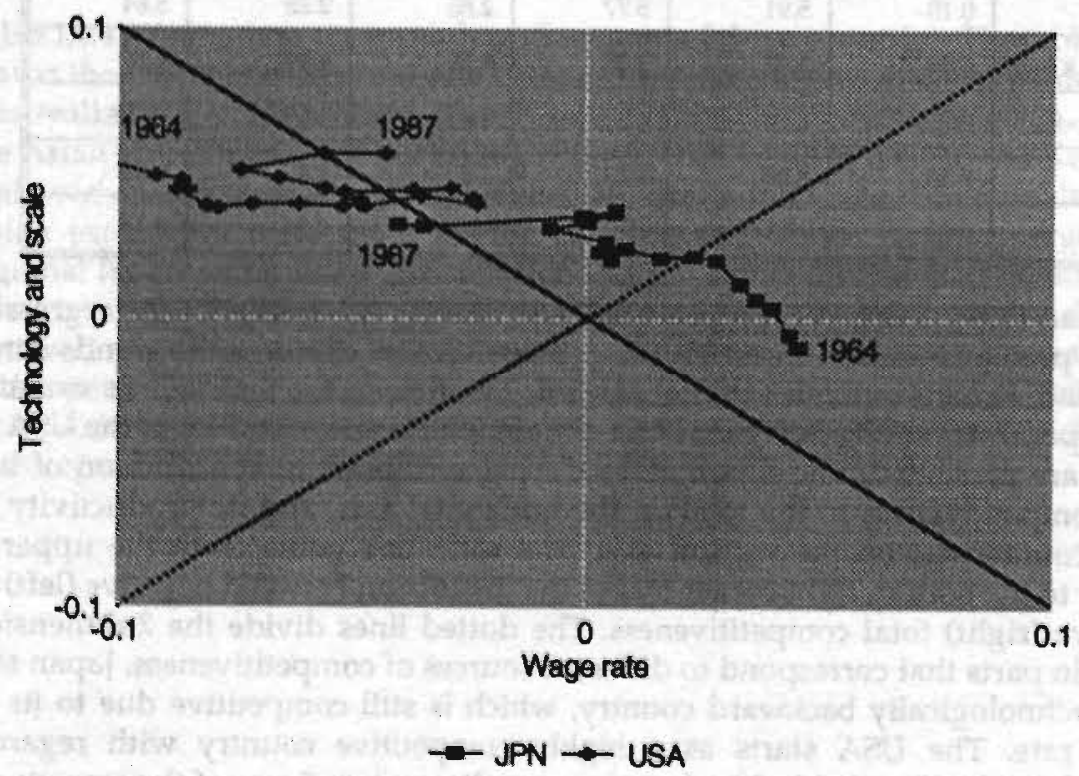

Figure IX.2a. The competitiveness profiles of Japan and the USA, 1960s-1980s 


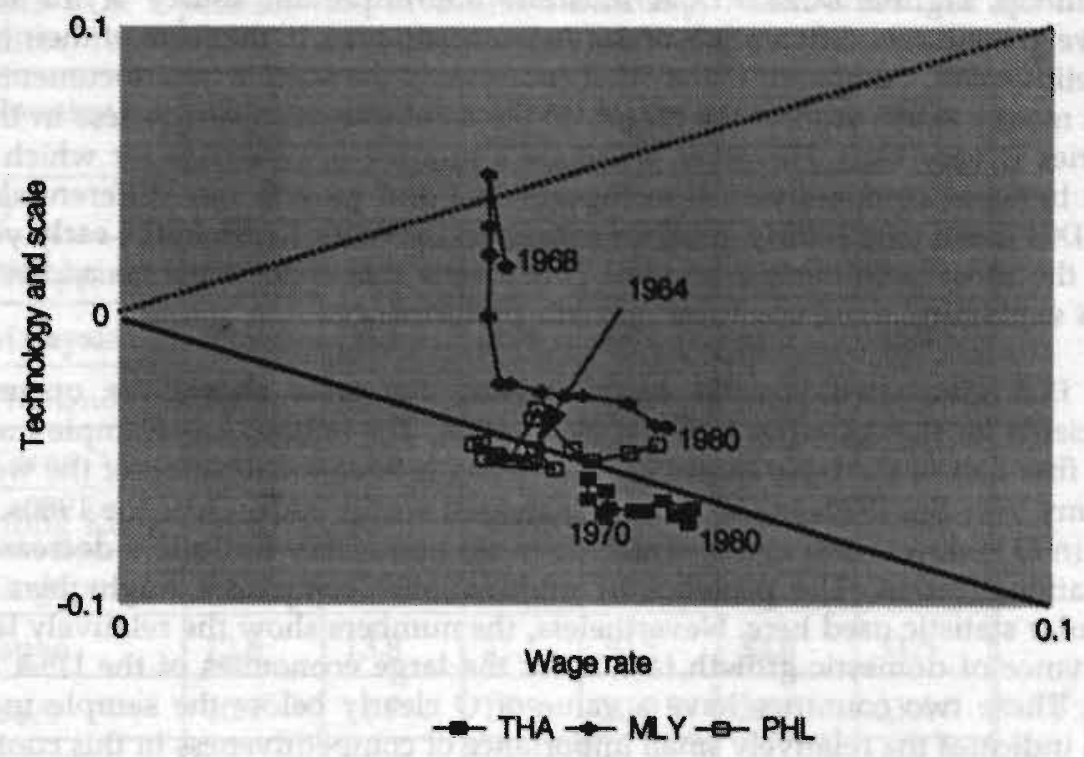

Figure DX.2b. The competitiveness profiles of Thailand, Malaysia and The Philippines, 1960s-1980s

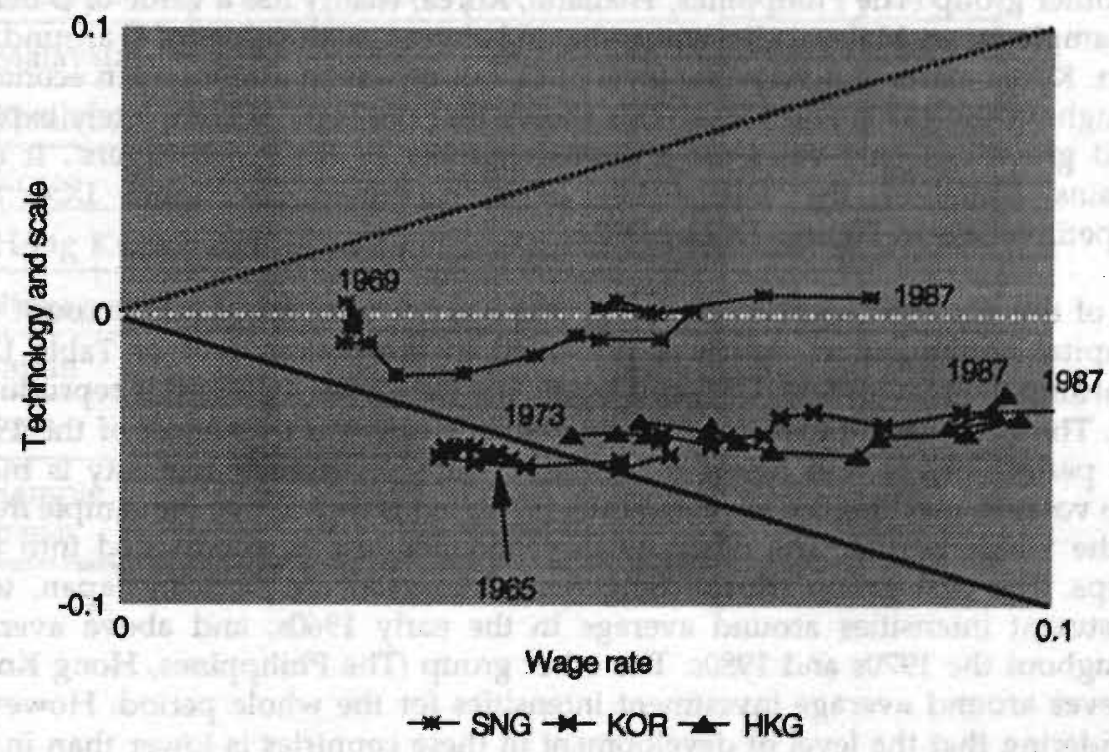

Figure IX.2c. The competitiveness profiles of Singapore, Hong Kong and Korea, 1960 s-1980s 
To sum up, Figures IX.2a - IX.2c illustrate one important source of the large positive growth rate differentials of the Asian economies, in the form of their high competitiveness. Compared to the other countries in the sample (not documented), which mostly move around the origin, or the solid line, competitiveness in these countries is very high. However, there are a number of countries for which the match between competitiveness in Figures $D X .2$ and growth rate differentials in Table IX.4 is not particularly good for some periods (with Korea in the early years being the most prominent example). This means that there must be additional factors explaining these countries' growth performance.

Table DX.5 gives two possible sources. First, the table shows the openness coefficients for the countries under consideration. The bottom line (sample mean) of the first half of the table shows the increasing internationalization of the world economy over the 1970 s in the form of increased world trade. Over the $1980 \mathrm{~s}$, the trend in $O$ is downward again, which does not necessarily indicate a decrease in internationalization. The presence of multinational companies might bias the particular statistic used here. Nevertheless, the numbers show the relatively large importance of domestic growth factors for the large economies of the USA and Japan. These two countries have a value of $O$ clearly below the sample mean, which indicates the relatively small importance of competitiveness in this context. Both countries, however, have an increasing trend in 0 , in line with the world trend. The other Asian NICs can be divided into two groups. One group (Hong Kong, Singapore) is highly dependent on international trade, and achieves values of $O$ far above the sample mean (in the case of Singapore even extremely high). The other group (The Philippines, Thailand, Korea) clearly has a value of $O$ below the sample mean. Malaysia lies somewhat in between, with values of $O$ around the mean. Korea starts at a very low level of 0 , but moves to a more open economy throughout the 1970s and 1980s. This shows that the logic of completely exportbased growth is only valid for a limited number of the Asian 'tigers'. It also explains some of the mismatches between growth in Table IX.4 and competitiveness in Figures IX.2a - IX.2c.

One of the domestic sources of growth that has not been taken into account yet, is capital accumulation, which is presented in the bottom half of Table IX.5. Regarding the two leaders, USA and Japan, the well-known pattern is reproduced here. The USA has an investment ratio which is constant over most of the 19601980 period, but is well below the mean. Japan's investment intensity is much more volatile, reaching a peak in the mid-1970s, but is well above the sample mean for the whole period. The other Asian economies can be subdivided into two groups. The first group (Korea, Singapore, Malaysia) are following Japan, with investment intensities around average in the early 1960s, and above average throughout the 1970s and 1980s. The other group (The Philippines, Hong Kong) achieves around average investment intensities for the whole period. However, considering that the level of development in these countries is lower than in the OECD countries, one might interpret this as relatively high. Thailand is an exception to the high investment intensity in Asia, with levels well below those of the USA. 
Table IX.5. Openness and investment Intensity, Asian NICs and technological leaders, 1963-1987

\begin{tabular}{|l|l|l|l|l|l|l|}
\hline Country & $\begin{array}{l}1964- \\
1965\end{array}$ & $\begin{array}{l}1965- \\
1970\end{array}$ & $\begin{array}{l}1970 \\
1975\end{array}$ & $\begin{array}{l}1975- \\
1980\end{array}$ & $\begin{array}{l}1980- \\
1985\end{array}$ & $\begin{array}{l}1985- \\
1987\end{array}$ \\
\hline O \\
\hline Philippines & 14.7 & 14.7 & 14.6 & 17.4 & 16.1 & 13.3 \\
\hline Malaysia & 39.9 & 36.4 & 38.4 & 48.1 & 47.3 & 45.4 \\
\hline Thailand & 12.5 & 12.6 & 14.0 & 18.1 & 17.8 & 16.4 \\
\hline Korea & 7.5 & 12.9 & 22.6 & 39.3 & 46.2 & 42.9 \\
\hline Hong Kong & 91.8 & 96.8 & 119.3 & 139.9 & 131.6 & 138.9 \\
\hline Singapore & 141.5 & 135.2 & 159.6 & na & na & na \\
\hline Japan & 12.8 & 13.8 & 21.1 & 30.5 & 32.8 & 31.5 \\
\hline USA & 10.9 & 11.7 & 15.5 & 20.9 & 22.7 & 21.4 \\
\hline $\begin{array}{l}\text { Sample } \\
\text { mean }\end{array}$ & 30.9 & 31.1 & 40.4 & 53.3 & 50.3 & 49.3 \\
\hline K & & & & & & \\
\hline Philippines & 18.3 & 19.2 & 19.4 & 23.9 & 20.2 & 12.6 \\
\hline Malaysia & 22.4 & 23.2 & 28.2 & 31.1 & 37.1 & 32.0 \\
\hline Thailand & 12.9 & 16.1 & 16.6 & 16.1 & 14.9 & 13.7 \\
\hline Korea & 13.2 & 22.9 & 27.4 & 30.9 & 28.1 & 28.3 \\
\hline Hong Kong & 25.8 & 19.4 & 19.5 & 22.3 & 21.4 & 18.3 \\
\hline Singapore & 18.1 & 23.5 & 35.3 & 34.7 & 40.0 & na \\
\hline Japan & 27.8 & 31.7 & 35.9 & 32.3 & 29.2 & 28.8 \\
\hline USA & 16.8 & 16.6 & 16.8 & 17.3 & 17.6 & 18.8 \\
\hline $\begin{array}{l}\text { Sample } \\
\text { mean }\end{array}$ & 23.6 & 23.9 & 25.3 & 24.6 & 23.0 & na \\
\hline & & & & & & \\
\hline
\end{tabular}




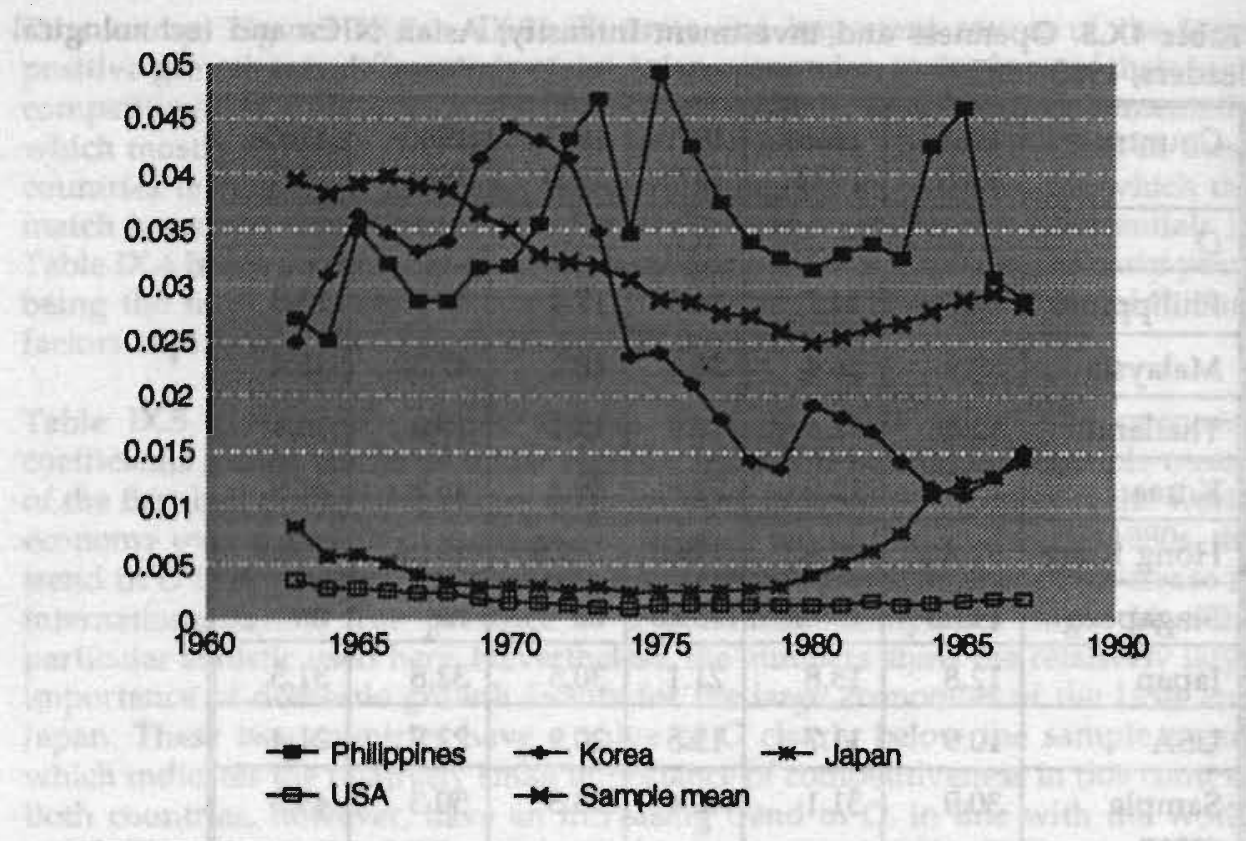

Figure IX.32. The evolution of the specialization index, low-specialization countries

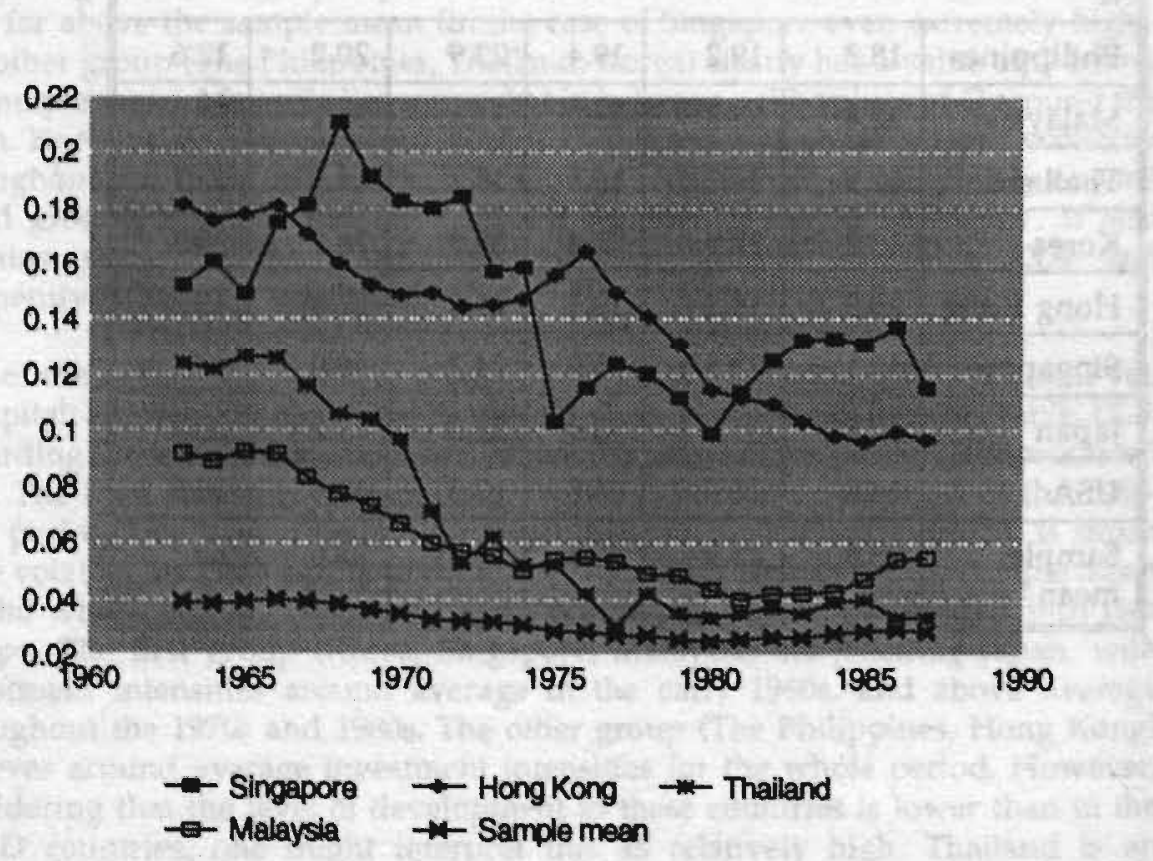

Figure IX.3b. The evolution of the specialization index, high-specialization countries 
Finally, the degree of specialization is investigated. The regressions in the previous section showed that this is a very strong factor explaining growth. As explained above, there are two sides to specialization, which can be broadly defined as demand side induced and supply side induced. Before separating these two, Figures IX.3a and IX.3b present the degree of specialization for the countries in the sample. The figures divide the countries into two groups, one with a high degree, and the other with a low degree of specialization. This division corresponds closely to the one made in the case of openness, which illustrates the relation between openness and specialization. The first group, in which the leaders Japan and the USA are found besides Korea and the Philippines, all have starting values of the variable $H$ below the sample mean. The second group has starting values above the sample mean. In Figure IX.3a, note the trends for Japan and Korea. In the case of Japan, the increased openness over the 1970s and 1980s has also lead to increased specialization. For Korea, however, increased openness has gone together with decreased specialization (except for the period since 1985). This indicates the very broad range of the Korean competitive manufacturing activities.

In Figure IX.3b, note that all series show a decreasing trend over time. These countries, which all started at very high levels of specialization, are becoming less specialized over time. The sample mean is also decreasing, which shows that this is indeed a trend that is not limited to Asia. In light of the increasing trend in openness that was observed earlier, this is surprising, since one would expect increasing openness to go hand in hand with increasing specialization.

One possible explanation for this might be the dynamics of sectoral shares at the world level. In line with some of the theory on diffusion of innovations, long waves and technological paradigms, the share of new technologies in total (world) production has been rising since the late 1970s (see the discussion in Chapter 3). Reshaping the division of labour at the world level on the basis of this new sectoral division of labour is a process which erodes the old division of labour, and thus leads to a decreasing trend in specialization initially. This is consistent with the rise in specialization in some of the countries in Figures IX.3a and IX.3b since the beginning of the 1980s.

Table IX.6 investigates this hypothesis in more detail for the DAEs. The table illustrates the dynamics of specialization patterns in a nonquantitative way. The underlying statistics for this table are revealed comparative advantages (RCA), calculated on the basis of production statistics. The table gives the top-3 sectors for different criteria for different periods, which have been chosen on the basis of the movement in $H$ in Figures IX.3a and IX.3b.

In the early 1960 s, all Asian economies (including Japan) were specialized in lowtech sectors. Tobacco, wood and textiles were among the sectors with the highest RCAs. The USA, on the other hand, were specialized in instruments, transport equipment (mostly cars and aircraft), and refined oil.

The USA economy's specialization pattern remained largely constant, with the high-tech sectors at the forefront. However, in line with the Japanese competition in the automobile industry, transport equipment vanished from the RCA top-3 in 
1987. Japan, on the other hand, showed major changes in its specialization pattern. The sectors which had been in the RCA top-3 in 1963 realized major losses in RCA (see the line top- 3 changes - ). The top- 3 changes + sectors (instruments, electrical machinery and iron and steel) increased their RCA to such an extent that they became the top-3 sectors in 1987. Thus, the picture of Japan as a country switching from low-tech to high-tech production that was clear from Figure IX.2a, is confirmed by the dynamics of its specialization pattern.

Table IX.6. Specialization patterns in a dynamic perspective, Asian NICs and technological leaders, 1963-1987

\begin{tabular}{|c|c|c|c|}
\hline Country & $T_{1}$ & $\mathrm{~T}_{2}$ & $T_{3}$ \\
\hline Philippines & 1965 & 1975 & 1987 \\
\hline Top $3+$ & $\begin{array}{l}\text { Tobacco }(9.1) \\
\text { Other chem (2.3) } \\
\text { Paper }(2.0)\end{array}$ & $\begin{array}{l}\text { Tobacco }(7.4) \\
\text { Refined oil }(2.8) \\
\text { Other chem }(2.4)\end{array}$ & $\begin{array}{l}\text { Tobacco }(7.1) \\
\text { Beverages (2.0) } \\
\text { Apparel }(2.0) \\
\end{array}$ \\
\hline Top 3 - & $\begin{array}{l}\text { Instruments }(0.01) \\
\text { Misc C\&O (0.07) } \\
\text { Iron \& steel }(0.1)\end{array}$ & $\begin{array}{l}\text { Misc C\&O (0.03) } \\
\text { Instruments }(0.04) \\
\text { Non-el mach }(0.2) \\
\end{array}$ & $\begin{array}{l}\text { Instruments }(0.02) \\
\text { Non-fer met }(0.02) \\
\text { Misc C\&O }(0.06)\end{array}$ \\
\hline Top 3 changes + & & $\begin{array}{l}\text { Refined oil (1.9) } \\
\text { Printing (0.4) } \\
\text { Iron \& steel }(0.3)\end{array}$ & $\begin{array}{l}\text { Fab met }(1.6) \\
\text { Apparel }(1.4) \\
\text { Beverages }(1.1)\end{array}$ \\
\hline Top 3 changes - & & $\begin{array}{l}\text { Tobacco }(1.7) \\
\text { Paper }(1.3) \\
\text { Pottery }(0.9) \\
\end{array}$ & $\begin{array}{l}\text { Refined oil (2.0) } \\
\text { Other chem (1.1) } \\
\text { Wood }(0.5)\end{array}$ \\
\hline Malaysia & & 1963 & 1987 \\
\hline Top 3+ & & $\begin{array}{l}\text { Rubber }(8.1) \\
\text { Wood }(3.6) \\
\text { Tobacco }(3.0) \\
\end{array}$ & $\begin{array}{l}\text { Rubber (8.2) } \\
\text { Wood (2.6) } \\
\text { El mach (2.1) }\end{array}$ \\
\hline Top 3 - & & $\begin{array}{l}\text { Misc C\&O (0.04) } \\
\text { Transport }(0.06) \\
\text { Instruments }(0.06) \\
\end{array}$ & $\begin{array}{l}\text { Misc C\&O }(0.07) \\
\text { Leather }(0.1) \\
\text { Instruments }(0.2)\end{array}$ \\
\hline Top 3 changes + & & & $\begin{array}{l}\text { El mach (1.3) } \\
\text { Apparel }(0.4) \\
\text { Fab met }(0.4) \\
\end{array}$ \\
\hline Top 3 changes - & & & $\begin{array}{l}\text { Tobacco (1.2) } \\
\text { Wood }(1.0) \\
\text { Food }(0.6) \\
\end{array}$ \\
\hline Thailand & & 1963 & 1987 \\
\hline Top $3+$ & & $\begin{array}{l}\text { Tobacco (3.6) } \\
\text { Oth man (3.2) } \\
\text { Food (3.1) }\end{array}$ & $\begin{array}{l}\text { Apparel (3.2) } \\
\text { Tobacco (3.2) } \\
\text { Rubber (2.9) } \\
\end{array}$ \\
\hline Top 3 - & & $\begin{array}{l}\text { Leather }(0.09) \\
\text { Transport }(0.1) \\
\text { Ind chem }(0.1)\end{array}$ & $\begin{array}{l}\text { Printing }(0.2) \\
\text { Non-el mach }(0.2) \\
\text { Instruments }(0.2)\end{array}$ \\
\hline \multicolumn{4}{|c|}{ Continued on next page... } \\
\hline
\end{tabular}




\begin{tabular}{|c|c|c|c|}
\hline Top 3 changes + & & & $\begin{array}{l}\text { Textiles }(1.2) \\
\text { Footwear (1.0) }\end{array}$ \\
\hline Top 3 changes - & & & $\begin{array}{l}\text { Qhim } \\
\text { Food }(1.2)(1,0) \\
\text { Wood fum }(0.5) \\
\text { Tobaceo }(0.4)\end{array}$ \\
\hline Korea & & 1970 & 1987 \\
\hline Top $3+$ & $\begin{array}{l}\text { Tobacioo (8.8) } \\
\text { Pottery }(5.0) \\
\text { Rubber }(4.0) \\
\end{array}$ & $\begin{array}{l}\text { Tobacco }(6.8) \\
\text { Oth man }(2.5) \\
\text { Refined oil (2.5) } \\
\end{array}$ & $\begin{array}{l}\text { Leather (3.1) } \\
\text { Rubber (2.4) } \\
\text { Textiles (2.3) }\end{array}$ \\
\hline Top 3 - & $\begin{array}{l}\text { Transport }(0.2) \\
\text { Leather }(0.2) \\
\text { El mach }(0.3) \\
\end{array}$ & $\begin{array}{l}\text { Leather }(0.1) \\
\text { Fab met }(0.2) \\
\text { Transport }(0.2) \\
\end{array}$ & $\begin{array}{l}\text { Printing }(0.2) \\
\text { Wood furn }(0.5) \\
\text { Fab met: }(0.5)\end{array}$ \\
\hline Top 3 changes + & & $\begin{array}{l}\text { Plastic (0.9) } \\
\text { Refined oil }(0.9) \\
\text { Ind chem }(0.8) \\
\end{array}$ & $\begin{array}{l}\text { Leather }(3.0) \\
\text { El mach }(1.5) \\
\text { Apparel }(1.4)\end{array}$ \\
\hline Top 3 changes - & & $\begin{array}{l}\text { Pottery }(3.6) \\
\text { Rubber }(2.3) \\
\text { Tobacco }(2.0)\end{array}$ & $\begin{array}{l}\text { Tobacco }(4.5) \\
\text { Refined ofl }(1.6) \\
\text { Wood }(1.5)\end{array}$ \\
\hline Hong Kong & 1963 & 1976 & 1987 \\
\hline Top $3+$ & $\begin{array}{l}\text { Apparel }(12.0) \\
\text { Textiles }(4.9) \\
\text { Plastic (4.4) }\end{array}$ & $\begin{array}{l}\text { Apparel (12.9) } \\
\text { Textiles (4.9) } \\
\text { Plastic (3.2) }\end{array}$ & $\begin{array}{l}\text { Apparel (11.2) } \\
\text { Insinuments (6.1) } \\
\text { Textiles (4.2) }\end{array}$ \\
\hline Top 3 - & $\begin{array}{l}\text { Ind chem }(0.1) \\
\text { Transport }(0.1) \\
\text { Non-el mach }(0.1)\end{array}$ & $\begin{array}{l}\text { Ind chem }(0.1) \\
\text { Transport }(0.1) \\
\text { Iron \& steel }(0.1)\end{array}$ & $\begin{array}{l}\text { Iron \& Steel }(0.1) \\
\text { Transport }(0.1) \\
\text { Non-fer met }(0.2)\end{array}$ \\
\hline Top 3 changes + & & $\begin{array}{l}\text { Apparel }(0.8) \\
\text { El mach }(0.7) \\
\text { Instruments }(0.7)\end{array}$ & $\begin{array}{l}\text { Instruments }(4.4) \\
\text { Oth man }(2.4) \\
\text { Tobacco }(0.8)\end{array}$ \\
\hline Top 3 changes - & & $\begin{array}{l}\text { Plastic (1.2) } \\
\text { Printing (0.8) } \\
\text { Oth man (3.5) }\end{array}$ & $\begin{array}{l}\text { Apparel }(1.7) \\
\text { El mach }(1.3) \\
\text { Textiles }(0.7)\end{array}$ \\
\hline Singapore & & 1968 & 1986 \\
\hline Top $3+$ & & $\begin{array}{l}\text { Rubber (7.2) } \\
\text { Refined oil (5.7) } \\
\text { Wood (2.7) }\end{array}$ & $\begin{array}{l}\text { Refined oil (5.6) } \\
\text { El mach (2.1) } \\
\text { Rubber (1.9) } \\
\end{array}$ \\
\hline Top 3 - & & $\begin{array}{l}\text { Paper }(0.1) \\
\text { Pottery }(0.1) \\
\text { Iron \& steel }(0.1)\end{array}$ & $\begin{array}{l}\text { Pottery }(0.1) \\
\text { Glass }(0.1) \\
\text { Textiles }(0.1)\end{array}$ \\
\hline Top 3 changes + & & & $\begin{array}{l}\text { El mach }(1.8) \\
\text { Apparel }(0.7) \\
\text { Ind chem }(0.4) \\
\end{array}$ \\
\hline Top 3 changes - & & & $\begin{array}{l}\text { Rubber (5.3) } \\
\text { Wood }(2.4) \\
\text { Footwear (1.0) }\end{array}$ \\
\hline \multicolumn{4}{|c|}{ Continued on next page... } \\
\hline
\end{tabular}




\begin{tabular}{|l|l|l|l|}
\hline Japan & 1963 & 1987 \\
\hline Top 3+ & $\begin{array}{l}\text { Wood (2.6) } \\
\text { Oth man (2.2) } \\
\text { Plastic (2.0) }\end{array}$ & $\begin{array}{l}\text { El mach (2.0) } \\
\text { Iron \& steel (1.4) } \\
\text { Instruments (1.2) }\end{array}$ \\
\hline Top 3- & $\begin{array}{l}\text { Footwear (0.3) } \\
\text { Instruments (0.5) } \\
\text { Refined oil (0.6) }\end{array}$ & $\begin{array}{l}\text { Footwear (0.4) } \\
\text { Apparel (0.5) } \\
\text { Wood furn (0.6) }\end{array}$ \\
\hline Top 3 changes + & & $\begin{array}{l}\text { El mach (1.1) } \\
\text { Instruments (0.7) } \\
\text { Iron \& steel (0.4) }\end{array}$ \\
\hline Top 3 changes - & & $\begin{array}{l}\text { Wood (1.6) } \\
\text { Wood furn (1.2) } \\
\text { Oth man (1.0) }\end{array}$ \\
\hline USA & & 1963 & \begin{tabular}{l} 
1987 \\
\hline Top 3+
\end{tabular} \\
\hline Top 3- & & $\begin{array}{l}\text { Instruments (1.5) } \\
\text { Refined oil (1.5) } \\
\text { Transport (1.3) }\end{array}$ & $\begin{array}{l}\text { Instruments (1.4) } \\
\text { Printing (1.3) } \\
\text { Refined oil (1.3) }\end{array}$ \\
\hline Top 3 changes + & Pottery (0.4) & $\begin{array}{l}\text { Footwear (0.4) } \\
\text { Pottery (0.4) } \\
\text { Leather (0.5) }\end{array}$ \\
\hline Top 3 changes - & & Textiles (0.6) & $\begin{array}{l}\text { Plastic (0.5) } \\
\text { Wood furn (0.3) } \\
\text { Printing (0.3) }\end{array}$ \\
\hline & & & $\begin{array}{l}\text { Iron \& steel (0.4) } \\
\text { Footwear (0.4) } \\
\text { El mach (0.3) }\end{array}$ \\
\hline & & & \\
\hline
\end{tabular}

The other Asian economies are less dynamic in this respect. Still, a number of them (Malaysia, Hong Kong, Singapore) manage to become specialized in at least one high-tech sector (electrical machinery or instruments). In Korea, electrical machinery is becoming increasingly important, as is clear from the top-3 changes + row, but in 1987, this sector did not rank among the top-3 RCA yet. Thus, all the economies which have shown an increasing trend in specialization over the last years, are becoming more specialized in at least one high-tech sector. This illustrated the value of the argument on the reshaping of the international division of labour.

Another point that is worth mentioning from Table IX.6 is the importance of natural resource-based industries such as refined oil, rubber and wood for some of the Asian economies. Being tied to one particular location, these sectors would be expected to have a high degree of specialization. Nevertheless, the fact that most Asian economies have been able to go beyond the exclusive exploitation of these natural resources, and specialize in other sectors as well, is indicative of their dynamic power. Take Korea, which was specialized in the natural resource based industries rubber and pottery in 1963. At that time, electrical machinery and transport were very weak. Over the 1960s, Korea experienced a wave of specialization, which led to a strong position in other manufacturing, and refined oil as a new, but more important, resource-based industry. After 1970, the Korean 
economy was once again reshaped, this time resulting in a net decline of specialization. During this period, a number of its weaknesses (leather, electrical machinery) in 1963 developed into strengths by 1987.

There are two other countries for which wave-like patterns in specialization were found. The Philippines switched to an oil-based economy during the 1960 s and early 1970s. Subsequently, it became specialized in low-tech sectors such as beverages and apparel. Note also the constant importance of tobacco over the total period. Hong Kong showed specialization waves too, but only over the most recent period was this accompanied by a real structural change in the sense that instruments became more and more important. Over the total period, this country is the best example of the importance of textiles(-related) industry in the Asian countries.

Thus, this table shows the supply side effects and causes of specialization. Table IX.7 shows the demand side effects related to specialization. The table gives the average value of the variable $S$ over different subperiods. Overall, the value of $S$ (compared to growth rate differentials and/or competitiveness) is small. However, as the regressions showed, the importance is still significant. The table shows that the two leaders (Japan, USA) mostly stay on the positive (including 0) side (Japan especially since it has become a technological leader). The other countries are mostly on the negative side, except for Hong Kong for the post-1960s period, and the other countries for the period around the first oil crisis. This indicates that the catching up of the Asian NICs is not due to the demand effects of structural differences. If anything, this effect was beneficial to the economic and technological leaders.

Table IX.7. Growth due to the demand side effect of structural differences, Asian NICs and Technological Leaders, in percentage points

\begin{tabular}{|c|c|c|c|c|c|c|}
\hline Country & $\begin{array}{l}1963- \\
1965\end{array}$ & $\begin{array}{l}1965- \\
1970\end{array}$ & $\begin{array}{l}1970- \\
1975\end{array}$ & $\begin{array}{l}1975- \\
1980\end{array}$ & $\begin{array}{l}1980- \\
1985\end{array}$ & $\begin{array}{l}1985- \\
1987\end{array}$ \\
\hline Philippines & -0.8 & -0.5 & 0.1 & -0.1 & -0.4 & -0.5 \\
\hline Malaysia & -1.3 & -0.5 & 0.2 & 0.1 & 0.2 & -0.2 \\
\hline Thailand & -1.7 & -1.3 & 0 & 0 & -0.5 & -0.4 \\
\hline Korea & -0.83 & -0.25 & 0.1 & -0.2 & -0.4 & -0.3 \\
\hline $\begin{array}{l}\text { Hong } \\
\text { Kong }\end{array}$ & -1.2 & -0.5 & 0.2 & 0.1 & 0.2 & 0.1 \\
\hline Singapore & -0.4 & 0.5 & 0.4 & -0.2 & -0.6 & -0.5 \\
\hline Japan & -0.1 & 0 & 0 & 0 & 0.3 & 0.2 \\
\hline USA & 0.2 & 0.1 & 0 & 0 & 0 & 0.1 \\
\hline
\end{tabular}


Summarizing the results, it is clear that there is not a general strategy for successful catching up, even when attention is limited to a small group of countries such as the Asian NICs. Table IX.8 summarizes the findings of this section in a qualitative overview of some the factors stimulating growth in the Asian economies. Overall, low wages seem to (have) be(en) a very strong factor stimulating growth in Asia. In addition to this, investment plays a (major) role in all countries, except Thailand. More recently, growth in high-tech industries has been a factor contributing in a positive way. Overall, the Asian economies do not seem to be specialized in sectors with very high (world) income elasticity. Other factors, such as specialization and openness vary between the different Asian economies. Some of the countries have benefited from these factors, while others have had a weaker position in this respect.

Table IX.8. Factors explaining growth in the Asian NICs

\begin{tabular}{|c|c|c|c|c|c|c|c|c|}
\hline Factor & Period & $\begin{array}{l}\text { Philip- } \\
\text { pines }\end{array}$ & $\begin{array}{l}\text { Malay- } \\
\text { sia }\end{array}$ & $\begin{array}{l}\text { Thai- } \\
\text { land }\end{array}$ & Korea & $\begin{array}{l}\text { Hong } \\
\text { Kong }\end{array}$ & $\begin{array}{l}\text { Singap } \\
\text { ore }\end{array}$ & $\begin{array}{l}\text { Japa } \\
\mathrm{n}\end{array}$ \\
\hline \multirow[t]{2}{*}{ Low wages } & early & ++ & ++ & + & + & ++ & + & + \\
\hline & late & ++ & $++\quad+4$ & ++ & ++ & ++ & ++ & 0 \\
\hline \multirow[t]{2}{*}{ Technology } & early & - & + & - & - & - & + & - \\
\hline & late & - & + & - & 0 & + & + & + \\
\hline \multirow{2}{*}{$\begin{array}{l}\text { Natural resource } \\
\text { based industries }\end{array}$} & early & +1101 & ++ & 0 & 0 & 0 & $++\quad 17$ & + \\
\hline & late & 0 & ++ & + & 0 & 0 & + & . \\
\hline \multirow{2}{*}{$\begin{array}{l}\text { High-tech } \\
\text { industries }\end{array}$} & early & 0 & - & 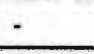 & 0 & - & 0 & 0 \\
\hline & late & 0 & + & - & + & + & + & ++ \\
\hline \multirow{2}{*}{$\begin{array}{l}\text { Growth from } \\
\text { trade }\end{array}$} & early & 0 & + & 0 & 0 & ++ & ++ & 0 \\
\hline & late & 0 & + & 0 & + & ++ & t+ & + \\
\hline \multirow[t]{2}{*}{ Specialization } & early & 0 & + & + & 0 & ++ & ++ & - \\
\hline & late & 0 & 0 & 0 & 0 & ++ & ++ & 0 \\
\hline \multirow{2}{*}{$\begin{array}{l}\text { Income elasticity } \\
\text { of demand }\end{array}$} & early & 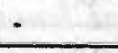 & - & - & $\cdot$ & - & 0 & + \\
\hline & late & $\therefore$ & 0 & - & - & + & $\therefore$ & 0 \\
\hline \multirow[t]{2}{*}{ Investment } & early & + & + & - & + & + & + & ++ \\
\hline & late & +89 & ++ & - & + & $+\quad 710$ & ++ & ++ \\
\hline
\end{tabular}




\subsection{Conclusions}

The tests performed in section 9.1 show the general relevance of the approach to growth in the model presented in Chapter 7. The results show the importance of the evolutionary argument that differences in economic structure and differences in competitiveness are related to growth rate differentials. Thus, the model and the tests based on it have shown to have some value in explaining the first stylized fact in Chapter 4 . It has also been shown that the second and third stylized fact are significant factors in explaining the first one. However, since the explanatory power of the regression is low, it also appears that one needs to consider more factors determining competitiveness than the limited set used here and in the previous chapter. To do so, further research must be carried out.

The case study approach adopted in section 9.2 also shows this. The growth pattern of the Asian NICs can be explained by looking at the variables in the regressions, but there are also parts which cannot be explained directly by this method. Moreover, the case study approach shows that variety is a very important concept in explaining growth. As the evolutionary logic stresses, there is not a generally valid strategy for catching up. Each of the countries considered has its own specific factors fostering growth.

This leads to a specific way of looking at growth that is quite different from the mainstream models outlined in Chapter 2 , which treat growth as a balanced phenomenon, having a gradual nature. The open economy evolutionary logic, on the contrary, looks at growth as induced by changes in trade and the selection environment, which can be quite sudden and unexpected. Thus, the growth paths of the economies are subject to sudden shocks and trend reversals.

However, the concluding section of this last empirical chapter is not the place to discuss this issue in depth. This will be done in the last chapter, which will summarize the main arguments and conclusions. 


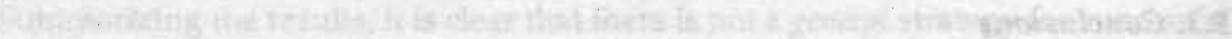

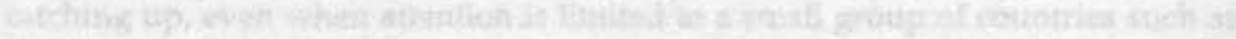

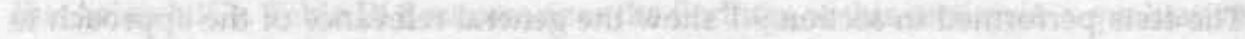

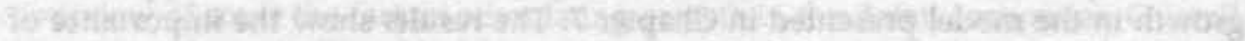

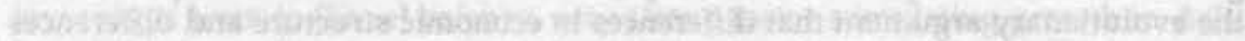

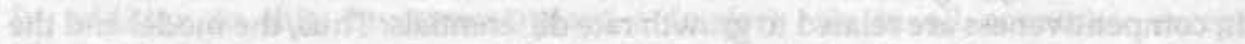

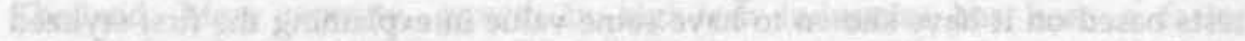

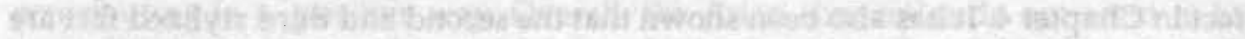

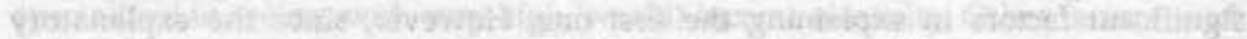

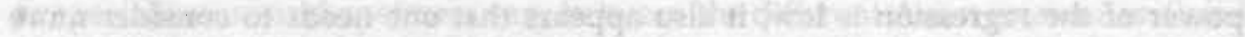

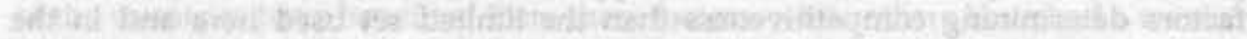

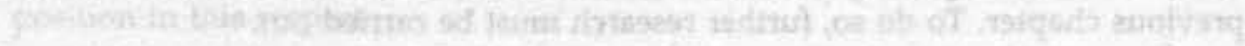

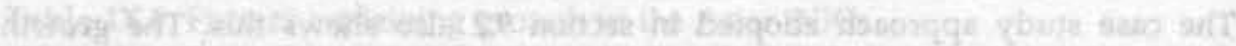

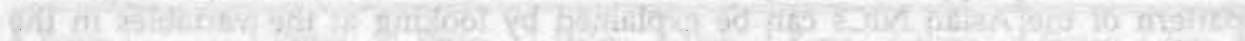

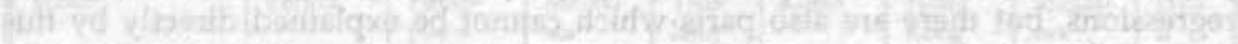

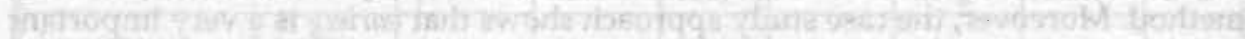

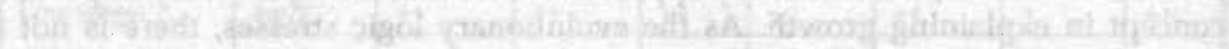

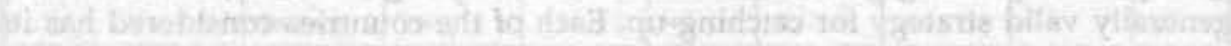

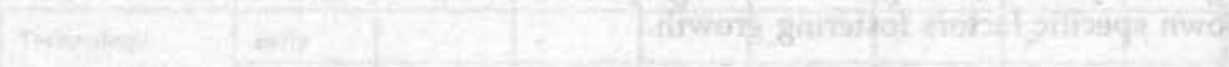

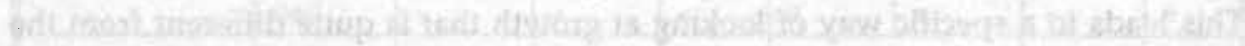

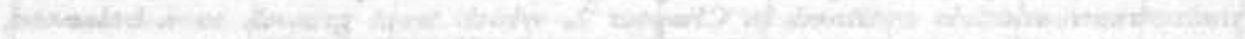

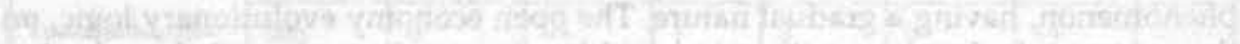

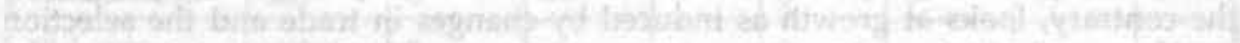

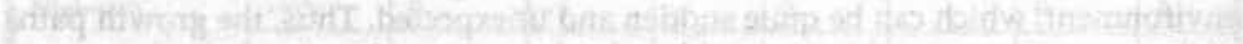

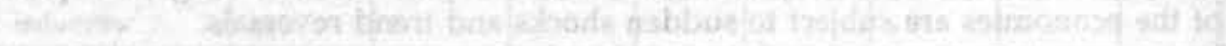

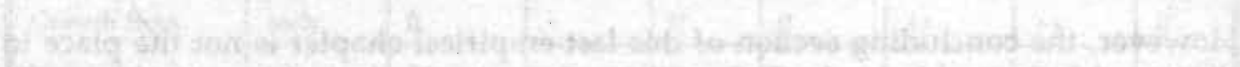

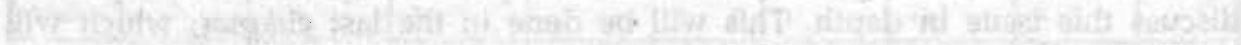

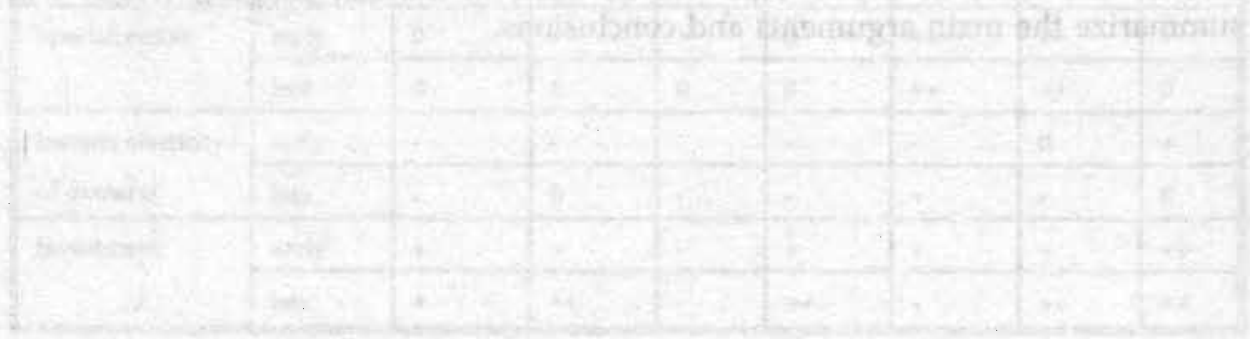




\section{PART FOUR}

\section{Summary and Conclusions}





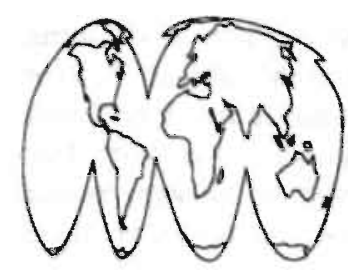

\section{CHAPTER 10. A Concluding Summary}

The main aim of this thesis was to examine the nature of the relation between economic growth and technological change in an international context. The analysis centred around three major themes. The first theme is the identification of the issues to be explained (stylized facts) and the choice of the methodological framework in which to analyze them. Part One was mainly devoted to these topics. The second theme is the influence of knowledge spillovers on international growth patterns. This was developed in theoretical and empirical detail in Part Two. The third theme is the relation between trade, competitiveness and the international division of growth. Part Three was devoted to setting up a model which gives a stylized overview of this relation, and exploring its consequences by means of simulation techniques and empirical analysis.

The concluding summary in this chapter will also focus on these three issues. Each of them will be discussed in a separate section. In addition, the last section will try to make some links between the current thesis and some other fields in the economics of technological change and (international) growth, thus outlining some possibilities for further research.

\subsection{The Merits of a Dynamic Evolutionary Approach}

The approach chosen in Chapter 3 and later developed in Chapters 5 and 7 can be characterized as dynamic and evolutionary. The main points that lend the presented models their specific character, are the idea of diversity (in behavioural patterns) as the driving force of the economic system, the idea of out-of-equilibrium behaviour of the agents and the system, and the notion of learning (in a Lamarckian sense) as the most important way of feedback between performance and behaviour. Looking back at the models presented and the tests undertaken, what can be identified as the specific advantages of this dynamic evolutionary perspective?

To answer this question is more difficult than it seems. The reason for this is that unlike some other areas of science (especially the natural sciences), the application of experimental or empirical methods cannot give a definite answer to the question which of the two alternative theoretical perspectives is better. However, a number of preliminary conclusions can be drawn on the basis of the above.

In the case of knowledge spillovers, considered in Part Two, the dynamic approach chosen obviously has big advantages. Spillovers constitute additions to the 
knowledge stock of a country (firm), and as such they require a dynamic perspective almost by definition, as in early approaches to the subject (Nelson 1968, Gomulka 1971). Apart from the methodological argument for a dynamic model of knowledge spillovers, the specific way of modelling used in Part Two (placing differences in learning capacity at the centre) proved to be very useful from a theoretical and empirical point of view. This will be discussed in more detail below.

The advantages of the dynamic evolutionary framework are even more prominent in the model presented in Chapter 7. As shown in Chapters 2 and 3, the mainstream growth theories in the literature start by specifying the relations between the variables in the model by means of static equations. The more recent new neoclassical growth models with endogenous technological change model the growth rate of knowledge by relating it to R\&D investments. However, in both cases, the outcome of the model is that an equilibrium growth rate is achieved in the long run, the so-called situation of balanced growth. This view of the world stresses that the economic system will at some point in time settle in a situation with a fixed growth rate differential between different economies. Changes in this equilibrium growth rate (differential) can be induced by changes in the parameters or exogenous variables, but not by the endogenous behaviour of the agents in the model.

In some cases, the equilibrium growth rate is not fixed, but has a more complicated regular pattern, as for example a growth cycle (Aghion and Howitt 1990). However, this does not change the basic characteristic of the model. Even in the case of a growth cycle, the regular pattern that the model generates cannot be changed without changes in parameters and / or exogenous variables.

The model developed in Chapter 7 is strongly opposed to this view of the world as a system in which regularity is the most important characteristic of growth. The dynamic evolutionary character of the model generates growth patterns which are far from regular, and in which the growth path of output, and fluctuations in employment, prices and productivity growth are quite unpredictable in the medium or longer run. The basic assumption that underlies this difference is the evolutionary idea that diversity is the driving force of the economic system, rather than a homogeneous behavioural pattern that is assumed in most mainstream growth theories.

The regularity of the growth path has also been raised in the debate on long waves (see for example Maddison 1982), a field in which the evolutionary approach to economics is fairly prominent (Schumpeter 1939, Clark et al. 1982). Some approaches (especially the early ones) to the subject of long waves have started from the assumption that the long wave is in fact a long cycle. This usage of the term cycle points to the inherent regularity in the growth path which connects upand downturns in the same way over and over again. Thus, although most of the contributions to the long-wave debate can be characterized as 'outside mainstream economic analysis', these particular interpretations conform quite well to a mainstream idea about the character of growth. 
Several authors have objected to this perspective on long waves (for example Clark et al. 1982 and Maddison 1982). They argue that there is no inherent mechanism which connects up- and downturns in a regular way, but that the explanation for observed wave-like patterns is more diffuse. Maddison argues that one should rather speak of different phases in long-term growth. In light of the model proposed here, the dynamic evolutionary way of modelling stresses this particular interpretation of growth. But even if the basic ideas underlying many of the assumptions of the model are due to Schumpeter (see Chapter 3 ), who is also considered the founder of the innovation-driven long-wave theory, the model has not shown any signs of a long-wave pattern. It would be interesting to see under what assumptions a model like the one in Chapter 7 could generate a growth pattern which resembles Maddison's phases in long-term growth. Such a model could contribute to the specific (methodological) long wave debate about the distinction between long cycles and waves.

One might be inclined to consider the conclusion of the irregularity of growth paths as not being a particularly interesting one, since the economic history of the (most recent) past contains lots of examples of this phenomenon. However, it is paradoxical to see that, for example, the major break in the growth path that occurred in the 1970s has led to a 'panicky reaction' among econonists. The mainstream theories developed until then were all aimed at explaining balanced growth, and the fact that reality did not conform to this idea was shocking to most people in the field. An example of this is the debate on the so-called productivity slowdown, which centers around the question why the (supposed) potential of technological progress has not yet materialized in higher productivity growth (for an overview of this debate, see for example Link 1987). The evolutionary idea of a complex relation between technological change and growth in which different countries react differently to different circumstances might be more fruitful in this debate than the mainstream 'linear' view of the production function (see for example Freeman 1986).

On the other hand, the extremely unequal growth between the developed and undeveloped world, did not seem to shock the mainstream economics profession until recently. Theories dealing with the falling behind of the third world otherwise than by pointing to exogenous factors have received little attention. The new neoclassical growth models might provide a promising new line of research in this field, although the first preliminary ways of 'translating' the new models into empirical relevant models for the poorest countries are perhaps a little disappointing (Romer 1989).

One of the reasons why the evolutionary view on growth put forward above did not receive much attention, is the lack of formal methods in the evolutionary tradition until recently (see Chapter 3 ). The current analysis has tried to add to the growing stream of work that is filling this gap. Although the models developed above are not really on par yet with the level of sophistication in methods and detail of much of the mainstream theory in the same field, the developments in the area of nonlinear mathematics seem to be promising in this respect (see for example Lorenz 1989). The nature of nonlinear dynamic models seems to make them highly suitable for application in the field of evolutionary theory (Silverberg 
1988), but also poses all sorts of problems with regard to testability and the nature of the conclusions drawn from them.

\subsection{Knowledge Spillovers: Catching Up or Falling Behind?}

Much in line with the way in which the notion of balanced growth has been taken for granted, the idea of automatic knowledge spillovers from rich to poor countries has gained ground in the catching-up debate. The idea that the advance of technological knowledge benefits everyone in the world eventually, seems to be implicit in this notion of automatic international diffusion of innovation. Starting from a situation which is described by inequality in innovation capacity, international knowledge spillovers are believed to radiate the beneficial effects of technological progress all over the world.

The analysis in Part Two has shown the inaccuracy of the view of knowledge spillovers as an unconditional blessing for the world as a whole. In line with arguments found in many fields of the economic literature, the model developed here argues that spillovers do not take place automatically, but require a certain assimilating capacity from the side of the receiving party. Moreover, it was assumed that the larger the technological distance between leader and follower, the less effective technology spillovers will be, an idea which is supposed to capture the effect of cumulativeness of technological change. The model was aimed at explaining two stylized facts of world long-run growth patterns formulated in Chapter 4. The first of these is that for a limited set of (OECD) countries, the initial levels of labour productivity are inversely related to the rate of technological progress. This stylized fact is the basis for the optimistic views on knowledge spillovers referred to above. The second stylized fact to be explained is that the inverse relation between initial labour productivity and the rate of technological progress, or the rate of growth of income, is not valid for the part of the world lagging furthest behind the technological or welfare frontier.

Using a functional, nonlinear specification of knowledge spillovers that is based upon some of the insights in parts of the economic literature on technological change, it was shown that for countries lagging too far behind the technological frontier, the effects of knowledge spillovers are much too small in order to be able to provide them with a catching-up perspective. For growing gaps, the actual knowledge spillovers tend to zero. The model predicts that countries which are relatively close to the technological frontier and have a relatively high intrinsic capability to assimilate knowledge spillovers are likely to catch up. Countries lagging far behind and / or having a low intrinsic capability to assimilate spillovers will fall (even further) behind. The empirical analysis in Chapter 6 proved the functional specification of the model to be most valuable as compared to other specifications in the literature and special cases of the equation proposed.

The different possibilities for growth patterns predicted by the model link up quite closely to the ideas of growth that were described in the above section. Instead of a regular growth pattern, the model predicts that (sudden) shocks and trend reversals in the growth path might arise if the intrinsic capability to assimilate knowledge spillovers changes over time. In a mathematical way, the model shows, 
even given its very simple nature, some of the possibilities of nonlinear dynamics referred to above, and generates a bifurcation pattern.

Since most of the factors influencing the intrinsic capability to assimilate knowledge spillovers - such as education and infrastructure, two variables which are used in the empirical test of the model - are more or less public goods, there is a possibility for governments to influence growth performance by means of an active policy in this field. As the analysis of the estimation results in Chapter 6 shows, this holds particularly true for the poorest, mostly African, countries, which are in a position in which the intrinsic knowledge assimilating capability is low to the extent that they cannot catch up, irrespective of the value of the initial gap. However, the brief discussion of policy alternatives in Chapter 6 has mentioned the problem that most of the governments of the countries involved do not have the money to pursue such a policy, or lack the political will to spend the money in this way.

\subsection{International Trade, Growth and Competitiveness}

Part Three of this thesis was aimed at explaining the first three stylized facts of international growth in Chapter 4. The first of these says that growth rates differ between countries, although the differences are smaller between groups of relatively homogeneous countries. The second and third stylized facts suggest a structural explanation for the question why growth rates differ. The second stylized fact stresses the differences between sectoral rates of technological change and the third stylized fact points to differences in the production (and consumption) structure between countries.

In an attempt to explain these phenomena, the three chapters in Part Three of the thesis have highlighted the role of technology (and wages) in the process of international competition for growth. The model that was presented in Chapter 7 has challenged the traditional view that free trade benefits every party involved. Although the static Ricardian logic of comparative advantages is undisputed, and actually comes out of the model in terms of emerging specialization patterns, the model has shown that some countries benefit more from trade than others. It was in this chapter that the evolutionary logic proposed was expanded fully into a model, stressing the importance of variety in the specification of the selection environment using the replicator equation, and using the idea of Lamarckian feedbacks between performance and (learning) behaviour in the specification of equations for the wage rate, productivity growth, the exchange rate and income elasticities of consumer demand.

A normative argument about whether or not a country is better off with free trade has not been given, because this proves to be impossible in the setting of the simple model used. The model showed that free trade induces specialization patterns, which are highly path-dependent due to feedback effects in the form of learning. It is hard to judge whether or not a country would have been better off if it had been on a different specialization path due to (initially) closing its economy. 
What the model did show is that growth rate differentials arise between heterogeneous economies that trade with each other. These differences in growth paths are partly due to demand side effects like income elasticities, and partly due to supply side effects like differential rates of technological change between sectors and countries. Thus, once again the conclusion is that technological change is not something that equally benefits everyone in the world.

The model stresses the interaction between trade and growth, and argues that the possibilities to grow faster than other countries are materialized by an increasing market share in world markets. This is why the model describes the competitive struggle for growth. The factor that determines trade performance, and hence growth, is competitiveness. In the theoretical model and in the empirical analysis, competitiveness has been divided into technological competitiveness and wage rate competitiveness.

In a framework where increasing market shares are the vehicle for growth, expansion of the economy beyond the capacity limits is a real threat for some (highly competitive) countries. Therefore, the models contains a negative feedback effect from performance to competitiveness. This feedback mainly works through the labour market, and takes the form of a modified Phillips curve. There is also a technological effect in the form of decreasing marginal returns to learning. Because of the multi-sector context of the model, there is a structural part to growth. Growth rate differentials can arise because of varying income elasticities. Also, specialization patterns are induced by technological advantages (comparative or absolute), the domestic consumption structure, and competitive pressure.

The resulting growth pattern in an open economy that is modelled in this way is best described as dynamic. With the exception of some special cases, in which countries and / or sectors are alike or very symmetric, each country will generally generate a growth rate different from that in the rest of the world. This result links up closely to the empirical finding in Chapter 4 that homogeneous groups of countries have shown more similar growth patterns than heterogeneous groups of countries. Moreover, due to the complex (Lamarckian) links between the different variables in the system, the growth rate differential itself is subject to sudden and unexpected shocks.

The empirical analysis of the model highlights the importance of the assumption of variety in the current framework. Regressions undertaken in Chapter 8, testing the specific way of modelling the impact of variety on trade performance, in general support the evolutionary way of modelling, although the evidence is not altogether conclusive.

With regard to the use of patents as indicators of innovation, the regressions in Chapter 8 showed that in the context of explaining the static, structural relation between trade and technology (in manufacturing) that is often found in other work (Dosi et al. 1990), significant and positive relations can be obtained. This result was also reached in previous work on the subject. However, using the same data in the dynamic context proposed in the model in Chapter 7, where the motion of market shares is explained by the level of competitiveness, patent variables behave in a 
much more unexpected way. Many of the estimated coefficients have a negative sign, as opposed to positive signs in the structural, static approach. As a preliminary explanation for this phenomenon, the specific role of patents as indicators of the (international) appropriation of technology was alluded to. Due to imitation and the presence of multinationals, patents might not be a very good indicator of innovative power in an international dynamic context. For example, patents are generally assigned to the country where the research lab of the applicant is located, but the application of the knowledge embodied in the patent might well take place in another country. In the current framework, this tendency might lead to a negative correlation between patents and growth of export market shares. This puts forward the interesting issue of the role of multinational corporations and low-wage countries in the process of international appropriation of knowledge. However, the exact nature of this relation is beyond the scope of this thesis, and requires more research.

Whereas the regressions in Chapter 8 show the merits of the approach with regard to trade alone, empirical analysis in Chapter 9 has shown the usefulness of the general approach of linking trade to growth in the dynamic evolutionary way proposed. Using the estimated values of the evolutionary elasticities from Chapter 8 , the value of competitiveness (defined as the expected percentage point additions to the growth rate differential of a country in manufacturing) are calculated. Regressions using these data show that there is a highly significant relation between competitiveness and structural differences between countries on the one hand, and aggregate (manufacturing as well as total GDP) growth rate differentials on the other. Other variables which could not be taken into account in the framework of Chapter 8, such as fixed capital accumulation and the degree of specialization of the economy, are shown to have a significant influence as well. Despite the significance of these variables, the explanatory power of the regressions is generally low. This deficiency was attributed partly to the lack of good indicators for various aspects of competitiveness.

One specific issue in the estimates was the role of openness in the relation between trade and growth. In order to test for this, a number of nonlinear regressions were set up. Together with the linear regressions, these showed the limits of the approach followed in Part Three with regard to countries that have relatively closed economies, especially the large ones like the USA and Japan. The more open a country, the higher the influence of competitiveness on growth. Thus, the model in Chapter 7 needs to be enhanced with regard to the domestic side of the economy in order to give a more complete description of growth for countries that are not so open.

An additional case study approach in Chapter 9 showed the importance of variety for explaining growth paths of the Asian NICs. The good performance of these countries, which had already been observed in Chapter 4, can be explained by several factors among which low wages, specialization and (recently) technological dynamism are at the centre. However, the analysis also showed that even in this limited sample of Asian 'tigers', there is not one single recipe for growth. Each of the countries has its own specific way in which high growth rates were achieved. 
The issue of international growth and technological change has been approached in this thesis from a macroeconomic perspective. Although the models proposed here are not very similar to the ones the current macroeconomic literature focuses on (see for example Blanchard and Fischer 1989), the basic equations underlying them can be found in other (older) parts of the macroeconomic literature. While the above discussion shows that a number of interesting points emerge from this approach, it would also have been possible to treat the main themes from a different perspective.

Two of these alternative frameworks which are quite close to the main methodological, evolutionary ideas underlying this thesis, and therefore come to mind directly, are the fields of national systems of innovation (Freeman 1986, Lundvall 1992, Nelson 1992 and the four contributions in Part V of Dosi et al. 1988), and the (mostly nonformal) part of the field of industrial economics that focuses on firm level dynamics of international production (Cantwell 1990), including such issues as the behaviour of multinational corporations (Cantwell 1989) and interfirm cooperation (in R\&D) (Hagedoorn and Schakenraad 1992). A much more elaborate discussion of the possibilities of both fields is in Soete (1991).

The importance of the effects of multinational corporations has already been outlined when discussing the paradoxical results of the regressions in Chapter 8 . But it is not only the presence of multinationals that makes industrial organization relevant. Basically, the dynamics that have been described in Parts Two and Three take place at the firm level. Competition takes place between firms rather than nations. And although it is justifiable to treat all firms in a country as a group, as was done in the above, performing the analysis at the firm level most certainly will add to the understanding of the dynamics of international trade and growth.

Recently, a lot of work on interfirm technology agreements has been done (for example Hagedoorn and Schakenraad 1992). Most of this work can be seen as concentrating on the question as to what determines technological strengths and weaknesses of firms, and how this affects their willingness to share inputs and costs in the innovation process with other firms. As such, 'traditional' issues such as diversification, vertical integration, protection of technologies, market structure, etc. are relevant to this field of research. Thinking about the application of this line of research leads to the question as to what is the relation between all these industrial organization topics and the topic of the current thesis. To what extent does the specific Japanese corporate structure influence the trade and growth performance of this country? What is the role of market structure upon innovativeness in an international context? What role does technology transfer between national units of multinational firms play? To what extent can small and open economies rely on the presence of multinational firms for their technological strength? Will international technological cooperation between firms facilitate knowledge spillovers, and under what circumstances will cooperation take place? All these questions are highly relevant to the central topic of this thesis, and might be answered by looking in more detail at the field of industrial organization. 
Of course, a great deal of work in the field of industrial organization falls under the heading of mainstream theory, and is thus subject to the critique that much of the current thesis has centred around. The narrow optimization perspective taken by much of the work in this field does not easily conform to the evolutionary view proposed here. Nevertheless, there are a number of interesting lines of research in the branch of industrial organization, among which those mentioned by Cantwell and Hagedoorn and Schakenraad, which seern to be more close to the evolutionary view, are perhaps the most prominent. It would be a useful exercise to see to what extent an integration between this work and the current macroeconomic approach could take place, much along the same lines along which new growth theory has combined Solow's model and the more traditional work from the field of industrial organization.

A second useful road for integration might be the recent work on national systems of innovation. The central idea in this field of research is that countries differ with regard to the general nature of institutions (government policy, educational systems, legal framework, managers attitude towards risk, etc.) influencing technological change. It is argued that each country has a specific system, which may or may not place it in an advantageous position at some point in time. One of the ideas in this field which is very close to the current topic, is the link between differences in national systems and performance (for example Freeman 1986). As such, this line of research provides an important way of analyzing one of the central themes of this thesis: national differences in technological capability. In much of the above analysis, these differences, despite their crucial importance for the line of the argument, have remained largely unexplained. They were either assumed to depend on policy variables (Part Two), or modelled in a very stylized way (Part Three). Therefore, the theory about national systems of innovations provides a useful way of further specifying one crucial issue in the current approach.

However, if one wants to integrate these two lines of research, one has to deal with the differences in methodological approaches. The current perspective has been one of formal methods, using models and statistical analysis. However, the most fruitful way to analyze national systems of innovation is by means of a descriptive, case study-like approach. The reason for this is obvious: Factors like institutional frameworks, (qualitative) government policy and legal issues are not easy to quantify in a model, and even harder to measure and put into a statistical analysis. Therefore, if one tried to apply a narrow formal framework to the issue of national systems, this would probably result in a loss of the most important benefits of the approach.

On the other hand, it is also clear that the current way in which national systems are analyzed could benefit from the increased use of formal methods. Due to the descriptive nature of much of the work, the evidence is fragmented, and open to doubts with regard to the generality of the results. Therefore, the conclusion that a compromise between both methodological frameworks would be most fruitful seems obvious. In any case, the collection of new, internationally comparable data on institutions and policy variables seems to be a promising way of integrating these two lines of research. 


\section{References}

Abernathy, W., (1978), The Productivity Dilemma: Roadblock to Innovation in the Automobile Industry Baltimore: John Hopkins UP.

Abramovitz, M.A., (1979), Rapid Growth Potential and its Realisation : The Experience of Capitalist Economies in the Postwar Period, in: Malinvaud, E. (ed.), Economic Growth and Resources, vol. 1 The major Issues, proceedings of the fifth World Congres of the IEA, London: Macmillan, pp. 1-51.

Abramovitz, M.A., (1983), Notes on International Differences in Productivity Growth Rates, in: Mueller, D., The Political Economy of Growth New Haven/London: Yale University Press, pp. 79-89.

Abramovitz, M.A., (1986), Catching Up, Forging Ahead and Falling Behind, Iournal of Economic History vol. 46, pp. 385-406.

Aghion, P. and P. Howitt, (1990), A Model of Growth Through Creative Destruction, NBER Working Paper, 3223.

Allen, P., (1988), Evolution, Innovation and Economics, in: Dosi et al. (ed.), Technical Change and Economic Theory London: Pinter, pp. 95-119.

Amable, B. and R. Boyer, (1992), The R\&D Productivity Relationship in the Context of New Growth Theories: Some Recent Applied Research Paper presented at the seminar on 'Quantitative Assessment of Technological Change', Brussels, 23-24 January 1992.

Amendola, G., Guerreri, P. and P.C. Padoan, (1991), International Patterns of Technological Accumulation and Trade, Mimeo, University of Rome.

Ames, E. and N. Rosenberg, (1963), Changing Technological Leadership and Industrial Growth, Economic Iournal, vol. 73, pp. 13-31.

Arrow, K.J., (1962), The Economic Implications of Learning-by-Doing, Review of Economic Studies vol. 29, pp. 155-173.

Arthur, B., (1988), Competing Technologies: An Overview, in: Dosi et al. (eds.), Technical Change and Economic Theory London: Pinter, pp. 590-607.

Axelrod, R., (1984), The Evolution of Cooperation, New York: Basic Books.

Baily, M.N. and R.J. Gordon, (1988), The Productivity Slowdown, Measurement Issues, and the Explosion of Computer Power, Brookings Papers on Economic Activity, vol. 2, pp. 347-431.

Basberg, B., (1987), Patents and the Measurement of Technological Change: A Survey of the Literature, Research Policy, vol. 16, pp. 131-141. 
Baumol, W.J., (1986), Productivity Growth, Convergence, and Welfare: What the Long Run Data Show, American Economic Review vol. 76, pp. 1072-1085.

Baumol, W.J., S.A. Batey Blackman and E.N. Wolff, (1989), Productivity and American Leadership: The Long View Cambridge Mass.: MIT Press.

Belsley, D., Kuh, E. and R. Welsch, (1980), Rgeression Diagnostics, Identifying Influencial Data and Sources of Collinearity New York: Wiley.

Blanchard, O.J. and S. Fischer, (1989), Lectures in Macroeconomics Cambridge Mass.: MIT Press.

Bosworth, D. L., (1984), Foreign Patent Flows to and from the United Kingdom, Research Policy vol. 13, pp. 115-124.

Boulding, K.E., (1981), Evolutionary Economics, Beverly Hills/London: Sage.

Boyer, R, (1989), Wage Labour Nexus, Technology and Long Run Dynamics: An Interpretation and Preliminary Tests for US, in: Di Matteo et al. (eds.), Technological and Social Factors in Long Term Fluctuations, Berlin Heidelberg: Springer Verlag, pp. 46-66.

Campbell, J.Y. and P. Perron, (1991), Pitfalls and Opportunities: What Macreeconomists Should Know About Unit Roots, NBER Technical Working Paper 100.

Cantwell, J., (1989), Technological Innovation and Multinational Corporations Cambridge: Basil Blackwell.

Cantwell, J., (1990), The Technological Competence Theory of International Production and its Implications Mimeo.

Cass, D., (1965), Optimum Growth in an Aggregative Model of Capital Accumulation, Review of Economic Studies, vol. 32, pp. 233-240.

Christensen, L.R., Cummings, D., and D.W. Jorgenson, (1980), 'Economic Growth, 1947-73 : An International Comparison', in: Kendrick and Vaccara (eds.), New Developments in Productivity Measurement and Analysis, Studies in Income and Wealth, vol, 44, Chicago/London: The University of Chicago Press, pp. 595-698.

Cimoli, M., (1990), Innovation, Endogenous Comparative Advantages and Long-Run Growth, Mimeo, University of Venice.

Clark, J., Freeman, C. and L. Soete, (1982), Unemployment and Technical Innovation, London: Pinter.

Clark, N. and C. Juma, (1987), Long-Run Economics. An Evolutionary Approach to Economic Growth, London: Pinter.

Cohen, W.M., and D.A. Levinthal, (1989), Innovation and Learning: The Two Faces 
of R\&D, Economic Journal, vol. 99, pp. ju, .

Cornwall, J., (1977), Modern Capitalism. Its Growth and Transformation, London: Martin Robertson.

David, P.A., (1990), The Dynamo and the Computer: An Historical Perspective on the Modern Productivity Paradox, American Economic Review Papers and Proceedings, vol. 80, pp. 355-361.

De Long, J.B., (1988), Productivity Growth, Convergence and Welfare: Comment, American Economic Review, vol. 78, pp. 1138-1154.

Den Butter, F.A.G., (1987), Model en Theorie in de Macro-Economie, Leiden: Stenfert Kroese.

Denison, E., (1967), Why Growth Rates Differ, Washington: Brookings Institution.

Diederen, P., (1991), Induced Factor Augmentation, Technological Expectations and Variable Factor Productivity MERIT Research Memorandum 91-009.

Dixon, R.J. and A.P. Thirlwall, (1975), A Model of Regional Growth-Rate Differences on Kaldorian Lines, Oxford Economic Papers, vol. 11, pp. 201-214.

Dollar, D. and E.N. Wolff, (1988), Convergence of Industry Labour Productivity Among Advanced Economies 1963-1982, Review of Economics and Statistics, vol. LXXX, pp. 549-558.

Dosi, G., (1982), Technological Paradigms and Technological Trajectories, Research Policy, vol. 11, pp, 147-162.

Dosi, G., (1988a), The Nature of the Innovative Process, in: Dosi et al. (eds.), Technical Change and Economic Theory, London: Pinter, pp. 221-238.

Dosi, G., (1988b), Sources, Procedures and Microeconomic Effects of Innovation, Lournal of Economic Literature, vol. 26, pp. 1120-1171.

Dosi, G. and Chiaromonte, F., (1990), The Microfoundations of Competitiveness and their Macroeconomic Implications, Paper presented at the OECD conference on Technology and Competiveness, 24-27 June.

Dosi, G., Pavitt, K. and L. Soete, (1990), The Economics of Technological Change and International Trade, Brighton: Wheatsheaf.

Dosi, G., Freeman, C., Nelson, R., Silverberg, G. and L. Soete (eds.), (1988), Technical Change and Economic Theory London: Pinter.

Dowrick, S. and D.T. Nguyen, (1989), OECD Comparative Economic Growth 1950-85: Catch-Up and Convergence, American Economic Review vol. 79, pp. 1010-1030. 
Durlauf, S.N. and Johnson, P.A., (1992), Local Versus Global Convergence Across National Economies, NBER Working Paper No. 3996.

Ethier, W.J., (1982), National and International Returns to Scale in the Modern Theory of International Trade, American Economic Review, vol. 72, pp. 389-405.

Fagerberg, J., (1988a), International Competitiveness, Economic loumal, vol. 98, pp. 355-374.

Fagerberg, J. (1988b), Why Growth Rates Differ, in: Dosi et al. (eds.), Technical Change and Economic Theory London: Pinter, pp. 432-457.

Fagerberg, J., (1991), Conditions of Competition Across Industries: Is There a Small-Country Problem in High-Tech? Mimeo, NUPI, Oslo.

Foster, J., (1987), Evolutionary Macroeconomics, Boston: Allen \& Unwin.

Freeman, C., (1982), The Economics of Industrial Innovation London: Pinter.

Freeman, C., (1986), Technology Policy and Economic Performance: Lessons from Iapan London: Pinter.

Freeman, C., (1989), The Nature of Innovation and the Eyolution of the Productive System MERIT Research Memorandum 89-016.

Freeman, C., (1991), Innovation, Changes of Techno-Economic Paradigm and Biological Analogies in Economics, Revue Economique vol. 42, pp. 211-231.

Freeman, C., and L. Soete, (1990), Fast Structural Change and Slow Productivity Change: Some Paradoxes in the Economics of Information Technology, Structural Change and Economic Dynamics, vol. 1, pp. 225-242.

Fudenberg, D. and J. Tirole, (1984), Learning-by-Doing and Market Performance, Bell Tournal of Economics, vol. 14, pp. 522-530.

Gerschenkron, A., (1962), Economic Backwardness in Historical Perspective Cambridge Mass.: Harvard UP.

Gomulka, S., (1971), Inventive Activity, Diffusion and the Stages of Economic Growth Aarhus: Skrifter fra Aarhus Universitets Okonomiske Institut.

Gomulka, S., (1990), The Theory of Technological Change and Economic Growth London: Routledge.

Goodwin, R.M., (1967), A Growth Cycle, in: Feinstein, C.H. (ed.), Socialism, Capitalism and Economic Growth, London: Macmillan.

Gould, S.J., (1977), Ever Since Drawin. Reflections in Natural History New York: Norton (page references refer to the Dutch Translation "Honderd Jaar Na Darwin", 
Utrecht: Spectrum, 1979).

Gourvitch, A., (1940), Survey of Economic Theory on Technical Change and Employment, New York: Augusta M. Kelley.

Green, P.E., Carmone, F.J. and S.M. Smith, (1989), Multidimensional Scaling. Concepts and Applications, Boston: Allyn and Bacon.

Griliches, Z., (1990), Patent Statistics as Economic Indicators: A Survey, Joumal of Economic Literature, vol. XXVIII, pp. 1661-1707.

Grossman, G.M. and E. Helpman, (1989), Growth and Welfare in a Small open Economy NBER Working Paper, 2970.

Grossman, G.M. and E. Helpman, (1990), Comparative Advantage and Long Run Growth, American Economic Review vol. 80, pp. 796-815.

Grossman, G.M. and E. Helpman, (1991a), Quality Ladders in the Theory of Growth, Review of Economic Studies, vol. 58, pp. 86-91.

Grossman, G.M. and E. Helpman, (1991b), Innovation and Growth in the Global Economy Cambridge Mass.: MTT Press.

Hagedoorn, J. and J. Schakenraad, (1992), Leading Companies and Networks of Strategic Alliences in Information Technologies, Research Policy Vol. 21, pp. 163190.

Harrod, R.F., (1939), An Essay in Dynamic Theory, Economic Journal, vol. XLIX, pp. 14-33.

Hodgson, G.M., (1990), Some Evolutionary Themes in the Old and New Institutionalisms, Paper presented at the 9th International Summer School of Advanced Economic Studies, Trieste, Italy, 21st-31st August.

Hofbauer, J, and K. Sigmund, (1988), The Theory of Evolution and Dynamical Systems, Cambridge: Cambridge UP.

Hughes, K., (1986), Exports and Technology Cambridge: Cambridge UP.

Iwai, K. (1984a), 'Schumpeterian Dynamics. An evolutionary Model of Innovation and Imitation', Iournal of Economic Behaviour and Organization vol. 5, pp. 159-190.

Iwai, K. (1984b), 'Schumpeterian Dynamics. Part II. Technical Progress, Firm Growth and Economic Selection', Iournal of Economic Behaviour and Qrganization, vol. 5, pp. 321-351.

Johnston, J., (1984), Econometric Methods, 3rd ed., MoGraw-Hill: New York. 
Jones, H., (1975), An Introduction to Modern Theories of Economic Growth, Nelson: Letchford.

Kaldor, N., (1957), A Model of Economic Growth, Economic Journal (page references are to the reprint in Kaldor 1980).

Kaldor, N., (1966), Causes of the Slow Rate of Growth of the United Kingdom, Cambridge: Cambridge UP.

Kaldor, N., (1970), The Case for Regional Policies, Scottish lournal of Political Economy vol. XVII (page references are to the reprint in Kaldor 1978).

Kaldor, N., (1978), Further Essays on Economic Theory London: Duckworth.

Kaldor, N., (1980), Essays on Economic Stability and Growth, 2nd ed., London: Duckworth.

Kamien, M.I. and N.L. Schwartz, (1981), Dynamic Optimization: The Calculus of Variations and Optimal Control in Economics and Management. Amsterdam: North Holland.

Kamien, M.I. and N.L. Schwartz, (1982), Market Structure and Innovation Cambridge: Cambridge UP.

Kay, N.M., (1984), The Evolving Firm: Strategy and Structure in Industrial Organization London: Macmillan.

Kennedy, C., (1964), Induced Bias in Innovation and the Theory of Distribution, Economic Iournal, vol. LXXIV, pp. 541-547.

Kleinknecht, A., (1987), Innovation Patterns in Crisis and Prosperity. Schumpeter's Long Cycle Reconsidered New York: Macmillan.

Kleinknecht, A. and B. Verspagen, (1990), Demand and Innovation: Schmookler Re-Examined, Research Policy vol. 19, pp. 387-394.

Kristensen, T., (1974), Development in Rich and Poor Countries New York: Praeger.

Kropotkin, P., (1902), Mutual Aid: A Factor in Evolution New York: Doubleday. Krugman, P., (1990), Rethinking International Trade, Cambridge Mass.: MIT Press.

Kwasnicki, W. and H. Kwasnicki, (1990), Market, Innovation, Competition. An Evolutionary Model of Industrial Dynamics, Mimeo.

Levin, R.C., Klevorick, A.K., Nelson, R.R., and S.G. Winter, (1987), Appropriating the Returns from Industrial Research and Development, Brookings Papers on Economic Activity Vol. 3, pp. 783-820. 
Link, A.N., (1987), Technological Change and Productivity Growth, New York: Harwood Academic Publishers.

Linneman, H., (1966), An Econometric Study of International Trade Flows, Amsterdam: Elsevier/North Holland.

Lippi, M., (1989), Permanent and Transitory Components in Macroeconomics, Paper presented at the International Economic Association Conference on Business Cycles, Copenhagen, June 1989.

Lorenz, H.W., (1989), Nonlinear Dynamical Economic Systems and Chaotic Motion, Berlin: Springer.

Lucas, R.E.B., (1988), On the Mechanisms of Economic Development, Journal of Monetary Economics, vol. 22, pp. 3-42.

Lundvall, B.A. (ed.), (1992), National Systems of Innovation: An Analytical Framework, London: Pinter.

Maddison, A., (1982), Phases of Capitalist Development Oxford: Oxford UP.

Maddison, A., (1987), Growth and Slowdown in Advanced Capitalist Economies: Techniques of Quantitative Assessment, Journal of Economic Literature, vol. 25, pp. 649-698.

Maddison, A., (1991), Dynamic Forces in Capitalist Development. A Long-Run Comparative View Oxford: Oxford UP.

Mankiw, N.G., Romer, D. and D.N. Weil, (1990), A Contribution to the Empirics of Economic Growth, NBER Working Paper No. 3541.

Mensch, G., (1979), Stalemate in Technology. Innovations Overcome Depression, Cambridge: Ballinger.

Mohnen, P., (1990), R\&D and Productivity Growth: A Survey of the Literature, Mimeo.

Mowery, D.C. and N. Rosenberg, (1979), The Influence of Market Demand Upon Innovation: A Critical Review of Some Recent Empirical Studies, Research Policy, Vol, 8, pp. 103-153.

Nelson, R.R., (1968), A Diffusion Model of International Productivity Differences in Manufacturing Industry, American Economic Review vol. 58, pp. 1219-1248.

Nelson, R.R., (1981), Research on Productivity Growth and Productivity Differences: Dead Ends and New Departures, lournal of Economic Literature, vol. 19, pp. 1029-1064.

Nelson, R.R. (ed.), (1992), National Innovations Systems: A Comparative Study 
forthcoming.

Nelson, R.R., and S.G. Winter, (1976), In Search of a Useful Theory of Innovation, Research Policy vol. 5, pp. 36-76.

Nelson, R.R. and S.G. Winter, (1982), An Evolutionary Theory of Economic Change, Cambridge Mass.: Harvard University Press.

Pasinetti, L.L., (1981), Structural Change and Economic Growth. A Theoretical Essay on the Dynamics of the Wealth of Nations, Cambridge: Cambridge UP.

Patel, P. and L. Soete, (1987), The Contribution of Science and Technology to Economic Growth: a Critical Reappraisal of the Evidence Mimeo, OECD: Paris.

Pavitt, K., (1985), Patent Statistics as Indicators of Innovation Activities, Scientometrics, vol. 7, pp. 77-99.

Pavitt, K. and L. Soete (1982), International Differences in Economic Growth and the International Location of Innovation, in: Giersch, $\mathrm{H}$. (ed.), Emerging Technologies: The Consequences for Economic Growth, Structural Change and Employment Mohr: Tübingen.

Perez, C., (1983), Structural Change and The Assimilation of New Technologies in the Economic and Social System, Eutures, vol. 15, pp. 375-375.

Perez, C. and L. Soete (1988), 'Catching Up in Technology: Entry Barriers and Windows of Opportunity', in: Dosi et al. (eds.), Technical Change and Economic Theory London: Pinter, pp. 458-479.

Pesaran, M.H. and A.S. Deaton, (1978), Testing Non-Nested Nonlinear Regression Models, Econometrica, vol. 46, pp. 677-694.

Phelps, E.S., (1966), Models of Technical Progress and the Golden Rule of Research, Review of Economic Studies, vol. 33, pp. 133-145.

Piel, J., (1991), Science in the 20th Century, Scientific American Special Issue "Science in the 20th Century", pp. 4-10.

Quah, D., (1990a), International Patterns of Growth: I. Persistence in Cross-country Disparities, Mimeo, Dept. of Economics, MIT.

Quah, D., (1990b), International Patterns of Growth: II. Persistence, Path Dependence, and Sustained Take-Off in Growth Transition, Mimeo, Dept. of Economics, MIT.

Rebelo, S., (1992), Growth in Open Economies, Paper presented at the European Science Foundation conference on 'Endogenous Growth, Sources of Productivity Change, Growth and Inequality', 9-13 June 1991, Barcelona. 
Rivera-Batiz, F.L. and L. Rivera-Batiz, (1985), International Finance and Open Economy Macroeconomics, New York: Macmillan.

Roberts, J., (1987), The Hutchinson History of the World Hutchinson: London (page numbers refer to the Dutch translation "Wereld-geschiedenis", Het Spectrum: Utrecht, 1988).

Romer, P.M., (1986), Increasing Returns and Long Run Growth, Iournal of Political Economy vol. 94, pp. 1002-1037.

Romer, P.M., (1989), What Determines the Rate of Growth and Technological Chanqe? Working Paper World Bank, Country and Economics Department, 279.

Romer, P.M., (1990a), Endogenous Technological Change, Iournal of Political Economy vol. 98 , pp. S71-S102.

Romer, P.M., (1990b), Notes on the Formation of a CIAR Program on Economic Growth Mimeo.

Romme, A., (1992), A Self-Organization Perspective on Strategy Formation Maastricht: Universitaire Pers Maastricht.

Rosenberg, N., (1976), Perspectives on Technology Cambridge: Cambridge UP.

Rostow, W.W., (1960), The Stages of Economic Growth: A Non-Communist Manifesto, Cambridge: Cambridge UP.

Rostow, W.W., (1980), Why the Poor Get Richer and the Rich Slow Down. Essays in the Marshallian Long Period Macmillan: London.

Samuelson, P., (1967), The Monopolistic Revolution, in: Kuenne, R. (ed.), Monopolistic Competition Theory New York: Wiley.

Schankerman, M., (1989), Measuring the Value of Patent Rights: Uses and Limitations, Paper presented at the OECD International Seminar on Science, Technology and Growth, 5-8 June, Paris.

Scherer, F.M. and D. Ross, (1990), Industrial Market Structure and Economic Performance. Third Edition Boston: Houghton Mifflin Company.

Schmookler, J., (1966), Invention and Economic Growth Cambridge Mass: Harvard UP.

Schumpeter, J.A., (1934), The Theory of Economic Development, Cambridge Mass.: Harvard UP.

Schumpeter, J.A., (1939), Business Cycles, (vol. I and II), New York: MacGraw Hill.

Schumpeter, J.A, (1954), History of Economic Analysis, Oxford: Oxford UP. 
Shell, K., (1967), A Model of Inventive Activity and Capital Accumulation, in: Shell (ed.), Essays on the Theory of Optimal Growth Cambridge Mass: MIT Press, pp. 67-85.

Silverberg, G., (1987), Technical Progress, Capital Accumulation, and Effective Demand: A Self-Organization Model, in: Batten, D., J. Casti and B. Johansson (eds.). Economic Evolution and Structural Adiustment. Lecture Notes in Economics and Mathematical Systems 293, Berlin: Springer Verlag, pp. 116-144.

Silverberg, G., (1988), Modelling Economic Dynamics and Technical Change: Mathematical Approaches to Self-Organisation and Evolution, in: Dosi $e t$ al. (eds.), Technical Change and Economic Theory London: Pinter, pp. 531-559.

Silverberg, G., Dosi, G. and L. Orsenigo (1988), Innovation, Diversity and Diffusion: A Self-Organisation Model, Economic Journal, vol. 98, pp. 1032-1054.

Simon, H.A., (1986), On the Behavioural and Rational Foundations of Economics Dynamics, in: Day, R.M. and G. Eliasson (eds.), The Dynamics of Market Economics, Amsterdam: North Holland, pp 21-44.

Soete, L., (1981), A General Test of the Technological Gap Trade Theory, Weltwirtschaftliches Archiv Vol. 117.

Soete, L., (1987), The Impact of Technological Innovation on International

Trade Patterns. The Evidence Reconsidered, Research Policy Vol. 16.

Soete, L., (1991), Technology in a Changing World Paris: OECD.

Solow, R.M., (1956), A Contribution to the Theory of Economic Growth, Quarterly Iournal of Economics vol. 70, pp. 65-94.

Solow, R.M., (1957), Technical Progress and the Aggregate Production Function, Review of Economics and Statistics, vol. 39, pp. 312-320.

Solow, R.M., (1970), Growth Theory: An Exposition, Oxford: Oxford UP.

Spence, M., (1981), The Learning Curve and Competition, Bell Iournal of Economics, vol. 11, pp. 49-70.

Stern, N. (1989), The Economics of Development: A Survey, Economic Journal, vol. 99, pp. 597-.

Stiglitz, J.E., (1987), Learning to Learn, Localized Learning and Technological Progress, in: Dasgupta, P. and P. Stoneman (eds.), Economic Policy and Technological Performance, Cambridge: Cambridge UP, pp. 123-153.

Stock, J.H. and M.W. Watson, (1988), Variable Trends in Economic Time Series, lournal of Economic Perspectives, Vol. 2, pp. 147-174. 
Summers, R. and A. Heston, (1987), A New Set of International Comparisons of Real Product and Price Levels Estimates for 130 Countries, 1950-1985, Review of Income and Wealth pp. 1-25.

Summers, R. and A. Heston, (1991), The Penn World Table (Mark 5): An Expanded Set of International Comparisons, (1950-1988), The Quarterly Journal of Economics, vol. CVI, pp. 1-41.

Taylor, C. and A. Silberston, (1973), The Economic Impact of the Patent System, Cambridge: Cambridge UP.

Thirlwall, A.P., (1979), The Balance of Payments Constraint as an Explanation of International Growth Rate Differences, Banca Nazionale del Lavoro, vol. 32, pp. 45-53.

Thirtle, C.G. and V.W. Ruttan, (1987), The role of Demand and Supply in the Generation and Diffusion of Technological Change, New York: Harwood Academic Publishers.

Uzawa, H., (1965), Optimum Technical Change in an Aggregative Model of Economic Growth, International Economic Review, pp. 18-31.

Veblen, T., (1898), Why is Economics Not An Evolutionary Science?, Quarterly lournal of Economics Vol. 12, pp. 374-397.

Verspagen, B., (1991), A New Empirical Approach to Catching Up or Falling Behind, Structural Change and Economic Dynamics, vol. 2, pp. 359-380.

Verspagen, B, (1992a) (forthcoming), Endogenous Innovation in Neo-Classical Growth Models: A Survey, Lournal of Macroeconomics, vol. 14, No 6.

Verspagen, B., (1992b), An Evolutionary Approach to Why Growth Rates Differ, in: Blaas, W. and J. Foster (eds.), The Mixed Economies In Europe, Edward Elgar Publishing, forthcoming.

Verspagen, B. (1992c), Trade and Knowledge Spillovers in an Evolutionary Model of Growth Rate Differentials, in: Wagner, A. (ed.), Dezentrale Entscheidungen bei Externalitäten Tübingen, forthcoming.

Viljoen, S., (1974), Econemic Systems in World History (2 parts), Longman Group: London (Page numbers refer to the Dutch translation "Economische Systemen in de Wereldgeschiedenis", Het Spectrum: Utrecht, 1976).

Westphal, L.E., Kim, L. and C.J. Dahlman, (1985), Reflections on the Republic of South Korea's Acquisition of Technological Capability, in: Rosenberg, N. and C. Frischtak (eds.), Intemational Technology Transfer, New York: Praeger. 


\section{Nederlandse Samenvatting - Dutch Summary}

Dit proefschrift behandelt de relatie tussen ekonomische groei, technologie en internationale handel. De manier waarop de analyse van deze relaties plaatsvindt is te kenschetsen als een modelmatige evolutionaire methode. De evolutionaire benadering van ekonomische processen onderscheidt zich van de meer gangbare neo-klassieke benaderingswijze door een aantal verschillende uitgangspunten. De belangrijkste van deze zijn:

1. Het proces van ekonomische groei en ontwikkeling kan niet gekenmerkt worden als evenwichtig en gelijkmatig. Er zijn desruptieve krachten, zoals technologische vernieuwing, aanwezig in het ekonomische systeem die ervoor zorgen dat steeds opnieuw een tendentie naar nieuwe groeipaden ontstaat. Dit resulteert in moeilijk te voorspellen fases waarin groei en stagnatie elkaar afwisselen.

2. De drijvende kracht achter ekonomische ontwikkeling ligt in de verscheidenheid tussen ekonomische agenten (bedrijven). In plaats van het gangbare begrip van de "representatieve agent", gaat de evolutionaíre ekonomie er van uit dat endogene verschillen tussen agenten aanleiding zijn voor een Darwiniaans selektie-proces. Nauw hiermee samenhangend, wordt het idee van volledige rationaliteit ingeruild voor dat van "bounded rationality". Deze vorm van rationaliteit laat ruimte voor sub-optimaal gedrag, en kenmerkt ondernemersgedrag eerder als "winst-zoekend" dan "winst-maximerend".

De toepassing van deze ideeën op het onderwerp van dit proefschrift leidt tot de volgende argumentatie. In het eerste gedeelte wordt een interpretatie van de bestaande literatuur gegeven. In hoofdstuk 1 wordt vanuit een historisch perspektief globaal uiteengezet hoe technologische vooruitgang de welvaart in de wereld beïnvloed heeft. Hoofdstuk 2 vat vervolgens samen hoe de ekonomische theorievorming aankijkt tegen de relatie technologie en groel. Hierbij komen achtereenvolgens het neo-klassieke, het post-keynesiaanse en het neo-keynesiaanse groeimodel aan bod. Bovendien wordt een samenvatting gegeven van de zogenaamde nieuw neo-klassieke groeimodellen, die sinds 1986 sterk in opkomst zijn. Ook wordt aandacht besteed aan de theorie-vorming met betrekking tot technologie en groei vanuit een internationaal perspektief.

In hoofdstuk 3 wordt aangetoond hoe men vanuit de analyse van het fenomeen technologische innovatie de voordelen van de hierboven geschetste evolutionaire benadering plausibel kan maken. Dit hoofdstuk biedt zowel een mikro- als een makro-ekonomische blik op het innovatie-proces. In hoofdstuk 4, dat tevens deel 1 afsluit, wordt een empirische invalshoek gekozen. In dit hoofdstuk worden enkele gestileerde feiten met betrekking tot het onderwerp van het proefschrift geformuleerd. Deze luiden als volgt:

1. Er bestaan verschillen in ekonomische groeivoeten tussen landen, en tussen groepen van landen, zowel op het nivo van gegaggregeerd inkomen (BBP), als sektorale produktie.

2. De snelheid van technologische vooruitgang verschilt tussen ekonomische sektoren. 
3. De produktie-struktuur verschilt tussen landen en over de tijd. Echter, binnen bepaalde groepen van landen zijn deze verschillen relatief klein.

4. De snelheid van technologische vooruitgang, gemeten op het makroekonomische nivo, is het sterkst gerelateerd aan het initiële nivo van de arbeidsproduktiviteit. Andere variabelen, zoals Onderzoek en Ontwikkelingsinspanningen en investeringen spelen een minder duidelijke rol.

5. De inkomens-kloof tussen de ontwikkelingslanden en de rijke landen wordt eerder groter dan kleiner. De kloof tussen midden-inkomen-landen en de rijke landen wordt echter kleiner.

Het verklaren van deze gestileerde feiten is de taak die de rest van het proefschrift zich stelt. Deel 2 probeert de feiten 4 en 5 te verklaren. Daarvoor wordt in hoofdstuk 5 een model geformuleerd dat de invloed van technologische "spillovers" beschrijft. In een kontext van twee landen wordt beschreven hoe technologische kennis van een geavanceerd land naar een minder ontwikkeld land vloeit. Hierbij wordt, in tegenstelling tot de zogenaamde catching-up modellen die men in de literatuur aantreft, benadrukt dat de kapaciteit om technologische "spillovers" te assimileren een belangrijke rol speelt. Verondersteld wordt dat deze kapaciteit afhangt van de technologische afstand tussen de twee landen, en een "intrinsiek" gedeelte, waarbij scholing van de arbeidskrachten en het nivo van de infrastruktuur een grote rol spelen.

De uitkomst van dit model, dat bestaat uit een aantal niet-linaire differentiaal-vergelijkingen, is als volgt samen te vatten. Voor kleine waarden van de intrinsieke capaciteit om technolgie "spillovers" te assimileren, zal de technologische kloof tussen het geavanceerde en minder ontwikkelde land steeds blijven groeien ("falling behind"). Voor waardes van de genoemde kapaciteit groter dan een bepaalde waarde (het zogenaamde bifurkatie-punt), onstaat de mogelijkheid dat de technologische kloof konvergeert naar een vaste, relatief kleine waarde ("catching up"). Deze mogelijkheid doet zich slechts voor indien de initiële technologische kloof niet te groot is. Is dit laatste wel het geval, dan is "falling behind" de uitkomst.

In hoofdstuk 6 wordt getest of het model uit hoofdstuk 5 de empirische data beter kan beschrijven dan de genoemde "catching-up" modellen. Deze modellen, die in het algemeen lineair zijn, bieden slechts de mogelijkheid van "catching up", en kunnen beschouwd worden als een speciaal geval van het model in hoofdstuk 5 . De ekonometrische analyse, die zowel gebruik maakt van geneste als niet-geneste toetsingsmethoden, toont aan dat voor de steekproef van groeipaden in de periode 1960-1985 voor meer dan honderd landen, het model in hoofdstuk 5 signifikant beter presteert dan lineaire varianten.

Deel 3 probeert de overgebleven gestileerde feiten te verklaren. Terwijl in deel 2 internationale handel nog slechts een ondergeschikte rol speelde, wordt in hoofdstuk 7 een model gepresenteerd dat de relatie tussen handel en groei vanuit een selektie-oogpunt voorstelt. Dit houdt onder meer in dat verondersteld wordt dat er belangrijke verschillen tussen landen bestaan op (onder andere) het gebied van inkomenselasticiteiten van konsumptie, leereffekten, en de arbeidsmarkt. In een mathematische beschrijving die ontleend is aan de biologie, wordt getracht het 
verband tussen konkurrentie-vermogen, dat bepaald wordt door een samenspel van technologische faktoren en arbeidskosten, en handelsprestaties weer te geven. De zogenaamde handelsbalans-restriktie aan ekonomische groei bepaalt vervolgens de groeivoet van een ekonomie. Het model, waarin lonen, technologie (in de vorm van kumulatieve leereffekten), handel, konsumptie-patronen en inkomensgroei endogeen bepaald zijn, kan niet analytisch opgelost worden, als gevolg van het komplexe niet-lineaire karakter.

Om deze reden wordt het model geanalyseerd door middel van komputersimulaties. Deze experimenten tonen an dat het model in het algemeen groeipaden vertoont die een hoge mate van diversiteit tussen landen en over de tijd laten zien. Met andere woorden, de experimenten leveren uitkomsten op die verschillend zijn van de evenwichtige en gelijkmatige groeipaden die men aantreft in de meer gangbare theorieen. Tegelijkertijd wordt aangetoond dat in een anntal specifieke gevallen, waarin de assumptie van heterogeniteit tussen landen vervalt, wel een evenwichtig en gelijkmatig groeipad ontstaat.

De laatste twee hoofdstukken van deel 3 zijn gewijd aan een empirische toets van de ideeën in hoofdstuk 7. Aangezien het model in dat hoofdstuk enkele gestileerde veronderstelingen bevat (waaronder de afwezigheid van kapitaal en monetaire stromen, en de handelsbalans-restriktie aan ekonomische groei), moet volstaan worden met een partiële en/of indirekte test. In hoofdstuk 8 wordt getracht om door middel van een ekonometrische toets de mathematische beschrijving van het selektie-proces te toetsen. De kontext die hiervoor is gekozen is de wereldmarkt voor exporten. De vergelijkingen die geschat worden verklaren het marktaandeel op de markten voor 28 industriële sektoren. De uitkomst van de schattingen geeft aan dat zowel loonkosten als technologie (in de vorm van arbeidsproduktiviteit) een rol spelen in het selektie-proces. Technologie voor zover die tot uitdrukking komt in patenten heeft een overwegend negatieve invloed op de markprestatie. Als een tentatieve verklaring voor dit laatste resultaat is gewezen op de rol van multinationale ondernemingen, die ervoor zorgen dat de lokatie van inventie en produktie (en origine van export) verschillen.

De resultaten van de schattingen in hoofdstuk 8 zijn in hoofdstuk 9 gebruikt om de geaggregeerde konkurrentie-kracht voor de totale industriële sektor te berekenen. Vervolgens is deze variabele gebruikt om de groelvoet van de produktie te verklaren. In een regressie blijkt de konkurrentie-kracht een signifikante invloed op de groeivoet te hebben, zowel voor de industriéle produktie, als voor de totale produktie (BBP).

Het tweede gedeelte van hoofdstuk 9 probeert de groei-prestatie van een aantal Aziatische landen te verklaren. Deze landen bleken in hoofdstuk 4 te behoren tot het gedeelte van de wereld dat het snelste gegroeid is in de na-oorlogse periode. Uit deze analyse, die een meer 'case-study' georiënteerd karakter heeft, blijkt dat zelfs voor deze geografisch geconcentreerde groep landen niet een enkele bundel van verklarende faktoren aan te wijzen is. Faktoren die van belang bleken te zijn zijn onder andere loonkosten, specialisatiepatronen, en openheid van de ekonomie. Hieruit blijkt dus dat heterogeniteit een belangrijke faktor is bij het verklaren van groei. 
In het laatste hoofdstuk, 10, worden de belangrijkste uitkomsten samengevat, en worden enkele mogelijkheden voor verder onderzoek aangegeven. Deze liggen met name op het gebied van de theorie omtrent $\mathrm{zgn}$. nationale innovatie-systemen, en industriële ekonomie, waarin ondermeer het gedrag van multi-nationale ondernemingen en samenwerking tussen ondernemingen op het gebied van onderzoek geanalyseerd worden.

\section{Curriculum Vitae}

Bart Verspagen werd op 28 mei 1966 geboren te Weert. Van 1976 tot 1984 volgde hij de Lyceum opleiding aan de Philips van Horne Scholengemeenschap te Weert. Van 1984 tot 1988 studeerde hij Algemene Ekonomie aan de Rijksuniversiteit Limburg te Maastricht. Het doctoraal diploma werd cum laude behaald.

Van 1988 tot 1992 was hij als AlO verbonden aan het Maastricht Economic Research Institute on Innovation and Technology (MERIT), onderdeel van de Fakulteit der Ekonomische Wetenschappen van de Rijksuniversiteit Limburg. Momenteel is hij als onderzoeker verbonden aan ditzelfde instituut. 
Authors Index

Abernathy 52, 232

Abramovitz 44, 106, 116, 120, 232

Aghion and Howitt 24, 27, 29, $31,33,34,224$

Amable and Boyer 46

Amendola et al. 191

Ames and Rosenberg 44

Arrow 13, 23, 31, 232

Arthur 51, 232

Axelrod 136, 232

Baily and Gordon 52

Basberg 162, 232

Baumol 44, 45, 52, 104, 106, $116,120-122,233$

Baumol et al. 45, 52, 104, 106, $120,121,122$

Belsley et al. 99

Blanchard and Fischer 230

Bosworth 163, 233

Boulding 58, 233

Boyer 6, 46, 53, 232, 233

Campbell and Perron 176

Cantwell 146, 230, 231, 233

Cass 35, 36, 233

Christensen et al. 42

Cimoli 135, 233

Clark and Juma 58,60

Clark et al. 224, 225

Cohen and Levinthal 13, 104

Cornwall 44, 234

David 51, 234

De Long 44, 234

Den Butter 148, 234

Denison 42, 45, 234

Diederen vii, viii, 41, 234

Dixon and Thirlwall 43, 103, $105,106,108,115$, 118

Dollar and Wolff 44

Dosi ii, viii, $7,8,10,13,14,30$, $47,51,53,56,58$, $61,75,139,161$, $193,228,230,232$, $234,235,239,241$

Dosi and Chiaromonte 53

Dosi et al. $7,8,10,14,30,58$, $139,161,193,228$,
230,232 ,

234,235 ,

239,241

Dowrick and Nguyen 43-45, 76

Durlauf and Johnson 87

Ethier 26, 30, 235

Fagerberg viii, 42, 122, 136 , $137,139,167,178$, $196,197,235$

Foster 130, 235, 242

Freeman viil, 48, 50-52, 225, $230,231,233-235$

Freeman and Soete 48

Fudenberg and Tirole 61

Gerschenkron 7, 43, 235

Gomulka 7, 42, 44, 52, 53, 55, $59,106,116,224$ 235

Goodwin 21, 148, 155, 157, 235

Gould 60, 235

Gourvitch 12, 49, 236

Green et al. 96

Griliches 162, 236

Grossman and Helpman 24, 27, $29,30,31,33-35$, 45

Hagedoorn and Schakenraad 230,231

Hodgson 58, 236

Hofbauer and Sigmund 59,61

Hughes $8,161,236$

Iwail 58, 236

Johnston $99,183,186,236$

Jones 41,237

Kaldor $13,20-22,41,43,74,76$, $146,147,237$

Kamien and Schwartz 13, 36

Kay 59,237

Kleinknecht 49, 51, 237

Kleinknecht and Verspagen 51

Kristensen 104, 237

Kropotkin 130, 237

Krugman 45, 139, 237

Kwasnicki and Kwasnicki 53

Levin et al. 162

Link 9, 14, 58, 107, 114, 116, $225,226,231,238$

Linneman 97, 238 
Lippi 176,238

Lorenz 225,238

Lucas $23-25,28,31,32,34,35$, $37,38,44,238$

Lundvall 230,238

Maddison ii, 5, 7, 42, 83, 84, $224,225,238$

Mankiw et al. 87

Mensch 49, 238

Mohnen 76, 238

Mowery and Rosenberg 51

Nelson 14, 44, 58, 76, 224, 230, $234,237-239$

Nelson and Winter 14,58

Pasinetti 51, 52, 91, 106, 138, 149,239

Patel and Soete 76

Pavitt 75, 138, 162, 234, 239

Perez 44, 48, 50, 52, 239

Perez and Soete 44, 50

Pesaran and Deaton 124, 126, 131

Phelps 14, 239

Piel 6, 239

Quah 44, 239

Rebelo 44, 239

Roberts 5, 240

Romer 23-28, 30-35, 46, 59, 87, $225,238,240$

Romme 55, 240

Rosenberg 41, 44, 50, 51, 232, $238,240,242$

Rostow 7, 104, 111, 240

Samuelson 60,240

Schankerman 162, 240

Scherer and Ross 13

Schmookler 14, 51, 237, 240

Schumpeter $8,13,23,27,47-49$, $57,224,225,237$, 240

Shell 14,241

Silverberg vii, 55, 58, 60, 146, $225,234,241$

Silverberg et al. $55,58,146$

Simon 31, 55, 241

Soete ii, vii, $44,48,50,75,76$, $138,161,230,233$, $234,235,239,241$

Solow $15-18,35,37,40-43,74$,

$$
\begin{aligned}
& 76,77, \quad 78, \\
& 86,87,231, \\
& 241
\end{aligned}
$$

Spence 61,241

Stiglitz 61, 241

Stock and Watson 78,176

Summers and Heston 62, 81, 164,198

Taylor and Silberston 52

Thirlwall 43, 103, 105, 106, 108, $115,118,136,139$, $196,197,234,242$

Thirtle and Ruttan 14

Utterback and Abernathy 52

Uzawa 14, 242

Veblen 60,242

Verspagen i, 23, 51, 103, 119, $135,237,242,246$

Viljoen 4, 6, 242

Westphal et al. 104 

DATAWYSE | Universitaire Pers Maastricht ISBN 9052780420

NUGI 681 